\title{
ENTER CULTURE, EXIT ARTS?
}

THE TRANSFORMATION OF CULTURAL HIERARCHIES IN EUROPEAN NEWSPAPER CULTURE SECTIONS, 1960-2010

Semi Purhonen, Riie Heikkilä,

Irmak Karademir Hazır, Tina Lauronen, Carlos J. Fernández Rodríguez and Jukka Gronow

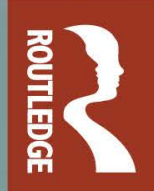




\section{Enter Culture, Exit Arts?}

Key debates of contemporary cultural sociology - the rise of the 'cultural omnivore', the fate of classical 'highbrow' culture, the popularization, commercialization and globalization of culture - deal with temporal changes. Yet, systematic research about these processes is scarce due to the lack of suitable longitudinal data. This book explores these questions through the lens of a crucial institution of cultural mediation - the culture sections in quality European newspapers from 1960 to 2010.

Starting from the framework of cultural stratification and employing systematic content analysis both quantitative and qualitative of more than 13,000 newspaper articles, Enter Culture, Exit Arts? presents a synthetic yet empirically rich and detailed account of cultural transformation in Europe over the last five decades. It shows how classifications and hierarchies of culture have changed in course of the process towards increased cultural heterogeneity. Furthermore, it conceptualizes the key trends of rising popular culture and declining highbrow arts as two simultaneous processes: the one of legitimization of popular culture and the other of popularization of traditional legitimate culture, both important for the loosening of the boundary between 'highbrow' and 'popular'.

Through careful comparative analysis and illustrative snapshots into the specific socio-historical contexts in which the newspapers and their representations of culture are embedded - in Finland, France, Spain, Sweden, Turkey and the UK - the book reveals the key patterns and diversity of European variations in the transformation of cultural hierarchies since the 1960s. The book is a collective endeavour of a large-scale international research project active between 2013 and 2018.

Semi Purhonen is Associate Professor of Sociology at the Faculty of Social Sciences, University of Tampere, Finland. Between 2013 and 2018, he worked as academy research fellow at the Academy of Finland and was the Director of the research project 'Cultural Distinctions, Generations and Change', which lays the ground for the present book. His research interests are in the fields of cultural sociology, consumption, lifestyles and social stratification; sociology of age, generation and social change; and comparative research and sociological theory. 
Riie Heikkilä is a postdoctoral researcher at the Faculty of Social Sciences at the University of Tampere, Finland. Her main research interests include cultural capital, cultural consumption and social stratification, and comparative sociology in general. Her research project 'Understanding Cultural Disengagement in Contemporary Finland' has funding from the Academy of Finland until 2020.

Irmak Karademir Hazır is Senior Lecturer in Sociology at the Department of Social Sciences, Oxford Brookes University, UK. Her research focuses on topics such as taste, socio-cultural change, Bourdiesian analysis of Turkish consumption scene and embodiment. She has worked as a board member of the European Sociological Association, Consumption Research Network and International Sociological Association, Research Committee on the Body in the Social Sciences.

Tina Lauronen is a $\mathrm{PhD}$ candidate at the Department of Social Research, the University of Helsinki, Finland. She has worked in the project 'Cultural Distinctions, Generations and Change' with a funding from Kone Foundation, and her dissertation focuses on the cultural globalization through the content analysis of the data from culture sections in quality European newspapers.

Carlos J. Fernández Rodríguez is Senior Lecturer at the Department of Sociology of Universidad Autónoma de Madrid, Spain. His research interests are sociology of consumption, sociology of work and organizations, and industrial relations. He currently acts as the President of the Research Committee of Sociology of Consumption at the Spanish Federation of Sociology.

Jukka Gronow is Professor Emeritus of Sociology at the Uppsala University, Sweden. His professional interests cover social theory, economic sociology and the sociology of consumption as well as the social and cultural history of the Soviet Union. His latest book is Fashion Meets Socialism: Fashion Industry in the Soviet Union after the Second World War (SKS 2015, co-authored with Sergey Zhuravlev). 


\section{Culture, Economy and the Social}

\section{A new series from CRESC - the ESRC Centre for Research on Socio- Cultural Change}

The Culture, Economy and the Social series is committed to innovative contemporary, comparative and historical work on the relations between social, cultural and economic change. It publishes empirically based research that is theoretically informed, that critically examines the ways in which social, cultural and economic change is framed and made visible, and that is attentive to perspectives that tend to be ignored or sidelined by grand theorizing or epochal accounts of social change. The series addresses the diverse manifestations of contemporary capitalism and considers the various ways in which the 'social', 'the cultural' and 'the economic' are apprehended as tangible sites of value and practice. It is explicitly comparative, publishing books that work across disciplinary perspectives, cross-culturally, or across different historical periods.

The series is actively engaged in the analysis of the different theoretical traditions that have contributed to the development of the 'cultural turn' with a view to clarifying where these approaches converge and where they diverge on a particular issue. It is equally concerned to explore the new critical agendas emerging from current critiques of the cultural turn: those associated with the descriptive turn for example. Our commitment to interdisciplinarity thus aims at enriching theoretical and methodological discussion, building awareness of the common ground that has emerged in the past decade and thinking through what is at stake in those approaches that resist integration to a common analytical model.

\section{Editors}

Professor Tony Bennett, Social and Cultural Theory, University of Western Sydney; Professor Penny Harvey, Anthropology, Manchester University; Professor Kevin Hetherington, Geography, Open University

\section{Editorial Advisory Board}

Andrew Barry, University of Oxford; Michel Callon, École des Mines de Paris; Dipesh Chakrabarty, University of Chicago; Mike Crang, University of Durham; Tim Dant, Lancaster University; Jean-Louis Fabiani, Écoles de Hautes Études en 
Sciences Sociales; Antoine Hennion, Paris Institute of Technology; Eric Hirsch, Brunel University; John Law, The Open University; Randy Martin, New York University; Timothy Mitchell, Columbia University; Rolland Munro, Keele University; Andrew Pickering, University of Exeter; Mary Poovey, New York University; Hugh Willmott, University of Cardiff; Sharon Zukin, Brooklyn College City University New York/Graduate School, City University of New York

\section{Speculative Research}

The Lure of Possible Futures

Edited by Alex Wilkie, Martin Savransky and Marsha Rosegarten

\section{Markets and the Arts of Attachment}

Edited by Franck Cochoy, Joe Deville and Liz McFall

\section{The Known Economy}

Romantics, Rationalists, and the Making of a World Scale

Colin Danby

\section{Unpacking IKEA}

Swedish Design for the Purchasing Masses

Pauline Garvey

\section{Film Criticism as a Cultural Institution}

Crisis and Continuity from the 20th to the 2 Ist Century

Huw Walmsley-Evans

\section{A World Laid Waste?}

Responding to the Social, Cultural and Political Consequences of Globalisation

Edited by Francis Dodsworth and Antonia Walford

\section{The Persistence of Taste}

Art, Museums and Everyday Life After Bourdieu

Edited by Malcolm Quinn, David Beech, Michael Lehnert, Carol Tulloch and Stephen Wilson

\section{Enter Culture, Exit Arts?}

The Transformation of Cultural Hierarchies in European Newspaper Culture Sections, 1960-2010

Semi Purhonen, Riie Heikkilä, Irmak Karademir Hazır, Tina Lauronen, Carlos J. Fernández Rodríguez and Jukka Gronow

For a full list of titles in this series, please visit www.routledge.com/CRESC/ book-series/CRESC. 


\section{Enter Culture, Exit Arts?}

The Transformation of Cultural Hierarchies in European Newspaper Culture Sections, 1960-2010

Semi Purhonen, Riie Heikkilä, Irmak Karademir Hazır,

Tina Lauronen, Carlos J. Fernández Rodríguez and Jukka Gronow

Routledge

Taylor \& Francis Group LONDON AND NEW YORK
$\mathrm{E} \cdot \mathrm{S} \cdot \mathbf{R} \cdot \mathrm{C}$ ECONOMIC \& SOCIAL RESEARCH COUNCIL

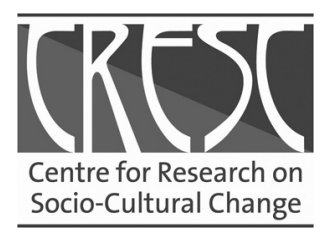


First published 2019

by Routledge

2 Park Square, Milton Park, Abingdon, Oxon OXI4 4RN

and by Routledge

7II Third Avenue, New York, NY I00I7

Routledge is an imprint of the Taylor \& Francis Group, an informa business

(C) 2019 Semi Purhonen, Riie Heikkilä, Irmak Karademir Hazır,

Tina Lauronen, Carlos J. Fernández Rodríguez and Jukka Gronow

The right of Semi Purhonen, Riie Heikkilä, Irmak Karademir Hazır, Tina Lauronen, Carlos J. Fernández Rodríguez and Jukka Gronow to be identified as authors of this work has been asserted by them in accordance with sections 77 and 78 of the Copyright, Designs and Patents Act 1988.

All rights reserved. No part of this book may be reprinted or reproduced or utilised in any form or by any electronic, mechanical, or other means, now known or hereafter invented, including photocopying and recording, or in any information storage or retrieval system, without permission in writing from the publishers.

Trademark notice: Product or corporate names may be trademarks or registered trademarks, and are used only for identification and explanation without intent to infringe.

British Library Cataloguing-in-Publication Data

A catalogue record for this book is available from the British Library

Library of Congress Cataloging-in-Publication Data

A catalog record has been requested for this book

ISBN: 978-I - I 38-74055-6 (hbk)

ISBN: 978-I-3I5-I8340-4 (ebk)

Typeset in Goudy

by Wearset Ltd, Boldon, Tyne and Wear 


\section{Contents}

List of figures $\quad$ xi

List of tables xiii

List of boxes $\quad \mathrm{xV}$

Preface and acknowledgements xvi

1 Introduction: newspapers and the study of changing cultural hierarchies

Prologue: the day that sealed the status of rock as art? 1

The themes of this book 3

Aims and definitions 6

Why study cultural change through newspapers? 9

Cultural stratification: beyond the consumption/production divide 10

Data and the comparative setting 12

Approach and methods 17

Outline of the book 19

\section{PART I}

The shift in cultural legitimacy

2 The transformation: on the rise of popular culture and the decline of classical highbrow arts

Introduction 27

The opening up of legitimate culture: theoretical perspectives 28

Comparative dimensions and expectations 31

Towards increased heterogeneity? The persistent dominance of the most established arts 34 
Transformations inside the established arts: literature and music 41

The decline of classical highbrow arts 46

Conclusion 52

3 Both legitimization and popularization: how evaluations

of pop-rock and classical music have become

increasingly similar

Introduction 61

The concepts of legitimization and popularization 63

An aesthetic dimension in the articles published in culture sections 68

Legitimization and popularization: quantitative approach 71

Legitimization of pop-rock 75

Popularization of classical music 82

The tension between artistic quality and commercial success in aesthetic evaluations 87

Conclusion 90

\section{PART II}

Dimensions of the transformation

4 Globalization: on the tension between national and international culture

Introduction 97

Perspectives on the globalization of culture 99

Cultural globalization: quantitative approach 103

Cultural globalization: qualitative approach 111

Conclusion 120

5 Commercialization: on the commercial dimension and advertisements

Introduction 123

From the enduring tension between art and money to commercialization of culture 124

Autonomy in peril? The commercialization of cultural journalism 126 
Commercial dimension in newspaper data: quantitative approach 130

The role of commercial elements in cultural coverage: qualitative approach 133

Advertising as another aspect of the commercial dimension 142

Conclusion 146

6 Beyond culture: politics and the role of culture in a wider socio-historical context

Introduction 149

Artistic valuation and politics: a complicated relationship 150

Political dimension in newspaper data: quantitative approach 153

Spanish and Turkish national identities in the making: political contexts 159

Continuity and change 162

Conclusion 170

\section{PART III}

The place and space of culture

7 Packaging of culture: on the 'crisis' of cultural journalism and journalistic popularization

Introduction 175

Changing cultural journalism 176

The space of culture 178

The place of culture 181

The packaging of culture 184

Is there a 'crisis'? 187

Culture cover stories 191

Conclusion 194

8 Conclusion

Epilogue: the death of a philosopher-celebrity 197

Enter culture, exit arts? 199

Transformation and stability 201

Problems in comparative research and studying cultural change 204 
Appendix A: collecting and coding the newspaper data 209

Appendix B: additional tables 213

References

Index 


\section{Figures}

2.1 Articles on film, radio, small emerging art forms and society, policy and media by year, separately on each newspaper (percentages)

2.2 Articles on literary fiction and non-fiction (of all articles on literature) by year, separately on each newspaper (percentages)

2.3 Articles on classical music and pop-rock (of all articles on music) by year, separately on each newspaper (percentages)

2.4 Articles on theatre and the visual arts by year, separately on each newspaper (percentages)

2.5 The proportion of articles on highbrow arts and popular culture (left) and the absolute number of articles on highbrow arts and popular culture (right) by year

3.1 At least half-page long classical music and pop-rock articles by year, separately on main article types (percentages)

3.2 Illustrated classical music and pop-rock articles by year, separately on main article types (percentages)

3.3 Classical music and pop-rock articles including aesthetic dimension by year, separately on main article types (percentages)

4.1 Origins of cultural products discussed in the articles by year, separately on each newspaper (percentages)

4.2 Origins of cultural products discussed in the articles by year, separately on classical music and pop-rock articles (percentages)

4.3 Origins of cultural products discussed in the articles by year, separately on four art forms (percentages)

4.4 Articles on highbrow arts and popular culture by year, separately on origins of cultural products (percentages)

5.1 Articles including aesthetic dimension, commercial dimension and both aesthetic and commercial dimensions by year, separately on main article types (percentages) 
5.2 The main content of the page in culture sections by year (percentages)

5.3 The topics of advertisements published in culture sections by year (percentages)

6.1 Articles on highbrow arts and popular culture including political dimension by year (percentages)

6.2 Articles including political dimension, both aesthetic and political dimensions and both commercial and political dimensions by year, separately on main article types (percentages)

7.1 Pages per issue (means) by year and whether the content has been published in 'core' newspaper or supplement, separately on the entire issue (left) and sections devoted to culture (right)

7.2 The quarter of the first cultural page by year and newspaper (means)

7.3 Size-adjusted proportions of main article types of all articles by year, separately on each newspaper (percentages)

7.4 At least half-page long and illustrated articles on highbrow arts and popular culture by year, separately on main article types (percentages) 


\section{Tables}

1.1 Basic information about the newspapers included in the study

1.2 Breakdown of the data by year and newspaper (percentage of total and number of articles)

2.1 Primary cultural area discussed in the articles by year (percentages)

2.2 Six largest cultural areas discussed in the articles by newspaper (percentages)

2.3 Articles on different literature genres (of all articles on literature) by year (percentages)

2.4 Articles on different musical genres (of all articles on music) by year (percentages)

2.5 Articles on popular culture and highbrow arts by year (percentages)

2.6 Articles on highbrow arts by newspaper and year (percentages)

3.1 'High art' and 'popular' aesthetic criteria potentially used in evaluations of popular and classical music

3.2 Articles including aesthetic dimension by newspaper and year (percentages)

3.3 Articles including aesthetic dimension by art form and year (percentages)

4.1 Origins of cultural products discussed in the articles by year (percentages)

5.1 Articles including commercial dimension by newspaper and year (percentages)

5.2 Articles including commercial dimension by art form and year (percentages)

6.1 Articles including political dimension by newspaper and year (percentages)

6.2 Articles including political dimension by art form and year (percentages)

7.1 The locations of culture sections in newspapers by newspaper and year 
7.2 Type of article by year (percentages)

7.3 Sizes of articles by year (percentages)

7.4 Coverage (size-adjusted proportion) of main article types by year (percentages)

7.5 Indicators of the journalistic popularization of cultural content by year (percentages)

7.6 At least half-page long first articles (cover stories) of culture sections by newspaper, art form and other characteristics and year (absolute numbers and percentages)

B.1 All cultural supplements included in the newspapers of this study with their main topics

B.2 Socio-demographic information about the countries in which the newspapers included in the study are published

B.3 Newspaper industry, readership and trust in the countries in which the newspapers included in the study are published

B.4 Indicators of cultural production in the countries in which the newspapers included in the study are published

B.5 Indicators of cultural consumption in the countries in which the newspapers included in the study are published

B.6 Indicators of cultural policy in the countries in which the newspapers included in the study are published

B.7 List of references for the quoted newspaper articles 


\section{Boxes}

2.1 Computer games: legitimate culture? 36

2.2 The shrinking theatre 48

2.3 Meanwhile, in Turkey: on the socio-political limits of
(Western) cultural transformation

3.1 Jazz: between highbrow and popular music 65

3.2 Television: from medium to an art form of its own 80

4.1 Finnish classical music nationalism 101

4.2 Connected by language and cultural ties: the case of Latin America

5.1 The price of art

5.2 Indisputably commercial: the case of the Spanish music industry

6.1 Meanwhile, in Sweden: cultural policy and politics in Dagens Nyheter

7.1 Choosing lifestyles: the emergence of cultural supplements 179 


\section{Preface and acknowledgements}

This is a book about changes in cultural classifications and hierarchies in Europe over the last half-century. We investigate cultural change through a crucial institution in cultural mediation capable of deciding what is good and valuable culture and art: the culture sections in 'quality' European newspapers. We show how classifications and hierarchies of culture have changed and the ways in which many key trends - such as globalization and commercialization of culture - are intertwined with the post-1960s transformation towards increased cultural heterogeneity and loosening of the old distinctions between 'high' and 'popular'. These trends and questions uncovered in the book have been widely discussed, but often also taken for granted, in contemporary cultural sociology. Thus, by bringing the temporal processes to the fore of cultural sociological research, the book aims to provide an empirically grounded and comprehensive analysis of these cultural changes.

Utilizing media data is a means of resolving the persistent problem of cultural sociology interested in temporal processes: the lack of good quality longitudinal data. In fact, the book has grown, at least partly, from the frustration towards the common situation in studies of cultural tastes and consumption: even if many, if not all, of the most interesting themes and debates revolve essentially around trends and processes, studies are usually impotent in analysing them due to their cross-sectional design. In the context of this study, newspapers and their special pages devoted to arts and culture offer a useful data source since the cultural content in these pages reflects changes in dominant cultural classifications and hierarchies.

The book is based on a research project 'Cultural Distinctions, Generations and Change', started in 2013 and led by Semi Purhonen, first at the University of Helsinki and since 2014 at the University of Tampere, Finland. The project has been essentially a collective and international endeavour, a fact that is reflected in the content of this book and in the team of its authors. Collecting and coding, not to speak of analysing and interpreting, the multilingual newspaper data made it clear from the start. Thus, it was both natural and serendipitous that the original, Finnish, team including Semi Purhonen, Riie Heikkilä, Tina Lauronen and Jukka Gronow, was complemented by Irmak Karademir Hazır and Carlos J. Fernández Rodríguez during 2014. 
In addition to the main team, several other people have helped carrying out the research for which we are grateful. In most practical terms, these people include research assistants Elias Lehtonen and Pekka Salminen at the University of Helsinki (2013-2014), Minttu Haaparanta and Olli Tiikkainen at the University of Tampere (2015-2016) and Emine Ecem Ece at the Middle East Technical University (2014); and coders recruited to help the main research team when coding the newspapers (2014-2015), namely, Pia Kostamo, Ukko Perttilä, Nelli Tiainen and Eveliina Wirtanen.

During its span, the research project organized and was invited to participate in several seminars and meetings, most importantly KuHiSE (the regular 'Culture, Hierarchy and Social Differentiation' seminar at the University of Helsinki between 2014 and 2016) and a series of workshops, held in London (February 2013), Madrid (October 2013 and November 2015), Helsinki (March 2014, May 2014 and December 2017), Manchester (May 2015 and May 2016), Tartu (November 2015), Rotterdam (June 2016) and Tampere (May 2017). We wish to thank all the people participating and commenting on our work in these events, in particular Susanne Janssen, Marc Verboord, Pauwke Berkers, Janna Michael and Rian Koreman; Keijo Rahkonen, Luis Enrique Alonso, Alan Warde and David Wright; Adrián Leguina and Predrag Cvetičanin; Marju Lauristin and Peeter Vihalemm; and Anu Katainen, Maarit Jaakkola, Arho Toikka and Olli Heikkinen. Most importantly, we are grateful to Susanne Janssen and Marc Verboord for sharing their experiences (as well as the codebook) of a large-scale, earlier research project 'Cultural Classification Systems in Transition' conducted in the Netherlands, which has inspired our own work in multiple ways. We have also benefited from the feedback given by our Tampere colleagues, especially Pertti Alasuutari, Ali Qadir and Taru Lindblom, and colleagues from Turkey, Agah Hazır and Özgür Yaren.

Early drafts of work published in this book have been presented in several national and international conferences, such as the ones of the American Sociological Association (Seattle, 2016), British Sociological Association (Manchester, 2017), Eastern Sociological Society (Boston, 2016 and Baltimore, 2018), European Sociological Association (Prague, 2015 and Athens, 2017), International Sociological Association (Yokohama, 2014 and Vienna, 2016), Nordic Sociological Association (Lund, 2014 and Helsinki, 2016), Spanish Sociological Association FES (Barcelona, 2015 and Gijón, 2016) and Westermarck Society (Jyväskylä, 2016 and Tampere, 2017). Out of all the useful comments, ideas and criticism, we want to thank especially the stimulating and always encouraging atmosphere of the ESA research network RN05 Sociology of Consumption.

We wish to thank also Routledge and our series editor Tony Bennett for making this book see the light of day.

Segments of this book have been adapted from three previously published journal articles. 'The Grand Opening? The Transformation of the Content of Culture Sections in European Newspapers, 1960-2010' (Purhonen, Heikkilä 
and Karademir Hazır, 2017), published in Poetics and used here by courtesy of Elsevier, has been utilized in parts of Chapters 1 and 2. Chapter 4 shares the same, basic research question (albeit with different empirical analyses) as the article 'Cultural Globalization on the Printed Page: Stability and Change in the Proportion of Foreign Cultural Products in European Quality Newspapers, 1960-2010' (Lauronen, Purhonen and Heikkilä, 2018), published in Acta Sociologica in 2018 and used here by courtesy of Sage Publications. Finally, a section of Chapter 7 overlaps with 'The Crisis of Cultural Journalism Revisited: The Space and Place of Culture in Quality European Newspapers from 1960 to 2010' (Heikkilä, Lauronen and Purhonen, 2017), published in European Journal of Cultural Studies and used here by courtesy of Sage Publications.

The research project behind the book has received funding from the Academy of Finland (2013-2018; project numbers 291619 and 309181), Kone Foundation (2013-2016) and the University of Helsinki research grants (2013-2015). 


\title{
Introduction
}

\author{
Newspapers and the study of \\ changing cultural hierarchies
}

\section{Prologue: the day that sealed the status of rock as art?}

John Lennon was murdered on 8 December 1980. Lennon, the ex-Beatle and one of the most popular and renowned rock musicians worldwide, was coming home late on a Monday evening, when Marc David Chapman shot him in front of his home in New York City. The death of John Lennon was instant news, and in the following days and weeks a global media event took place, marked by mass mourning by fans and evaluations of Lennon's music, career and personality by critics and journalists (Fogo, 1994; Elliot, 1999). The news was widely reported the next day, but it was on the following day, Wednesday 10 December 1980, when the press published the first proper obituaries and remembrances on Lennon. On that day, among many other media outlets, several broadsheet newspapers across Europe devoted significant space to writings about John Lennon in their culture and arts sections.

The Guardian in the UK published two articles on Lennon on the first page of its 'Arts Guardian' section. Several pictures of Lennon accompanied the articles that shared a brief vignette: 'Honest, sardonic, passionate, bitter, funny, harsh, idealistic - Guardian writers remember John Lennon'. The articles presented obituary-style personal reminiscences about Lennon's career and characteristics as a person. The first article, titled 'They are Going to Crucify Me...', describes Lennon as 'unpredictable, but with a genius for popular song that kept re-emerging in his work despite his sometimes childish excesses' (GU/10/12/80_10a). ${ }^{1}$ The second article, titled 'The Cruel and Uncompromising Working Class Hero', refers to his 'genius', 'intelligence' and 'extraordinary character' and states that Lennon was the 'Ernest Hemingway of rock music' (GU/10/12/80_10b). Thus, the articles predictably painted a very strong picture of Lennon as an artist and a genius, although also as a contradictory person. Of course, obituary as a writing genre is emotional and allows the use of an exceptional number of superlatives (Johnson, 2006), but similar types of characterizations of Lennon - as an ingenious yet ambivalent character and a true artist - have been subsequently repeated, elaborated and debated in countless articles and monograph-length studies (e.g. Wiener, 1984; Norman, 2008). 
Similar articles with essentially similar types of characterizations of Lennon were also published on 10 December 1980 outside the UK, in other major European newspapers. Le Monde in France covered 'La mort de John Lennon' with a large ensemble of articles starting on the front page of the newspaper and continuing in the culture section. ${ }^{2}$ Le Monde approached Lennon in a very artistically oriented style, even calling him 'the master singer of the sixties, the pope of rock, our assassinated Mozart' (LM/10/12/80_1). Interestingly, a few Beatles' song lyrics were quoted in full as French translations, and the qualities of Lennon as a musician were emphasized along with praising the songs written by him as 'the most important ones of the rock movement, those which have modified the behaviour, mentality, gests and appearances of the young generation of the entire world' (LM/10/12/80_24).

In Spain, the leading broadsheet newspaper El País had two full pages on Lennon's death in its culture section. The first page was compiled by a correspondent of the newspaper and concentrates on the event as a piece of news (the exact surroundings are described in great detail; EP/10/12/80_40). Then comes a long part about Lennon as a person and the history of the Beatles. Two smaller and more personal articles complete the compilation. A personal memory from a 1964 Beatles concert in Belfast emphasizes the genius-like character and working-class origins of Lennon and the band ('four guys who, more than talent, had genius, genius as musicians, as poets, and who in the variety of their art touched all ranges of emotion'; EP/10/12/80_41b). Finally, there is a column, a kind of homage to Lennon, which discusses the death very dramatically, as something that 'killed an entire generation, our generation' (EP/10/12/80_41a). The column is written in a ceremonial style with several words in Latin (primus inter pares, requiescat in pace).

Lennon also received attention in the leading newspapers of smaller European countries. In Sweden, Dagens Nyheter wrote both a news piece describing in detail the tragic events of 8 December and, in the culture section, a more comprehensive account of Lennon's career (DN/10/12/80_24 and 25). Compared to the articles published in The Guardian, Le Monde and El País, the tone of the articles is perhaps more mundane, and it is not very evaluative or focused on Lennon's talents or unique art. One part in this section, however, includes reminiscences of contemporaries. Three Swedish journalists talk about their memories and impressions of Lennon, concentrating on Lennon's political significance and symbolic status as the voice of the 1960s generation. The most polemic statement goes: 'It is logical: the ideals of the 60 s are dead, so why not kill the guy who started the party?' (DN/10/12/80_24).

In Finland, an even smaller Nordic country than Sweden, the leading newspaper Helsingin Sanomat remained silent about Lennon in its culture section of the day. At the beginning of the newspaper, however, was a mention of the largish obituary of Lennon, published among other obituaries. ${ }^{3}$ Besides two pictures, the obituary includes first a brief news section on Lennon's death and then starts listing his qualities. Helsingin Sanomat mentions that Lennon was 
'one of the few personalities and experimentalists of rock music' and that he had 'moved the emphasis of rock from America to Europe' (10 December 1980, p. 18). After that starts the worship, which is interestingly focused on distinguishing the exquisite talent of Lennon from that of the more mundane and uninteresting talents attributed to the other members of the Beatles. 'The Beatles was a trailblazer; Lennon was its brain. Ringo and George were mere extras; Paul McCartney was at his best in prettyish ballads, but John Lennon was the insatiable experimentalist who pushed the music of the Beatles further' (Helsingin Sanomat, 10 December 1980, p. 18).

At the other end, on the south-eastern border of Europe, the Turkish newspaper Milliyet also reported the murder of John Lennon. Similar to Helsingin Sanomat in Finland, Milliyet did not cover Lennon in its culture section but in another part of the newspaper of the day, namely, in a 'lifestyle' themed supplement. A nearly half-page long and illustrated article on Lennon appeared on the cover page of the supplement (MIL/10/12/80_Yaşam_1). The article is most of all a detailed news story about the tragic events, but it also reports reactions to Lennon's murder from other countries, for instance how 'all radios in the world [...] played his songs. Belgrade's radio station in Yugoslavia played Beatles songs after announcing his death and also broadcast his previous interviews' and that 'the murder has been condemned in Japan as well. The recording companies stopped their ongoing agendas and began to publish old Beatles records again' (MIL/10/12/80_Yaşam_1).

What do these newspapers' reactions to Lennon's murder tell us, and why have we bothered to start this book with a close look at them? Obviously, Lennon was almost a perfect case for the European press: he was very widely beloved and an international superstar; he had a long and interesting career behind him; he was living an interesting life; he was from a global centre, the UK, and operated in a global lingua franca, English. Moreover, he died in a mediatically spectacular and non-self-inflicted way (unlike many of his fellow dead rock stars of the time). These are all examples of factors playing a role in the wide coverage on Lennon, but none of them weakens the illustrative power of the case of Lennon's death, which captures the diverse, intersecting dimensions of the cultural transformation we will study in this book. Thus, instead of analysing the case of Lennon's death in itself - or the surrounding fuss further, ${ }^{4}$ we argue that it crystallizes and resonates with a host of key themes, dimensions and questions that are of great interest to sociologists of culture and anyone interested in cultural change in the Western world over the last halfcentury. These themes and dimensions of cultural change are precisely the themes and questions this book will address.

\section{The themes of this book}

The first of the themes concerns the transformation in cultural hierarchies and the changes in what is seen as prestigious and legitimate culture; what is counted 
as valuable and distinctive culture and how the boundaries and tensions between 'high' and 'low', or 'art' and 'entertainment', have been shifting (Bourdieu, 1984; DiMaggio, 1987; Baumann, 2007). The question is, on the one hand, about the legitimization of popular culture but also, on the other hand, about the popularization of traditional highbrow arts. The elevation of the status of popular culture to a level comparable with the highest arts is clearly seen in how John Lennon was characterized in the European newspapers immediately after his death: as a rock star who was also - and perhaps even primarily - a serious artist or even a genius, comparable to Mozart or Hemingway.

Second, and to specify the first theme, Lennon's murder invites us to probe deeper into the issue of the process nature, or temporal trajectory, of the shift in cultural legitimacy. Even if it would be exaggerating to argue that Lennon's murder was a proper 'turning point' in the legitimation process of rock music, or popular culture more widely, it is still useful to consider what stage this process was at 1980 (cf. Regev, 2013: 105-122; Varriale, 2016). Considering the rather long period from the breakthrough of popular culture in the 1950s and 1960s until the present, or the 2000s, the time of Lennon's death in 1980 arguably represents some sort of a hinge or bridge period between the old and the new times, during which popular music was consolidating its status as 'art'. Perhaps not coincidentally, the period was also largely the same as when the academic (including sociological) study of popular music started to institutionalize (Bennett, 2016)..$^{5}$ Moreover and relating to the temporal perspective, remembrances of Lennon exemplify the power of retrospective consecration (Schmutz, 2005). Death offers a perfect moment of punctuation from which to look back and codify the canon - in this case, to write the history of rock music (Jones and Jensen, 2005).

The third question raised by the case of Lennon concerns the boundaries and boundary crossing - between art forms and genres. John Lennon was 'not only' a rock star, although his main merits are usually seen in widening the conception of pop music and bringing pop music to the level of serious art, characterized by complexity, adventurousness, intellectual content, seriousness and an attempt to constantly renew itself (cf. Moore, 1997; van Venrooij and Schmutz, 2010). But Lennon was also more: by the 1960 s, he had already published books, including poems, short stories and drawings. Together with the Beatles, Lennon had been involved in making films. And via Yoko Ono, Lennon had been involved in performance art and other collaborative projects. Thus, Lennon embodied the possibility to cross over the boundaries of art forms and cultural genres, often seen as a pivotal feature of increased tolerance and the loosening of cultural classifications (DiMaggio, 1987; Peterson and Kern, 1996).

John Lennon, the rock star, was a global celebrity and a brand. Thus, the fourth theme, which can be substantiated with his life and career, is cultural globalization, the supposedly accelerated geographical mobility of cultural products and influences across national borders (Appadurai, 1996; Tomlinson, 1999; Janssen, Kuipers and Verboord, 2008). Born in Liverpool, starting his 
international career in Hamburg, marrying a Japanese-born woman and living and dying in New York City - Lennon's personal life also exemplifies global and cosmopolitan tendencies. Most importantly, however, Lennon's murder as a globally recognized incident and its subsequent media reception provide a helpful point of reference as it allows the posing of the question of how the same event was reacted to at the same time in various parts of the world.

John Lennon was a millionaire and a former member of the most popular and commercially successful band of all time. Therefore, the fifth theme exemplified and embodied in his career and music is the significance of the commercial aspect and the potential tension between commercialism and popularity on one hand and aesthetic quality and artistic autonomy on the other. Clearly, one of the ambivalences and contradictions of Lennon as an artist that was referred to in the newspapers' obituaries is due to this charged dimension between ambitious artist and popular entertainer. Using Pierre Bourdieu's (1993, 1996) terms, the picture created from the media reception of Lennon's life and music suggests that Lennon managed to walk the line between the 'field of large-scale cultural production' and the 'field of restricted cultural production'. Or, at least, he was capable of preserving his credibility in the latter (art field), despite his success in and the main area being the former (the field of popular culture).

Sixth, John Lennon, the 'working-class hero' and a politically active, rebellious and anti-war figure, exemplifies and embodies - besides the troubled relationship between commercialism and artistic autonomy - the similarly troubled and ambivalent relationship between politics and artistic autonomy, the role played by politics in artistic work and aesthetic evaluations. If commercialization has been seen as challenging the autonomy of the arts, the same goes for the forces brought to bear on the arts by means of politics and the politicization of the arts (Bourdieu, 1993). Even if there are opinions that may valorize or even expect political commitment from artists and art to be 'socially relevant', 'critical' or 'progressive' (e.g. Rancière, 2004), there is a strong consensus that if politics are given too strong a role in cultural life, the autonomy of the arts is in serious peril. Even if the role of politics as a threat to the autonomy of the arts has been quite weakly pronounced during recent decades in Western countries, it is enough to go back to 1970s Francoist Spain or the 1980s Soviet bloc countries, not to speak of Turkey, oscillating between Western openness and Middle Eastern religiously driven regimes, to see the power of politics shaping culture and the arts - all of them also historical contexts where John Lennon and likeminded rock musicians have been considered dangerous and every now and then ended up being censored.

Seventh, an additional dimension to the previous themes is whether the format and means of reporting about arts and culture - the layout and use of illustrations, the size and type of articles and even the ways of writing and stylistic features of the text - have changed over time. One thing to notice from the coverage of Lennon's murder was, for instance, that there appeared to be clear similarities among articles published by different newspapers. Surely, by 1980, 
there were news agencies that had just put the stories forward, which were therefore repeated in more or less the same formats in all newspapers (regarding news details such as 'how many bullets' and 'fell in front of the doorstep' but also notions such as the 'voice of the generation' and a 'rebel who fought for peace'). Thus, some of the material in the Lennon coverage looks as if it has just been digested and shuffled a tiny bit by the newspapers' editorial staffs. However, apart from that, Lennon's case invites us to explore more broadly the ways in which cultural content has been 'packaged' (Verboord and Janssen, 2015) in the cultural pages of European newspapers.

Eighth, and finally, elaborating on the fourth question of globalization and the ways in which Lennon's murder was received in various parts of Europe, the case of Lennon can be used to raise an overarching question of cross-cultural variation among the media representations regarding all the previous themes and dimensions. To what degree do media outlets reflect their respective national contexts and 'evaluative repertoires' (Lamont and Thévenot, 2000) in their reception and writings of culture? Are there society-level structural characteristics that can help in understanding the systematic differences of cultural coverage in the media along national borders (cf. Hallin and Mancini, 2004)? Of course, there is a danger to be avoided of going to a level too low in inspecting (and finding) variation between differently located media. In a single case, it is hard if not impossible to say whether a difference - such as the Swedish Dagens Nyheter's reporting about Lennon's murder in a more descriptive, mundane and non-evaluative tone compared to the reporting in the French Le Monde - is in any important sense a meaningful finding. However, if differences such as these are systematically repeated in dozens or hundreds of cases, there is obviously a more solid ground for trying to find substantial reasons and interpretations for the patterned variation among newspapers published in different national contexts.

\section{Aims and definitions}

Instead of focusing any longer on the case of Lennon, or on rock and the field of music alone, this book will explore these themes - the processes of the heterogenization, legitimization, popularization, globalization and commercialization of culture as well as the changing nature of the link between arts and politics and questions of how cultural content has been 'packaged' and to what degree there is cross-cultural variation with respect to all these issues - by covering all forms of art and culture discussed in European newspapers' culture sections from 1960 to 2010. This is done by means of a systematic content analysis of a dataset covering fifty years - which happens to include the day two days after Lennon's murder and thus the previously cited articles - from the major European newspapers already mentioned: The Guardian (in the UK), Le Monde (in France), ABC and El País (in Spain), Dagens Nyheter (in Sweden), Helsingin Sanomat (in Finland) and Milliyet (in Turkey). 
The underlying question behind all these themes and processes is how cultural classifications and hierarchies have changed over the research period between 1960 and 2010. There is a broad consensus that cultural classifications and hierarchies are neither natural nor eternal; they are social products that are continuously being made and remade (see e.g. Bourdieu, 1984; Janssen, 1999; Lena and Peterson, 2008). Moreover, the period since 1960 has been marked by rapid social change in Western societies, including the six countries in which our newspapers are published. Thus, and as already shown by previous studies on cultural change (e.g. Peterson and Kern, 1996; Janssen, Verboord and Kuipers, 2011; Schmutz, 2016), it is expected that cultural hierarchies and ways of valuating and evaluating arts and culture have profoundly changed over this period.

We are particularly interested in two aspects regarding the trends in how cultural classifications and hierarchies have changed. The first concerns crosscultural variation. It has been argued widely that cross-national differences in cultural classifications are related to cross-national differences in social structural features (DiMaggio, 1987; Lamont, 1992; Janssen et al., 2008). While there are plenty of possible indicators of societal-level factors shaping cultural classifications according to socio-geographical boundaries, there are also organizational (or field-level) factors concerning the newspapers themselves, on the one hand, and the art world or cultural domains (their 'inner' trajectories outside the newspaper coverage), on the other. All of these play a role in how classifications and hierarchies represented on the pages of our newspapers may vary. The second aspect of special interest deals with differences among art forms, cultural domains and genres. Do the ways in which hierarchies have changed vary among these? To what degree do the changes apply to the articles on traditional highbrow arts, on one hand, and popular culture, on the other hand? And are the relationship and balance between 'highbrow' and 'popular' at the heart of the transformation of cultural hierarchies and, if so, in which ways?

Before going into the topic of why we have chosen to study the cultural transformation through newspapers, it is important to emphasize three aspects. First, our primary focus is on the varying amount of value given to different forms of art and culture - either through the disproportional space assigned to such cultural forms or, more directly, in the ways that such forms of culture are valuated and evaluated. Thus, the question is about what is considered as prestigious and distinguished culture and thereby counted inside the 'content' of legitimate culture. These questions are directly related with the boundary drawn between 'high' and 'popular' culture and whether its symbolic strength has faded. Consequently, the other key processes we will analyse, such as cultural globalization or commercialization, are not considered as independent but rather as supplementary dimensions to this major concern of how cultural hierarchies have changed. Thus, they are not analysed separately from, but intertwined with, the context of the post-1960s cultural change and the transformation in the content of legitimate culture this has brought about. 
Second, in this book, we use the term 'highbrow' culture and 'popular' culture as value-neutral and empirically fixed concepts (cf. Gans, 1974). This is because we want to examine what exactly has happened to the forms of art and culture conventionally defined under these categories and, most of all, whether the cultural forms traditionally considered as 'popular' have gained legitimacy and if the traditional 'highbrow' arts have become popularized. By 'highbrow', we refer to the classical art forms such as opera, ballet, classical music, the visual arts, poetry and literary fiction, which have been associated with the upper echelons of society and considered widely to be the most prestigious of all arts in the Western world for at least three centuries and especially since the late eighteenth century. ${ }^{6}$ By 'popular' culture, we mean broadly all forms of art and culture that are not included in the (conventionally defined) highbrow arts. Hence, the meanings of 'highbrow' and 'popular' thus defined receive their meanings vis-à-vis each other. Even though popular culture has a long history (Burke, 2009), the major and most visible part of it, in the view of this study, emerged and grew due to mass-mediated distribution channels during the second half of the twentieth century, such as pop and rock music, television, film, comics and video games. When referring to these specific forms of popular culture as distinguished from more traditional folk culture, we might highlight the notion by the word 'emergent' or call them 'pop culture' instead of 'popular culture'. While being aware of the normative roots and problems associated with these concepts, especially the concept of 'highbrow', we follow a research tradition in which it is customary to use them in this instrumental manner, providing a conventional shorthand for clusters of art forms falling inside these two categories. $^{?}$

Third, it is equally important to clarify what this book is not about. Most importantly, our aim is not to explain causally why these cultural trends have happened. ${ }^{8}$ At best, we can observe associations between the indicators of transformation in the newspapers and society-level factors of the nations in which the newspapers are published. However, there are a variety of factors and levels involved in the processes (including, as already mentioned, not only factors at the societal level but also at the organizational levels concerning newspapers and the art world), many of which we cannot control for or separate from each other. These associations are, accordingly, far from explanations, and should be interpreted with appropriate caution. Moreover, apart from technical difficulties, on a more profound level, the problem is that 'cultural hierarchy is always multicausal' (Baumann, 2007: 176). Thus, instead of causal analysis, we focus on documenting and describing the trends, taking into account their multiple dimensions and interrelationships among the dimensions. Thus, we see value in describing and exploring the change in its own right (cf. Savage and Burrows, 2007; Savage, 2009). 


\section{Why study cultural change through newspapers?}

The media, as an institution, plays a key role in how different cultural classifications and hierarchies appear, spread, become legitimized and are debated (Janssen, 1999). For this reason, widely circulated 'quality' newspapers, with their pre-defined sections devoted to arts and culture, provide useful data (e.g. DiMaggio, Nag and Blei, 2013; Janssen et al., 2011; Verboord, Kuipers and Janssen, 2015). Moreover, sociologists interested in cultural change often encounter a lack of suitable datasets enabling the tracking of long-term trends over several decades and across a variety of national contexts; using newspaper data is a means to overcome this problem.

Specialized sections on arts and culture were established in many major European newspapers around the middle of the twentieth century (Jaakkola, 2015). Especially during the golden age of print media - the latter part of the twentieth century - quality newspapers were among the key institutions of cultural mediation, attributing symbolic value to cultural forms and objects by framing them as valuable enough to be showcased as 'art' (Bourdieu, 1993; Janssen, 1999; Verboord et al., 2015). ${ }^{9}$ The content in quality newspapers 'reproduces representations current among public intellectuals' and thereby 'provides clues as to what elites are thinking' (DiMaggio et al., 2013: 573). More specifically, as for the culture sections, the space allocated to varying cultural domains can be considered a proxy of their prestige: 'The (relative) amount of newspaper space for information on art, particular art forms, or specific works and producers is indicative of their cultural status at a given point in time' (Janssen, 1999: 300).

The contents of culture sections are based on socially legitimized experts' aesthetic selections (Janssen et al., 2011), thus exposing the existing hierarchies of respective time periods. ${ }^{10}$ Moreover, newspapers are unique forums for opinion-making. As DiMaggio and his colleagues put it, 'press coverage both reflects and represents one stream of influence in the formation of elite and public opinion' (2013: 547). Therefore, cultural journalists and critics are significant cultural intermediaries - both gatekeepers who select what will be showcased and tastemakers who define what counts as 'good' taste. ${ }^{11}$ Thus, the cultural content in newspapers provides an excellent lens through which one can investigate cultural change.

The concept of cultural intermediary, originally championed by Bourdieu (1984) and recently a topic of intense debate (Matthews and Smith Maguire, 2014), is revealing in clarifying the role of cultural journalists. The concept provides an empirically grounded perspective on the multitude of processes in which social groups, labelled as cultural intermediaries, 'perform critical operations in the production and promotion of consumption, constructing legitimacy and adding value through the qualification of goods' (Matthews and Smith Maguire, 2014: 1). For Bourdieu, cultural intermediaries are most of all 'taste makers and need merchants' from specific occupational groups that are instrumental in matching the correspondence between cultural production and 
consumption (i.e. supply and demand): 'producers of cultural programmes on TV and radio or the critics of "quality" newspapers and magazines and all the writer-journalists and journalist-writers' (Bourdieu, 1984: 325; see also Hesmondhalgh, 2006; Smith Maguire, 2014).

Lately, this view has been heavily criticized because the mediation of cultural forms - the creation of symbolic value and participation in the legitimation of cultural products - can be seen as a much broader process, performed by a range of occupations and not just those Bourdieu imagined (Negus, 2002; McFall, 2014; see also Karpik, 2010). Overall, cultural mediation is itself a complicated process in which many different kinds of actors take part, and subsequently it might become hard if not impossible to distinguish who the cultural intermediaries are and who are not. Luckily, even if this critique might be well justified, from the point of view of this study, it is important that nobody likely disagrees with the notion that cultural journalists and reviewers are 'for sure' cultural intermediaries who create and attribute symbolic value to cultural objects, even if there would be many others as well.

\section{Cultural stratification: beyond the consumption/ production divide}

The concept of cultural intermediary invites us to pose a question concerning the relationship between cultural production and consumption, ${ }^{12}$ which is directly relevant for this book, as it has implications as to what we can and cannot say based on our newspaper data and what the information derived from the newspaper culture sections is really indicative of.

While cultural intermediaries, in the traditional sense at least, indeed mediate culture and thus operate between the fields of cultural production and consumption, we approach our main question of how cultural classifications and hierarchies have changed from the perspective of cultural stratification, which is a framework that does not highlight the difference between production and consumption. ${ }^{13}$ On the contrary, and despite the fact that the studies of the consumption and the production of culture have mostly been separated in recent sociological research (Wright, 2015: 119), the fundamental starting point - explicitly stressed by some foundational works of the tradition (DiMaggio, 1987; Bourdieu, 1993, 1996) - is that the perspective of cultural stratification should involve both production and consumption. Theoretically, consumption and production are two sides of the same coin, and they are incomplete or even meaningless if taken independently from each other as separate phenomena (Marx, 1973: 88-94; Bourdieu, 1993, 1996). Especially when looked at from a long-term historical perspective, consumption and production 'must' correspond with each other. For example, in The Rules of Art, when discussing the formation of the literary field and the role of authors and consumers in it (and critics in a mediating position between the two), Bourdieu highlights the correspondence between cultural producers and consumers by writing that it is: 
a coincidence so miraculous that it may appear as the product of a deliberate adjustment of the supply to the demand. While cynical calculation is obviously not absent, particularly at the 'commercial' pole, it is neither necessary nor sufficient in order to produce the harmony observed between producers and consumers of cultural goods.

(Bourdieu, 1996: 162)

The consumption side of cultural stratification - including tastes, cultural practices and lifestyles; the ways in which they enjoy varying amounts of prestige and legitimacy; and whether they are systematically organized (or not) according to social cleavages (Bourdieu, 1984; Bennett et al., 2009) - is dependent on the availability of cultural products and thus the production of culture. The production side - referring to artists, cultural industries and producers responsible for creating cultural objects - is equally obviously dependent on the consumers of culture and the 'markets of symbolic goods' (Bourdieu, 1993, 1996). Meanings, classifications, aesthetic standards and valuations attributed to cultural objects, however, can be seen as made by all actors on both sides (cf. Negus, 2002; Karpik, 2010), even if some specific groups working as professional cultural intermediaries (such as cultural journalists) are particularly influential in this process. Moreover, the hierarchies and distinctions of culture do not concern the world of symbols alone; they translate into the classifications, boundaries and characterizations of social groups and people. ${ }^{14}$ This two-way transposability of cultural hierarchies into social groupings, identities and attitudes (and vice versa) highlights the relevance of cultural classifications and hierarchies at the level of individuals and consumption. The argument can be summarized with regard to Bourdieu's famous concept of cultural capital, which clearly has its main reference point on the side of individuals and consumption: cultural capital 'presupposes the existence of institutions with the power to establish authoritatively the value of different forms of culture: in effect, to create and to defend boundaries among varying kinds of aesthetic [...] products and practices' (DiMaggio, 1991: 21).

Besides Bourdieu, it has indeed also been Paul DiMaggio (1987, 1991, 1992) who has forcefully suggested that analysing cultural stratification should be done by going beyond the dichotomy between cultural consumption and production. DiMaggio's (1987) idea of artistic classification systems - originally meant for analysing relationships among art forms and genres but lately more often adapted for purposes of cross-national comparisons of entire nations - started from a social system perspective inspired by classical sociology and steers towards making comparisons over time or across cultural contexts. DiMaggio proposed the framework explicitly in order to advance analyses on 'the relationships between social structure, patterns of artistic production and consumption, and the ways in which artistic genres are classified' (1987: 440-441). Moreover, DiMaggio maintains, 'analysis of change in the cultural economy requires attention both to individual and collective action and to institutions of cultural 
production and consecration' (DiMaggio, 1991: 134; emphasis in original). Put simply, DiMaggio distinguishes among four dimensions: differentiation, hierarchy, universality and boundary strength, and his already classical thesis goes that in Western societies, the trend has recently been that 'artistic classification systems are becoming more differentiated and less hierarchical, classifications weaker and less universal' (DiMaggio, 1987: 452). This thesis is a crucial starting point for analyses of this book.

Taken together, it follows from the above discussion of cultural stratification comprising both cultural production and consumption that the information derived from widely circulated quality newspapers' culture sections, at least when used in large amounts to reveal macro-level trends, is reflective of the dominant classifications and hierarchies in a culture at a given point in time. Furthermore, these dominant cultural classifications reflect characteristics of both cultural production and consumption: on one hand, what cultural objects are produced for the markets, from which cultural journalists as intermediaries gate-keep, filter and select certain products to be discussed in the newspapers and thus grant them value and legitimacy (the side of cultural production); on the other hand, what the educated middle classes, the main audience of quality newspapers, value and consider potential objects of consumption in the first place, through and channelled by the taste-making processes by cultural journalists (the side of cultural consumption). ${ }^{15}$

\section{Data and the comparative setting}

We investigate the post-1960s cultural change through quality European newspapers' culture sections. These newspapers come from six European countries, ranging from two Nordic countries (Helsingin Sanomat from Finland and Dagens Nyheter from Sweden) to two large Western European countries (Le Monde from France and The Guardian from the UK) and, finally, two Mediterranean countries (ABC and El País from Spain and Milliyet from Turkey). Together the newspapers form a comparable, European-level dataset through which to inspect cultural trends and changes.

The newspapers were selected from these particular countries for several reasons. ${ }^{16}$ On the one hand, the countries differ in many dimensions relevant to this study: size of the country (e.g. in terms of population, language area, economy and the cultural industries, in particular; Janssen et al., 2008); location of the country in the global cultural system along the dimension between centre and periphery (Appadurai, 1996); cultural and journalistic traditions (Jaakkola, 2015); political histories and events (Fishman and Lizardo, 2013); media system model (Hallin and Mancini, 2004); and cultural policy regimes (Looseley, 2011). Nevertheless, we should not be too surprised that these countries are not too dissimilar, despite having distinct and different collective histories and traditions, with Turkey perhaps being an exception, as a nation located between Europe and the Middle East. The inclusion of Northern and Southern 
Europe - with Turkey literally at the border of Europe - will allow us to question the limits and variations of post-1960s cultural changes, which are usually observed as general trends only on the basis of large and central-positioned European countries and the United States (e.g. Janssen et al., 2011; Schmutz, van Venrooij, Janssen and Verboord, 2010). Enlarging the coverage towards national contexts that are positioned farther away from the core of Europe in many regards (e.g. the level of integration to globalization and the history of democratization) will accentuate the cross-cultural differences and eventually allow us to analyse the cultural transformation more thoroughly.

When selecting the time-frame for the study - from 1960 to 2010 - it was essential, first, to have a period long enough to allow for tracing trends over several decades. Second, one of the key issues was to choose the first time point before the apparent rise of the popular youth culture of the 1960s (Marwick, 1998) to allow grasping the nature of the transformation of cultural hierarchies fully in its many dimensions. Third, one decade earlier, in 1950, there would have not been clearly identifiable culture sections in all of the newspapers. It is an important principle that by concentrating on 'explicit' culture sections, we can let the newspapers decide on our behalf what counts as culture and what is valuable enough to be included under the culture section.

Samples of the culture sections of these newspapers were collected at tenyear intervals, including volumes from six time points (1960, 1970, 1980, 1990, 2000 and 2010). The sample included 18-21 editions of each newspaper per year, amounting to 711 editions altogether. Next, the data was coded, following a pre-defined coding system, into a statistical matrix according to the principles of quantitative content analysis (Neuendorf, 2002; Krippendorff, 2004a). The coding process involved a team of eleven members and lasted through all of its stages about one year. The unit of our content analysis is an individual article, and the final sample includes 13,161 articles. The data includes only articles with journalistic content published in culture sections - both the core cultural pages inside the newspaper as well as thematic cultural supplements that have been increasingly published since the 1990s (about supplements, see Box 7.1 and Appendix Table B.1). The details of the data collection, sampling procedure and coding process are reported in Appendix A.

All the selected newspapers are major national leading papers - quality or even 'elite' papers in contrast to tabloids (cf. Jaakkola, 2015; Verboord et al., 2015) - sharing a comparable level of circulation, albeit published in different geographical and cultural regions in Europe. Additionally, they tend to be politically moderate social-democratic or centre-left (with the exception of the Franco-era $A B C$ ). Table 1.1 provides some basic information about the newspapers.

Helsingin Sanomat, founded in 1889, has a moderate social-democratic tendency and is Finland's most widely read newspaper, with almost no national competition (Jaakkola, 2015). Helsingin Sanomat set the model for choosing the other newspapers. The Guardian has many UK competitors but is similar to 


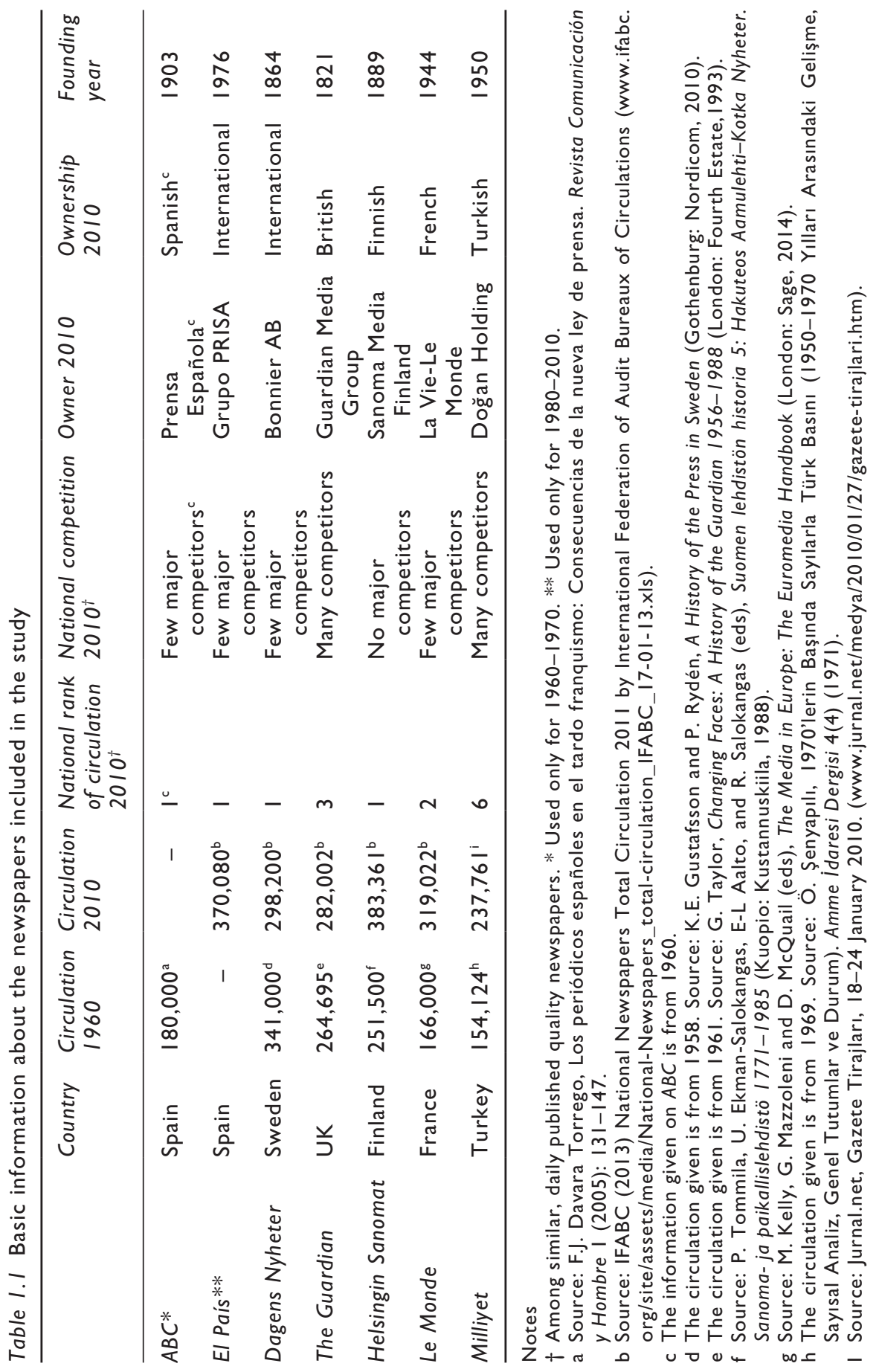


Helsingin Sanomat in both its moderate centre-left voice and circulation levels (Taylor, 1993). Dagens Nyheter is the biggest quality newspaper in Sweden and more or less shares the centre-left political leanings of the other newspapers (Hadenius, 2002). Le Monde, together with its main competitor, the politically centre-right Le Figaro, is the most widely read newspaper in France and from the two options fits with purposes better because of the previously mentioned newspapers' moderate leftist political tendencies (Eveno, 2004). In Spain, El País, founded just after the end of Franco's right-wing dictatorship in 1976, is a logical counterpart to the other selected newspapers. However, for the period of 1960 to 1970, with no comparable alternative available, we had to use the monarchist, right-wing (albeit relatively 'liberal' compared to many other publications of the era) $A B C$, the most influential Spanish newspaper at the time (Olmos, 2002). ${ }^{17}$ For Turkey, we chose Milliyet because it is the most widely circulated newspaper, published without interruption between 1960 and 2010 (many of the competing newspapers that in 2010 had a larger circulation level than Milliyet were only established in the 1990s or 2000s). The other alternative, Hurriyet, has had wide readership but it was considered a middle-market newspaper aiming to entertain its readers. Milliyet's archive was also in much better shape in the National Museum and recently has been made available online for the period between 1950 and 2007. Moreover, Milliyet is a politically centred paper that falls in line with the rest of the sample (Şenyapil1, 1971; Topuz, 2003).

Table 1.2 presents the distribution of the data across years and among newspapers. The way our sample is distributed by year for each newspaper reveals how the culture sections have been structured and changed in terms of volume (as reflected in the number of articles). ${ }^{18}$

Overall, the data is quite evenly distributed both in terms of years and newspapers, albeit with some exceptions. The total number of articles generally increased towards the 2000s. In the sense of pure volume, the newspapers fall into two categories: larger (ABC/El País, Dagens Nyheter, Helsingin Sanomat) and smaller (The Guardian, Le Monde, Milliyet). Moreover, the Nordic papers, Helsingin Sanomat and Dagens Nyheter, differ from both the Central European and Southern European cases in the amount of journalistic attention given to culture in 1960. In the case of Milliyet, there was quite a dramatic increase in 2010, while in the case of El País there was a clear decrease in 2010 compared to 2000 or 1990 . It is clear that these changes in the volume of articles published in the culture sections of the individual newspapers are the result of both social and organizational factors. For instance, the shrinking cultural content in El País in 2010 can be seen as reflecting the major economic crisis faced by the country a couple of years earlier, whereas the 2010 increase in Milliyet was mostly due to the paper's editorial reorganization, which is also evidenced in the culture section's title change from 'culture' to 'cultural life'.

When interpreting the findings, we must remember the nature and context of quality European newspapers and their culture sections. These are a kind of 


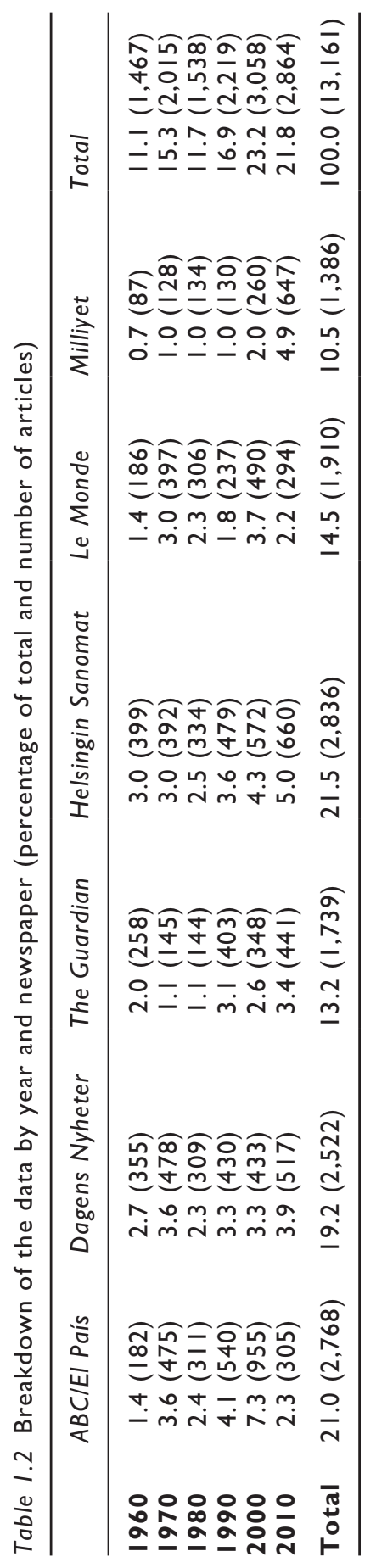


'home court' of classical highbrow arts through which many people follow the arts even when they lack interest in them otherwise (cf. Jaakkola, 2015; Janssen et al., 2008, 2011). Put differently, quality European newspapers' culture sections should provide a relatively conventional and conservative arena for different forms of art and culture to be represented and discussed as the attention received there - and the legitimacy of the content published on those pages - are strongly guarded by journalists and intellectuals.

Furthermore, it is important to stress that we do not claim that our newspapers, selected from six European countries, are nationally representative cases and thus that they directly and without problems express national differences. Indeed, the newspapers, and the cultural classifications of which the newspapers are indicative of, are embedded in specific European contexts with their own socio-historical and structural characteristics, which the newspapers' content reflects. But, as already mentioned, there are also several other influential factors to consider. We will expand on and discuss in detail these comparative aspects - as well as their implications for further analyses in the book - in Chapter 2 when analysing the transformation of the content of the culture sections in our newspapers.

Given their potential as a longitudinal and comparative data source for the purposes of not only media scholars but also cultural sociologists and anyone interested in the study of changing cultural hierarchies, newspaper cultural pages remain surprisingly understudied. A major exception, however, is a recent large-scale Dutch research project (e.g. Janssen et al., 2008, 2011), which has been a major source of inspiration for our own study. ${ }^{19}$ This book contributes to this previous work on changes in the valuation of culture through its visibility in quality newspapers and thus provides our answer to the call to 'uncover further national or longitudinal differences' (Janssen et al., 2011: 161).

\section{Approach and methods}

The most general-level methodological guideline that we follow in this book is that we combine both structured and less-structured elements in our approach as well as aiming to be both thorough and comprehensive. The latter feature is due to the nature of the book. Besides a careful study of how newspaper culture sections and thereby cultural hierarchies have changed over the fifty years (where the aim is to be empirically thorough), this is at least as much a book that addresses and discusses a number of key theoretical questions and debates of contemporary cultural sociology (where the aim is to be thematically comprehensive and broad in scope). These themes and processes are the core of the book. Here, it is worth underscoring that we do not want to pretend that we can 'solve' or give final answers to these major concerns. On the contrary, we want to practise an upfront approach when confronting theoretical problems or issues that arise from our empirical analyses.

Comprehensiveness is seen from the empirical coverage of the study as well: from the longitudinal time-frame of half-century; from the cross-cultural 
comparative setting including newspapers from six countries; and from the variety of art forms and cultural domains - ranging from popular music and classical music to literature, theatre, film, television, the visual arts and, for instance, cultural policy - that are touched upon in the course of this book. Typically, studies in cultural sociology on similar themes, no matter how finegrained and sophisticated, have concentrated on one national setting alone and remained temporally limited as they are based on cross-sectional data (e.g. Bennett et al., 2009). Also the few monograph-length studies including crossnational comparisons have utilized cross-sectional data (e.g. Chan, 2010). At the same time, the studies addressing temporal processes have concentrated on single art forms or cultural fields within one national context (e.g. Baumann, 2007 on film in the United States).

The first part of the general guideline, aiming at the interplay between structured and less-structured elements, has to do with the methodological approach of the book (in the conventional sense) but also including a presentational means of reporting. Most importantly, we employ a multilingual, mixed-methods approach, including both quantitative and qualitative content analysis (see e.g. Schrauf, 2016). Thus, the elements put in dialogue in the empirical analyses include a host of statistical analyses (and more concretely, tables and figures) on one hand and qualitative close readings of rich illustrations quoting the newspapers from different decades and national contexts on the other. An additional feature is the typographically separated 'boxes' dispersed throughout the book, which, by operating at a different level of narrative from that of the main body text, provide small snapshots and excursions about specific topics of interest.

The quantitative analyses are mostly presented in the format of simple crosstabulations and line charts presenting trends over time. ${ }^{20}$ The purpose is to be as clear and efficient as possible in statistical reporting. The main focus of quantitative analyses is on differences in the attention paid to various forms or genres of culture and the arts - for instance, the relative amount dedicated to music compared with other art forms and, within the field of music, the relationship between classical music and pop music. The data originally included forty-nine variables, of which less than half (twenty) are used in the analyses of this book. We will introduce the variables and their categories at the points in the chapters where they are used (see also Appendix A). The time point (year) and the newspaper are the two most important independent variables throughout the book. The key variables measuring the cultural content include, for instance, the primary cultural area (or art form) of the article, the music subgenre (in the case of all articles on music) and the national origin of the cultural product discussed in the articles. Besides these content-related variables, there are many variables on the format and structure of the articles and the newspapers, such as the article type, length, illustration and the number of cultural pages in the newspaper issue. In addition, variables measuring the textual features of the articles (such as the amount of 'cultural references' mentioned or whether the text is written in the first person) are also included. 
In addition to quantitative analysis using standard statistical techniques, our mixed-methods approach includes qualitative analysis. ATLAS.ti software, which was used in the coding process, allowed us to go back from the statistical matrix to the articles themselves and delimit the data by different criteria into particularly characterized subsamples for close reading. For instance, when we wanted to read all the theatre reviews of a certain length from one particular newspaper and one particular year, or all the classical music articles including the 'commercial dimension' (i.e. explicit mentions of money or other economic indicators), creating subsamples was easy. The process of close reading the subsamples proceeded inductively but, informed with the topics and theories at hand in the relevant chapter, focused on the identification of the recurrent and most important themes, or frames, included in the selected articles. ${ }^{21}$ Qualitative close reading is warranted to complement, illustrate and ease interpreting macro-level quantitative analyses of the entire data. However, it also provides a means to investigate questions that remain hidden behind the quantitative trends (e.g. how evaluations and aesthetic judgements are articulated, the tone of the texts, etc.).

Finally, we do not use the entire dataset in all of our analyses. Rather, we have decided case by case in which analyses we use all the data or whether we should delimit the material for the purposes of particular analyses. This principle applies to both quantitative and qualitative analyses and will be reported in the relevant places before each analysis. As will be revealed, the Turkish Milliyet will be excluded from some of the analyses for reasons that will be discussed in Chapter 2. Similarly, some of the qualitative analyses have been conducted by concentrating on certain newspapers only (e.g. the analysis comparing poprock and classical music aesthetic evaluations in Chapter 3 uses articles that have been published in two newspapers, the Finnish Helsingin Sanomat and The Guardian from the UK). These decisions for selecting the material for close reading have been made to increase the resolution and precision of the analysis on one hand (this reason also applies in cases where the data has been limited in quantitative analyses); on the other hand, they have been made under the practical limitations of conducting the analysis (such as work economy and the languages involved).

\section{Outline of the book}

Besides this introductory chapter, the book includes seven main chapters, divided into three parts. Part I, 'The Shift in Cultural Legitimacy', includes two chapters (Chapters 2 and 3); Part II, 'Dimensions of the Transformation', includes three chapters (Chapters 4, 5 and 6); and Part III, 'The Place and Space of Culture', includes the remaining two chapters (Chapter 7 and the concluding chapter, Chapter 8).

The thematic focus of the book is directly reflected in the structure of the book, as each of the main chapters will be devoted to one of the 'big' themes 
and processes. The aim is also that all chapters will work as relatively independent 'mini studies' in regard to the respective questions they are focused on, albeit obviously they have their places, and reasons to be included, in the larger context of the book's structure.

Thus, Chapter 2 asks whether the content of legitimate culture has become more open and heterogeneous and focuses on the expansion of popular culture and the corresponding decline of classical highbrow arts. Chapter 3 goes on to probe how the hierarchy between highbrow and popular culture has been articulated and whether it has changed, conceptualizing the transformation into two simultaneous processes: one concerning the legitimization of popular culture and the other concerning the popularization of traditional highbrow culture. Chapter 4 tackles cultural globalization: how the distinction between local and national culture versus global and international culture is expressed and how it is intertwined with the transformation of the content of legitimate culture. Chapter 5 focuses on the commercialization of culture and asks how the autonomy of aesthetic assessments from commercial influences varies temporally and cross-nationally. Similar to the chapter on commercialization, Chapter 6 investigates the changing relationship between aesthetic assessments and politics. It also pays special attention to two extremely interesting and important - and extreme - cases of national political histories, that of the Francoist dictatorship and the subsequent rapid transition to democracy in Spain and that of a young republic's challenges with Westernization, neoliberalization and military interventions in Turkey. Chapter 7 asks how the journalistic means of the 'packaging' of arts and culture have changed and whether our newspapers' culture sections support the claims about a 'crisis of cultural journalism' and journalistic popularization in the ways in which arts and culture are reported. Finally, Chapter 8 concludes the book by summarizing its main findings and discussing selected key issues in the study of changing cultural hierarchies.

\section{Notes}

1 The Guardian, 10 December 1980, p. 10. When referring to the newspaper data that we will analyse throughout this book, we use the following type of code for each newspaper page: GU/10/12/80_10a. The first letters refer to the newspaper (in this case, 'GU' is The Guardian), and the next numbers refer to the date (day/month/ year), followed by the page number (here, 10) and a letter (here, a) specifying the article clockwise from the top left, if more than one article from the same page is referred to. In addition, if the article was published in a supplement, the name of the supplement is indicated in the code by using suitable letters before the page number. The data is described in detail in Chapter 1 as well as in Appendix A. A comprehensive list of references for all newspaper articles quoted in the book is presented in Appendix Table B.7.

2 All quotes from Le Monde - as well as the subsequent quotes from the Spanish ABC and El País, the Swedish Dagens Nyheter and the Finnish Helsingin Sanomat - have been translated into English by Riie Heikkilä, unless otherwise noted. Quotes from the Turkish Milliyet have been translated by Irmak Karademir Hazır. 
3 Helsingin Sanomat, 10 December 1980, pp. 3 and 18. This obituary of Lennon in Helsingin Sanomat is not included in our main newspaper data as it was published outside the culture section of the issue.

4 There is a substantial body of previous literature on the life and death of John Lennon, including the study by sociologist Fred Fogo (1994) on the 'social drama' created in the reception of Lennon's murder. Fogo's study is faithful to the common interpretation according to which the death of Lennon received its importance from symbolizing a dramatic end of the era starting in the 1960s and the hopes and dreams of the 1960s generation. To our knowledge, there are no previous studies focusing on the aftermath of Lennon's death from the point of view of the legitimization of rock music or the transformation of cultural hierarchies.

5 The first monograph-length book on 'rock sociology' was Simon Frith's The Sociology of Rock (1978), followed by its updated version three years later (Frith, 1981). Other important contributions of the time include, for instance, American sociologists' affirmations that popular culture is also, indeed, culture in its own right (Peterson, 1977) and Birmingham school's cultural studies on the meaning of pop music in youth cultures (e.g. Hebdige, 1979). Cf. Baumann's emphasis on the parallel 'link between academic film study and the intellectualization of film in reviews' in the 1960s (2007: 174).

6 For the history of the demarcation between 'high' and 'popular' arts, see, for example, DiMaggio, 1982b; Levine, 1988; DeNora, 1995; Peterson, 1997.

7 The previous body of literature that could be referred to here is huge, as most studies on the cultural omnivore (Peterson, 2005; Karademir Hazır and Warde, 2016), taste patterning (van Eijck, 2001), arts participation (Katz-Gerro, 2002; DiMaggio and Mukhtar, 2004) and even 'emerging forms of cultural capital' (Prieur and Savage, 2011) rely on the conventionally defined categories of 'highbrow' and 'popular'.

8 The identification of causal determinants for the cultural trends we are interested in is clearly too challenging a question, which would probably also require a different kind of research design (and different data). It is always possible to refer, in the spirit of sociologists' pet narratives, to the large-scale processes of modernization and postindustrialization or, more concretely, to the demographic shifts after the Second World War or the massification of higher education since the 1960s and so on. Besides being rather unspecific, most probably it would not solve the question of causal order. Thus, it remains outside the scope of this study whether (and which of these) societal processes are really capable of 'explaining' the post-1960s transformation of cultural hierarchies. We will return to this question at the end of the book in Chapter 8.

9 Obviously, the Internet and other digital devices have recently become significant competitors of traditional print newspapers. It is yet unknown what this means for newspapers' and traditional critics' authority as cultural mediators (Verboord, 2010). While this new situation does affect our data, it does so only regarding 2010, the last year in our sample.

10 Besides socially legitimate experts' aesthetic selections, there may also be other factors affecting cultural coverage in newspapers, most of all commercial factors driven by strategic interest in advertisement revenue (which we will touch upon in Chapter 5). While acknowledging that it can be considered as a limitation of our measurement strategy that we are unable, in technical terms, to disentangle the relative strengths of these factors, we hold that, as an institution, the essence of culture sections in quality European newspapers is built on the idea of telling the readers what 'art' and 'culture' are.

11 See, for example, Bourdieu, 1984, 1993; Smith Maguire and Matthews, 2014; Janssen and Verboord, 2015. For a classic account emphasizing the role of 'mass media 
gatekeepers' in cultural production, see Hirsch, 1972. For an early and brilliant account of the concept of 'tastemakers', see Lynes, 1955.

12 One can question the fixed and one-dimensional understandings of both categories, consumption and production, and rather highlight the complexity and interrelatedness of both (see e.g. Warde, 1992). Recently, a popular way to do this has been using the concept of 'prosumption' (Ritzer and Jurgenson, 2010).

13 We define cultural stratification as referring to the ways in which cultural objects including equally concrete cultural products and works of art as well as cultural practices and people's tastes - are classified relationally and granted varying amounts of value and the degree to which symbolic hierarchies thus constructed relate to social divisions (see e.g. Bourdieu, 1984; DiMaggio, 1987; Janssen, 1999; Lizardo, 2010; Lamont, 2012).

14 On the ways how this can happen and approaches to study it, see, for example, van Rees, Vermunt and Verboord, 1999; Lamont and Molnár, 2002; Ollivier, Gauthier and Truong, 2009; Lizardo and Skiles, 2016.

15 Of course, this does not mean that it would not be ideal to have data more comprehensively from all sides of cultural stratification: from the consumption, production and mediation of culture. Under the current circumstances of data scarcity, especially when it comes to the period from 1960 to 1980, we have to rely on data on cultural mediation only.

16 As always, some of the reasons were very practical. When starting the project, the original team happened to have good contacts in each country, which greatly facilitated the study. Moreover, Riie Heikkilä, who was the key person for collecting the data and carrying out the most comprehensive qualitative analyses, is fluent in five out of the six languages involved in the study (all except Turkish).

17 In most of the subsequent quantitative analyses in the book, ABC (1960-1970) and El País (1980-2010) are merged under the same category 'ABC/El País' of our newspaper variable, with the assumption that the reader remembers the two Spanish papers covering different decades of the research period.

18 Later in the book, we will return to this question of the size of the culture sections in the newspapers in Chapter 7. Furthermore, it is worth noting that the number of the articles does not equal the size of the cultural coverage in the newspapers, as the size of the articles varies from very small to full-page or even multiple-page articles. To address this, we run the analyses presented in the book in many alternative ways, including adjusting the number of articles by our variable measuring article size, which should reflect better the newspaper coverage understood literally as space on the newspaper pages than the mere number of articles (cf. Janssen, 1999). However, the overall result was that the distributions and trends we are interested in were essentially the same irrespective of taking into account the article size (see also Purhonen et al., 2017: 35-37). There were only two specific occasions - on which we will report briefly in Chapter 2 and Chapter 7 - where we observed a notable difference. Otherwise, we will present all of our analyses without adjusting the number of articles by article size.

19 The Dutch project 'Cultural Classification Systems in Transition', began in 2003 and led by Professor Susanne Janssen at the Erasmus University Rotterdam, conducted an extraordinarily extensive quantitative examination of cultural coverage in Dutch, German, French and American quality newspapers from 1950 to 2000 (see e.g. Janssen et al., 2008, 2011; van Venrooij and Schmutz, 2010). Our study, and this book as part of it, has followed the example of the Dutch project mostly in terms of data collection. However, the projects are also distinct in a number of ways, for instance with regard to country selection (with the exception of France, the nations included in these studies are different) and methodology used (our mixed-methods 
approach extensively utilizes qualitative close reading of the newspaper articles, in addition to quantitative analysis).

20 Because also very small differences in the proportions can be statistically significant due to the large sample size, we do not report tests of statistical significance. Overall, we focus on interpreting substantial differences in terms of magnitude, all of which are also statistically significant (e.g. when using chi-square tests).

21 Here, we have been inspired by recent contributions in cultural sociology employing the qualitative analysis of media outlets, such as the study of gourmet food writing by Johnston and Baumann (2007) and Varriale's (2016) study on pop music criticism. 


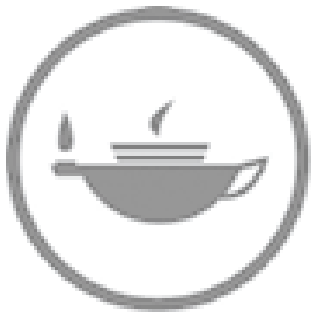

Taylor \& Francis Taylor \& Francis Group

http://taylorandfrancis.com 
Part I

The shift in cultural

legitimacy 


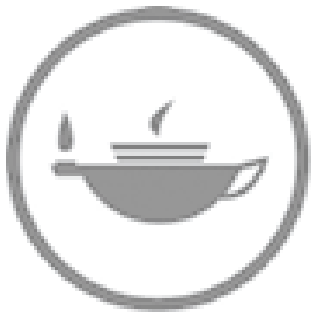

Taylor \& Francis Taylor \& Francis Group

http://taylorandfrancis.com 


\section{The transformation \\ On the rise of popular culture and the decline of classical highbrow arts}

\section{Introduction}

A strong tradition in sociology has argued that classical 'highbrow' arts - such as classical music, poetry, opera and so on - play a key role in structuring lifestyles, signalling cultural capital and creating and maintaining cultural inequalities in contemporary Western societies. ${ }^{1}$ Highbrow arts have been seen as exemplary cases of legitimate culture, and their consumption and appreciation as prime indicators of cultural capital in Western contexts for a variety of reasons. Not only do the highbrow arts enjoy substantial public funding and other allocated resources, they are also strongly institutionalized, most notably in higher education institutions (i.e. curricula, professorships, etc.) but also through ceremonies and museums, as well as canons, prizes and criticism (DiMaggio and Useem, 1978; DiMaggio and Mukhtar, 2004; Daenekindt and Roose, 2015). Additionally, their prestigious status as a potential cultural asset or a high-status signal is widely recognized (Lamont and Lareau, 1988). It is against this background that Bourdieu (1984) famously argued that cultural and social hierarchies are homological (e.g. that a taste for highbrow arts is strongly dependent on class), ${ }^{2}$ resulting in a situation in which the command of legitimate culture contributes to the reproduction of inequality.

However, cultural hierarchies and classifications vary historically and crossnationally. Thus, legitimate culture - what counts as 'high' and 'low' - is not a universal, unchanging entity (e.g. Bourdieu, 1984; Janssen, 1999; Lamont, 2012). Consequently, many recent discussions of cultural sociology have revolved around the question of whether the content of legitimate culture has changed. More precisely, it has been suggested that the classical highbrow arts may no longer be considered to be the main, or at least the sole, element of legitimate culture. Instead, legitimate culture itself may have become more heterogeneous and inclusive, combining items from both highbrow and popular culture.

This chapter presents an analysis of changes in the coverage of culture in major European newspapers from 1960 to 2010. Employing a content analysis of the newspapers, we examine how culture sections have changed in terms of art 
forms and cultural domains covered. As cultural coverage in quality newspapers is an indicator of cultural legitimacy, the analysis reveals whether and how the 'content' and composition of legitimate culture has transformed during the research period. More precisely, we ask whether the content of cultural coverage has become more heterogeneous and open and whether the newspapers embedded in different European contexts differ in this respect. By providing a bird'seye view on the long-term trends in cultural coverage, this chapter sets the scene for subsequent chapters in this book, which will complement this analysis through qualitative close reading and highlighting additional dimensions of the transformation of cultural hierarchies.

This chapter begins by revisiting previous literature that suggests a change in the condition of legitimate culture. Next, we discuss the comparative dimensions of our analysis, as we are interested in exploring the geographical and cultural limits of post-1960s cultural transformation towards increased openness and heterogeneity. The following empirical analysis begins by exploring the cultural coverage in newspapers. To assess heterogeneity, we first ask whether the coverage of emerging popular art forms has increased at the expense of coverage of established arts. Then, we turn our attention to some of the most established and largest art forms - particularly literature and music - and ask whether the transformation has primarily taken place within these domains. Finally, opposite emerging popular culture, we inspect change from the perspective of classical highbrow arts and ask whether their coverage, indicative of their role as a status marker, has declined.

\section{The opening up of legitimate culture: theoretical perspectives}

There are numerous and partly overlapping discussions on, and ways to conceptualize, the processes that might be behind changes in cultural hierarchies over the latter part of twentieth century. Perhaps most famously, this trend of 'opening up' and increasing the heterogenization of legitimate culture's content is conceptualized as the rise of the cultural omnivore (Peterson, 1992, 2005; Peterson and Kern, 1996). The premise behind omnivore scholarship is that contemporary Western societies have become so differentiated that the exclusiveness of highbrow arts is not compatible with the ethos of the time (Peterson, 2005; Peterson and Rossman, 2007; cf. also Lahire, 2011). Thus, high-status groups have started to appreciate broad repertoires of taste, whereas low-status groups' tastes are narrower and univorous (for a review, see Karademir Hazır and Warde, 2016). While this does not necessarily contradict Bourdieu's model (if omnivorousness is taken as a new form of cultural capital yielding various benefits; Lizardo and Skiles, 2012), it nevertheless implies that the concept of legitimate culture has widened and become more heterogeneous. However, it is worth noting that, despite omnivorousness being perhaps the 'most well-documented empirical generalization in the sociology of cultural taste' (Fishman and Lizardo, 2013: 214), there is 
no theoretical agreement on the definition of such an eclectic taste profile (Warde, 2015). In fact, the empirical findings on omnivorousness regarding change over time are also ambiguous. For instance, a recent longitudinal study in the United States shows that the proportion of cultural omnivores decreased in the 2000s, contrary to expectations (Rossman and Peterson, 2015).

Omnivorousness, however, is only one way to approach post-1960s cultural transformation. There are plenty of intertwined perspectives and research strands that conceptualize the transformation and its key elements: the increased heterogenization of legitimate culture and the two sides of that process, the rise of popular culture and the decline of traditional highbrow culture's status. Studies analysing cultural participation longitudinally ask whether audiences of highbrow arts are shrinking and ageing, thus causing the 'meltdown' of highbrow arts' status as a means for distinction (DiMaggio and Mukhtar, 2004; van Eijck and Knulst, 2005; Donnat, 2011). However, while problems renewing highbrow audiences have been reported widely and are corroborated by the findings of countless cross-sectional studies (e.g. Bennett et al., 2009; Chan, 2010; Coulangeon, 2017), it is important to note that, despite its wide resonance, DiMaggio and Mukhtar's seminal study analysing data from the United States from 1982 to 2002 found no unambiguous evidence to support meltdown theory. Instead, they concluded that: 'the decline of fine arts as a form of cultural capital in the U.S. is taking place more slowly than many observers had predicted, if indeed it is taking place at all' (DiMaggio and Mukhtar, 2004: 192). In France, Donnat (2011) reports considerable stability in the rates of cultural participation in highbrow activities, using perhaps the most systematic and longest longitudinal data available on the subject, covering 1973 to 2008.

A more recent discussion on the emerging forms of cultural capital argues that distinctions and hierarchies are increasingly developing within the realm of popular culture (Prieur and Savage, 2011, 2013; Friedman, Savage, Hanquinet and Miles, 2015; Savage et al., 2015). According to the argument, the aforementioned processes (albeit sceptical about the value of the concept of a cultural omnivore), have created a situation in which the distinctions made by privileged fractions of society are 'linked to a knowing, distanced or verbalised, appropriation of culture and to the so-called cosmopolitan attitudes and preferences' (Prieur and Savage, 2013: 263). Other recent formulations include the contention by Friedman et al. that:

the descriptive claim made through the idea of emerging cultural capital is that actually the content of elite culture is being remade, even if it might take many decades of generational replacement for these new practices to become definitively dominant [emphasis in original].

(Friedman et al., 2015: 3)

On the other hand, Savage et al. adopt a more cautious view regarding the current status of highbrow arts: " Old style" - what we have called "highbrow" 
- cultural capital is still very much with us, but is increasingly confined to an older age group' (2015: 125).

One related stream of research on cultural transformation deals with the legitimation of popular culture via intellectualization and aestheticization (e.g. Regev, 1994; Baumann, 2001; Schmutz, 2016; see Chapter 3). It highlights how new forms of culture can be transformed 'from entertainment to art' (Baumann, 2007) by extending the high-art criteria of evaluative practices (van Venrooij and Schmutz, 2010) or by other processes of 'artification' (Heinich and Shapiro, 2012). Then again, studies and debates on the commercialization of culture (see Chapter 5) probe whether changes in the balance of established arts and popular culture result from competition between commercial legitimation and aesthetic legitimation, in which commercial values might take over artistic values and the autonomous status of the arts. ${ }^{3}$

An intersecting line of research focuses on the role of cultural globalization and aesthetic cosmopolitanism (Tomlinson, 1999; Janssen et al., 2008; Regev, 2013; see Chapter 4). Classical highbrow arts - the core content of traditional legitimate culture - have represented a European cultural canon, which has been challenged by global flows and influences, especially the emergence of popular world culture. The most notable example of this is the 'poprockization' of music throughout the world: the growing influence of American and British pop-rock music and its local adaptations, which is conceptualized as 'expressive isomorphism' standardizing national peculiarities in world culture (Regev, 2013; Varriale, 2016). Finally, technological changes, especially digitalization, may play a role in the increase of cultural heterogeneity, as the proliferation of distributable and portable cultural forms and their easy consumption - distinct from traditionally ceremonial methods of consuming highbrow culture such as visiting concerts or museums - are clearly factors behind the present 'cultural abundance' (Wright, 2011, 2015; Leguina, Arancibia-Carvajal and Widdop, 2017).

Undoubtedly, these myriad aspects of the heterogenization of legitimate culture could be considered to be parts of a more general sociological narrative about changes in the Western world over the latter part of the twentieth century, in which there has been a shift from traditional and unquestionable authority to more flexible and plural authorities, be they aesthetic authorities or other types of rules of conduct. This shift can be called, for instance, 'informalization' (Wouters, 2007) or 'expressive revolution' (Martin, 1981).

However, as important and interesting as these discussions are, they are not problem-free. Particularly, the discourse on the decline of the status of highbrow culture is often unspecific and impressionistic, to the point that affirmations can be made without specific references or empirically grounded evidence. Most importantly, strong claims about changes over time are often made based on cross-sectional data alone. In other words, the decline has often been assumed rather than empirically shown, which stems from a persistent lack of goodquality longitudinal datasets allowing for analysis of the changes in the status of 
highbrow arts over a long period. Moreover, not enough is known about the differences between specific art forms or about variations across geographical and cultural contexts. It is hardly convincing that all highbrow art forms would be declining at the same rate or in the same ways irrespective of cultural context. Indeed, highbrow culture or arts have been treated mostly as an undifferentiated chunk, without distinguishing between specific art forms. The claim has mostly been that 'highbrow' has decreased in significance (e.g. Prieur and Savage, 2013; Friedman et al., 2015; Savage et al., 2015).

Furthermore, a paradox remains: there is no consistent evidence that the position of highbrow culture has declined if measured by participation rates, public funding or other institutional recognition, which are all key indicators of high cultural legitimacy. Participation rates for highbrow cultural activities have remained relatively stable during recent decades (DiMaggio and Mukhtar, 2004; Donnat, 2011; Heilbrun and Gray, 2001; Roose and Daenekindt, 2015). Most importantly, highbrow participation has continued to be strongly stratified according to social cleavages, particularly education, occupational class and income (e.g. Bennett et al., 2009; Purhonen, Gronow and Rahkonen, 2011). Additionally, public funding for the arts, especially state funding, has increased significantly in many Western countries over the latter part of the twentieth century, and even if trends began slowing in the United States and in some other countries in the late 1980s, there have not been significant cuts in public funding for the arts during the past few decades apart from very recent cases in the Netherlands, the UK and Spain (Council of Europe, 2016; Heilbrun and Gray, 2001; Klamer, Petrova and Mognosa, 2006; Lewis and Rushton, 2007). ${ }^{4}$ Finally, highbrow arts have also largely preserved their institutional role in school curricula (Daenekindt and Roose, 2015). Of course, new cultural forms have begun competing with highbrow arts for public funding and institutional recognition, but this does not automatically weaken the status of highbrow arts.

Overall, these observations suggest that there are no clear, unambiguous signs of the dissolution or 'deinstitutionalization' of highbrow arts' legitimacy (DiMaggio, 1991; Daenekindt and Roose, 2015). Moreover, these observations highlight the need for empirical and, most importantly, longitudinal analyses, to shed new light on cultural legitimacy and processes affecting it over the last decades from various angles. It is this task that we focus on by analysing quality European newspaper data.

\section{Comparative dimensions and expectations}

Our analysis is guided by the expectation that, between 1960 and 2010, the conception of legitimate culture has indeed opened in terms of forms and genres discussed in newspaper culture sections, revealing the dwindling dominance of classical highbrow arts. We should be able to track this trend through the increased heterogeneity of cultural content caused by the appearance of emerging popular art forms that have gained space at the expense of traditional and 
established art forms, through the shift in the volume of articles from highbrow to popular inside the most established arts (e.g. in music, from classical music to pop-rock music), and through the declining trend of newspaper coverage of conventional highbrow arts in general.

Moreover, we expect to find significant variation in the thoroughness and timing of the opening of cultural content among the newspapers studied, because the newspapers are embedded in different European contexts characterized by specific cultural, historical and socio-political features, in addition to differences in newspapers' institutional and field-level (organizational) characteristics. ${ }^{5}$ But how exactly do we expect our European newspapers (from Finland, France, Spain, Sweden, Turkey and the UK) will differ from each other in the supposed increase in heterogeneity and openness of cultural content? Which society-level dimensions do we expect to reflect these differences? ${ }^{6}$

First, we must pay attention to the different locations in the global and Western-dominated cultural system, our expectation being that the opening happened earlier and more thoroughly in central countries (Appadurai, 1996; Janssen et al., 2008). It is widely recognized that cultural flows and new orientations gain popularity in centres first and only afterwards trickle down to peripheries (e.g. Janssen et al., 2008, 2011). According to this dimension, the UK and France represent the centre, whereas Spain, the Nordic countries (among which Sweden is clearly closer to the global cultural centres than Finland) and especially Turkey are examples of more peripheral locations in the global cultural system. This dimension of centre-periphery can be understood in terms of national levels of cultural production and consumption (see Appendix Tables B.4 and B.5), besides countries' sizes and development trajectories (see Appendix Table B.2). For instance, the UK has been a global superpower of pop culture since the 1960s, and Sweden is a relatively small country that has been successful in exporting pop music (Seabrook, 2015). The cultural role of Finland has been much more modest in global cultural flows. The differences are also well pronounced in capital-intensive fields of cultural production, such as the film industry. France, Spain and the UK have internationally recognized film production industries, and all of them have been classified as 'major producer' countries in the context of the global film industry (Crane, 2014). In contrast, film production in countries such as Turkey (classified as 'medium producer country'), which has a strong national film industry but practically no cultural exports, or smaller countries and language areas such as Sweden (a 'minor producing' country) and Finland (falling outside classification due to its small film industry) are much more limited and have not received particular international success (Crane, 2014; cf. Appendix Table B.4).

Second, we assume that different media system models play a significant role behind the differences across the newspapers. Hallin and Mancini (2004), in their influential work on media system models, distinguish among four dimensions: structure of media markets (e.g. newspaper circulation rates; see Appendix Table B.3 on differences in newspaper industry and readership), political 
parallelism (degree to which newspapers and audiences are segmented by political opinions), professionalization of journalism (to what degree journalists are autonomous and acknowledge the ideals of their public service profession) and the role of the state in media systems (state regulations, ownership, funding, etc.). Based on these dimensions, Hallin and Mancini classify different nations into three ideal-typical models of media systems: the Mediterranean Polarized Pluralist model, the North/Central European Democratic Corporatist model and the North Atlantic Liberal model. The countries included in this study fall almost perfectly into these three categories: the UK represents the liberal model country; Finland and Sweden represent the democratic corporatist model; and France, Spain and Turkey represent the polarized pluralist model. ${ }^{7}$ Our expectation is that the opening happened earlier and more thoroughly in marketoriented liberal model countries than in democratic corporatist or polarized pluralist models. Based on Hallin and Mancini's (2004) classification, we cannot expect the democratic corporatist and polarized pluralist models to be different regarding the thoroughness and timing of the opening of legitimate culture. However, what can be expected is that the polarized pluralist model - due to its characteristics regarding the least autonomous journalists, strong state intervention and strong instrumentalization of journalism under the pressures of political and commercial constraints (Hallin and Mancini, 2004: 34-37; cf. Chapters 5 and 6) - produces the most volatile and unstable cases of cultural changes becoming articulated in newspaper culture sections. We expect that this is the case with Spain and Turkey, which are marked by late democratization, whereas France, which is somewhere between the polarized pluralist and democratic corporatist models (Hallin and Mancini, 2004: 70), is arguably more stable.

Third, different cultural policy regimes have a strong influence on the dynamics of cultural fields and hierarchies (Looseley, 2011; Katz-Gerro, 2015). According to this dimension, our countries can be divided into two groups (cf. Mulcahy, 2003). The first includes those countries (France, Finland and Sweden) with significant state funding for established high arts. The second includes countries (Spain, the UK and Turkey) where traditional art forms have not been as heavily state subsidized (ACE, 1998; Council of Europe, 2016; on cultural policy differences, see Appendix Table B.6). As both newspaper coverage and public funding are institutionally anchored indicators of cultural legitimacy, we expect that newspapers embedded in countries where highbrow arts have been heavily state subsidized have experienced the opening of legitimate culture later and faced less decline in highbrow art coverage than other newspapers (cf. Janssen et al., 2011). This suggests that France and the Nordic countries might have adopted new cultural forms later than the other countries.

Taken together, these three society-level dimensions suggest that the newspapers under scrutiny can be ordered according to how their national contexts have facilitated cultural opening so that the UK's The Guardian represents the earliest opening and the Turkish Milliyet the last. Whereas the UK's national context facilitates a thorough and early cultural transformation in terms of all 
three dimensions (a global centre with a liberal media system model and cultural policy), Turkey's context is almost the opposite (a peripheral position in the global cultural system combined with a polarized pluralist media system model amenable to volatile changes and a centralized albeit weak cultural policy system from the point of view of arts funding). Among the other newspapers, we expect Finland's Helsingin Sanomat to be the second latest (published in a small and peripheral country with a Nordic media system model and cultural policy), whereas it is more difficult to differentiate the expected order between France's Le Monde, Spain's ABC/El País and Sweden's Dagens Nyheter, all of which should be placed between The Guardian and Helsingin Sanomat. While the media system model differentiates the national contexts behind Le Monde, ABC/El País and Dagens Nyheter, it does not suggest any clear hypothesis regarding increased heterogeneity. Moreover, the position in the global cultural system and the cultural policy model point to divergent directions: France is arguably the most central and largest of the three countries, but French cultural policy has been famously state driven and protectionist regarding foreign influences (cf. Mulcahy, 2003; Looseley, 2011). Sweden also represents a strong cultural policy model, but Sweden's place in the global system is not as central as France's. Spanish cultural policy has not been as strongly state subsidized as in France or Sweden (cf. Bonet and Négrier, 2010), but the country is clearly in a more peripheral position compared to France.

\section{Towards increased heterogeneity? The persistent dominance of the most established arts}

To start the analysis of the cultural coverage of our newspapers and the supposedly increased heterogeneity in the content of their culture sections, we first calculated the distributions of each article's primary cultural area. Table 2.1 shows how they have changed over time. Cultural areas are ordered according to their total size (Table 2.1, last column).

Our key variable here - the primary cultural area discussed in the articles was coded into twenty-one categories ranging from the most established and classical art forms (music, literature, etc.) to more popular and modern areas of culture, such as film or computer games (cf. Janssen et al., 2011; Jaakkola, 2015). Because an article may include a discussion on multiple cultural areas, the coding system defined the 'primary cultural area' of the article as the cultural area mentioned first, preferably deducible from the headline of the article itself. The variable also included cultural areas other than conventional art forms (e.g. cultural policy), hence the use of the term 'cultural area'. Table 2.1 shows all categories.

The overall largest primary cultural area is music, covering one-fifth of all articles in the data. Music is followed by literature, film, television, theatre and the visual arts. All other cultural areas represent only a tiny proportion of articles. Already this is very informative about the supposed increase of 
Table 2.I Primary cultural area discussed in the articles by year (percentages)

\begin{tabular}{lrrrrrrr}
\hline & 1960 & 1970 & 1980 & 1990 & 2000 & 2010 & Total \\
\hline Music & 12.8 & 17.8 & 21.3 & 21.4 & 18.8 & 24.8 & 20.0 \\
Literature & 18.7 & 10.6 & 19.8 & 18.2 & 20.5 & 18.6 & 17.9 \\
Film & 10.8 & 11.4 & 9.5 & 11.0 & 14.3 & 12.4 & 12.0 \\
Television & 2.9 & 7.5 & 6.4 & 8.0 & 14.4 & 18.8 & 11.0 \\
Theatre & 20.1 & 18.1 & 10.1 & 9.4 & 5.8 & 4.0 & 10.0 \\
Visual arts & 6.9 & 7.2 & 6.1 & 7.5 & 6.1 & 4.2 & 6.2 \\
Science, society, & 3.9 & 4.7 & 3.8 & 3.2 & 2.2 & 2.0 & 3.1 \\
$\quad$ philosophy & & & & & & & \\
Cultural policy & 2.0 & 4.1 & 4.9 & 3.8 & 2.2 & 2.3 & 3.1 \\
Opera & 4.1 & 2.8 & 2.4 & 3.4 & 1.5 & 1.4 & 2.4 \\
Dance & 1.2 & 2.5 & 2.4 & 2.9 & 2.3 & 2.1 & 2.3 \\
Radio & 4.0 & 3.3 & 2.4 & 0.9 & 0.6 & 0.5 & 1.6 \\
Media/journalism & 2.2 & 1.0 & 1.3 & 1.0 & 1.9 & 1.6 & 1.5 \\
Cabaret, musical & 1.0 & 2.2 & 0.9 & 1.4 & 0.6 & 0.6 & 1.1 \\
$\quad$ show & & & & & & & \\
Photography & 0.4 & 0.3 & 0.9 & 1.3 & 1.6 & 1.2 & 1.1 \\
Architecture & 0.9 & 0.9 & 1.3 & 1.1 & 1.1 & 0.8 & 1.0 \\
Design & 1.2 & 0.6 & 0.3 & 0.5 & 1.1 & 0.5 & 0.7 \\
Comics & 0.2 & 0.4 & 0.3 & 0.5 & 0.6 & 1.0 & 0.6 \\
Fashion & 0.5 & 0.2 & 0.0 & 0.3 & 0.3 & 0.9 & 0.4 \\
Multimedia/video & 0.0 & 0.1 & 0.1 & 0.2 & 0.6 & 0.4 & 0.3 \\
Computer/ & 0.0 & 0.0 & 0.0 & 0.2 & 0.0 & 0.2 & 0.1 \\
$\quad$ console games & & & & & & & \\
Other & 6.2 & 4.5 & 5.7 & 3.8 & 3.5 & 1.7 & 3.9 \\
Total & 100.0 & 100.0 & 100.0 & 100.0 & 100.0 & 100.0 & 100.0 \\
(N) & $(1,430)$ & $(1,988)$ & $(1,519)$ & $(2,185)$ & $(2,980)$ & $(2,802)$ & $(12,904)$ \\
\hline Nation & & & & & & & \\
\hline
\end{tabular}

heterogeneity in cultural content. Traditional and established art forms clearly dominate the coverage, whereas many emerging areas of popular culture, such as comics, fashion, multimedia or computer games (the smallest area, with only twelve articles in the entire dataset), have not yet made their breakthrough into the cultural pages. From the emerging cultural areas, only film and television have coverage comparable to the most established art forms. However, it would be erroneous to consider even the smallest of the rising trends as insignificant, as they represent the first steps in legitimization of their respective art forms (see Box 2.1 on computer games).

Interpreting Table 2.1 from a temporal point of view indicates stability rather than major transformation. Some emerging areas were literally non-existent in the culture sections of earlier decades, and they remain very marginal, even in the 2000s. The prevalence of most of the largest areas has been rather stable. In fact, there are only two very clear cases of cultural areas that have experienced a major transformation in their newspaper coverage during the five decades considered: television, with its dramatically increased coverage (see Box 3.2), and theatre, with its equally dramatic decrease (see Box 2.2). 


\section{Box 2.1 Computer games: legitimate culture?}

The term 'computer games' refers to video games played on personal computers (PC), using the equipment of the PC itself. The golden era of computer games started in the mid-1980s, tightly linked to the enormous proliferation of PC purchases.

While they are a much smaller domain of culture than cinema, computer games - as written about in the press - seem to share many of the features of the evolution of writing on other initially popular art forms that later gained cultural legitimacy. According to Baumann's (2007) work on the artistic legitimation of cinema in the United States, there were three crucial elements behind the elevation of cinema's status from mere entertainment to art. Cinema needed, first, an 'opportunity space' (referring to favourable demographical and technological changes, such as increasing numbers of university graduates and the emergence of a more popular media - television - as a new competitor to films); second, suitable institutional changes (such as the creation of cinema festivals and academic institutions studying cinema); and third, the birth of a discourse of cinema as art (performed by film critics). In our data, there are only twelve articles with the first cultural area coded as 'computer and console games'. The amount is indeed marginal, but it shows the first steps towards the legitimation of computer games in a conservative, traditionally very highbrow-inclined mainstream media. It is also significant that all the articles were published in Dagens Nyheter and El País, both of which are early openers in terms of popular culture.

Referring to and challenging the general belief that gaming is negatively associated with social competences (cf. Kowert, 2015), a Dagens Nyheter article from 1990 on computer games shows early optimism associated with the educational qualities of computer games. The article displays a drawing of a child wearing a helmet and playing at the computer, while, in front of him, an airplane smashes out from within the screen and disappears into space. It is labelled '90s cultural revolution. Today's youth is not more intelligent than their parents, they just have a different way of thinking. Forget Aristotle and Descartes, bring on Basic and Pascal!' (DN/06/12/90_B1). The article emphasizes that all the 'scary propaganda' about new technologies is exaggerated, and that, in fact, they will teach children to cooperate and facilitate learning skills such as flying or driving.

The few computer games reviews resemble reviews of other cultural domains. For instance, a review on Conquest of Camelot (DN/06/12/90_B2a) uses expressions such as 'impressive work' and 'not only dramatics but also humour', which could be drawn from any review on literature or theatre. Details such as sets and costumes are also mentioned. Another review, published on the same page as the Conquest of Camelot review, of a sci-fi game called Rymdresa (Space trip) (DN/06/12/90_B2b) is written by Swedish Academy member Kirsten Ekman, another sign of legitimacy. The article uses traditional review elements, and again asks whether parents and teachers should be worried. The answer reflects the fact that computer games are treated like most highbrow cultural domains: 'the game thus has all the qualifications for being able to bring young people valuable cultural capital' (DN/06/12/90_B2b). By 2000, some journalists were calling themselves 'computer game critics' (DN/15/05/00_B3), emphasizing further the legitimation of the field. 
In the 1990s and 2000s, articles only reviewed computer games assessed as 'good' by newspaper editorial staff. Nevertheless, by 2010, an important boundary was drawn between entertainment and art. There are listings of the best games of the season, stressing the different statuses of popularity and real quality. The main division is between 'pure toys - games with plastic parts that have become a more and more essential part of pre- and afterparties' and 'games that can be categorized as artistic works ... In the best games we are able to feel like co-narrators, not only listeners, spectators or readers' (DN/11/09/10_Kultur20).

The only El País article on computer games is an almost full-page report about Peacemaker, a videogame created by the Israeli student Asi Burak. From the first paragraph, it is clear that it is a highly legitimate videogame: 'In videogames, there are two groups: the one of large productions such as Call of Duty or GTA, visually attractive but without any kind of message, and another one that tries to change the mentality of people' (EP/11/06/10_EP3_6). Peacemaker clearly is ranked in this second group: it is designed to make people understand the complexities of the conflict between Israel and Palestine and grasp that solving it is a demanding compromise (It is mentioned that the ex-leader of Israel's intelligence service Mossad played the game live on television and lost immediately). The article shows a tolerant and legitimizing discourse towards videogames as platforms for bringing forward knowledge and democracy, and in a quote from Asi Burak, games are compared to newspapers as a medium for enhancing understanding: 'What people liked the most was that they learned more about the conflict playing than reading about it in newspapers for years' (EP/11/06/10_EP3_6).

While computer games are still a small cultural domain in the quality press, they have gained both 'opportunity space' (technological and digital advances) and suitable institutional changes (there are a wide range of museums and exhibitions dedicated to computer or video game art, and 'game studies' have made it into several universities worldwide) (cf. Baumann, 2007). There are also clear traces of legitimizing discourse, which raises artistically valuable games above other, more mundane ones: distinctive audio-visual aesthetics, identifiable authors and a meaningful message are ways to elevate 'art games' above others (Parker, 2013).

Besides analysing the relative sizes of primary cultural areas as proportions based on number of articles, we also calculated size-adjusted proportions of all cultural areas, to better capture the actual coverage, understood as literal space given to each cultural area in the culture sections. ${ }^{8}$ The only notable difference compared to the results in Table 2.1 was that in terms of size-adjusted proportions, literature is the largest cultural area (its proportion increases from 17.9 per cent in Table 2.1 to 20.3 per cent) and music is only the second largest (its proportion declines from 20.0 per cent to 16.3 per cent). In other words, the coverage of literature is actually larger than the coverage of music, irrespective of the fact that there are more articles on music, the reason being that articles on literature are, on average, longer than the articles on music.

To find out whether the newspapers are different in their cultural content, Table 2.2 presents the six largest cultural areas discussed in each newspaper. 


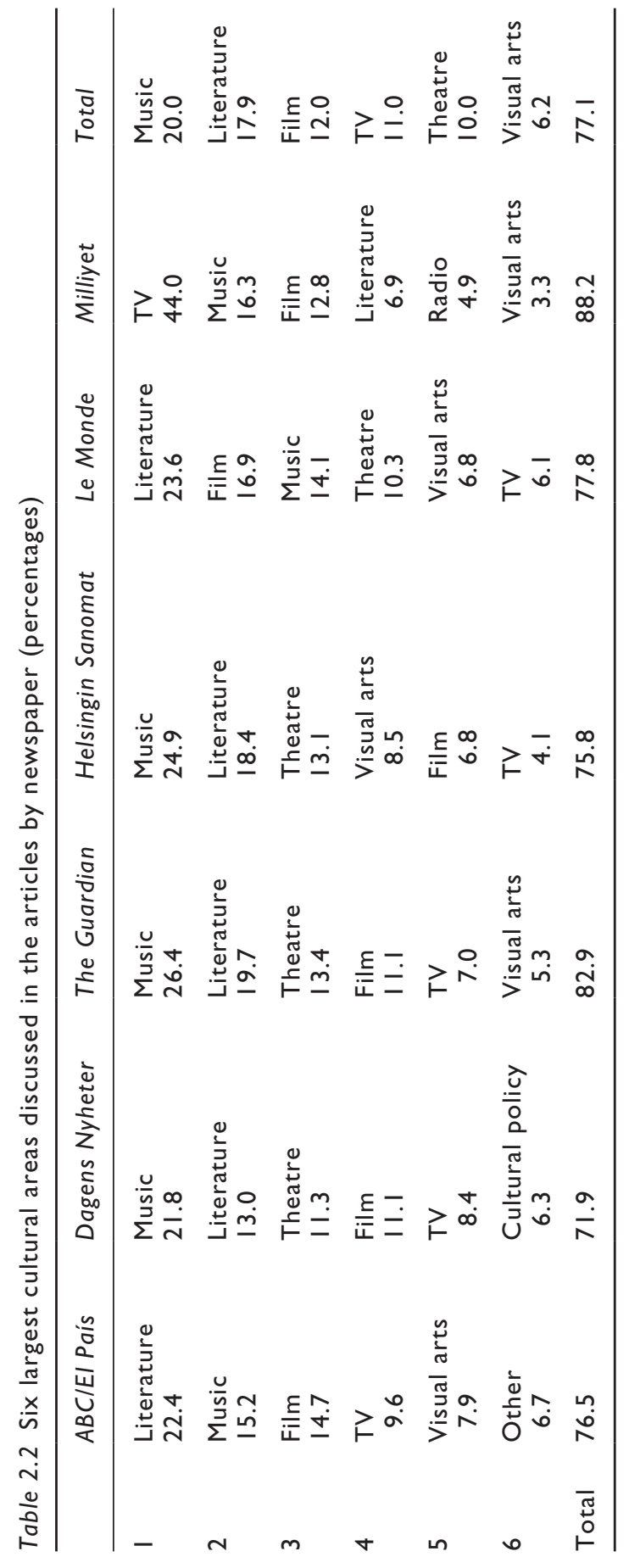


The result suggests a considerable stability in the largest primary cultural areas discussed in articles across newspapers.

Similarities among newspapers are evident regarding the dominant position of music and literature. Film, theatre and the visual arts are usually among the top-six cultural areas. A very small peculiarity is the category of 'other', ranked sixth in ABC/El País (reflective of the coverage of bullfights, especially in earlier decades). ${ }^{9}$ Another special case is cultural policy in Dagens Nyheter, similarly ranking at sixth (see Box 6.1). The only major exception from the striking conformity is represented by Milliyet, as nearly half its cultural articles cover television. ${ }^{10}$ The next most popular items in Milliyet, music and film, are in accordance with the overall pattern. Furthermore, Milliyet is the only newspaper with wide coverage of radio. It is no surprise that Milliyet diverges from the other newspapers, as television viewing became typical in average middle-class Turkish households relatively late in the 1980s, allowing radio to remain the main broadcast medium (Çaplı and Dündar, 1995).

As seen in Table 2.1, emerging cultural areas have not really challenged the dominant position of more established art forms in cultural pages. It is still worthwhile to examine the trends of some emerging cultural forms in separate newspapers. This reveals some main characteristics of each newspaper. Figure 2.1 presents the proportions of articles on films, radio, a group of 'small and emerging' cultural forms and politics, society and the media.

The proportion of film articles was relatively stable across the years, comprising around 12 per cent of all articles. Figure 2.1 reveals, however, that the trend of film articles has been slightly increasing in El País, The Guardian, Helsingin Sanomat and Le Monde. Meanwhile, in Dagens Nyheter, the proportion has been slightly declining, and, in Milliyet, has had notably low levels since 1980, compared to 1960 and 1970 . There are also clear differences in the total level of film coverage (shown also already in Table 2.2): Helsingin Sanomat having the least and Le Monde the most.

Second, radio coverage was not only a small but also clearly a declining cultural area. Figure 2.1 shows that in the Spanish newspapers and Helsingin Sanomat radio has never had proper coverage inside the culture sections. The other extreme is Milliyet, which had substantial coverage on radio until 1980. Dagens Nyheter and Le Monde also had regular radio coverage in 1960 and 1970, after which coverage almost disappeared. In The Guardian, radio coverage experienced a small revival in 1980, after which it declined again.

The group of 'small and emerging' art forms in Figure 2.1 includes the following six popular culture domains that could be expected to increase their prominence since the 1960s: comics, computer/console games, design, fashion, multimedia/video and photography. Together, their share is 3.1 per cent of all articles $(n=395)$, and the proportion has indeed increased in the entire data from 2.3 per cent in 1960 to 4.1 per cent in 2010. However, when observing each newspaper separately, the trend is, in most cases (especially in $A B C / E l$ País, Dagens Nyheter, Helsingin Sanomat and Le Monde) more clearly increasing, 


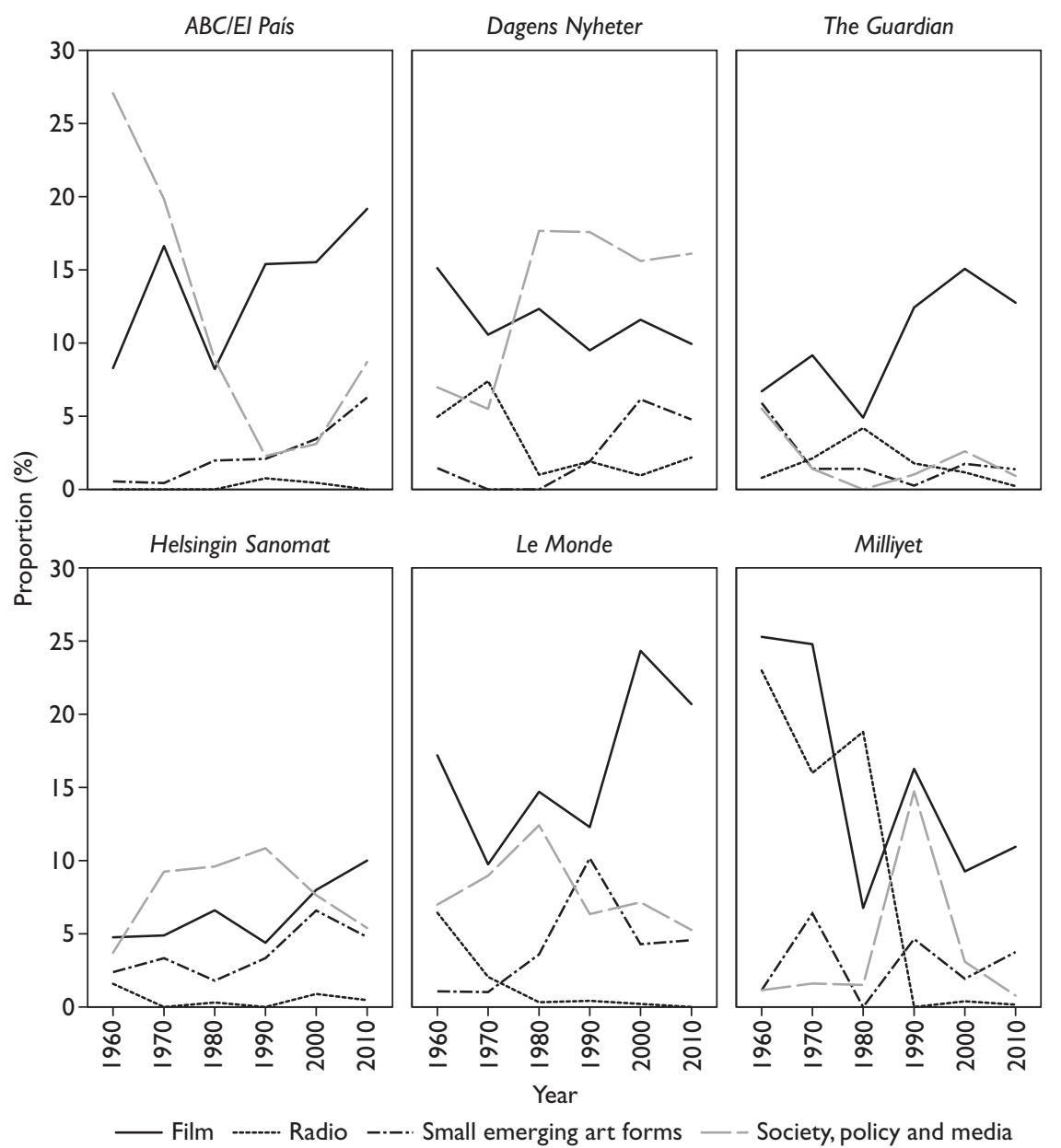

Figure 2.I Articles on film, radio, small emerging art forms and society, policy and media by year, separately on each newspaper (percentages).

from 1-2 per cent in 1960 to 4-6 per cent in 2010. However, in The Guardian, 1960 was the peak year with 5.9 per cent and ever since the proportion of these small popular cultural forms has been below 2 per cent. Thus, as expected, The Guardian seems to be the earliest newspaper to give emerging areas space, but its interest in writing about them decreased over the following decades.

Finally, society, policy and media coverage (Figure 2.1) shows the extent to which culture sections have published articles on socio-politically oriented topics without any conventional art form. ${ }^{11}$ In total, 7.7 per cent of all studied articles primarily discuss society, policy and media, and this trend has been 
relatively stable. When looked at newspapers separately, two of them stand out: ABC published more articles on society, policy and media between 1960 and 1970 than El País has published since 1980; and Dagens Nyheter has published substantially more articles on society, policy and media than the other newspapers since 1980. These cases and the dynamics of the interrelationship between socio-political and cultural content published in the culture sections in these newspapers, will be discussed in detail in Chapter 6.

Our results indicate the persistence of the dominance of most established art forms in cultural coverage. Next, we shall examine more closely changes in the largest and most established art forms: literature and music.

\section{Transformations inside the established arts: literature and music}

Expectedly, literature and music were the two largest primary cultural areas discussed in quality European newspapers' culture sections. Because of obvious variety in the various types of literature and music, both art forms were further coded for subgenres. Both literature and music were coded into nine categories, and the classifications were not intended to be all-encompassing but representative of the most theoretically interesting genres (cf. e.g. Peterson, 2005; Schmutz et al., 2010; Janssen et al., 2011; Berkers, Janssen and Verboord, 2014). It has been noted that, in quality newspapers' culture departments, the typical division between classical music and popular music 'is supported by a relatively clear division of work between classical music journalists and reviewers, on one hand, and popular, world music, folk music etc. journalists and reviewers, on the other hand' (Jaakkola, 2015: 142). The division is not so straightforward in the case of literature and other art forms: 'there is often no equivalent stable division of work organization between followers of prose and poetry, painting and photography, or serious drama and more popular or experimental forms of performances' (Jaakkola, 2015: 142). Indeed, the case of music is particularly useful as it enables us to measure the relative amount of space dedicated to traditional high culture and more recent popular cultural forms within perhaps the most established and institutionalized art form in modern Western society (Frith, 1996; Peterson and Kern, 1996; Roy and Dowd, 2010). In contrast, typical genres of literature do not directly follow the division between highbrow and popular (even if genres such as romance and thriller are often considered less legitimate than other novel types; see e.g. Bennett et al., 2009). Against this background, it is likely that music will show clearer trends than literature.

Table 2.3 shows how the proportions of literature genres evolved from 1960 to 2010. The nine genres involve different forms of fiction and non-fiction. Novels have always been the most common topic for literature coverage, and their coverage proportion is very stable. Articles on poetry and plays have decreased, especially in the 2000s. Whodunit/thrillers, a genre that clearly represents popular culture in literature, has been covered very little throughout 
Table 2.3 Articles on different literature genres (of all articles on literature) by year (percentages)

\begin{tabular}{lrrrrrrr}
\hline & 1960 & 1970 & 1980 & 1990 & 2000 & 2010 & Total \\
\hline Novels & 37.6 & 38.6 & 38.1 & 36.7 & 38.1 & 42.7 & 38.9 \\
Poetry and plays & 16.3 & 12.9 & 11.6 & 17.3 & 10.9 & 8.0 & 12.2 \\
Whodunit/thriller & 5.3 & 3.0 & 1.3 & 1.3 & 3.1 & 4.7 & 3.2 \\
Other fiction & 10.2 & 8.9 & 5.0 & 9.3 & 6.9 & 6.0 & 7.4 \\
(Auto)biography & 4.9 & 6.4 & 5.3 & 10.1 & 8.0 & 13.4 & 9.0 \\
History & 9.0 & 5.9 & 11.3 & 6.9 & 7.7 & 5.0 & 7.4 \\
Science/nature & 1.6 & 5.4 & 7.9 & 3.7 & 4.0 & 3.3 & 4.2 \\
Philosophy/religion & 2.4 & 2.5 & 4.0 & 4.3 & 3.1 & 3.1 & 3.3 \\
Other non-fiction & 12.7 & 16.3 & 15.6 & 10.4 & 17.3 & 13.8 & 14.4 \\
Total & 100.0 & 100.0 & 100.0 & 100.0 & 100.0 & 100.0 & 100.0 \\
(N) & $(245)$ & $(202)$ & $(302)$ & $(376)$ & $(549)$ & $(515)$ & $(2,189)$ \\
\hline
\end{tabular}

the years, and the category shows no increase. For non-fiction, articles on (auto)biographies have grown over time. In 2010, biography was the secondlargest book genre behind novels discussed in culture sections. There are no unambiguous trends among other non-fiction books (history, science/nature, philosophy/religion or other non-fiction).

Figure 2.2 shows how the newspapers differ regarding major changes in literature coverage when divided into highbrow genres of literary fiction (novel, poetry and plays and other fiction) (see Janssen et al., 2011) and all non-fiction genres. ${ }^{12}$ The difference between the coverage of literary fiction and non-fiction has been the most stable and widest in ABC/El País (with changes to the newspaper after democratization not affecting this result) and Helsingin Sanomat. In Dagens Nyheter and Le Monde, the proportion of articles on literary fiction have been declining (and the proportion of articles on non-fiction correspondingly rising), which has led to literary fiction and non-fiction coverage being more or less equal (in the case of Le Monde since 1980 and in the case of Dagens Nyheter since 2010). The Guardian shows a relatively even distribution of articles between literary fiction and non-fiction beginning in 1960, but with a new gap emerging in favour of literary fiction in the 2000s. Finally, Milliyet shows no systematic trends. Articles on literary fiction have generally been published more than non-fiction articles, but volatile changes are due to a very limited number of articles being published in literature in the first place. Milliyet published only ninety-one articles on literature in the studied period in our sample, whereas the newspaper with the second-smallest number of articles on literature (Dagens Nyheter) has published them more than three times as often (281 articles).

To test whether the heterogeneity of musical coverage has increased, we focus on the music field and investigate how music coverage is divided according to genre and how it has changed over time (Table 2.4). Similar to the articles covering literature, articles discussing music were coded into nine 


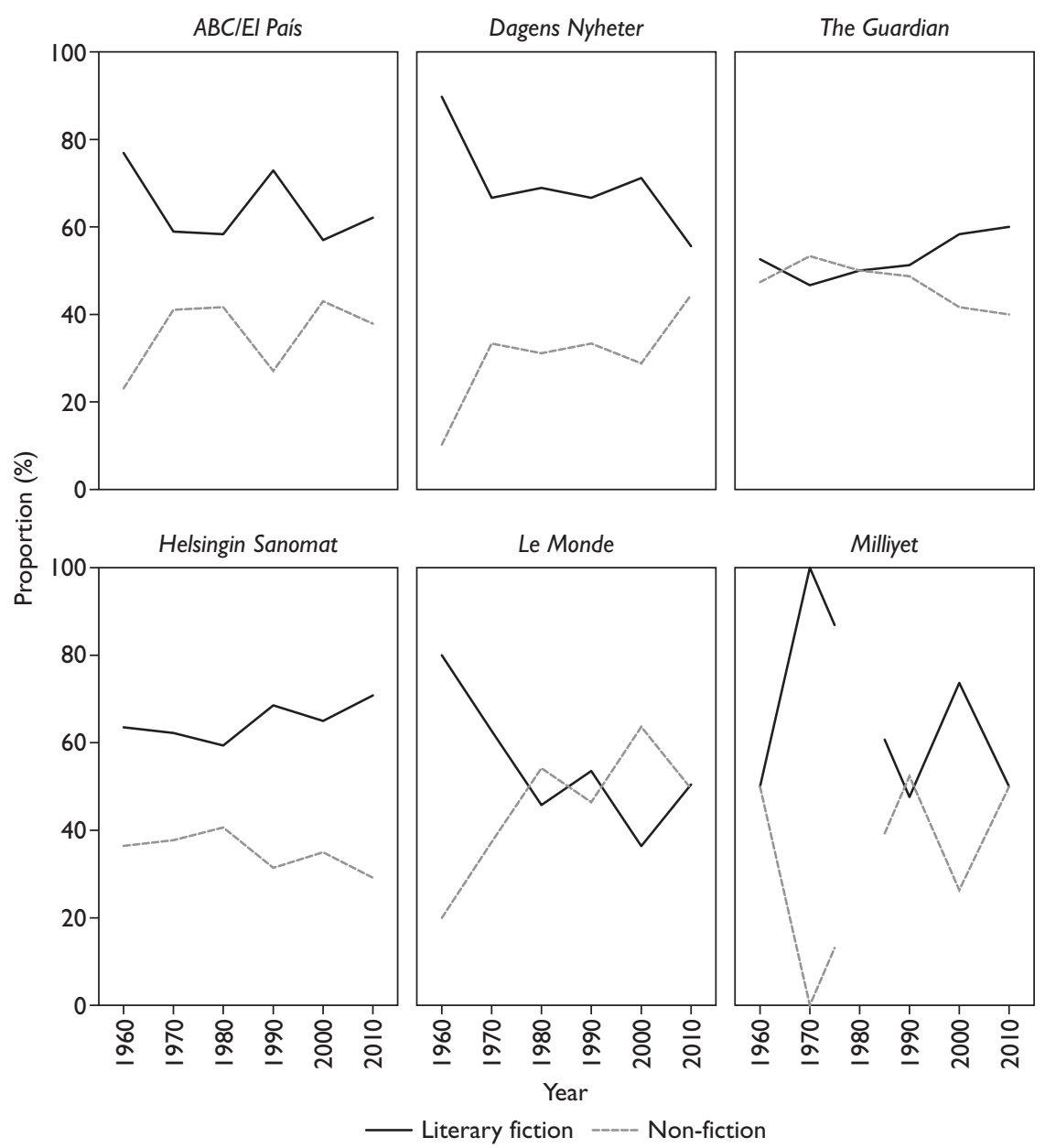

Figure 2.2 Articles on literary fiction and non-fiction (of all articles on literature) by year, separately on each newspaper (percentages).

categories: Western classical/art music; pop \& rock music (with a wide definition including rock, heavy metal, punk, indie, etc.); electronic dance music; rap and hip-hop; jazz; world music; traditional folk music; domestic hit music (such as chansons in France and schlagers in Nordic countries); and other. Following categorizations in previous studies, opera (which was originally coded as a separate primary cultural area) was included within the category of classical music (Janssen et al., 2011).

Two genres, classical music and pop \& rock, differ from the rest of the sample by size. Almost 44 per cent of all music articles cover classical music, and almost 
Table 2.4 Articles on different musical genres (of all articles on music) by year (percentages)

\begin{tabular}{lrrrrrrr}
\hline & 1960 & 1970 & 1980 & 1990 & 2000 & 2010 & Total \\
\hline $\begin{array}{l}\text { Classical music } \\
\quad \text { (including opera) }\end{array}$ & 83.9 & 61.5 & 45.8 & 50.9 & 33.4 & 22.8 & 43.6 \\
Pop and rock & 1.6 & 14.7 & 26.6 & 24.7 & 35.8 & 47.1 & 29.7 \\
Jazz & 2.7 & 7.5 & 12.2 & 11.7 & 9.1 & 7.1 & 8.7 \\
Domestic hit music & 4.7 & 4.2 & 4.3 & 2.0 & 2.8 & 4.3 & 3.6 \\
World music & 0.4 & 0.5 & 1.0 & 2.9 & 7.1 & 4.4 & 3.4 \\
Traditional folk & 2.4 & 4.7 & 3.5 & 2.7 & 2.6 & 1.9 & 2.9 \\
Electronic dance & 0.0 & 0.2 & 0.0 & 1.3 & 4.0 & 4.9 & 2.4 \\
$\quad$ music & 0.0 & 0.0 & 0.0 & 0.7 & 1.8 & 3.5 & 1.4 \\
Rap and hip hop & 4.3 & 6.8 & 6.6 & 2.9 & 3.4 & 4.0 & 4.4 \\
Other & 100.0 & 100.0 & 100.0 & 100.0 & 100.0 & 100.0 & 100.0 \\
Total & $(255)$ & $(429)$ & $(395)$ & $(546)$ & $(650)$ & $(773)$ & $(3,048)$ \\
(N) & & & & & & & \\
\hline
\end{tabular}

30 per cent focus on pop \& rock. While their proportions are relatively similar, they have opposite trajectories: pop \& rock coverage has increased dramatically, while classical music coverage has sharply decreased. Jazz, with 9 per cent coverage, and some other smaller genres (e.g. domestic hit music, traditional folk music, world music) have remained relatively stable over time, notwithstanding the fact that world music was fairly unrepresented until 1990 and jazz saw a clear rise from 1960 to its height in 1980-1990 (see Box 3.1). Electronic dance music and rap and hip-hop are small but emerging music styles that have been considered increasingly often in the 2000s as valuable enough to be given space in quality newspapers' culture sections.

For further analyses, we merged the genres of electronic dance music and rap and hip-hop into the category of pop \& rock music. This resulted in a wider genre of 'pop-rock' (Regev, 2013), which reflects the gamut of pop music styles that have attracted young people in Western countries since the 1950s and 1960s, a meaningful category and genre of music in itself (Frith, 1996; Regev, 2013; Varriale, 2016). Altogether, pop-rock accounts for one-third of all music articles, and there has been a significant and steady increase in its proportion, as shown in Table 2.4. But how has this proportion evolved between 1960 and 2010 in each of the six newspapers? Are there significant differences in the victorious trajectory of pop-rock?

Figure 2.3 answers these questions by contrasting the rise of pop-rock with the decline of classical music separately in the case of all newspapers. This allows us to inspect the moments when pop-rock articles outnumbered classical music articles in each newspaper. The increase in the prevalence of pop-rock articles has occurred in different ways across the newspapers. This is expected, since previous research also shows that the 'size and timing of the shifts towards greater attention to popular music' (Schmutz, 2009b: 305) has varied between 


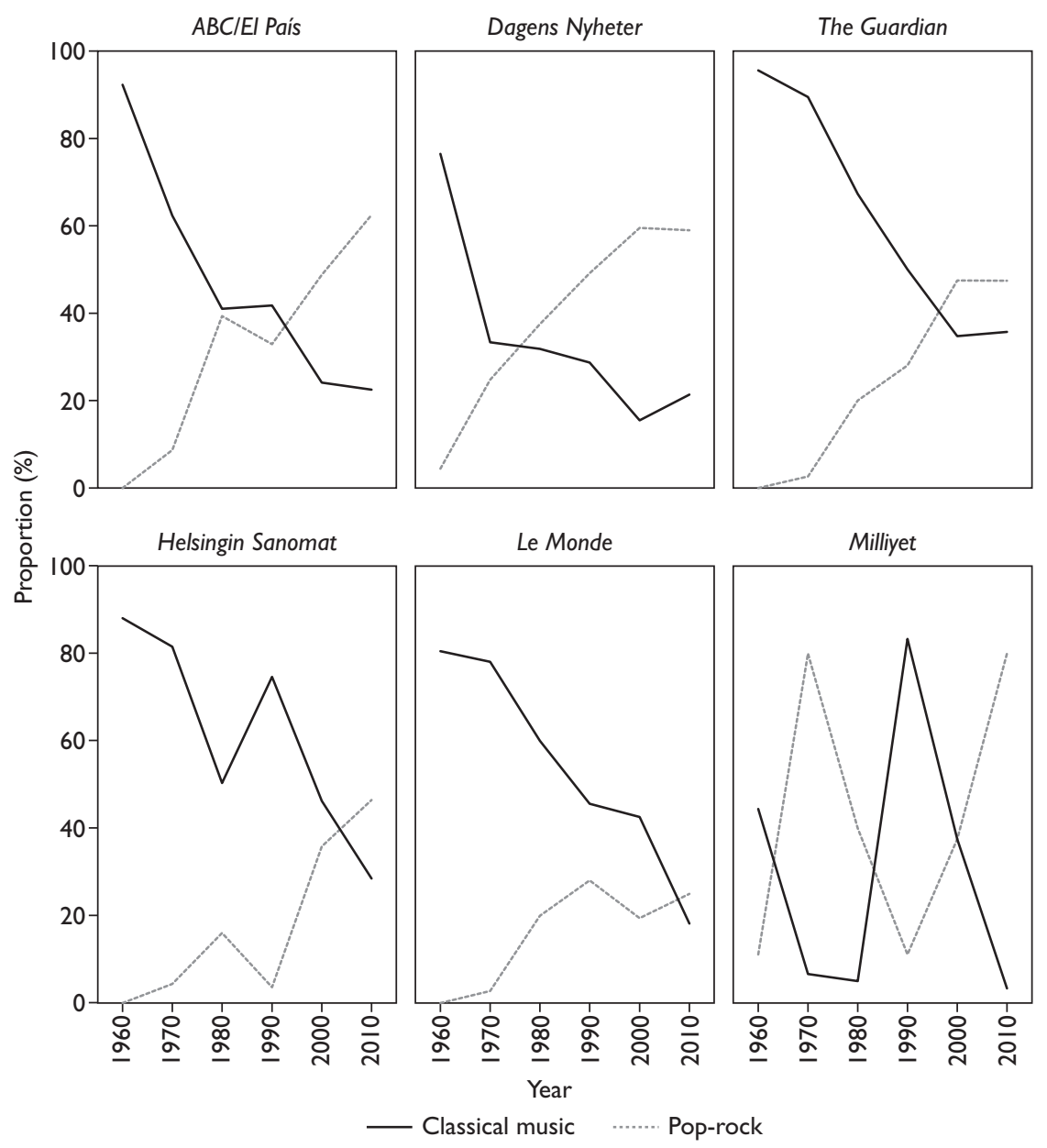

Figure 2.3 Articles on classical music and pop-rock (of all articles on music) by year, separately on each newspaper (percentages).

countries, even if the main trend is clear. However, the differences are not entirely similar to our expectations.

First, while pop-rock coverage increased clearly in all newspapers, there are also significant differences in its overall level, with The Guardian, Helsingin Sanomat and Le Monde in particular, having published fewer articles on poprock than ABC/El País, Dagens Nyheter and Milliyet. As for trends over time, Milliyet surprisingly shows the earliest opening, but we should note that Western classical music never had a status in Turkey similar to other European countries. Thus, we cannot expect classical music to have attracted more journalistic 
attention in earlier decades. The high and volatile proportion of pop-rock articles is due to the fact that the main category against which pop-rock is analysed has been so marginal in Turkey. Only 16 per cent of all articles on music in Milliyet are on classical music, while the proportion across the data is 44 per cent. Dagens Nyheter and ABC/El País interestingly turned their attention to pop-rock music earlier than The Guardian, Helsingin Sanomat and Le Monde. In the latter group of newspapers, pop-rock did not begin to outnumber classical music until the 2000s. ${ }^{13}$

Taken together, while the trends in literature subgenres show stability, the trends in music genres show fundamental transformation. Thus, literature and music, as the two largest art forms, signify entirely different roles in the context of post-1960s cultural transformations: continuity versus change. Our genrespecific examination of literature and music coverage also has methodological implications for the next section, in which we focus on the supposed decline of highbrow arts. In other words, the analysis clearly shows via cultural coverage in Milliyet (see Figures 2.2 and 2.3 in particular) that the categories of highbrow and popular are not well suited to understanding the dynamics of cultural hierarchies in Turkey. Indeed, the very Western and European classical highbrow arts never had a canonized and strong position in the cultural history of Turkey (Belge, 1996). ${ }^{14}$ Therefore, Milliyet has not been included in the data used in the following analyses on the decline of highbrow cultural coverage. We will return to this decision at the end of this chapter (see also Box 2.3 on the historical background of the Turkish case).

\section{The decline of classical highbrow arts}

We examine our data on the culture sections of quality European newspapers for highbrow arts covered from 1960 to 2010 to specify and bring systematicity to debates on the decline of the status of highbrow arts. In the analysis, when singling out highbrow arts, we follow the classification by Janssen et al. (2011), in which highbrow arts include architecture, ballet and modern dance, classical music (including opera), literary fiction, theatre and the visual arts. ${ }^{15}$ This conventional operationalization of 'highbrow' comes close to the original eighteenth-century conception of 'fine arts', which included only poetry, painting, sculpture, architecture and music, 'as opposed to crafts and popular arts (shoemaking, embroidery, storytelling, popular songs etc.)' (Shiner, 2001: 5). Moreover, the category of popular culture against which the highbrow arts are viewed includes all other cultural forms but excludes those primary cultural areas that are not proper art forms (science, society, philosophy; cultural policy; media/journalism; and other).

Table 2.5 shows varied trends in the coverage of highbrow arts. Architecture and dance have had very little coverage during the period under examination, and there is no clear trend in their coverage. Classical music, opera included, is the largest of the art forms, or equal with theatre. However, its coverage is in 
Table 2.5 Articles on popular culture and highbrow arts by year (percentages)

\begin{tabular}{lccccccc}
\hline & 1960 & 1970 & 1980 & 1990 & 2000 & 2010 & Total \\
\hline Popular culture & 37.3 & 43.9 & 47.5 & 51.8 & 64.2 & 63.4 & 53.7 \\
Highbrow arts & 62.7 & 56.1 & 52.5 & 48.2 & 35.8 & 36.6 & 46.3 \\
Classical music & 16.4 & 16.0 & 14.6 & 14.0 & 7.9 & 8.2 & 12.1 \\
Theatre & 23.8 & 21.5 & 12.6 & 10.3 & 6.6 & 5.3 & 12.0 \\
Literary fiction & 11.9 & 6.6 & 13.4 & 12.1 & 11.4 & 13.9 & 11.6 \\
Visual arts & 8.3 & 8.7 & 7.7 & 7.7 & 6.6 & 5.9 & 7.3 \\
Ballet/modern dance & 1.2 & 2.4 & 2.4 & 2.9 & 1.8 & 2.4 & 2.2 \\
Architecture & 1.0 & 1.0 & 1.7 & 1.2 & 1.4 & 0.9 & 1.2 \\
Total & 100.0 & 100.0 & 100.0 & 100.0 & 100.0 & 100.0 & 100.0 \\
$(\mathrm{~N})$ & $(1,189)$ & $(1,617)$ & $(1,195)$ & $(1,866)$ & $(2,518)$ & $(2,018)$ & $(10,403)$ \\
\hline & 7 & 7 & & & &
\end{tabular}

decline: there is an evident drop after 1990, but otherwise there is no clear trend. Literary fiction has been a substantial category in terms of size during the period studied, but there is no trend. Theatre shows the clearest trend in terms of coverage: overall, it is a large area; and in the 1960s and 1970s, it was the most-covered area by far. After 1970, theatre coverage faced a dramatic decrease, from more than 20 per cent to only 5 per cent (see Box 2.2 on the case of 'shrinking' theatre). The visual arts show only a slight decreasing trend.

Next, we examine whether trends across newspapers are consistent if specific highbrow art forms are inspected separately by exploring the two largest categories of highbrow arts after classical music and literary fiction, which we already discussed, according to year and newspaper: theatre and the visual arts. From Figure 2.4, we see that theatre shows a consistent decline across newspapers. The decline has been the most dramatic in Helsingin Sanomat and Le Monde, two newspapers that had the widest theatre coverage in the earliest decades. In the case of the visual arts, we see a mild declining trend in all papers except Dagens Nyheter, in which the proportion of articles on the visual arts actually increased after 1970. Dagens Nyheter was different in this respect because it clearly published more visual arts coverage than any other newspaper. In 2010, all the papers were similar in terms of the proportion of visual arts articles.

Despite the art-form-specific differences, an evident general trend can be seen from Table 2.5 in the proportions of the categories of popular and highbrow arts: when calculated together, the coverage of highbrow arts declined from almost two-thirds in 1960 to just over one-third of all articles in the 2000s. Thus, it makes sense to calculate all highbrow art articles together and analyse more closely how this composite measure of the proportion of highbrow arts has changed and whether the newspapers are different in that respect (Table 2.6).

There are significant differences between newspapers. Most importantly, Helsingin Sanomat has far more highbrow content than other newspapers. 


\section{Box 2.2 The shrinking theatre}

Theatre is in all senses an essential element of highbrow art, but little is known about how its reporting and evaluation has changed over time. In this section, we use Helsingin Sanomat and The Guardian to briefly outline key dynamics of theatre coverage from 1960 to 2010. These newspapers differ from each other in that, while theatre articles in Helsingin Sanomat have declined both in relative and absolute terms (from 101 published in 1960 to only twenty-four published in 2010), the decline in The Guardian has been purely relative (the number of theatre articles published in 1960 and 2010 remaining almost identical, at fortytwo and forty-three, respectively).

In earlier decades, most theatre articles published in both newspapers were short, providing, especially in Helsingin Sanomat, only very descriptive information on the plays. Despite the decline in the numbers of articles over time, those published have rich, evaluative content. A clear rise in theatre article length happened after 1990, which, in the case of Helsingin Sanomat, has meant more informative and evaluative articles. In The Guardian, coverage been rather elaborate over the entire period, focusing on various aspects of productions.

In Helsingin Sanomat, the reviewers often positioned themselves as professional figures with expertise that audiences lack. This hierarchical tone in reviews is noticeable across decades, especially in articles written by male critics. Popular recognition in the form of audience approval has not been considered important in reviews; in fact, when audience and critic responses do not match, it is implied that the distinction between art and entertainment can only be noticed by a trained eye. The Guardian's coverage is similar in this sense.

From theatre coverage, it seems as if all parties involved (critics, producers, actors) have been aware that an effort must be made to renew theatre in order to keep up with the increasingly dynamic and cosmopolitan cultural field. From the 1980s onwards, the critics of Helsingin Sanomat began to express interest in novelties, for instance in the use of new technology in theatres (e.g. video installations) and dissolving the boundaries between different art forms. Similarly, in The Guardian, new kinds of projections were discussed in reviews, and, in most cases, reviewers were happy with the results. In this atmosphere of renewal, perhaps the harshest critiques were directed towards classical plays. For instance, in Helsingin Sanomat, Dario Fo and Franca Rame's Donna is reviewed negatively for having an outdated historical expression:

Maybe the horribleness of the issue would have reached the desired historical dimension, if it was whispered. Now the spectator can peacefully be enchanted by the outdated theatre expression in his chair and forget the previous parts as funny specialities.

(HS/26/09/80_22)

Similarly, in The Guardian, a play is appreciated because the director was able to create something more than a 'museum piece' by adapting it to 'present-day sensibilities, thus bringing the centuries, but without altering the substance or spirit of classical dramatic type' (GU/09/07/60_3). 
The decline in audience numbers and the impact of reduced public funding is a noticeable theme in both newspapers. Commercial expectations are contrasted with the quality and authenticity of the theatre play in many instances. Reviewers acknowledge bitterly that the market shapes many decisions in the theatre world. The same theme is easily noticeable in Helsingin Sanomat, especially with a focus on the fate of publicly funded theatre companies. For instance, a 1990 article expresses serious concerns over the management and marketing of the Turku city theatre: 'The worst scenario is that there is no city theatre in Turku in this form when the autumn season 1991 begins' (HS/31/05/90_B8). Another article reports the financial problems of a children's theatre company: 'Last spring, we found out that the losses are going to be massive. The deficit is at least a million in total' (HS/17/10/00_B6). In The Guardian, this topic is sometimes discussed in relation to political shifts in a broader sense, or, more specifically, by questioning the consequences of losing public money and autonomy. For instance, a critic mentions how the chief executive of Britain's largest commercial sponsor of performing arts felt the right to express his 'concerns' over the 'extravagant' use of actors in a production of Il Trovatore by the Royal Shakespeare Company (GU/31/05/90_26). The political dimension, in general, is surprisingly common in theatre coverage; as we will show in Chapter 6 in light of the quantitative data, the articles on theatre evinced a strong increase a political dimension in the 2000s and 2010s.

To sum up, the theatre coverage of Helsingin Sanomat and The Guardian suggests that the decline in one of the most established domains of highbrow culture is indeed acknowledged by cultural journalists. The explicitly recognized decrease led reviewers to show some tolerance towards 'renewal' attempts and to keep the economic pressures on the agenda. Especially in the 2000s and 2010s, this often translated into a quest for the extraordinary and an approving attitude towards different extra art elements, as, for instance, in the following excerpt of an enthusiastic review on a play: 'It begins in a patchwork Bedouin-style tent where you are offered tea and a choice of three stories. The whole thing is pleasingly ritualistic' (GU/14/06/10_36).

Despite a decline in their numbers and relative coverage, the articles on theatre maintain an articulated language and rich content both in Helsingin Sanomat and The Guardian. It shows that, while theatre may be 'shrinking', to paraphrase the title of a theatre review in The Guardian (GU/02/11/90_37a), it is still a respectable cultural field, even to the degree that theatre critics have seen it necessary to fight for its position.

The Guardian and Le Monde come next, and Dagens Nyheter and El País have the least highbrow content. Notwithstanding these differences in the level of highbrow content, the shape of the declining trend is relatively consistent across the newspapers. The most notable differences include Helsingin Sanomat experiencing a very late (albeit dramatic) change in the 2000s. The difference is sharp compared to Dagens Nyheter, which had a similarly low level of highbrow coverage from 1970 onwards - a level which Helsingin Sanomat declined to in 2010. Perhaps surprisingly, The Guardian shows the least clear declining trend 


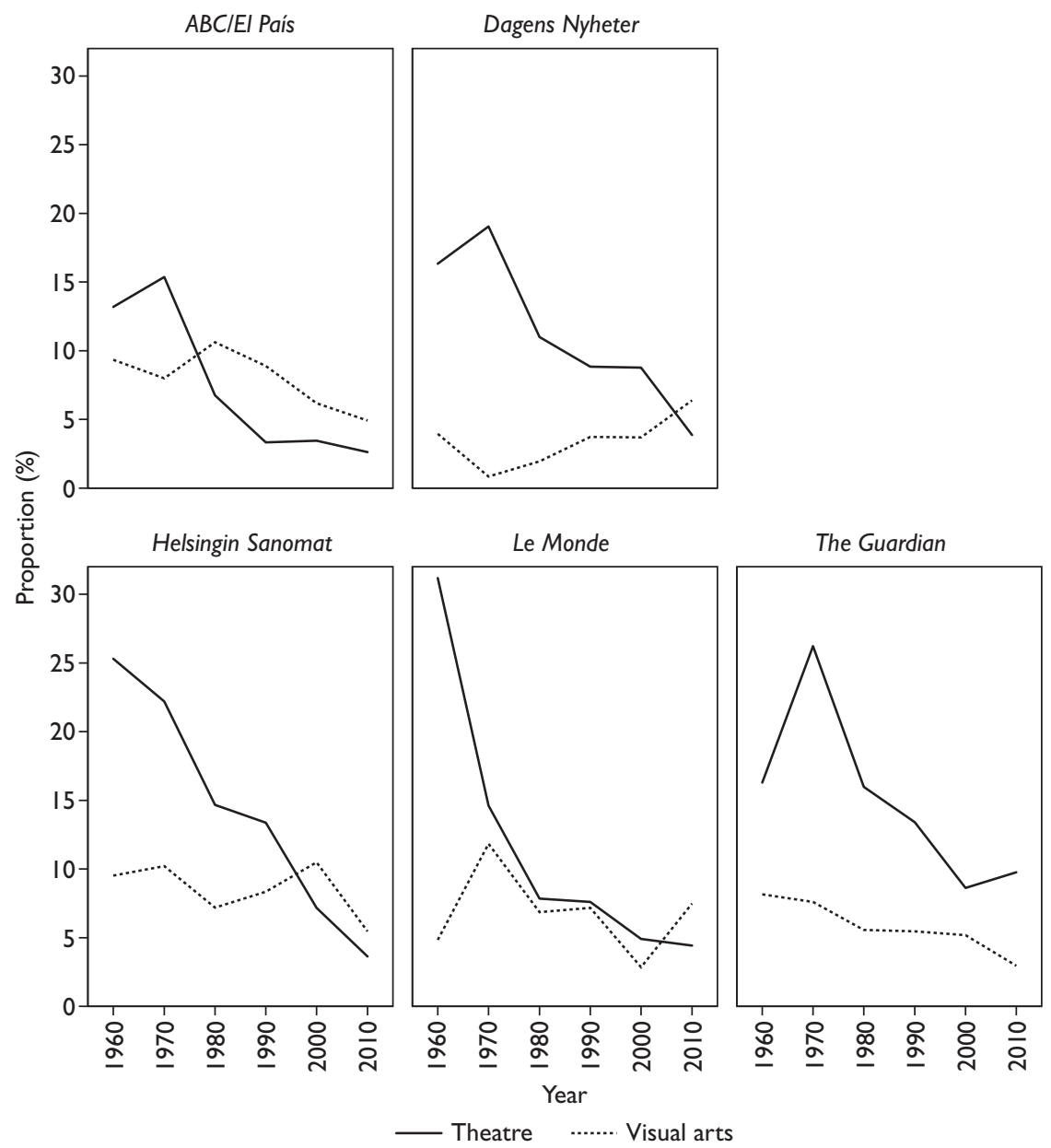

Figure 2.4 Articles on theatre and the visual arts by year, separately on each newspaper (percentages).

overall, having remained the most loyal to highbrow content between 1960 and 2010 .

It is important to note that the decline observed in highbrow arts is most of all a relative decline rather than an absolute one (see the last two rows in Table 2.6). The overall cultural content in newspapers has expanded so heavily during the studied period that the coverage of highbrow arts, while stable in absolute terms, can only account for a decreasing portion of total cultural coverage (see Figure 2.5). Moreover, if examined field by field and calculated from the whole content of culture sections, as shown in Table 2.5, the relative decline is 
Table 2.6 Articles on highbrow arts by newspaper and year (percentages)

\begin{tabular}{lcccccccc}
\hline & 1960 & 1970 & 1980 & 1990 & 2000 & 2010 & Total & $(N)$ \\
\hline ABCIEI País & 66.4 & 54.0 & 49.6 & 39.2 & 29.3 & 31.2 & 39.3 & $(929)$ \\
Dagens Nyheter & 53.0 & 34.8 & 43.5 & 38.3 & 34.2 & 30.1 & 37.9 & $(785)$ \\
The Guardian & 60.2 & 66.9 & 54.9 & 43.5 & 41.0 & 45.9 & 48.8 & $(817)$ \\
Helsingin Sanomat & 72.5 & 76.4 & 64.5 & 73.8 & 49.5 & 37.4 & 59.4 & $(1,529)$ \\
Le Monde & 58.0 & 59.0 & 48.3 & 42.5 & 29.9 & 36.0 & 44.0 & $(758)$ \\
Total & 62.7 & 56.1 & 52.5 & 48.2 & 35.8 & 36.6 & 46.3 & \\
$(\mathrm{~N})$ & $(745)$ & $(907)$ & $(627)$ & $(899)$ & $(901)$ & $(739)$ & & $(4,818)$ \\
\hline
\end{tabular}

Note

Total $N=10,403$, of which 53.7 per cent $(n=5,585)$ were articles on popular culture.
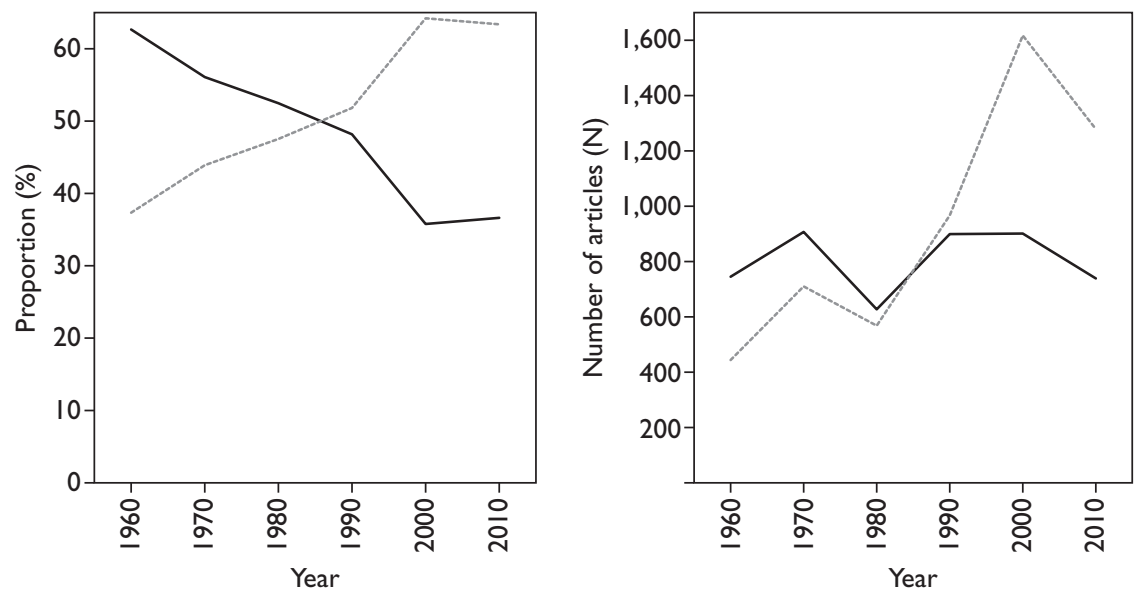

- Highbrow arts

Popular culture

Figure 2.5 The proportion of articles on highbrow arts and popular culture (left) and the absolute number of articles on highbrow arts and popular culture (right) by year.

dramatic only in the case of theatre (and, to a lesser degree, classical music). Thus, the decline of the status of highbrow culture is best understood as a relative decline that has taken place under the circumstances of the expansion of popular culture and the subsequent 'cultural abundance' (Wright, 2011, 2015).

Here, our findings parallel previous research showing that participation in highbrow culture has remained relatively stable, while the consumption of popular, commercial culture has dramatically increased since the 1960s (Roose and Daenekindt, 2015; Donnat, 2011). While this does not contradict the idea that popular culture is an increasingly important area in games of cultural distinction (Prieur and Savage, 2011, 2013), the rise and abundance of popular culture may nevertheless mask the sustained significance of highbrow arts. 


\section{Conclusion}

In this chapter, we have engaged with literature that suggests a change in the ways culture and art have been classified and valued in recent decades (DiMaggio, 1987; Peterson and Kern, 1996; Baumann, 2007; Janssen et al., 2011). To explore the heterogenization and opening of the content of legitimate culture empirically, and to track trends in a longitudinal manner, we used European newspaper data. We consider newspaper culture sections to be a valuable medium for achieving this goal, especially when set against our focus on quality newspapers, as much of the literature is particularly concerned with high-status groups' tastes and practices (cf. Janssen et al., 2011: 159). Moreover, for decades, print media has been a crucial institution of cultural mediation, capable of attributing symbolic value by framing certain cultural forms as 'culture' and 'arts' when including them systematically in their culture sections and supplements.

The results suggest an opening of the content of legitimate culture, albeit not as straightforward one as one might have expected. First, established art forms hold their mainstream position, while most of the emerging popular forms are validated at a slower pace than expected. Thus, established cultural forms (literature, music, etc.) are still the backbone of the arts and culture content of newspapers, despite the proliferation of other cultural forms in recent years. However, film and television rank among major cultural domains, so they have managed to cross over validation boundaries (cf. Baumann, 2007; Lavie and Dhoest, 2015).

Second, of the two major and most established art forms, only music has experienced a radical transformation, whereas the other, literature, shows considerable stability. Attention to pop-rock music (Regev, 2013) has almost exponentially increased, whereas the coverage of classical music is in sharp decline. This finding echoes Schmutz et al.'s (2010) analysis of the United States, France, Germany and the Netherlands (see also Schmutz, 2009b). When evaluated with this study, it is easier to suggest that the opening of culture via the diversification of legitimate musical genres resonates on a wide geographical level across Europe.

Third, highbrow arts have declined in coverage, but not across all highbrow arts. The coverage of some art forms decreases (most of all theatre and, to some extent, classical music), whereas other forms maintain their position (e.g. literary fiction and, to lesser degree, the visual arts). While differing in their overall highbrow coverage, newspapers show relatively stable trends. Rather than declining in absolute terms, we argue that the changing status of the highbrow arts is best understood as a relative decline, caused by the post-1960s expansion of popular culture.

These findings challenge expectations about the order in which quality European newspapers manifest the timing and thoroughness of the opening of legitimate culture content, highlighting the complexity of factors shaping newspapers' cultural coverage. When the evolution of the proportions of emergent popular art forms over time is used as a proxy for cultural opening, the newspapers can 
be placed in the following order of approximate openness: (1) ABC/El País, Dagens Nyheter, (Milliyet), (2) Le Monde, (3) The Guardian and (4) Helsingin Sanomat. However, when the between-genre evolutions within an established art form, in this case classical versus pop-rock music, is taken as a proxy for cultural opening, the order is slightly different: (1) Dagens Nyheter, ABC/El País, (Milliyet), (2) The Guardian, (3) Le Monde and (4) Helsingin Sanomat. Finally, when assessed based on declining trends of classical highbrow arts, an analysis from which we exclude Milliyet, the order of openness is approximately as follows: (1) Dagens Nyheter, ABC/El País, (2) Le Monde, (3) The Guardian and (4) Helsingin Sanomat. In other words, Dagens Nyheter and ABC/El País consistently rank among the earliest and most thorough openers, whereas Helsingin Sanomat is placed as the last opener according to all three analyses.

In all cases, the position of The Guardian as a relative latecomer was unexpected, since the UK is more centrally positioned in the global system than other countries in the sample, its media system is arguably more liberal and it is not included among the countries where state funding for the established arts is high. In other words, rather than indicating society-level dimensions, the result relates to the characteristics and position of The Guardian itself. Moreover, Milliyet can be ranked in the first category in the first two measures, but its position is parenthetical: the journalistic attention that Milliyet shows to emergent cultural forms and pop-rock today is not part of a gradual opening process, since Western highbrow culture was never canonized in Turkey (Belge, 1996). Given this historical background, the journalistic interest shown to such new fields in Milliyet can hardly be interpreted as a cultural opening in the same sense as in other newspapers. Rather, Turkey occupies a peripheral position in the globalization scale, and the state's attempt to Westernize its cultural sphere following the foundation of the secular republic was never effective enough to heighten highbrow art forms. ${ }^{16}$ In that sense, Milliyet demonstrates the geographical and cultural limits of the Western cultural canon rather than suggesting a trend towards cultural declassification. Thus, the main lesson taken from Milliyet in this chapter is that, while Milliyet does not show the same European trends evident in other newspapers, it can nevertheless be interpreted as indirectly validating the results on the opening of legitimate culture in other European countries. As for a practical implication of this regarding what follows in this book, Milliyet has not been included in any of the analyses for which the categories of highbrow and popular are used (see also Box 2.3). Moreover, Milliyet exemplifies the volatile trends in cultural coverage caused by political and economic constraints, which can be predicted by the polarized pluralist media system model that is most vulnerable to external pressures limiting the autonomy of journalism (Hallin and Mancini, 2004). Thus, we discuss Milliyet and the case of Turkey in detail in Chapter 6, which focuses on the relationship between cultural evaluations and politics.

Taken together, our results are divergent when it comes to the three societylevel dimensions discussed: the newspaper's position in the global cultural 


\section{Box 2.3 Meanwhile, in Turkey: on the socio-political limits of (Western) cultural transformation}

Since the beginning of Ottoman modernization in the late eighteenth century, cultural forms that originated from or have ties with the Western cultural fields have been imbued with high symbolic value. To put it in terms of present-day cultural practices, listening to a European band or reading a Western novel have allowed people to perform cultural distinction, regardless of the possible lower positions of these practices in their native classification system. Many cultural activities considered to be popular or middle-brow in the Euro-American contexts (e.g. going to the cinema, listening to popular music) still mark the taste repertoire of the culturally privileged in Turkey (Rankin, Ergin and Goksen, 2014). However, Turkish cultural fields have also been situated at the intersection of Eastern and Western global cultural flows, making it manifest various characteristics ranging from 'hybridization of the local and the western' to the 'revival of imagined Islamic roots' (Ger, 2017).

Thus, it is logical that the trends identified in Milliyet's coverage have turned out to be quite different from those found in the rest of the sample; Turkey's cultural and socio-political structure is significantly different from other core European cases. The similarities and differences in temporal trajectories tell an important story about the margins of the European cultural canon (a systematic comparison between Milliyet and other newspapers of this study is presented in Karademir Hazır and Purhonen, 2017).

As evidenced in Chapter 2, Milliyet exhibits the earliest opening to emerging areas. However, the longitudinal design of the study allows us to see that the current high interest in popular and emergent forms has not been a product of a gradual process of opening. This finding is more meaningful when it is contextualized in the history Turkish culture and arts. At the end of the nineteenth century, established art forms began to arrive in Turkey (then part of the Ottoman Empire) and conflicted with traditional arts immediately. It is important to note that, historically, Sunni Islam has not encouraged the development of figurative and performing arts, which are central elements of European legitimate arts. However, during Ottoman modernization, many famous artists in these areas were invited to the palace to teach and to disseminate their art. These attempts were eventually curtailed by the periods of censorship and popular resistance. For instance, while 'Western theatre' was established in 1839 as the new reform movement of the time, it was pressured and censored after the despotic period following 1884. Even before the modernization period, the sculptures brought to the palace by Suleiman the Magnificent were removed soon after his inauguration under the argument that they facilitated idolatry. The same tension can be observed in the field of literature. The novel, as a style, was imported from the West in the late nineteenth century but did not cohere well with the oral literature tradition that had been prominent in the region for so long.

Formed in 1923, the new Republic aimed to develop these established cultural forms through opening up art schools and institutes, recruiting international staff, and by establishing publicly funded theatre and opera houses. In line with the modernization agenda, the policies implemented in that period imbued competences in 
such Western cultural fields with high symbolic value. Public policies supported the field of production of established arts. For instance, in 1934, the first opera was composed to honour the Iranian Shah's visit to Turkey. New legislation introduced in the 1950s also expanded the field of theatre by allowing private investors to open new theatre houses.

The new Republic's culture and arts policies aimed to fill the category of legitimate arts with forms and genres that did not have roots in the region's history (Belge, 1996). Nevertheless, these aspirations of a large cluster of highbrow culture in Turkey are not reflected in our data on Milliyet: the proportions of articles published between 1960-2010 on opera, theatre, classical music and literature are 0.7 per cent, 3.2 per cent, 2.2 per cent and 3.4 per cent, respectively.

Following the introduction of a new and more liberal constitution in 1961 albeit the result of a military coup - political and cultural spheres became more dynamic. At the same time, Turkey was experiencing significant socio-economic transformations stemming from high rates of rural-to-urban migration, rapid industrialization and high rates of unionization. All these changes were reflected in the cultural sphere, especially affecting the literature, cinema and music of the time. Between 1960 and 1970, many new national awards and festivals, some of which survive today, were introduced. New genres were being experimented with by writers, directors and composers of the period. For instance, in the 1970s, 'Anatolian rock', a new musical genre mixing rock and Turkish folk sounds and touching primarily upon social matters, was born, an example of worldwide 'poprockization' in which originally Anglo-American rock music was adopted and domesticated locally as a hybrid form of pop-rock (Regev, 2013: 44).

Using the escalated violent confrontation between different political groups (mainly the nationalist front and the leftists) as an excuse, the military intervened in politics via another coup in 1980. This brought close supervision and direct censorship to the cultural sphere, as well as to the journalistic field. Social and political elements in the arts, as well as a more cultivated interest in culture and the arts, began to diminish. Moreover, in the early 1980s, Turkey swiftly moved from having a state-controlled economy to a liberal one, which facilitated privatization and global investment and trade. All these changes, as well as the intensification of globalization, integrated the field of culture and art to the newly created free market economy. The cultural sphere, which was once financed by the state with the hope of creating a national culture, was now left open to privatization.

The state of the Turkish socio-cultural sphere and cultural policy in the last two decades has mostly been discussed in relation to rising conservatism. Mobilizing voters from a right-wing ideological spectrum ranging from Islamism to nationalism, the Justice and Development Party has managed to stay in power and enact what they label a 'conservative democratic' political agenda since 2002. More details as to how politics interferes in cultural classifications and cultural journalism can be found in Chapter 6. For the purpose of this section, this political shift has been considered to be the periphery taking over the centre (secular, republican factions), further escalating tensions between secular and Islamist factions. Political aspirations for a neo-Ottoman presence in the region are reflected in the cultural sphere as well. To begin with, traditional art forms (e.g. marbling) began to attract more attention, while key political figures spurned some forms of 
modern art on the grounds that they were destructive to authentic Turkish culture. Some intellectuals argue that conservatives were unable to claim authority over the cultural field, which generated frustration towards art forms known to be enjoyed by seculars. To challenge the popular view on art being intrinsically progressive, radical and revolutionary, a number of conservative artists have debated the possibility of conservative art. In fact, the well-known professor of literature and bestselling novelist İskender Pala drafted and published a manifesto listing the principles of a potential conservative art.

While this antinomy and tension between two ideological camps has grown on many fronts, the boundaries dividing the traditional and the modern have become fuzzier in the realm of culture. New forms and genres ranging from 'green pop' (Islamic pop music) to Islamic anime add further dynamism to Turkish cultural field, requiring us to refine our understanding of cultural classifications and how they align with established cultural tensions of the time.

system (Appadurai, 1996); media system models (Hallin and Mancini, 2004); and cultural policy regimes (Mulcahy, 2003). For instance, European (and even global) centres of popular culture, such as the UK and France, have, in the cases of The Guardian and Le Monde, a traditional outlook on culture. In addition, Finland and Sweden, similar countries both politically and policy-wise, show clear differences through Dagens Nyheter and Helsingin Sanomat, irrespective of the fact that both newspapers are embedded in a similar cultural policy regime and democratic-corporatist media system.

The data nevertheless reflects some structural similarities. For instance, the peculiar political history of Francoist Spain could be traced through the cultural coverage of $\mathrm{ABC} / \mathrm{El}$ País, turning rapidly from a conservative perspective towards popular culture. Also, the difference between Dagens Nyheter and Helsingin Sanomat, with Helsingin Sanomat representing the most conservative newspaper in this sense and Dagens Nyheter being characterised by its early breakthrough of popular cultural coverage, is again illustrative. Though Helsingin Sanomat and Dagens Nyheter share similar media system models and cultural policy regimes, the difference may be due to Sweden's more central position in the global and European cultural system, as expected. Moreover, rather than being reduced to any of the three society-level dimensions considered, the difference could be better accounted for with field-specific and institutional factors. As for music, Sweden has deeper roots in the popular music industry (Seabrook, 2015), whereas, in Finland's field of music and general culture, the position of classical music was strong throughout the twentieth century (Korhonen, 2002; see Box 4.1). Furthermore, the difference might be due to generational changes in newspaper culture departments (Hurri, 1993; Jaakkola, 2015).

Thus, it is difficult to demarcate the roles of field-specific characteristics and society-level characteristics in the shaping of newspapers' cultural coverage. It may be tempting to overestimate the role of the latter, whereas the organizational or field-level factors may sound relevant only when the results 
are not in line with society-level expectations. ${ }^{17}$ Overall, however, we see that newspapers are a good source for studying shifts in cultural legitimacy and hierarchies, while different extra-cultural contexts (whether socio-cultural, historical, policy-related, organizational or the results of editorial decisions) also play a role in what newspapers legitimize and present as art and culture.

Many theoretical perspectives on cultural heterogenization discussed in the beginning of the chapter offer interpretations and conceptual tools for further investigations of this situation. For instance, from the point of view of globalization and aesthetic cosmopolitanism, what are the countries of origin of the poprock music that has appeared on cultural pages of newspapers, and how are different countries of origin related to legitimacy and hierarchies (cf. Janssen et al., 2008; Regev, 2013)? These questions will be analysed in Chapter 4 on cultural globalization. Furthermore, the key question, in line with debates on emerging forms of cultural capital and the legitimation processes of popular culture, would seek to understand, under the circumstances of increased heterogeneity and, in music, the dominance of pop-rock, what the major hierarchies are and how they are articulated. Is it a matter of extending the high-art criteria of evaluation to the sphere of popular culture, or are there other bases for making distinctions (cf. van Venrooij and Schmutz, 2010; Prieur and Savage, 2013)? These questions are examined in Chapter 3. It is also clear that the quantitative content analysis in this chapter is far from exhaustive; rather, it maps the overall trends that merit closer attention and a qualitative approach.

\section{Notes}

1 See, for example, Goffman, 1951; Gans, 1974; DiMaggio and Useem, 1978; DiMaggio, 1982a, 2012; Ganzeboom, 1982; Bourdieu, 1984; De Graaf, De Graaf and Kraaykamp, 2000; Katz-Gerro, 2002; and DiMaggio and Mukhtar, 2004.

2 Besides the homology between social positions and cultural practices (or, social and cultural hierarchies), Bourdieu (1984) posited also a homology in the sense of consistency of tastes and lifestyles across different fields. Habitus is the 'unifying principle', or mechanism, behind both parts of Bourdieu's 'homology thesis'.

3 See, for example, Bourdieu, 1993; Hesmondhalgh, 2007; Scardaville, 2009; Throsby, 2010; Verboord, 2011; and Schmutz, 2016.

4 Long-term data on the public funding of arts that would be comparable across different national contexts is notoriously scarce, and the same goes for crossnationally comparable data on trends in arts participation over time (Madden, 2005; Schuster, 2007; Gronow and Southerton, 2010). There have been some attempts to collect and maintain comparable databases regarding both, of which the most salient to this study is the Council of Europe's (2016) web portal 'Compendium: Cultural Policies and Trends in Europe' (see also ACE, 1998; Heilbrun and Gray, 2001; Klamer et al., 2006). For information on how our research countries differ across dimensions of cultural participation and cultural policy, see Appendix Tables B.5 and B.6.

5 Again, it should be stressed that we do not consider the newspapers nationally representative cases capable of directly expressing national differences. Besides the societylevel differences that expectedly have influenced the newspapers' cultural coverage, 
there are organizational-level (newspaper-specific) factors that also play a role. Therefore, our comparative analysis is not to be taken as cross-national but crosscultural.

6 Previous research, particularly by Janssen et al. $(2008,2011)$, shows that depictions of cultural products in different national contexts are largely consistent with countryspecific structural dynamics. For instance, the relatively less open cultural classification system identified in the analysis of German newspapers is in accordance with the German educational system (conducive to cultural hierarchy), Germany's journalistic field (state-dominated media system) and Germany's cultural policy system (decentralized) (Janssen et al., 2011). Moreover, there seems to be a relationship between the form of journalistic attention devoted to particular art forms and genres and the locations of those genres within the wider national cultural hierarchy. For instance, the increase in popular music reviews, especially rock music, since the 1960s in the US press granted those genres legitimacy earlier than in other national contexts (Schmutz et al., 2010).

7 Only the case of Turkey is somewhat difficult to locate, which is illustrated also by the fact that the country is not included (or even mentioned) by Hallin and Mancini $(2004,2012)$. However, Hallin and Mancini present the polarized pluralist model as the most applicable outside the countries of their focus (2012: 278). Of course, the decision to include Turkey under the label of polarized pluralist media is natural because of geographical proximity (as the label of the model is, after all, the Mediterranean polarized pluralist model).

8 Our variable 'size of the article' measures article size in relation to a newspaper page. It included the following categories, which were recoded into a numerical weightvariable: multiple pages (recoded as 1.5), full page (1.0), half page (0.5), quarter of page (0.25), smaller (0.125) and very small article (0.0625). See Chapter 7.

9 While it might in the first place appear surprising that bullfighting is covered in the culture sections, it should be kept in mind that it has long roots in Spain. Fighting bulls dates back to the Bronze Age as a prehistoric form of bull worshipping, which has developed in Spain since the twelfth century into a highly canonized art. The eighteenth century is when its main rules were organized and Plazas de Toros (large bullfighting arenas) were built in main cities. As an 'art', contemporary corridas are highly canonized: they consist of three distinct stages, each with specific stages and highly differentiated paraphernalia. In the 2000s, with more general attention towards animal rights and bullfighting bans, most notoriously in Catalonia in 2010 (overturned since), bullfighting has remained a hot topic in Spain, also from the point of view of the highbrow/lowbrow divide. While a certain cultural goodwillladen middle-class discourse shuns the violent and atavistic side of bullfighting, it remains a recognized manifestation of Spanish culture, and a spectacle enjoyed by both popular masses and the rich political elite, with fervent support from both the centre-right prime minister party and from the monarchy.

10 It is a well-known fact that television has had a very significant place in people's cultural practices in Turkey from the very beginning of the state broadcast in 1968. Low literacy levels and a lack of effectively distributed printed press in rural regions increased the impact of television broadcasting across the country (Çapl 1 and Dündar, 1995). Its centrality to the lifestyles of both the urban and rural population increased in the 1990s, when private television channels began to initiate broadcasts individually. Although it is considered to be a middle- to low-brow activity in European contexts, studies in Turkey demonstrate that selective television viewing is an important element even in the repertoires of the culturally privileged (Arun, 2015). However, the sudden increase in television news in Milliyet can also be linked to the foundation of a television channel (Kanal D) by the owners of Milliyet in 1993, which 
then became one of the most popular channels in Turkey. This is an exemplary case of how both society-level and organization-level factors have shaped Milliyet's cultural coverage and an example of the instrumentalization of journalism, in this case through commercial interests (cf. Hallin and Mancini, 2004).

11 The primary cultural areas of this variable include the following three: science, society, philosophy; media/journalism; and cultural policy.

12 Thus, only the category whodunit/thriller is left out of this binary variable.

13 As we report elsewhere (Purhonen et al., 2017), there is a significant interaction between year and individual newspapers, signalling that the shape of the rising trend of pop-rock content is not similar across newspapers. This is due to Milliyet's deviance from other newspapers. In fact, if the analysis is re-run excluding Milliyet from the data, the interaction between year and newspaper is statistically insignificant, which means that the trends are relatively similar among other newspapers.

14 With the absence of Western legitimate arts and its hierarchies, the Turkish region maintained, as in any other society, its own system of legitimacies (cf. Daloz, 2010). During the mid-nineteenth century, Tanzimat (a period of state reorganization) facilitated the Western-inspired reforms that started over a century ago and began to change the Ottoman Empire's visual culture. Until then, Ottoman (legitimate) art, considered to be a sub-category of Islamic art, was dominant (Shaw, 2011: 3). The visual arts had a dominant place in this tradition: it involved calligraphy, manuscript painting, miniature and tezhip art (Ottoman illumination). In addition, Diwan Poetry, a very ritualistic and symbolic art form common in the Muslim Cultures of the Middle East and North Africa, was established as a legitimate form in the imperial courts. Many high political figures, including Sultans, were producers of this lyric poetry. After Tanzimat, the Diwan tradition dwindled giving way to Turkish folk and European literature. The Latin alphabet reform enacted by the new Republic further disconnected the newer generations from Ottoman literary tradition. Ottoman classic music, produced in the Sufi lodges and palaces, had high symbolic value as well. It evolved into 'Turkish classical/art music' after going through a modernization period in the twentieth century during which the elements of Islam and mysticism were eliminated. Classical Western art forms began to have more influence and to change the cultural field of the modernizing empire, and were systematically sponsored by the reformers of the new Republic. However, the art history of the region is far too fragmented and turbulent for a single tradition to emerge as the only source of legitimate art forms.

15 Architecture, opera, theatre and the visual arts are directly derived from the categories of the variable primary cultural area, while in the case of dance, music and literature, subgenre variables were used to exclude popular genres from these cultural areas. In the case of dance, only ballet and modern dance were included, whereas folk dance and other dance types were left out. From nine genres of music, only classical music was included. Additionally, for literature, only novels, poetry and plays and other non-fiction were included, leaving out whodunit/thrillers and all non-fiction genres (see Janssen et al., 2011).

16 The finding regarding the rise of emergent cultural forms can also relate to the peculiar position of Milliyet in the Turkish media field (Adakl1, 2009). Milliyet was known to lean into the social democratic tradition, until it was bought by a major industrial conglomerate in Turkey in the 1980s, which led to a change in the paper's publishing style. Moreover, the business group that bought Milliyet established a television channel in 1993, which has become one of the most popular private channels in Turkey. It is likely that an important portion of the newspaper's dramatic increase in television articles stems from the economic field's monopoly over media and cultural journalism (see note 10 in this chapter). 
17 This question has been identified and addressed by previous research (see Schmutz et al., 2010; Janssen et al., 2011). For instance, Janssen et al. conclude that the differences they observe in cultural coverage in newspapers from the Netherlands, Germany, France and the United States 'may be primarily associated with field-level rather than society-level factors' (2011: 160). 


\section{Both legitimization and popularization}

\section{How evaluations of pop-rock and classical music have become increasingly similar}

\section{Introduction}

Our examination of the content of quality European newspapers' culture sections - reflective of the content of what is considered to be legitimate and valuable culture - in Chapter 2 paints a twofold picture of the transformation that has taken place: the rise of popular culture and the decline of classical highbrow culture. Both processes, most sharply manifested inside the field of music, have contributed to the increased heterogenization and opening of the content of legitimate culture. But what is the deeper meaning and sociological significance of these trends? Our argument, which will be empirically substantiated in the course of this chapter, is that the essence of the transformation can be captured by conceptualizing them as two simultaneous processes: the one of legitimization of popular culture (signalling the trend 'from entertainment to art'); and the other of popularization of traditional legitimate culture (signalling the trend 'from art to entertainment'). Accordingly, if the boundary between highbrow culture and popular culture has lowered and lost at least some of its strength, it is not only because popular culture has been increasingly recognized as art (legitimization), but also because highbrow arts have been increasingly treated as entertainment (popularization). Previous studies have usually concentrated on one side of the process only, with much more sociological research being done on legitimation processes of popular culture. ${ }^{1}$ Both sides are nevertheless important and corresponding parts in the post-1960s transformation of cultural hierarchies.

How can the processes of legitimization and popularization be analysed? The main expectation guiding the analysis stems from the nature of the processes themselves. If there has indeed been a two-way and simultaneous process of legitimization of popular culture and popularization of highbrow culture, we should be able to observe from our quality European newspaper data that articles on highbrow culture and articles on popular culture have become increasingly similar over the years. In other words, if highbrow culture really becomes popularized, and if popular culture is increasingly given the status of genuine art, they should start to resemble each other in terms of various indicators. We can analyse our data from this perspective both quantitatively and qualitatively. 
Most importantly, the expected convergence concerns the ways in which cultural objects are evaluated: how often the newspaper articles include aesthetic evaluations in the first place and, if they do, have the evaluative principles and criteria used become increasingly similar (cf. Blank, 2007; van Venrooij and Schmutz, 2010; Lamont, 2012)? In addition, articles on popular and highbrow culture could have started to resemble each other also in terms of more technical, format-related features - such as the length of articles or whether articles are illustrated - that do not directly concern evaluations but rather the journalistic means to represent culture and the arts (cf. Verboord and Janssen, 2015).

One of the main results of Chapter 2 was that, even if the main trends of declining highbrow arts and rising popular culture were clear (if the space given to different art forms were calculated together using categories of 'highbrow' and 'popular'), not all highbrow arts have similarly declined and not all popular art forms have similarly grown in coverage. Therefore, to increase the resolution of the analysis on whether highbrow and popular culture articles have become similar, we focus only on articles on music and, particularly, compare articles on pop-rock and classical music. While we compare these articles in terms of quantitative trends, the main analysis involves a qualitative close reading of all articles on pop-rock and classical music in two of our newspapers, the Finnish Helsingin Sanomat and the British The Guardian. The choice to focus on these two particular newspapers is a further means to increase the resolution of the analysis as well as the sensibility to contextual issues. Furthermore, Helsingin Sanomat and The Guardian represent a suitable coupling of papers to be compared, both in terms of the national contexts in which they are published (which are oppositely located along many of the dimensions important for this study, see Chapter 2) and in the way the articles on pop-rock and classical music are distributed in their culture sections (cf. Purhonen and Wright, 2013; Purhonen, Lauronen and Heikkilä, 2015). Moreover, the amount of explicit evaluative content included in their articles is very different, as will be shown in this chapter. As seen from Chapter 2, Helsingin Sanomat had the widest coverage of classical music of all the newspapers and was the latest opener in terms of breakthrough of pop-rock content in its pages. The difference from The Guardian regarding these features is clear, but The Guardian also has a sufficient amount of both pop-rock and classical music coverage to make the comparison balanced. Overall, the qualitative emphasis is warranted to be able to sensitively observe the ways and tones of evaluations and valuations. As emphasized by Baumann, 'because discourse is the means by which experts participate in art worlds, a special attention to discourse is essential for understanding cultural hierarchy' (2007: 178).

The chapter opens with a brief discussion on the concept of cultural legitimacy and what we mean by the processes of legitimization and popularization. In the next section, we inspect how common the aesthetic evaluative content in our quality newspaper culture sections is in the first place and how it varies through time and across newspapers and articles on different art forms. Then we turn to the quantitative comparisons between pop-rock and classical music 
articles, followed by the qualitative analysis of evaluations in pop-rock and classical music coverage in Helsingin Sanomat and The Guardian.

\section{The concepts of legitimization and popularization}

In the background of the concepts of legitimization and popularization, both referring to temporal processes, there are obvious, respective root concepts: popularity and legitimacy. Both of these are arguably very basic dimensions that all research on cultural stratification must take into account. ${ }^{2}$ Popularity refers to how common and widely shared the cultural objects are among which classifications and hierarchies might be constructed. The dimension of popularity is directly linked with classical debates on the level of differentiation and universality of cultural classifications within societies (DiMaggio, 1987) as well as the debates on the individualization and fragmentation of culture (Lahire, 2010) and the contrasting debates on the massification and homogenization of culture (Wilensky, 1964). Sociologists mainly agree that, at least in the Western world and over the latter part of the twentieth century, the change has been mainly towards higher differentiation and fragmentation and not universality, which has thus limited the area of common or mainstream culture shared by almost all members of a society.

The concept of legitimacy, in turn, refers to the varying degrees of symbolic value and prestige given to cultural objects and the hierarchies constructed accordingly (cf. Bourdieu, 1984; Lamont, 2012). The most general-level expectation regarding legitimacy (again, in the Western world and since the 1960s) is that the relative sharpness of legitimacy-related differences is likely in decline, which would be in line with the discussions on de-hierarchization and the rise of cultural omnivorousness (DiMaggio, 1987; Peterson and Kern, 1996). Moreover, the level of legitimacy often goes together with the level of popularity: the most popular cultural objects seldom, if ever, enjoy very high legitimacy because objects that are 'too' popular tend to lose their distinctiveness. Thus, changes in the level of popularity and legitimacy are often interdependent processes. This is shown already by the classical 'trickle-down' mechanism (Veblen, 1899; Simmel, 1904) of the melting down of the status of an object along with the process of increasing popularity and its counterpart, the 'trickle-up' mechanism, in which the cultural object originally typical of the bottom of the social ladder becomes valued by the higher strata (Trigg, 2001). ${ }^{3}$

Our way of defining legitimacy is congruent with a broader sociological approach of the subject, which 'explicitly distinguishes an object of legitimation at one level of analysis and a framework of beliefs, values, and norms that actors in the situation presume are broadly accepted at a more encompassing social level' (Johnson, Dowd and Ridgeway, 2006: 56). Furthermore, it is also congruent with, and has its roots in, Bourdieu's understanding of cultural legitimacy (Bourdieu, 1984, 1993). ${ }^{4}$ The polarity between legitimate and illegitimate culture is, for Bourdieu (1984, 1993), a similarly fundamental binary opposition for the constitution of the social world as the distinction between the sacred 
and the profane. However, there are also gradual differences in cultural legitimacy and what is legitimate and what is not is continuously debated, particularly in the field of cultural production, which is based on the competition for cultural legitimacy (Bourdieu, 1993, 1996). Moreover, it is possible to identify specific processes of legitimization, in which some cultural objects (or styles and genres, more widely) are made valuable and consecrated by different institutional operations. In fact, Bourdieu distinguishes among three competing principles of cultural legitimacy, based on from whom the recognition and value is received: 'the specific principle of legitimacy' (attributable to other cultural producers, 'meaning art for artists'); 'the principle of legitimacy corresponding to bourgeois taste' (attributable to dominant classes and 'bourgeois public'); and 'the popular' principle of legitimacy (attributable to the 'choice of ordinary customers') (1993: 50-51). Evaluations by cultural journalists can be thought to primarily represent the category of 'bourgeois' principles of legitimacy, but the three principles can also be seen as evaluative repertoires that can appear and coexist inside cultural journalists' writings. ${ }^{5}$ Often, cultural consecration is done only retrospectively, for instance, by writing best-of-all-time lists or giving prizes and awards (Allen and Lincoln, 2004; Schmutz, 2005).

Given our definitions of legitimacy and popularity, it is fairly straightforward to proceed into defining the processes of legitimization and popularization. ${ }^{6}$ Legitimization is a process in which the legitimacy of some cultural object, the perception of being valuable, increases. Popularization is a process in which the popularity of some cultural object increases, or, more precisely, the image or perception of being 'popular' increases, not necessarily the objective level of popularity, which is a different matter. Similarly, in the case of legitimization, the perception of being legitimate or valuable does not reveal the 'real' value of the object. ${ }^{7}$ Therefore, legitimization and popularization refer essentially to changes in the ways in which cultural objects have been received and evaluated (ideally, in the case of legitimization, from entertainment to art, and in the case of popularization, from art to entertainment). In principle, there might be changes in the cultural objects or art forms themselves that are partly responsible for the change of their status (for instance, whether pop music has developed 'in reality' into a more complex and challenging art form over the decades, which would be the intrinsic reason why its status could have been elevated, or whether classical music has actually become lighter and started to include more entertaining elements, which would have potentially caused its image to be more popularized than before). However, and as it is difficult to measure changes in cultural objects themselves, the key from the sociological perspective is whether the cultural objects and art forms have been evaluated and valued differently, using different repertoires and criteria than before (cf. Baumann, 2001, 2007; see also Box 2.1 on computer games and Box 3.1 on jazz). In practice, this highlights the salient role of evaluative discourse around cultural objects and thus the role of cultural intermediaries (critics, journalists and reviewers) who have produced that discourse. 


\section{Box 3.1 Jazz: between highbrow and popular music}

When discussing legitimate forms of music, the status of jazz is complex. It has evolved throughout the twentieth century and beyond into a range of different styles addressed to various audiences. Jazz emerged as the quintessential form of popular music: in its earliest New Orleans style it represented the epitome of street music, with its big brass marches, ragtime and blues influences, remaining popular with big bands. However, in the 1940s, jazz music started to offer more cerebral and challenging music. Jazz motifs were already present in classical music compositions by Stravinsky or Gershwin, but styles such as bebop, hard bop or free jazz offered new musical experiences, gaining a new status. Acclaimed by writers such as Jack Kerouac and Julio Cortázar, jazz quickly became part of the countercultural canon. Moreover, while jazz music is key in the development of music during the twentieth century, its lasting influence was rarely accompanied by huge sales, and it has often been considered to be minority music despite charted success. In this research, and taking into consideration the wide range of music that fits into this category, jazz has been understood as part of popular music because, in its beginnings, it was clearly linked to popular tastes; moreover, it is deeply rooted in the popular background shared by folk music, country and western or blues. However, jazz has partly succeeded in reaching a higher status.

When looking at the culture sections of the different newspapers, certain patterns are easily observed. In the first place, there are barely any articles covering jazz from the 1960s and 1970s. The few references are mostly announcements, particularly in Le Monde, which proves that, at least in France, jazz was widely played in clubs. In $A B C$, jazz concerts are announced along domestic music or cabarets. This is surprising because several jazz classics were published around that time (e.g. 'Kind of Blue', 'Time Out', 'Giant Steps', 'Bitches Brew'). There are some references to jazz in classical music articles, and the views vary depending on the newspaper. Sometimes jazz is referred to in a subtle highbrow context, as in the case of The Guardian; however, in Helsingin Sanomat, the boundaries drawn between classical and popular music are far more evident, and jazz is certainly included as an example of popular music. As an example, in a concert review of a Nordic festival of modern music (HS/13/10/70_14), a composition for a jazz group and a symphony orchestra is excluded from the review and discussed separately in a different article by a different reviewer because of the jazz influences, making the division between classical music and jazz very visible. This is an interesting contrast with the US context. In his classic sociological analysis of jazz, Lopes (2002) argues that jazz music was already clearly highbrow in the United States in the 1950s; in Europe, this did not seem to be the case yet, though different countries adapted jazz at different paces.

From the 1980s onwards, jazz was covered more regularly. One feature is its highbrow status, evident in the Spanish and French newspapers. In Le Monde, jazz appears clearly as a highbrow art; its popular roots are rarely mentioned, and its evaluation standards follow the pattern of the highbrow genres. The tone of Le Monde is twofold: it emphasizes the great classics and milestones (e.g. Miles Davis, Thelonious Monk) but also underlines the improvisation/novelty principle of jazz (e.g. 'a new trumpeter plays great classics'; LM/22/04/00_30). What is more, 
almost all the reviews have a positive connotation, emphasizing jazz as an innovative genre. Interesting and worthwhile jazz 'watches towards tomorrow' (LM/14/09/10_24) and shows an 'absence of clichés from noise music typical for other improvised music styles' (LM/24/07/10_19). This could be interpreted as a sign of growing tolerance and an opening of the highbrow canon itself.

The approach of El País is no different, though the intellectual side of jazz is rarely highlighted. While there are far fewer reviews of jazz than of pop-rock or classical music, the reviews are professional. In a concert by the Dannie Richmond Group, the reviewer uses specialized vocabulary such as hi hat, chaston or clusters in their original English forms and relies on name-dropping of musicians and styles (EP/02/12/80_33). When discussing an album by John Zorn, the reviewer provides interesting research on obscure Jewish-American explorations in jazz (EP/07/10/00_Babelia_22). From 2000 onwards, articles on jazz tended to be longer, giving more space to different excursus. In general, jazz is considered to be an important form of music: it is historical and highbrow. In this sense, the lamentations that jazz is being colonized by pop-rock artists and ignorant audiences are logical. This ironic review of the Jazz Festival of San Sebastián is a good example:

Another thing is whether the audience that goes to a jazz festival to hear Patti Smith understands where things are going, which I very much doubt. The evening flew by quickly, with Carter, Mallone \& Miller interpreting Black Orpheus [...] and meanwhile the audience were leaving little by little.

(EP/24/07/10_51)

El País jazz reviews are usually approving. For instance, while a review of a concert by Chucho Valdés considered it to be too pretentious, the reviewer still paid due respect to the musician, his trajectory and his musical skills (EP/24/08/00_29). With time, the private life of musicians have gained more emphasis. For instance, an El País article covering festivals focuses on anecdotes such as Archie Shepp demanding a pay rise just before turning up at a jazz festival, or Gato Barbieri being seen drunk (EP/24/07/10_49). These long articles also pay attention to the background of the festivals, describing the locations, the nightlife around the concerts and insights into the behaviour of artists and audiences. This feature is, indeed, also shared with articles on other cultural domains, featuring a turn towards 'the emotional' and 'the personal' that implies a significant milestone in the history of art coverage.

Sociologists have studied widely, albeit with varying conceptualizations, legitimacy and legitimization processes (see Johnson et al., 2006), but previous literature that would have analysed popularization in the sense described here is very limited. Of course, popularization as a concept is widely used, but its meaning is often unspecific and when used can overlap with other concepts such as the commercialization of culture, which refers to a social process of its own (see Chapter 5). Moreover, previous literature on legitimization is obviously aware of the possibility that legitimacy may also decrease and dissolve 
(e.g. different versions of the trickle-down mechanism; cf. Lynes, 1955), but our perspective in focusing on culture and the arts is particularly interested in the possibility of mutual movement between cultural objects labelled as art and objects labelled as entertainment. Here, the study by van Venrooij and Schmutz (2010) examining popular music evaluations published in early 2000s in German, Dutch and US newspapers, renders itself very useful as it compares two evaluative repertoires used by reviewers, the 'high art' and 'popular' aesthetic criteria. What is more, van Venrooij and Schmutz provide a comprehensive list of these evaluative criteria, which they have used (by calculating points if a music review used each criterion) in their own quantitative content analysis. While the analysis performed in this chapter does not follow the same strategy, ${ }^{8}$ the high art and popular aesthetic criteria by van Venrooij and Schmutz are summarized in Table 3.1.

Table 3.I 'High art' and 'popular' aesthetic criteria potentially used in evaluations of popular and classical music

High art aesthetic criteria

\section{Context}

Does the evaluation locate the music or musician in its social, cultural, political or biographical context or, especially, the context of the history of classical/popular music (or a more specific genre)?

\section{Creative source}

Is the performer or musician granted the status of an 'artist' or the 'creative force' behind the music (e.g. characterizations such as 'composer' or 'singer-songwriter')?

\section{Connection to high arts}

Does the evaluation explicitly link or compare the music or musician with (conventional and established) forms of highbrow culture?

\section{High art criteria \\ Does the evaluation refer to the following as sources of value: \\ 4a. originality or innovation; \\ 4b. complexity or ambiguity; \\ 4c. seriousness or intelligence; \\ 4d. timelessness?}

Popular aesthetic criteria

\section{Negative stance to high art criteria}

Does the evaluation oppose the high

art criteria mentioned in the left column?

\section{Participatory experience}

Does the evaluation focus on whether the music attracts its listeners to participate in the musical experience (e.g. descriptions of music as 'irresistible', 'hypnotic', 'joyful' or 'energetic')?

\section{User orientation}

Does the evaluation predict or suggest which kind of audience will like the music best (e.g. mentions the functional uses of the music or situations particularly suited for listening to it)?

\section{Oral}

Does the evaluation describe the music by using oral or food-related metaphors that emphasize mundane, 'primary' tastes (e.g. 'sugary melody')?

Source: adapted from van Venrooij and Schmutz, 20I0: 405-406. 
The list of high art and popular aesthetic criteria in Table 3.1 is based on a more or less consensual view of the main elements that are valued in the high arts and popular culture. As with any conceptual model, van Venrooij and Schmutz's classification surely simplifies the complex reality as, in practice, the high art and popular aesthetic criteria are not necessarily mutually exclusive or clearcut. ${ }^{9}$ However, the value of the classification lies in how it systematizes information from many sources and, in so doing, provides the possibility to formulate operational definitions for legitimization and popularization. To put it roughly, in the sense of this classification, the case in which high-art criteria are increasingly used in evaluations of pop-rock signals legitimization, while popular criteria increasingly being used in evaluations of classical music signals popularization. ${ }^{10}$

\section{An aesthetic dimension in the articles published in culture sections}

To start our analysis, we shall first look at how common it is that there are explicit aesthetic evaluations included in the articles in our quality European newspaper culture sections. To assess this, we use a variable measuring 'aesthetic dimension', which is defined as 'explicit judgements on the good or poor quality of the piece of art treated in the article'. Thus, aesthetic dimension usually manifests itself through clear artistic judgements shown by adjectives such as 'good', 'bad', 'sublime', 'innovative', 'poetic' or 'spectacular'. What this variable does not indicate is whether the judgements and evaluations are positive or negative; it just measures whether there are clear and manifest aesthetic-normative judgements. It is also worth noticing that the aesthetic dimension was coded for all article types, not only for reviews. However, all reviews did not necessarily include aesthetic dimension thus defined. Notwithstanding the limitations of such a simple measure, the variable provides the possibility to explore the proportion of aesthetically evaluative content of all journalistic content published in our newspaper culture sections. ${ }^{11}$

Table 3.2 presents the proportion of articles including an aesthetic dimension and how this varies across the years in all of our newspapers. Across the newspapers, an aesthetic dimension can be found in 40.6 per cent of all articles. Thus, the majority of the cultural coverage in our newspapers does not include explicit aesthetically normative evaluations. The trend over the years shows that articles including aesthetic dimension have become slightly more common, especially since 1990, than they were in 1960 or 1970 . However, the newspapers show major differences in the prevalence of aesthetic dimension. The newspaper that most often included an aesthetic dimension in its cultural coverage is The Guardian (with more than three out of four articles having the dimension). The differences among the other newspapers are not particularly remarkable (all of them have $30-45$ per cent articles with aesthetic dimension), except the Turkish Milliyet, whose articles include the aesthetic dimension strikingly rarely 
Table 3.2 Articles including aesthetic dimension by newspaper and year (percentages)

\begin{tabular}{|c|c|c|c|c|c|c|c|c|}
\hline & 1960 & 1970 & 1980 & 1990 & 2000 & 2010 & Total & $(N)$ \\
\hline BC/El País & 47.3 & 37.1 & 30.2 & 32.2 & 47.2 & 48.5 & 40.8 & $(1,129)$ \\
\hline Dagens Nyheter & 22. & 19.9 & & & & & 37 & $(956)$ \\
\hline The Guardian & 56.6 & 73.1 & 89.6 & 79 & 81.0 & 80.7 & 77.1 ( & $(I, 34 I)$ \\
\hline $\begin{array}{l}\text { Helsingin } \\
\text { Sanomat }\end{array}$ & 33.3 & 18.6 & 27.8 & 27.6 & 32.7 & 38.9 & 30.9 & $(875)$ \\
\hline Le Monde & 80 & 33.0 & 49.0 & 61.6 & 47.3 & 43.9 & 44.0 & $(840)$ \\
\hline Milliyet & 12.6 & 11.7 & 9.7 & 17.7 & 30.8 & 10.0 & 14.9 & (207) \\
\hline $\begin{array}{l}\text { Total } \\
(\mathrm{N})\end{array}$ & $\begin{array}{l}34.6 \\
(507)\end{array}$ & $\begin{array}{l}29.6 \\
(596)\end{array}$ & $\begin{array}{c}38.2 \\
(587)\end{array}$ & $\begin{array}{c}45.2 \\
(1,002)\end{array}$ & $\begin{array}{c}46.8 \\
(1,432)\end{array}$ & $\begin{array}{r}42.7 \\
(1,224)\end{array}$ & 40.6 & $(5,348)$ \\
\hline
\end{tabular}

Note

Total $N=13,161$, of which 59.4 per cent $(n=7,813)$ did not include aesthetic dimension.

(14.9 per cent). The only year when Milliyet published a roughly comparable level of articles including explicit aesthetic evaluations is 2000 (30.8 per cent). The rarity of evaluative content in the cultural coverage of Milliyet therefore further strengthens the image discussed earlier that Milliyet is distinct from our other quality European newspapers. Thus, and following the decision taken already in Chapter 2, Milliyet is excluded from the following analyses that rest on the division between highbrow versus popular categories. Apart from this, the newspaper in which the articles including aesthetic dimension have increased most clearly is the Swedish Dagens Nyheter. Moreover, it is noteworthy that if Milliyet would have not been included in the data presented in Table 3.2, the proportion of articles having an aesthetic dimension in the last year would be 52.3 per cent of all articles (compared to 42.7 per cent with Milliyet included). In other words, by excluding Milliyet, the proportion does not drop from 2000 to 2010 but rather increases steadily after 1970 .

Table 3.3 shows how the proportion of articles including aesthetic dimension varies across articles on different art forms over the years. Popular music and, especially, classical music articles show increasing trends in the prevalence of aesthetic dimension. In fact, the proportion of articles including aesthetic dimension doubles in the case of classical music articles from 1960 and 1970 to 2010. If the trends of classical music and popular music are compared, it can be seen that the proportion of articles including aesthetic dimension was almost identical between 1990 and 2000. The last year 2010 marks a difference in favour of classical music articles, whereas the total level of articles including aesthetic dimension is very similar in articles on both types of music.

The proportion of aesthetic dimension is more or less stable in the case of literature, whereas in the case of articles on theatre, the aesthetic dimension becomes more and more prevalent in the coverage. These results should be interpreted against the background of how the coverage of these art forms has 
Table 3.3 Articles including aesthetic dimension by art form and year (percentages)

\begin{tabular}{lcccccccr}
\hline & 1960 & 1970 & 1980 & 1990 & 2000 & 2010 & Total & $(\mathrm{N})$ \\
\hline Popular music & 37.0 & 25.0 & 50.8 & 58.9 & 67.2 & 61.3 & 57.7 & $(786)$ \\
Classical music & 38.9 & 38.4 & 56.7 & 58.5 & 66.1 & 78.0 & 54.8 & $(643)$ \\
Literature & 52.3 & 38.0 & 44.5 & 50.9 & 56.2 & 52.4 & 50.8 & $(1,125)$ \\
Film & 28.6 & 41.1 & 41.9 & 54.1 & 52.1 & 55.4 & 48.2 & $(659)$ \\
Theatre & 33.2 & 37.2 & 39.7 & 50.0 & 52.4 & 73.1 & 43.7 & $(545)$ \\
Television & 46.3 & 29.7 & 54.2 & 24.7 & 10.3 & 29.0 & 23.3 & $(190)$ \\
Visual arts & 39.4 & 32.9 & 52.2 & 51.0 & 57.8 & 54.4 & 48.3 & $(364)$ \\
Other & 30.0 & 16.9 & 21.0 & 30.9 & 37.6 & 37.2 & 29.4 & $(728)$ \\
Total & 37.2 & 31.2 & 40.9 & 46.6 & 49.1 & 53.2 & 44.2 & \\
(N) & $(492)$ & $(574)$ & $(561)$ & $(948)$ & $(1,323)$ & $(1,142)$ & & $(5,040)$ \\
\hline
\end{tabular}

Note

Total $N=11,4 \mid 2$, of which 55.8 per cent $(n=6,372)$ did not include aesthetic dimension.

evolved in size, which was analysed in Chapter 2. That literature's overall coverage was relatively stable over the years, and the proportion of articles including aesthetic dimension does not change substantially from 1960 to 2010, further highlighting the status of literature as a very consolidated and established, thus stationary, part of the content. The case of theatre is in striking contrast with the literature: the coverage of articles on theatre was dramatically declining, while the aesthetic dimension increases significantly at the same time. Thus, fewer articles on theatre over time are countered by more pronounced content, including explicit aesthetic evaluations. In the case of film, articles including an aesthetic dimension increased over the first decades, but plateaued after 1990. In the case of the visual arts, the proportion of articles including an aesthetic dimension grew during the first decades but remained rather stable after 1980. Articles on television show the most volatile trajectory and include the fewest aesthetic dimensions compared to other major art forms.

Overall, these results suggest that the majority of all journalistic content published in quality European newspapers' culture sections do not include manifest aesthetical evaluations. These evaluations, however, when viewed through the variable of aesthetic dimension, are differently presented in different newspapers and articles on various art forms. Moreover, when the Turkish Milliyet is not included in the analysis, the overall volume of aesthetic evaluations becomes more prevalent leading up to the 2000s. Because it is clear that the picture derived from these analyses using the variable of aesthetic dimension is very limited, we will next examine more precisely the transformation taking place by asking whether the articles on pop-rock and classical music have become more similar over the years. 


\section{Legitimization and popularization: quantitative approach}

To investigate whether highbrow and popular culture articles' trends converge over time, in this section, we will compare only classical music and pop-rock articles. Moreover, we have selected three indicators, which we use when inspecting the trends. We consider these to be particularly important, both from the point of view of journalistic ways of presenting and reporting about culture and, more substantially, from the perspective related to evaluative content. Article size and use of illustrations are both crucial formal characteristics of newspaper articles and how they report cultural matters. Whether an article includes an aesthetic dimension is, in turn, an important feature concerning the content and tone of the articles; it reveals whether the article is aesthetically evaluative or not. Besides the pop-rock/classical divide, the period over which the changes take place and the three indicators in which we are interested, the following analysis shows the trends regarding three main article types. Separately presenting the results on reviews, feature reports and interviews and, finally, news stories provides a means to standardize the results given the heterogeneous and multifaceted newspaper content. The analysis also strongly demonstrates the significance of the article type in general. Reviews, the group of articles inside which most evaluations are found, are very different from news articles that are by definition more neutral and journalistically oriented. Moreover, reports and features, combined here with interviews, are the article group featuring the longest articles and may be very different from both reviews and news. ${ }^{12}$

The first indicator scrutinized is the size of the article, of which we here measure long articles, defined as articles that are at least half a page long (Figure 3.1). If long articles were increasingly equally distributed among articles on poprock and classical music, that would be a signal of democratization between their statuses. Long articles are not only considered to be a more prestigious article type but also provide more space to thoroughly discuss topics.

Figure 3.1 shows very clearly how strongly article type and size are related with each other. News stories generally comprise small articles, reviews are generally somewhat larger and interviews and reports/features are often much longer (here, at least a half-page). The second thing demonstrated by Figure 3.1 is that the proportion of long articles is increasing in all main article types towards the present day, but most clearly in the case of interviews and reports/ features. Finally, Figure 3.1 shows that, as for the proportion of long articles, classical music articles and articles on pop-rock have become increasingly similar to each other over the years. Classical music reviews have been longer than pop-rock reviews across the time-span except for 2010, when pop-rock reviews were at least a half-page long equally as often. News articles show the same pattern in reverse: long news stories on classical music reached the level of similar news stories on pop-rock in the 2000s. Finally, long interviews and 


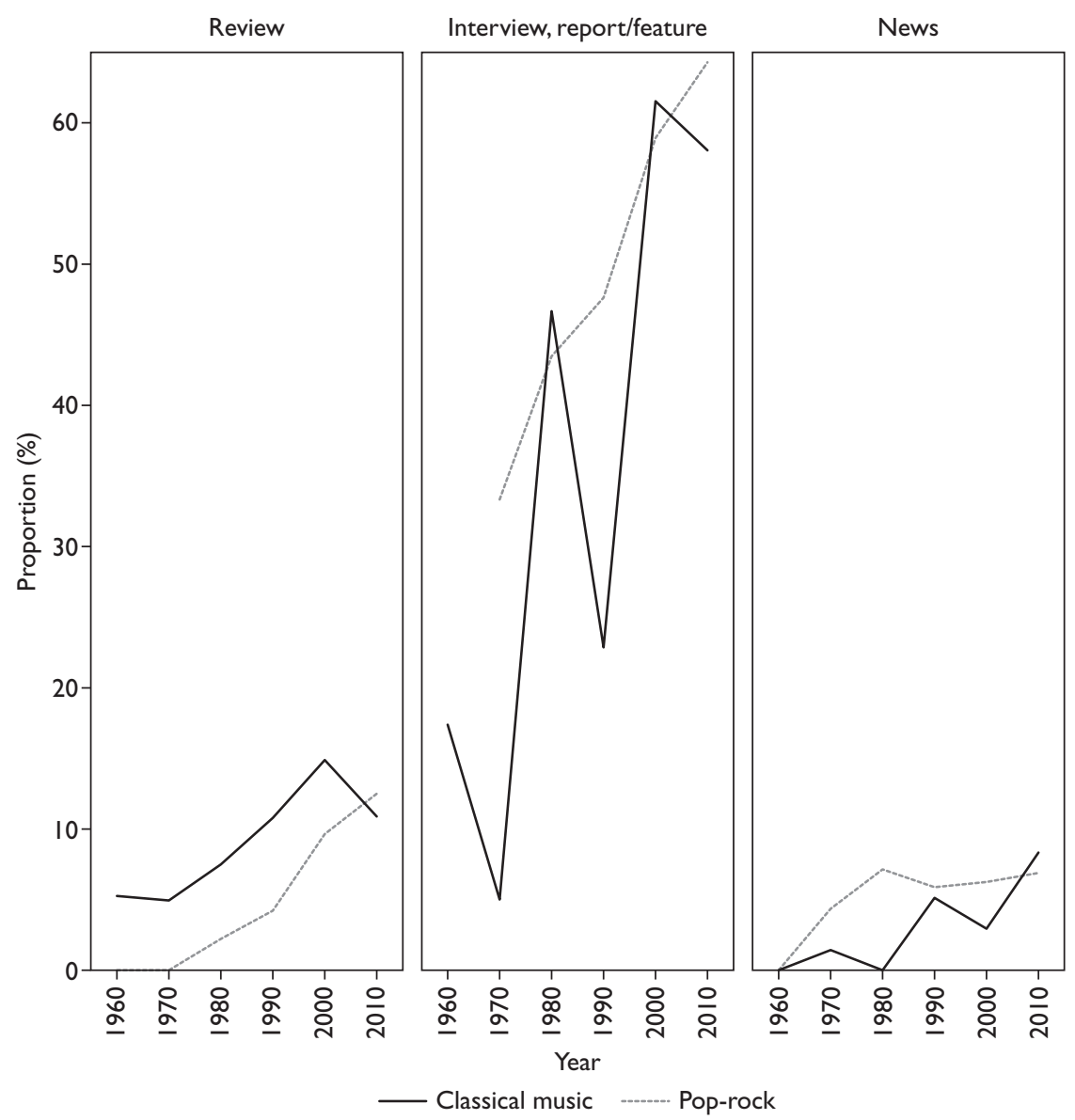

Figure 3.I At least half-page long classical music and pop-rock articles by year, separately on main article types (percentages).

reports/features increased dramatically both in the case of pop-rock and classical music articles (in classical music articles, the change is less systematic, but nevertheless there is an upward trend). The result is that, in the 2000s, there was no noticeable difference between pop-rock and classical music interviews and reports/features in this respect: about 60 per cent of articles for both were at least half a page long. ${ }^{13}$

Our second indicator is whether articles are illustrated (Figure 3.2). The option to have illustrations is a crucial journalistic decision related to how the topic of the article is presented. Moreover, visualization has been seen as a major means of popularization in media and communication studies as well as broader culture (e.g. Hartley, 1992). This is discussed further in Chapter 7. 


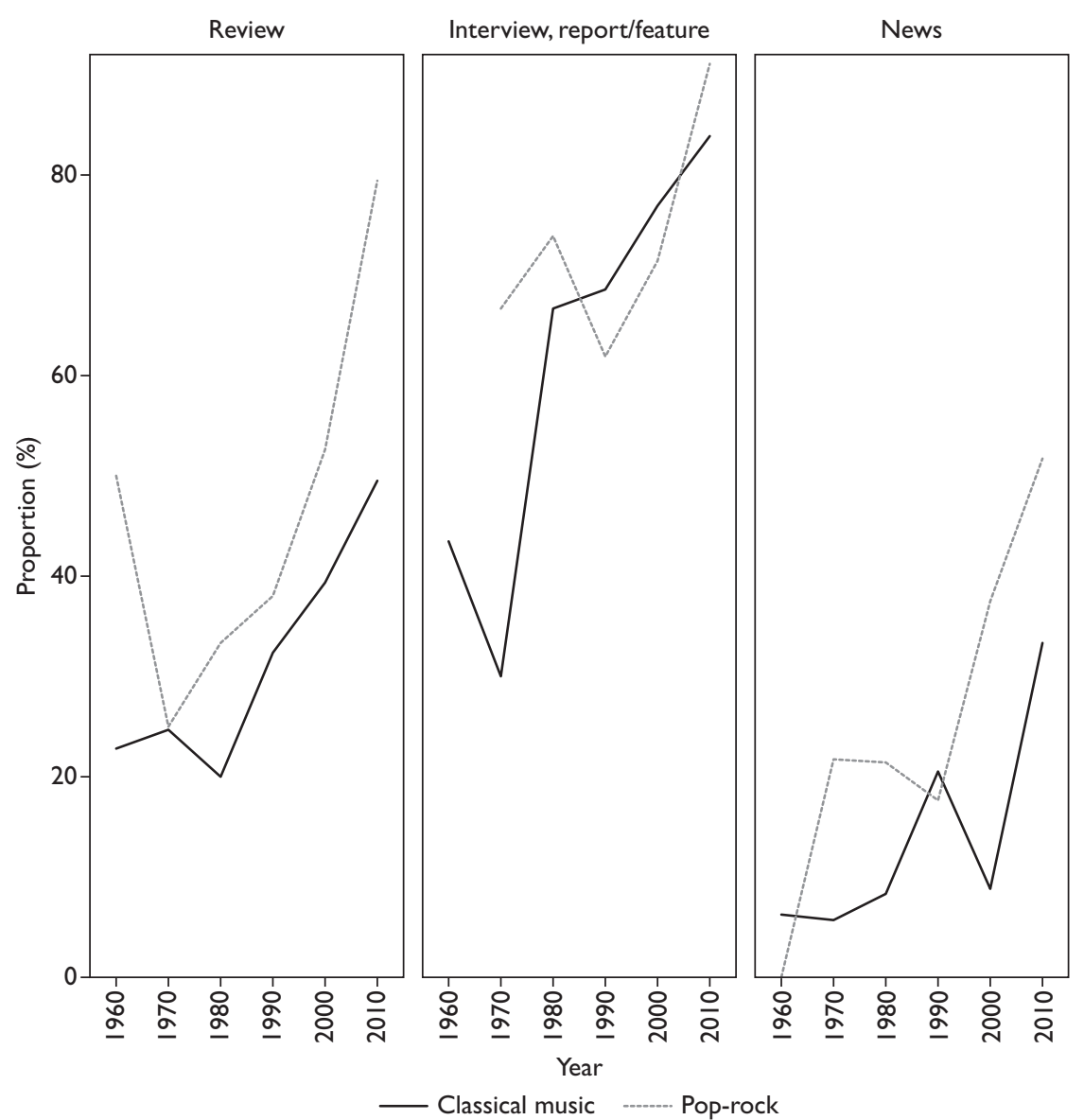

Figure 3.2 Illustrated classical music and pop-rock articles by year, separately on main article types (percentages).

Figure 3.2 not only reveals sharply rising trends in the case of all major article types, but also that the proportion of illustrated articles is highest in the case of interviews and reports/features and lowest in the case of news stories. However, our specific point of interest, whether articles on classical music and pop-rock converge through time in terms of illustrations, receives only partial support. Exclusively in the case of illustrated interviews and reports/features, classical music and pop-rock articles were no different in the 2000s (around 80 per cent of both of them were illustrated). In the case of reviews and news stories, pop-rock and classical articles remain different (in both cases, pop-rock articles were illustrated more often than articles on classical music). 
Our third indicator is whether the article includes an aesthetic dimension, the variable of our focus in the previous section. Even if our analysis already showed (see Table 3.3) that including an explicit aesthetic dimension does not strongly differentiate classical music articles from popular music articles, especially during 1980-2000, here we use a more specific measure of popular music pop-rock. Moreover, we inspect whether the trends of an aesthetic dimension converge between pop-rock and classical music articles by examining the main article types separately.

Figure 3.3 demonstrates, once again, the significance of article type, the single most important factor in determining whether the article includes manifest aesthetic evaluations or not. Aesthetic evaluations are most common in reviews and least common in news stories. Interviews and reports/features fall

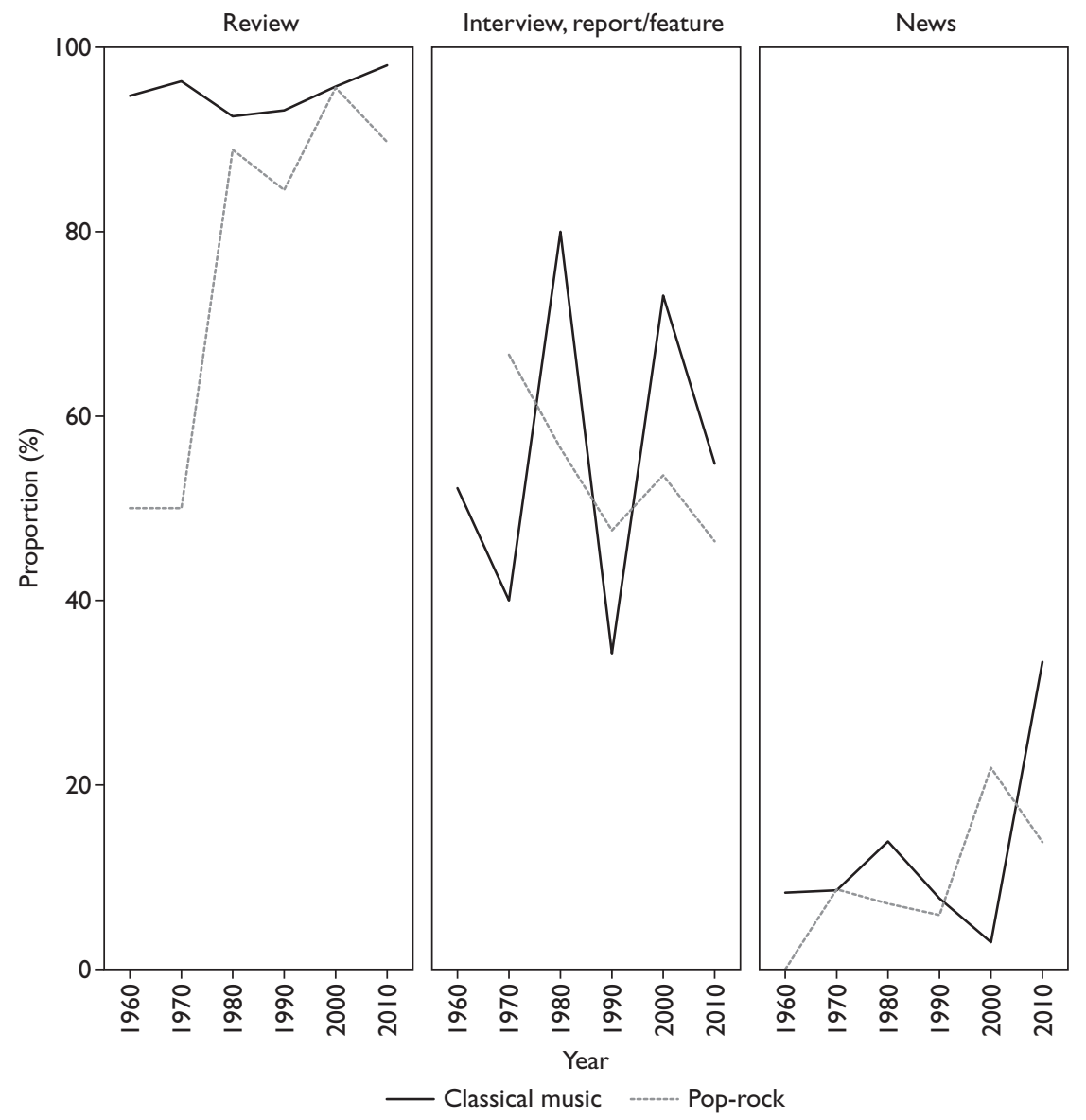

Figure 3.3 Classical music and pop-rock articles including aesthetic dimension by year, separately on main article types (percentages). 
between these opposite poles. Classical music reviews across the research period almost always include an aesthetic dimension. However, the first few pop-rock reviews before 1980 did not include an aesthetic dimension as often as one would expect reviews usually do. After 1980, pop-rock reviews have included an aesthetic dimension nearly as often as classical music reviews. As for interviews and reports/features, the trend of including an aesthetic dimension in pop-rock articles is declining, whereas in classical music the trend is unclear and volatile. In 1980 and 2000, there were more classical music interviews and reports/features including an aesthetic dimension than in the other four time periods. In the case of news, the trend is more consistent. An aesthetic dimension appears rarely but increasingly often, both in pop-rock and classical music news stories. Most importantly, the difference between the music genres is relatively small.

The analysis in this section suggests that journalistic formats (article length and illustrations used in interviews and reports/features) have become increasingly similar between articles on classical and pop-rock music. Apart from the convergence of journalistic formats, since 1980, there have been no major differences between classical music and pop-rock reviews in the prevalence of aesthetically normative evaluative content.

\section{Legitimization of pop-rock}

In this and the following section, we will present a qualitative analysis of the evaluations of pop-rock and classical music articles to identify whether our argument about the legitimization of popular culture and popularization of highbrow culture holds up. This is done by a close reading of all the relevant articles from Helsingin Sanomat and The Guardian. In the case of pop-rock articles, this subsample includes 185 articles from Helsingin Sanomat and 178 articles from The Guardian. As shown in Chapter 2, pop-rock is perhaps the prime example of an 'emerging' popular cultural form that has gradually expanded its coverage, starting from zero coverage in 1960 and becoming one of the most widely covered of all art forms in the 2000s.

The analysis proceeds by presenting a collection of concrete examples that are expressive of more general patterns in the subsample following a rough chronological order starting with pop-rock in Helsingin Sanomat. The next section focuses on The Guardian and highlights how it is different from Helsingin Sanomat. By concentrating on the examples, the qualitative approach not only complements and adds nuance to the quantitative trends, but also makes it possible to focus more closely on how evaluations and aesthetic judgements are articulated.

\section{Pop-rock in Helsingin Sanomat}

In Helsingin Sanomat in 1960, there were no articles in which the primary cultural area would be pop-rock. In 1970, there were four such articles. Two of 
them are about Ruisrock, the first big rock festival ever organized in Finland (HS/23/08/70_22a and 22b). These articles essentially introduce and showcase rock as a cultural form to readers. The expectation is clearly that readers do not necessarily know much about rock music and that they might be surprised to read about Ruisrock in the culture section of Helsingin Sanomat.

The main article, 'Rock Music Hits like a Tsunami in Turku', shows amazement at the size of the audience (25,000 per day) and the peacefulness of the gathering (only one assault occurred and a policeman was interviewed). The main space of the article, however, is given to a musicologist and a 'rock author', who were speaking in a seminar organized in relation to the festival. Referring to the United States and Woodstock (obviously one model behind the first Ruisrock), the experts state that 'rock culture is a channel by which youngsters can best express their thoughts about war, life and society'. They also remind readers that only a part, perhaps a minority, of all young people are interested in rock, but that it is nevertheless a significant and entirely new cultural form that should be taken seriously. Finally, they go on to say that, in recent years, 'The Rolling Stones have been listened to more than Beethoven over his whole career' (HS/23/08/70_22a).

All this contributes to legitimating pop-rock music as an art form. The main article, which did not include any direct aesthetic evaluations of the event, is complemented by a smaller sub-article ('Family and Ivanhoe, Trained Pop Musicians') discussing the music performed at Ruisrock. The review focuses solely on the technical aspects of the performances. The main idea is that only the most experienced musicians (i.e. the two bands referred to in the title of the article) managed to properly master their instruments and the sound system. The critic liked both bands also because they featured unusual instruments for a pop-rock band, such as harp, organ and flute. In fact, it is obvious that the critic was personally more interested in jazz than rock in the first place, as indicated by the starting phrase of the article: 'It is shocking to realize how massive support and popularity pop music has managed to win itself in such a short time. [...] But let's make it clear that this applies only to the mass-scale interests' (HS/23/08/70_22b).

In the Helsingin Sanomat of the 1980s, the position of pop-rock and how it is usually discussed and reviewed was already very different from 1970. Part of the articles on pop-rock, however, were published in connection to the "youth section' of the newspaper, which reflects the low status of rock in Helsingin Sanomat at the time. A concert review of the UK-based rockabilly band Matchbox, who were playing in Finland (HS/12/04/80_15), is illustrative. The critic mentions as a positive evaluation that the band is 'experienced' and then describes in detail the feelings evoked during the performance and how the audience reacted enthusiastically to the most popular songs. Matchbox's playing exhibited 'speed, expressiveness and freshness'. In these respects, all elements included in the category of 'popular' rather than 'high art' evaluative criteria, the critic contrasts the performance by Matchbox with domestic bands and how 
they lack such qualities: 'It is rare to see in these latitudes an equally excited and, at the same time, fun action' (HS/12/04/80_15). The contrast is accentuated by the fact that the same critic negatively reviews two Finnish bands on the same page below the main article.

The peculiar feature of Helsingin Sanomat is the very limited pop-rock coverage in $1990 .{ }^{14}$ Clearly, the fact that major changes in Helsingin Sanomat's music coverage - and cultural coverage more generally - happened only after 1990 was not only due to societal changes, general shifts in the zeitgeist or changes in the ideals of cultural journalism, but also caused by generational changes inside the culture department (cf. Hurri, 1993). One of the 1990 articles is very provocative (HS/07/01/90_A16) and reveals the lack of interest towards pop-rock in the newspaper. It is a review of a concert given by the large, well-known Finnish jazz orchestra UMO, featuring famous domestic pop singers as their vocalists. The review is clearly written by a jazz expert who adapts a paternalistic, derisive attitude to pop music and a remarkable scepticism towards the possibility to successfully combining jazz and pop (cf. Brennan, 2017): 'It never came to mind at any stage to seek anything new or special here - that was not the point. As such, the concert fulfils well the task of an obligatory entertainment' (HS/07/01/90_A16).

In the 2000s, pop-rock coverage exploded in Helsingin Sanomat to correspond with the level of the other reviewed newspapers. An interesting article (HS/07/10/00_B1) from 2000 concerns the Helsinki-based Tavastia Club, the most well-known, medium-sized venue for rock concerts in Finland, celebrating its thirtieth anniversary. The full-page article features impressive pictures of artists who have performed in Tavastia over the years. It reports the history of the club and interviews the manager. If contrasted against the 1970 account of the first Ruisrock festival, the article exemplifies a radical transformation. While the Ruisrock article was introducing rock to the Helsingin Sanomat's readers, the article on Tavastia shows how a fully established cultural institution, which is an obvious and everyday part of the Finnish music scene, celebrates and remembers itself. In so doing, the article writes the history of Finnish pop-rock music and thus contributes to its canonization and retrospective consecration.

In 2010, Helsingin Sanomat features one of the most striking examples of personification of aesthetic evaluations ('Art made Fragile and Caused Goosebumps'; HS/06/01/10_C1). Two full pages are devoted to a collection of small stories in which two dozen cultural journalists write about where their 'greatest art experiences' occurred in 2009 (the article was published in early January). Of all the stories, five are related to pop-rock music. The first story is about the joint concert by Laurie Anderson and Lou Reed in Helsinki (Anderson's history as a crossover artist between music and performance art is mentioned). Two other stories cover pop-rock festivals and the festivals themselves as personal experiences rather than focusing on any particular performance or artist. Cultural journalists tell their stories as 'ordinary' members of the audience - what touched them individually, not as professional journalists - although one cannot 
entirely avoid the impression that many of their stories on small curiosities are told in order to pursue distinction. The fundamentally subjectivist nature of art experience, and the fact that almost anything can be experienced as art, which seems to be the main message from the compilation, is underlined by the large illustration focusing on the faces of the rock festival audience members during a concert, leaving no details of who is performing on stage.

Overall, during the 2000s, Helsingin Sanomat's pop-rock coverage mostly used popular and high-art criteria side by side in reviews (e.g. HS/11/06/10_C3). A very critical review of an album by the Kings of Leon is an amusing example from the perspective of van Venrooij and Schmutz's (2010) formulation of popular evaluative criteria because it mentions many food-related metaphors: 'songs are sloppily arranged lasagne. [...] The musical salad and other side dishes, not to speak of good red wine, are missing entirely from the table' (HS/05/11/10_NYT_25). Furthermore, the review even gives direct advice to the readers: 'those who look for proper compositions and the dynamics inside the album need this album as much as teetotallers need pre-Christmas party season' (HS/05/11/10_NYT_25).

\section{Pop-rock in The Guardian}

How does the pop-rock coverage in The Guardian differ from that of Helsingin Sanomat? In terms of quantity, the trends of pop-rock coverage are roughly similar in these newspapers: in The Guardian, too, it is only from 1980 that the number of articles starts to rise. However, there is a clear difference regarding what article types are used for articles on pop-rock. In Helsingin Sanomat, only 24.9 per cent of articles on pop-rock are reviews, whereas in The Guardian the proportion of reviews is twice as big at 49.2 per cent. Furthermore, The Guardian has more interviews than Helsingin Sanomat, whereas Helsingin Sanomat has more news, announcements and lists than The Guardian. Focusing on the sheer number of all articles thus masks the fact that, because of these substantial differences in types of the articles, The Guardian has more room to write about and evaluate pop-rock music than Helsingin Sanomat. ${ }^{15}$ In practice, this means that in the case of The Guardian, besides the larger number of reviews, the many interviews, which were often quite long, turned out to be important for how pop-rock is evaluated. Long interviews are important for the legitimization of pop-rock: they deepen the view of musicians as artists by providing contextualizing information about their careers and connections with other musicians, genres and traditions. Thus, they are instrumental in creating the canon and the 'official' history for pop-rock.

Despite all this, close reading of all the articles suggests that the basic ways in which these evaluations of pop-rock are carried out are more or less similar in these newspapers. One difference lies in The Guardian's complex, often ironic and 'clever' way of writing and evaluating music, which typically includes a respectable number of cultural references, something that Helsingin Sanomat's 
did not incorporate until the 2000s (and then only rarely). To put it bluntly, the question is largely of differences in journalistic cultures and pop music criticism in particular, which has been a more serious and intelligent writing genre in the UK than in Finland. ${ }^{16}$

More voluminous pop-rock coverage began in 1980. A telling difference between The Guardian and Helsingin Sanomat is linked to where reviews are published in the newspapers. For instance, a review of Blondie's concert in Hammersmith (GU/14/01/80_9a) is the lead review on a page otherwise full of reviews of classical music concerts. This is in stark contrast with the 1980 Helsingin Sanomat, where pop-rock reviews were published in connection with the youth section of the newspaper. This intra-newspaper spatial division can be seen as signalling a stronger symbolic boundary separating art and entertainment in Helsingin Sanomat than in The Guardian. As a review, the text is not unique in how it evaluates Blondie and their performance. Characteristics from both high art and popular evaluative criteria are used $-\mathrm{a}$ feature that became typical in Helsingin Sanomat only in the 2000s.

In 1980, The Guardian featured two detailed interviews that both represent a historical look at rock, thus contributing to the retrospective consecration of rock. The same genre of writing the history of rock appeared in Helsingin Sanomat only in 2000 (cf. the article about the Tavastia Club). The first interview in The Guardian is about Mike Stoller ('In Person, the History of Rock'; GU/05/04/80_10), in which rock is presented as a self-evidently interesting and valuable form of art to be examined, focusing on aspects such as how 'classic' tracks were written and produced. The second interview is about John Lydon (better known as Johnny Rotten of the Sex Pistols; GU/26/09/80_9a). Even though its historical point of reference (late-1970s punk rock) is much closer than was the case in the article on Stoller, the function and tone of the article is similar: the question is of creating and consolidating the canon. Consequently, even punk is looked back on as a valuable period in the context of the larger story of the history of rock music.

In The Guardian, pop-rock reaches the full status of a legitimate and 'unquestionable' art form in 1980-1990, compared to 2000 for Helsingin Sanomat. The key demarcating line between 'good' and 'bad' pop-rock is essentially related to the tension between commercial and aesthetic values, a key feature in evaluations of pop-rock in Helsingin Sanomat and a theme to which we will return at the end of this chapter and in Chapter 5. Moreover, in many cases, it is considered to be a merit (a sign of open-mindedness and adventurousness) if poprock music takes influences from other music styles or from other forms of art, and this tendency increased even further in the 2000s. A good example of this is a review describing music by Johnny Cash as too predictable while praising Robert Plant for his adventurousness, as he had used in his music 'even some Arabic chanting, just to prove he really is a global music fan' (GU/15/03/90_24) (cf. Chapter 4). When the reviewed pop-rock artists are within the limits of having enough artistic ambition and not being too business-minded, the 
combination of both high art and popular aesthetic criteria is usually used in evaluations (e.g. GU/12/09/90_38; GU/02/11/90_36).

The pop-rock coverage of The Guardian in 2000 and 2010 more or less repeats the main lines that could be found already in 1990 (and sometimes even in 1980). One identifiable difference is that the topics of the articles become even more unconventional and experimental. It seems that in the 2000s, at least in the case of longer articles, it was no longer sufficient to write mere reports or profiles of bands or artists; there needed to be something more extraordinary, some specific point of view or some peculiar feature to make the article worthwhile. A typical strategy was to include some kind of genre or art form crossover. Telling examples include an 'anthropological' report about 'pub rock' as an 'overlooked art form' (GU/11/02/10_G2_22) and an article about how the rock band Waterboys was intending to play a whole concert to the lyrics of poet W.B. Yeats (GU/12/03/10_FilmMusic_9). This apparent search of something extraordinary for an article topic can be found also in Helsingin Sanomat in the 2000s (see e.g. HS/18/10/00_B10), but not as strikingly as in The Guardian.

\section{Box 3.2 Television: from medium to an art form of its own}

Television is among the youngest of the cultural domains that managed to secure a considerable space in cultural newspaper sections. The first regularly scheduled television services in Europe date back to the early twentieth century, but only after the 1950s did television sets become a widespread household item and a medium for a popular cultural practice (e.g. Abramson, 2002). Despite its rather brief history, there have been significant changes in the way television products were presented and evaluated by the reviewers within the period under study. We will take the television coverage of The Guardian as a case to capture the subtler dynamics playing out in this cultural domain. From the early years on, The Guardian regularly published columns in which television programmes were evaluated in the culture sections in columns such as Mary Crozier (née McManus)'s 'Television'. Television reporting has also been well established in the case of The Guardian because of the UK's strong broadcasting sector. Partly due to the strength and the scope of the national field, television products evaluated in The Guardian, especially in earlier decades, were mostly domestically produced.

In the early years, as television was yet to emerge as a cultural domain, there was not much variety in the programmes available to viewers. This narrow repertoire is reflected in journalistic coverage of television products. Early reviews tend to focus on, for instance, screenings of operas shown on television or television adaptations of literature. Resonating with the reviews on established art forms, these reviews articulately explored various aspects of the programme (e.g. acting, use of music, directing).

It is important to note that television, especially in its early years, was seen as a medium to represent different forms of art rather than as an emerging area producing its own products. For instance, while praising the BBC's decision to air a new opera, the reviewer suggests that: 'one must admire the BBC's determination to 
commission and to perform opera, not the easiest kind of performance for television, but certainly not to be left out if the television is to present a complete spectrum of the arts' (GU/20/05/60_11b). Since television is considered to be a medium, the evaluation of its products mirrors that of the general cultural field; television products are considered to be worthier of serious evaluation if they are based on traditional highbrow culture. Reviewers seem to refer to and acknowledge the hierarchies within the art forms and their audiences quite explicitly. While the previous quote demonstrated that the reviewer expects very little overlap between television audiences and opera audiences, another reviewer approves of the television channel for prioritizing aesthetic value during prime time: 'The times of showing, too, are a distinct improvement; it is not always assumed that a story adopted from a serious novel must be shown either very late or very early, to avoid peak hours' (GU/15/10/60_5).

Although reviews on television products appear in the culture sections, their artistic value is rarely discussed elaborately. From the very early years on, reviewers considered television as a medium to entertain people. Compared to the reviews of other established cultural forms, the evaluations of television products were mostly based on personal experience. There is very little reference to products' popular recognition (in the form of audience response) or professional recognition (in the form of awards or other official recognitions). Reviewers were reluctant to situate their analysis in the wider television field by referring to producers' or actors' previous works.

In general, television is treated as a medium that is expected to deliver entertainment to a mass audience. However, this does not mean that all products have the same value in the eyes of reviewers. On the contrary, there seems to be an established understanding of good quality television across the decades. One widespread judgement is the low value attributed to American cultural products (cf. Chapter 4). This devaluation of US products is crystallized in an article titled 'Block Buster: Nancy Banks-Smith gets a Headache Watching American Imports', where it is suggested that:

Out there in Hollywood is a feller called Fred with a foot pump whose job is to blow up TV films until they squeak. They then have many and variable uses. You can balance them on the noses of seals. [...] What you can't do is watch them.

(GU/24/07/80_11)

This sarcastic tone is not unique to the evaluations of programmes considered to be lowbrow by reviewers. For instance, a reviewer reveals their dissatisfaction by pointing out that: 'The weekend's viewing was hellish. Always is, I hear you cry' (GU/14/05/90_36), whereas another one suggests, 'It has to be admitted: one does get pathetically grateful for anything half way original and decently crafted in this TV autumn' (GU/26/09/80_9b).

The number of television channels and programmes has grown dramatically over time, as has the journalistic coverage and descriptive sections on costumes, plots or the crews. Compared to reviews published in the earlier years (such as on screenings of opera and theatre), more recent reviews tend to use criteria that are less similar to those used in evaluations of highbrow forms. For instance, a review 
on the BBC Young Musicians competition suggests that the judges always made positive evaluations, which made the programme less entertaining:

And some idiot forgot to give the judges buzzers to get the rubbish ones off. The audience doesn't help ... There is no standing up, spontaneous cheering, or shouting 'off, off, off'. And they wonder why not as many people watch as they used to. Duh!

(GU/24/04/10_50)

Our closer reading of the articles demonstrates how television moved from being primarily a medium for other cultural forms to an independent art form producing a wide range of its own entertainment products. In the meantime, however, audience response seems to occupy an even more central place in journalistic coverage of the field.

\section{Popularization of classical music}

Classical music coverage exemplifies a trend typical of traditional highbrow arts more generally: its relative coverage has dramatically dropped because of the expansion of popular music coverage, but in terms of absolute numbers, the coverage has remained more or less stable and wide. For the purposes of this section, we have closely read all the classical music articles from Helsingin Sanomat $(n=463)$ and The Guardian $(n=276)$. The section is organized in a similar fashion as the previous section on pop-rock, but this time we will start with The Guardian and later point out how classical music coverage in Helsingin Sanomat is different from The Guardian's. Because the rise of pop-rock and the (relative) decline of classical music represents two sides of the same coin, it is only logical to analyse both trends using the same newspapers.

\section{Classical music in The Guardian}

In terms of the number of classical music articles, The Guardian has never had as wide a coverage as Helsingin Sanomat. While the trends are largely similar, a sharp difference, similarly to the case of pop-rock coverage, is that a clear majority (64 per cent) of classical music articles in The Guardian have been reviews, whereas in Helsingin Sanomat, the same proportion is only 32.7 per cent. Overall, there are only very slight signs of increased diversification of article types of classical music over the years; only interviews emerged as a new and visible article type in the 2000s. Helsingin Sanomat has published reports and features on classical music throughout the years, but in The Guardian, it was another emerging (but still relatively rare) article type in the 2000s.

In 1960 and the following years, The Guardian's classical music coverage was dominated by professional expert reviews using high-art criteria and special terminology in their evaluations. A good example of a critical expert review, 
which is authoritative and keen to detail what went wrong in a live performance, is a review of a choir concert featuring religious music from Bruckner and Bach. The reviewer seemed to dislike almost everything in the concert: 'everything in the performance - choral singing, solo singing, orchestral playing, and general musical conception - was at best undistinguished and at worst almost comically inept' (GU/07/09/60_7). Another example of how expert reviews may adopt a headmaster style of 'correcting' the mistakes of orchestras and conductors is a review of a concert featuring Tchaikovsky's music. The reviewer notes that:

the last movement - two themes repetitively alternated and a presto coda is certainly a problem [...] [the conductor] could have been rather more imaginative - a little rubato perhaps in the more lyrical of the two themes, or at least more tempo variety.

(GU/23/11/70_8)

The Guardian's early classical coverage, especially between 1960 and 1980, is marked by a clear tendency to value and support new and experimental music. An example of this (as well as of abundant usage of expert vocabulary) is a concert review featuring a new composition by Spanish contemporary composer Roberto Gerhard. The composition includes accordion in the instrumentation, which is unusual, and 'The snatched, sforzando chords, the quick and slow crescendos and diminuendos, even the occasional dynamically level single note, that Gerhard has written for it here, all immediately catch the ear as new and fascinating sounds' (GU/20/05/60_11a). A review of the Cheltenham Festival exemplifies the tendency to appreciate new influences; the reviewer says that the 'Festival's most valuable function is still the encouragement of [contemporary] British composers', and the article even includes a positive reference to popular music ('the use of jazz rhythms') (GU/04/07/70_8).

The Guardian's classical coverage in 1980 was essentially the same as in 1970. Key themes included supporting and giving space to new music (e.g. GU/19/03/80_12) and occasional references to jazz and even pop music. Though rarer, there were still many expert reviews that could be brutal and authoritative. In terms of format, reviews were brief and often presented in clusters. The review of a premier concert of a new composition by the British composer Barry Guy is a telling example of an expert review referring to both other fields of highbrow art and popular culture. On the one hand, it is 'an ambitious attempt at a composition analogous to Samuel Beckett's radio play Cascando' (GU/14/01/80_9b). On the other hand, it includes 'an abundance of fast scuddering string sounds (familiar to anyone who has heard Guy's double bass playing in jazz or in other works of his own)' (GU/14/01/80_9b). Thus, jazz is referenced in a very subtle and highbrow-related context, and it needs no special attention (see Box 3.1).

A peculiarity to The Guardian in 1980 is that, while otherwise there are no long articles, there are three journalistic articles on the availability of classical 
music recordings in different formats. One of them is titled 'Hello to Good Buys': 'Confused by the abolition of fixed retail prices? You won't be, if you follow Edward Greenfield's sympathetic tour of recent additions at the lower end of the market' (GU/13/08/80_8). These articles represent shameless 'service journalism', trying to inform readers about good buys and focusing on different record companies and their well-priced classical music series: 'The price is still only $£ 1.99[\ldots]$ and though the catalogue has to be limited [...] the completely new issues often present amazing value' (GU/13/08/80_8). Thus, while the purpose of these articles is to serve customers, they also adopt the perspective of the music industry as opposed to music itself, even if the selected recordings are briefly described and evaluated in the articles. ${ }^{17}$

There are some evident changes in The Guardian's classical music coverage in 1990 compared to earlier years. Most notably, there seem to be more long articles than before, and there are occasionally pages in the newspaper devoted only to classical music. Professional expert reviews are still present, and the ways in which classical music is written about are more journalistic. There are some profile articles that, rather than concentrating on the music itself, are very individual-centred (good examples are articles on baritone Dmitri Hvorostovsky and conductor Simon Rattle published on the same page; GU/31/05/90_25a and $25 \mathrm{~b})$. This kind of personification can be seen as a popularizing way to write about classical music. The same is true regarding the article reporting on the 'best classical music records of the year' (GU/06/12/90_28), which, by adopting an article genre that is more frequent in popular cultural journalism, clearly popularizes classical music (cf. Bourdieu, 1998b). Illustrations and a table summarizing the critic's picks and labelling them into different categories accompany the text, which starts by emphasizing the personal nature of the selections: 'If music is about enjoyment, then there is little doubt which new issue of 1990 should be my record of the year, a very personal choice but one to share.' Even if the records chosen represent highly legitimate classical music, the format of the article is very popular.

The most conspicuous features of classical music coverage in the 2000s issues of The Guardian are the long, even multiple-page profile articles (published in the supplement G2) and their journalistic orientation. There are still some traditional expert reviews, mostly published in big clusters comprising many tiny reviews, but the format of the reviews has been standardized among all art forms and genres (e.g. GU/18/09/00_16; GU/17/10/00_23). The field or genre is mentioned in the heading of the review (e.g. 'classical', 'pop', 'theatre' or 'comedy') and below the heading are the stars that summarize the evaluation (cf. Blank, 2007: 160-162). The changes in the presentation of reviews (the shrinking format and a uniform layout, besides the system of stars rating) mark a change from traditional 'connoisseurial reviews' (Blank, 2007) to a modern-day 'list culture' rating (Wright, 2015). However, the classical music reviews mostly try to keep their old style: they still represent professional expert reviews in some respects. Perhaps the lack of space has caused the use of certain popular 
catchphrases, for example, 'Outstanding stuff - very highly recommended' (GU/28/01/00_FridayReview_19).

Long interviews exemplify the person-centred approach. One example is an article about the Russian pianist Mikhael Pletnev. The subheading reads, 'Mikhael Pletnev has a passion for fast cars and playing piano so loudly that audiences fear the instrument will fall apart. Yet in person he refuses to play superstar' (GU/16/05/00_G2_14). In contrast to the title, the article clearly builds the image of a superstar on Pletnev. The article discusses scantly the music itself; rather, it focuses on the mysterious and reckless personality of Pletnev and even touches on topical issues of Russian politics, such as Putin and the war in Chechnya. Everything is written in a plain, human-interest mode without musical terminology or other 'difficult' text features. Overall, the classical music coverage in 2010's issues of The Guardian is characterized most of all by the journalistic style, human-interest orientation and other 'extra art' elements (cf. Box 2.2). Expert reviews have not disappeared, but they do not use the special terminology of the previous decades.

\section{Classical music in Helsingin Sanomat}

Professional reviews, often written in a ceremonial style and sometimes with a very authoritative in tone, form the backbone for classical music coverage of Helsingin Sanomat. Almost all the characteristics of 'high-art' evaluative criteria as described by van Venrooij and Schmutz (2010) are easy to detect in many of the typical reviews: contextualization of the artist or music, expert vocabulary, focus on technical mastery and so on. Especially in early decades, judgements were harsh and criticism extremely detailed (cf. Heikkilä and Gronow, 2018). For instance, in a concert review of a young Finnish singer, it is stated that: 'one cannot believe avoiding glissandos, wrong vowels and erroneously pronounced consonants could be so difficult' (HS/01/03/60_21). Besides the expert reviews, particular nationalistic emphasis, such as obsessive interest in Jean Sibelius and the continuous following of how Finnish musicians are received abroad, is also a recurring feature in the classical music coverage of Helsingin Sanomat (see Box 4.1).

In the 1970s' Helsingin Sanomat, there was still a very tight distinction between classical and popular music. A good example is a commentary article about a composition contest organized by a concert hall in Helsinki (HS/06/05/70_18). The composer Erkki Salmenhaara had complained about the jury's decision to welcome 'light music" ${ }^{18}$ to the contest, although in a separate category from the main contest, which was only for classical music. More precisely, Salmenhaara argued that there is no reason to include 'light music' at all, because "light music" should not be supported by public funding this way' (HS/06/05/70_18). In the article, the secretary of the jury explains why this decision was taken. Thus, the article, by reporting the discussion, demonstrates the symbolic strength of the boundary between 'serious' classical music and 'light music'. 
An article titled 'Nordic Contemporary Music' (HS/13/10/70_14) is another example of the boundary between classical and popular music, this time for jazz (see also Box 3.1). It is a concert review of a Nordic festival of modern music held in Helsinki. While praising the Finnish performance and dismissing the Danish one for being 'bad avant-garde', the article ends with a small mention of the Swedish performance, a composition for a jazz group and a symphony orchestra: 'As the composition, regarding all its elements, belongs under the category of jazz, it is evaluated by my colleague in a separate review' (HS/13/10/70_14). This decision to exclude the performance from the review and discuss it in a different article by a different critic makes the boundary between classical music and popular music (jazz) concrete. In the different article located on the same page, the jazz critic starts his review with a long introduction about the history of classical music and jazz and the context of the idea of combining them, even if they are 'as such almost completely different musics'.

The core of the classical music coverage in Helsingin Sanomat in 1970, 1980 and even in 1990 is concert reviews that use professional musicological vocabulary and thus show high expertise. The concert review of the Swedish pianist Valma Rydström, for example, states that:

The rippling patterns of Chopin's berceuse in D flat major, the intensive melody of the $\mathrm{F}$ major nocturne, the flickering trills of the B major nocturne, the contrasting colours of the double melody of the bridge of the $\mathrm{B}$ flat minor scherzo - amongst many others, these enjoyable details stick in one's mind from the vast repertoire of Chopin.

(HS/18/02/70_14)

In the 2000s, Helsingin Sanomat was no longer publishing reviews using this kind of specialized and erudite terminology. Moreover, the vocabulary used in Helsingin Sanomat from 1960 to 1990 is arguably even more specialized than the expert terminology used in The Guardian.

In stark contrast to The Guardian, during the period from 1960 to 1990, in which classical music dominates the overall music coverage in Helsingin Sanomat, the attitude towards new or avant-garde modern music is ambivalent. For instance, in a highly critical article on the international contemporary music festival, the reviewer argues that most of the performances represented 'not avant-garde but academia', that 'new impulses are conspicuously absent', and that one particular performance was 'a blatant proof of the crisis of contemporary music' (HS/10/07/70_14).

Indeed, 1990 was the last year when Helsingin Sanomat's culture section was clearly dominated by old-fashioned and 'serious' highbrow content without much challenge from popular culture. In this respect, the change from 1990 to 2000 (and 2010) is substantial. Thus, the difference compared to The Guardian is that, while the most visible change in classical music coverage in both 
newspapers happened between 1990 and 2000, The Guardian in 1990 was already showing some new tendencies that could be seen in full scale in the 2000s. Another clear difference is that the symbolic boundary between classical and popular music remained insurmountable for longer in Helsingin Sanomat than in The Guardian. In The Guardian, positive cross-references between classical and popular music were already being made in 1970 and 1980, compared to 2000 in Helsingin Sanomat.

In 2000, Helsingin Sanomat's number of reviews decreased from the peak year 1990, and there are some signs of a growing heterogenization of classical music coverage in terms of article type and style of writing towards a less aesthetically authoritative and more journalistic and neutral approach. In terms of the layout and in relation to the coverage of other art forms, classical music articles may appear in the shadows of popular culture content, and the division between classical music and jazz and other forms of popular music has been relaxed. In a concert review of the Radio Symphony Orchestra performing the contemporary Finnish composer Jukka Tiensuu's 'jazz styled composition' 'Mood', references are made to the 'classics' of popular culture such as Buster Keaton. The distinction between high and low may be taken as a topic of play or irony in the articles (e.g. HS/06/01/10_C1; HS/24/07/10_C2). Interviews that focus on the personality and the career of one single star musician, often written from a journalistic and neutral, even human-interest, perspective, emerged in the 2000s (e.g. HS/30/04/00_B4). Moreover, a trend can be seen that long articles were published on classical music only if there was a unique aspect involved, such as a topic combining elements from many art forms or exhibiting some sort of crossover orientation. With these tendencies, Helsingin Sanomat follows in the footsteps of The Guardian.

\section{The tension between artistic quality and commercial success in aesthetic evaluations}

A crucial issue left out from the above analysis of the legitimization of pop-rock and the popularization of classical music in Helsingin Sanomat and The Guardian is the relationship between commercial success and popularity vis-à-vis the artistic or aesthetic value of music. Especially in pop-rock evaluations, the key demarcating line between legitimate and illegitimate seems to be essentially related to the tension between commercial and aesthetic values: the ambition, seriousness, originality and authenticity of pop-rock are often presented as being jeopardized by overly calculative and cynical commercialism. Popularity is not necessarily bad, but if the business attitude behind the music is too obvious, the music is to be shunned. This tension is equally strongly pronounced on the pages of both Helsingin Sanomat and The Guardian.

In a review of the Talking Heads album Remain in Light in 1980 in Helsingin Sanomat (HS/27/12/80_14), the critic forcefully points out that what makes this band so special is its ability to combine artistic quality and commercial success 
(the idea being that it is difficult and exceptional to do so). Talking Heads are described as being an original and 'open-minded experimenter', and the critic emphasizes the fact that it demands time and effort to be able to fully understand their music. By praising the band for successfully combining artistic ambitiousness and commercial success, the article thus explicitly discusses the relationship between aesthetic and commercial valuation. However, it is much easier to find articles in which an aesthetic evaluation based on the ambivalent relationship between commercial success and artistic value is negative rather than positive, such as in the review of Talking Heads. In fact, the limits between suitable and unsuitable commercialism seem to form the basis for most common evaluative principles used in deciding whether pop-rock music is good or bad. Only references to 'originality' or the lack of it are comparably usual evaluative principles in pop-rock reviews in both newspapers from 1980 onwards (e.g. GU/31/05/90_24; GU/17/11/10_38). In many cases, however, the lack of originality and the wrong type of commercialism are tightly intertwined in critical evaluations. A telling example is a crushing review of James Blunt's album in 2010 in The Guardian, which describes it as a 'shallow, soulless and strangely cynical [...] depressing listen' (GU/05/11/10_FilmMusic_9).

While commercial success is often presented as at least potentially compromising artistic ambition, and the aesthetic integrity of an artist is often harder to prove if the artist is very popular, pure and honest entertainment is sometimes appreciated even from very popular artists. An example of this is a positive review of Ricky Martin's 2000 concert in The Guardian, which states that the concert was good as 'mere entertainment' (GU/15/05/00_16). The reason why the concert was nevertheless good was its difference from boring or cynical corporate pop; the review suggests that to be popular is not a bad thing, if the artist is honest and not too commercial in the wrong sense: the concert 'has a Michael Jacksonian effect - you don't want to like him, but can't help it' (GU/15/05/00_16). As a result, 'what threatened to be a corporate-pop ego-fest turns into a fine time' (GU/15/05/00_16). Thus, commercialism can be tolerated if it is hidden, or compensated by the right kind of artistic ambition or authenticity.

Taken together, critical assessments of commercialism in evaluations of poprock have to do with the dominant idea that art, in order to be real art in the first place, should be autonomous from external constraints, be they economic or political (we will discuss these in Chapters 5 and 6). According to Regev (2013), the idea of autonomy from commercialism is even a characteristic feature of pop-rock's ideology. An obvious paradox is that pop-rock is 'hardly ever created under pure aesthetic circumstances', and thereby the key 'aesthetic ideological question' for critical discourse about pop-rock is 'how to define and find the contours of autonomy within commercial practices' (Regev, 2013: 72). The answer, according to Regev and what has been detailed here, is that autonomy can be achieved 'by musicians whose commercial success allows them to fight for and negotiate artistic freedom' (Regev, 2013: 74). ${ }^{19}$ 
However, as pop-rock has been legitimized and received the status of art, and as the ideology of autonomy is a defining feature of art, it follows logically that pop-rock, as a young art form, faces ambivalence regarding the relationship between artistic legitimacy and commercial success. What, then, is this situation in classical music? Put briefly, in classical music evaluations, aesthetic quality and commercial success are not usually treated as mutually exclusive, but as logical features of the same package. This can be showcased by an article in Helsingin Sanomat from 1990 (HS/12/09/90_B9; see also, e.g. HS/19/02/90_B9) about the German violinist Christian Tetzlaff, which is titled 'To the Top Without Success in Competitions' (the article also demonstrates Helsingin Sanomat's emphasis on competitions in its classical music coverage; see Box 4.1). The article includes not only aesthetic evaluations (that Tetzlaff is an outstanding violin player) but also commercial elements (that Tetzlaff is a very successful and popular star violinist). The background reasoning seems to be that Tetzlaff is successful because of his talent and artistic quality, and high quality as an artist is also proven by his popularity and success. Thus, success and quality 'guarantee' each other.

Therefore, unlike the case in pop-rock music evaluations, in which artistic quality and popularity were often treated as antithetical (being too popular might be risky if one wants to be taken seriously as an artist), the aesthetic quality and success goes more hand in hand in classical music. In classical music evaluations, aesthetic valuation is rarely if ever based on the ideology that opposes commercial success. However, even if the quality-versus-success relationship seems to be relaxed, there are limits to the tolerance for commercialism in classical music: a cynical or wrong kind of calculative commercialism can corrupt the quality of artists and art. The borderline cases in this respect include some of the most popular artists of classical music such as the Three Tenors (in 2000, Helsingin Sanomat wrote unsympathetically that you can 'smell how they are making money' during their performances; HS/02/03/00_B13) and, specifically, Luciano Pavarotti (labelled an 'operatic popster' by The Guardian; GU/26/06/90_37). In addition, a similarly suspiciously received classical music performance by the Vienna Philharmonic was reviewed in 1990 in The Guardian. The reviewer argued that the conductor had selected a too boring and comfortable programme and that the performance 'seemed to reflect the attitudes of a comfortable middle-age' and 'leisurely approach' (GU/02/11/90_37b).

Thus, the difference between pop-rock and classical music clearly shows the problematic relationship between artistic quality and commercial success in evaluations in the cultural pages of the studied newspapers. Unlike the case of pop-rock, it seems as if classical music, as one of the most established art forms, does not need to be particularly worried about the threat of commercialism to its artistic value. This question will be further analysed in Chapter 5 (see also Box 5.1). 


\section{Conclusion}

The large-scale macro-level trends that were the starting points for this chapter were very clear: the cultural coverage in our quality European newspapers show both the decline of classical highbrow coverage and the rise of popular culture coverage. We have argued that these trends can be conceptualized as two simultaneous processes marking discoursive shifts in the ways in which culture and the arts have been evaluated since the 1960s: the legitimization of popular culture and the popularization of highbrow arts. After first substantiating this argument theoretically, and after starting empirical analysis by showing the degree to which our newspaper culture sections include manifest aesthetically normative content in the first place, we have analysed the twofold process both quantitatively and qualitatively to identify whether the articles on highbrow (classical music) and popular culture (pop-rock) have become increasingly similar through time. Most importantly, informed by the sociology of reviewing and evaluation (Blank, 2007; Lamont, 2012), research on legitimization (Regev, 1994; Baumann, 2007) and, especially, van Venrooij and Schmutz's (2010) distinction between 'high art' and 'popular' evaluative criteria, we focused on whether and how the evaluations of pop-rock and classical music have changed.

While quantitatively we found evidence for highbrow and popular cultural articles starting to resemble each other (most importantly in terms of format of the articles), our qualitative close reading of articles on pop-rock and classical music revealed and specified the nature of the processes of both legitimization of popular culture and popularization of highbrow culture. Albeit not straightforward or linear, both processes are very clearly manifested in our quality European newspaper data from 1960 to 2010.

The analysis of pop-rock in Helsingin Sanomat and The Guardian revealed a clear process of legitimization in which pop-rock has built and consolidated its status as a serious art form over the research period. In earlier years (1970/1980), there was much focus on the reactions of the audience and the technical mastery of the musicians, whereas from 1990 onwards, there was a more serious and specialized writing style, mixing elements from both high art and popular evaluative criteria (van Venrooij and Schmutz, 2010). Diversification of article types in the 2000s matters: long reports and interviews about artists and musicians have been important for the legitimization of pop-rock. Finally, the basic ways in which these evaluations are carried out are largely similar in the two newspapers. However, the key difference between Helsingin Sanomat and The Guardian is timing. In The Guardian, pop-rock reached the status of a legitimate art earlier (1980-1990) than in Helsingin Sanomat (2000).

Our similar analysis of classical music from the same two newspapers shows that the expert reviews that dominated classical music coverage for decades did not disappear, showing only modest and slow changes (e.g. not as much difficult terminology used in the 2000s). A more substantial change is that, in the 2000s (and in The Guardian's case in 1990), classical music coverage became more 
heterogeneous and journalistically oriented in terms of format and style of writing, a trend accompanied by increased article length and use of illustrations. Another feature that emerged in the 2000s is the 'extra elements' of classical music articles (e.g. a person-centred focus and cross-references between art forms). Overall, the same journalistic means are increasingly used in both classical music and pop-rock articles (e.g. personification, the best-of-the-year lists and star ratings). All this supports our argument that traditional highbrow culture is being popularized and treated increasingly similarly to popular culture, especially in the later years in our data.

However, what the analysis of classical music articles has not shown is that the evaluative principles themselves would have changed to be more popular or entertainment-oriented. Rather, the changes are due to the format, perspective and the ways in which articles on classical music are written and packaged. Overall, the process of popularization of classical music is perhaps not as apparent as the process of legitimization of pop-rock, but when inspected closely, the ways in which classical music have been reported upon and represented have fundamentally changed over the years, even if the traditional format of expert reviews is still more or less alive. Another major conclusion concerns the oppositional relationship between commercial success and artistic value in pop-rock evaluations. Apart from extreme cases, the evaluations of classical music are clearly more tolerant of this relationship than are pop-rock reviews. Unlike in pop-rock, commercial success and artistic quality are seen in classical music evaluations as two sides of the same coin.

This chapter has shown that, on the pages of a key institution of cultural mediation, quality European newspapers' culture sections, the boundary between highbrow arts and popular culture has weakened substantially. This is shown, for instance, through the fact that references made to pop-rock have become possible in articles on classical music during the research period. This is not only because popular culture has been increasingly recognized as 'art' but also because highbrow arts have been increasingly treated as 'entertainment'. The chapters in Part II will explore further this post-1960s transformation of cultural hierarchies by focusing on additional dimensions: globalization (Chapter 4), commercialization (Chapter 5) and the changing role of the relationship between culture and politics (Chapter 6).

\section{Notes}

1 See, for example, Regev, 1994; Lopes, 2002; Lindberg, Guđmundsson, Michelsen and Weisethaunet, 2005; Baumann, 2007; Schmutz, 2009a, 2016; van Venrooij, 2009; van Venrooij and Schmutz, 2010; and Varriale, 2016.

2 See our definition of cultural stratification in note 13, Chapter 1.

3 In this sense, the 'trickle-up' mechanism can actually be seen as a special case of the more general process of legitimization.

4 Bourdieu's conception of cultural legitimacy was, in turn, heavily influenced by Max Weber's famous definition of the three types of legitimate authority, characterized by 
the fact that the dominated follow the rules and recognize and acknowledge authority 'automatically', usually without questioning it, and therefore there is no need to use force or direct oppression (see Weber, 1978: 215-216).

5 If the role and position of a cultural journalist is to be a peer to the artist, the evaluations and recognition given come close to 'specific legitimacy', whereas in the case of a cultural journalist who has adapted an orientation towards 'service journalism' and accommodates the needs of the readers of the newspaper, recognition represents 'popular legitimacy'.

6 Some scholars highlight the process nature of legitimacy and therefore do not distinguish clearly between legitimacy and legitimization (e.g. Johnson et al., 2006).

7 It is a topic of endless debate whether objects can have any intrinsic value in the first place. In this sense, popularity is different from legitimacy because the objective level of popularity is possible to determine empirically. This, however, does not contradict our emphasis that the strengthening of the image of being popular (in contrast to being 'refined', 'distinguished', 'distinctive', etc.) is the key to understanding what 'popularization' means. One should also remember that the discoursive shift along the lines of popularization (ideally, 'from art to entertainment') does not necessarily weaken, objectively speaking, the socially restricted nature of those cultural objects or the arenas in which they are consumed.

8 The analysis by van Venrooij and Schmutz (2010) uses data from only one time point and thus does not focus on the question of primary interest here, namely, whether and how the use of evaluative criteria changes over time. Moreover, this analysis is quantitative, whereas the analysis here, touching on the issue of using different evaluative criteria, is qualitative. Third, the empirical material studied is different, both in terms of countries involved in the studies and the type of newspaper material analysed (van Venrooij and Schmutz focused on pop reviews whereas here the analysis includes all articles on pop-rock and classical music irrespective of article type).

9 One can point out, for instance, that the emphasis on context as a high art aesthetic criterion is problematic given the fact that many traditional art discourses (following the model of 'pure' Kantian aesthetics) claim eternal value for works that are typically abstracted from their social and historical contexts in order to be ascribed this status (e.g. Gronow, 1997).

10 However, the interpretation cannot necessarily always be so straightforward, especially in the case of legitimization of pop-rock. This is highlighted by one of the results by van Venrooij and Schmutz (2010), according to which pop reviews using solely high-art criteria were most common in Germany, which employs the most hierarchical and universal cultural classification system of the countries included in their study. At first glance, this sounds contradictory, because it is reasonable to think that the use of high-art criteria signals legitimization (exemplifying the case in which pop music is evaluated as real art). However, the fact that reviews use popular criteria can be interpreted as a sign of legitimization in situations in which newspapers are willing to provide space to pop music and treat it as valuable without trying to make it something other than popular culture. In this case, the 'growth of a secondary discourse about popular music does not exclusively entail the legitimation of popular music by invoking the "existing parameters of art" but might also have led to the legitimation of popular aesthetic criteria' (van Venrooij and Schmutz, 2010: 399). From the longitudinal perspective, it may be expected that pop-rock evaluations on the pages of quality newspapers would primarily use high-art criteria during the period when pop-rock is introduced to readers and legitimized as a valuable art form. Second, it may be expected that it will be possible only later (after pop-rock has consolidated its status as art) for reviews to openly use popular evaluative criteria. In previous research, some have conceptualized pop-rock's legitimization as a relatively 
straightforward adaptation to the traditional ideology and ideals of art (Regev, 1994, 2013), whereas others have emphasized the fact that pop-rock is multifaceted in that both artistic and popular orientations coexist within it (Frith, 1996).

11 Similar to the cases of 'commercial dimension' (Chapter 5) and 'political dimension' (Chapter 6), the reasons for defining 'aesthetic dimension' as it was done was to facilitate reliability in the coding. It was necessary to try to minimize the subjective interpretative work of coders of the data by selecting objective indicators that determined whether articles included these dimensions or not. Despite these efforts, albeit not unexpectedly, the inter-coder reliability levels of our 'dimension' variables (aesthetic, commercial, political) were lower than in other variables used in this book. With agreement percentages of 77.3 per cent (aesthetic dimension), 80.0 per cent (commercial dimension) and 73.3 per cent (political dimension), the inter-coder reliability of these variables is between 'acceptable in most situations' (threshold 0.80) and 'appropriate' (threshold 0.70), thus being suitable at least 'in some exploratory studies for some indices' (Neuendorf, 2002: 145). According to Krippendorff's alpha, a much more strict measure of inter-coder reliability than the agreement percentage, the dimension variables remain below the satisfactory threshold level (0.67) suggested by Krippendorff (2004a). Nevertheless, an important reason to use these variables has also been to create respective subsamples of the data for close reading that contain articles that should include aesthetic, commercial or political dimensions. As for the quantitative analyses, all the results including these variables should be interpreted with necessary caution and considered tentative.

12 For the significance of different article types in cultural journalism, see, for example, Jaakkola, 2015; and Verboord and Janssen, 2015. See also Chapter 7.

13 As can be seen from Figure 3.1, there are no reviews or interviews and reports/features about pop-rock in 1960 that were at least half a page long. Overall, the number of articles on pop-rock in 1960 and 1970, irrespective of article type, is extremely limited. We have rerun and plotted the figures in this section (Figures 3.1-3.3) in many alternative ways, for instance by excluding the year 1960; by merging the year 1960 with the year 1970; and by limiting the number of time points into three by merging 1960 and 1970, 1980 and 1990, and 2000 and 2010, and the results remain essentially similar. We ultimately decided to keep the original six time points untouched. We considered it a strength of the visualization if the case is that, as in Figure 3.1, there were simply no articles on pop-rock published in 1960 because that reflects the speed with which pop-rock emerged and made its way to the culture sections of our newspapers. However, it should be remembered that the information on pop-rock in 1960 and 1970 is based on very few articles.

14 This is in contrast with some previous studies on the legitimization of popular music in Finland, arguing that popular music would have already been considered as legitimate art in the early 1980s (e.g. Mattlar, 2015).

15 This directly reflects the difference in number of articles with an aesthetic dimension between the newspapers (see 'An aesthetic dimension in the articles published in culture sections', pp. 68-70).

16 For early rock criticism in the UK, see, for example, Lindberg et al., 2015.

17 A similar type of service-oriented article series can be found in The Guardian in 2000 (see GU/07/07/00_FridayReview_21).

18 A direct translation of the word 'viihdemusiikki' would be 'entertainment music'. The word is commonly used in Finnish to make the distinction between art and entertainment inside different music genres, but it has a slightly different connotation to the term 'popular music'.

19 It can also be noticed that in 1980, the first year when pop-rock coverage was properly covered in our newspaper data, pop-rock was strongly associated with punk rock's 
ideology of anti-commercialism, the 'furious disgust with consumption, and the place of pop culture and Punk itself within it' (Savage, 2001: xv-xvi). Besides punk, the request to be anti-commercial has ever since been most visible in indie and alternative rock genres, whereas the case has been different, for instance, in US hip-hop and rap, in which money and success are valorized openly. Indeed, the demand for serious artistry and disinterest in money has been predominantly targeted at white, male pop-rock musicians - the same musicians that have tried hardest to be considered 'artists' (cf. the subgenre 'art pop'). 
Part II

Dimensions of the transformation 


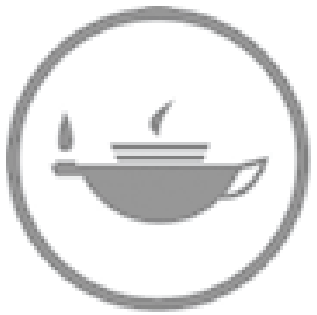

Taylor \& Francis Taylor \& Francis Group

http://taylorandfrancis.com 


\section{Globalization}

\section{On the tension between national and international culture}

\section{Introduction}

Culture changes and evolves not only in time but also across the relations between different spaces. Thus, the geographical fluidity or mobility of cultural products and influences across national borders - which can be investigated by focusing on the national origin of cultural products - is one of the key engines of the dynamics of cultural classifications and hierarchies in national contexts (Crane, 2002; Janssen et al., 2008). International connectedness, whether measured by trade, migration flows or cultural exchange, is by no means a new historical phenomenon, but there is a broad consensus that globalization has intensified and reached an unprecedented level in the latter part of the twentieth century and, therefore, especially during our research period from 1960 to 2010. Against this background, it is no wonder that globalization has been one of the most central and contested concepts in sociological debates in recent decades. Broadly defined as a 'rapidly developing and ever-densening network of interconnections and interdependences that characterize modern social life' (Tomlinson, 1999: 2), sociologists mostly agree that globalization is not solely an economic or political phenomenon, but rather a multidimensional process. ${ }^{1}$ The mechanisms of globalization are surely complex, but one of its cores can be located in the media, which has been not only a key channel for cultural flows and the ever-growing number of products of cultural industries (Hesmondhalgh, 2007) but has also facilitated new international and, according to some (Beck, 2000b), even cosmopolitan awareness and identities by creating a 'global village' (McLuhan, 1962).

In this chapter, we draw a picture of cultural globalization as it is visible in our quality European newspaper culture sections. The focus is in the origins of the cultural products discussed: whether they are domestic or foreign, and from where exactly the foreign products have originated. Here, we highlight two aspects: variation among the newspapers on the one hand and variation across the art forms on the other hand. The national context in which the newspapers are being published merits attention, as there are reasons to expect that the balance between national and foreign culture (and inside foreign culture, the 
exact source of it) manifests itself in divergent ways in newspapers published in different European locations. Moreover, as the question of national origin of cultural products is supposedly closely related to the themes of cultural legitimacy and hierarchies, we pay attention to the art form of cultural products discussed in the newspapers.

After the analysis of coverage of domestic and foreign culture in our newspapers, we have selected a few special cases for qualitative scrutiny. One of the most pervasive assumptions of cultural globalization in the twentieth century has been the supposed 'Americanization' of culture: in this chapter, we will find out how our European newspapers have written about US cultural products between 1960 and 2010. Furthermore, we examine the articles covering cultural products that did not originate in the Western world as well as cultural products described as multinational.

Our general expectation is that, over the half-century of our research period, the process of cultural globalization has increased and become more thorough (cf. Janssen et al., 2008). Moreover, the expectation is that culture from abroad would be increasingly received as positive and associated with high cultural legitimacy (cf. Wright, Heikkilä and Purhonen, 2013) because increased cultural heterogeneity (and its supposedly increased appreciation) should include a geographical dimension. Put differently, the ideals of cultural openness and tolerance are strongly related to cosmopolitanism and adventurous interestedness towards foreign cultures (Peterson, 2005; Ollivier, 2008; Wright et al., 2013). Overall, we will approach cultural globalization as intertwined with the trends of the rise of popular culture and the decline of classical highbrow arts (cf. Chapters 2 and 3).

It is worth emphasizing that our quality European newspapers can be considered to be a relatively critical and conservative arena for discussions of foreign, and perhaps especially American, culture. The primary audiences of our newspapers are domestic, and, as previously discussed, these newspapers have long been the natural source of discourse for classic European highbrow arts. Therefore, the significance and status of global culture would be very different if studied through more commercial forms of media, such as tabloid newspapers, radio or television. Moreover, it is important to note that newspaper attention and the legitimacy it gives to cultures from various parts of the world are guarded by journalists and intellectuals (Janssen and Verboord, 2015). Therefore, our quality newspapers' cultural content provides a quite specific measure to explore cultural globalization, the results of which will not necessarily be in line with information about the thoroughness of global culture derived from sales lists or other means of directly measuring consumption behaviour (cf. Achterberg, Heilbron, Houtman and Aupers, 2011). 


\section{Perspectives on the globalization of culture}

While much of the discussion on globalization has concerned politics, economy or environmental issues, cultural flows and influences are increasingly important topics. Cultural globalization, too, is a complex concept; it has various theoretical definitions and perhaps even more numerous empirical approaches. This is a result not only of the multidimensionality of globalization but also of the multifaceted nature of the concept of culture (e.g. Small, Harding and Lamont, 2010). Cultural globalization has been summarized as a 'tension between cultural homogenization and cultural heterogenization' (Appadurai, 1996: 20), or a dimension of globalization affecting peoples' identities and experiences in their everyday lives (Tomlinson, 1999).

There are at least three main ways to conceptualize cultural globalization. The differentialism paradigm assumes that separate cultures remain different despite globalizing influences; the convergence paradigm suggests that different cultures lose their specific characteristics and become blurred and, finally, uniform; and the mixing paradigm simply argues that different cultural elements become mixed and result in new global cultural forms (Pieterse, 2003). The differentialism paradigm emphasizes the enduring significance of national cultures, or, more broadly, of relatively stable similarities and differences between groups of nations, thus echoing the idea of the possibility of a 'clash of civilizations' (Huntington, 1993). The idea of convergence is close to that of the homogenization of culture, which, in turn, is related to various critical narratives and concepts such as 'Americanization', 'cultural capitalization', 'Westernization', 'McDonaldization', 'cultural imperialism', 'Disneyization' and 'Cocacolonization' (see e.g. Tomlinson, 1991, 1999; Ritzer and Stillman, 2003; Bryman, 2004). The third view on cultural globalization, that of hybridization or mixing, differs radically from the other two. Mixing refers to the dynamic relationships between global and local, local ways of adapting to global influences and forming new hybrids, as suggested by the idea of glocalization (Appadurai, 1996; Hahn, 2012; Pieterse, 2003). These ideas have been further conceptualized within world polity theory (Meyer, Boli, Thomas and Ramirez, 1997; Regev, 2013).

A popular and persistent perspective on globalization has been the critical or negative observation of the homogenization of culture, caused by Western commercial capitalism, which has spread and colonized almost the entire world. An essential part of these discourses is Americanization, the idea that mass culture from the United States propagates, colonizes, commercializes and destroys the cultural diversity and genuine ideals of cultures and arts. However, as with cultural imperialism, Americanization is neither a coherent social-scientific theory nor a research field or tradition (Crane, 2002; Tomlinson, 1991; though, see Shor, 2010); it is just a normative, pejorative frame within which to discuss the phenomenon (Kroes, 1996). According to Kroes, the concept 'normally serves in a discourse of rejection to point to the variety of processes through which 
America exerts its dismal influence on European cultures' (1996: x-xi). Although 'Americanization' has recently been used almost exclusively in this negative or critical sense, it is worth noting that it is entirely possible to address and empirically investigate the growing influence of US culture without adopting the normative attitude and without committing to the simplistic critical discourse of Americanization. That is, the global influence of US culture and how it has evolved is a genuinely interesting empirical question. The supposedly growing influence of US culture is also an important dimension of cultural globalization: even if the simplistic view of Americanization is to be rejected, it is hard to disagree that global flows and influences are not proportional between centres and peripheries.

As well as the diversity of conceptions of cultural globalization, with Americanization as one of its special forms, sociological debates have revolved around the concept of cosmopolitanism (see e.g. Hopper, 2007; Kendall, Woodward and Skrbis, 2009). Sociologically, it has been broadly defined as an international or multicultural way for people to behave and form identities (Hopper, 2007: 158). One of the strongest proponents of the concept, Ulrich Beck (2004), has distinguished between a normative cosmopolitanism referring mainly to values and ideals (of openness, tolerance, etc.) and a 'banal' cosmopolitanism referring to everyday interaction with cultural objects produced in (or originating from) foreign cultures and countries (e.g. 'ethnic' dishes and foreign films or songs). From the point of view of this conceptualization, investigating the newspaper space given to cultural products from various national origins sheds light on the mediatic landscapes of 'banal cosmopolitanism' within which people live in those contexts where the newspapers are published.

Against the diversity of theories and concepts, it is not unexpected that empirical strategies to study cultural globalization are various as well. Significant research, both quantitative and qualitative, has examined cultural consumption and tastes from the cosmopolitan point of view, focusing on, for instance, cosmopolitan cultural knowledge, tastes in world music or tastes based on preferences for foreign cuisines. ${ }^{2}$ The challenge facing these empirical studies is the process-oriented nature of cultural globalization, which means that questions such as whether the globalization of culture is increasing or not should be analysed from a longitudinal perspective.

While good-quality longitudinal datasets on consumption and tastes are scarce (Gronow and Southerton, 2010), other strategies have been employed to account for the temporal dimension in the study of cultural globalization. One such stream of research has been the study of music charts (e.g. Achterberg et al., 2011; Bekhuis, Meuleman and Lubbers, 2013; Bekhuis, Lubbers and Ultee, 2014; Verboord and Brandellero, 2018). For instance, Bekhuis et al. (2014) studied the top-100 pop lists in nine Western countries from the early 1970s to contemporary times, focusing on the geographic origin of the artist and the language used. The main finding was that, after steady growth and years of hegemony, the popularity of global (mostly American) pop music decreased slightly 
during the late 1980s and 1990s in many countries, while domestic popular music increased in popularity. On the other hand, in their study covering the period from 1960 to 2010, Verboord and Brandellero (2018) found that pop charts have clearly become increasingly globalized in Western countries (except in the United States), and that songs from centrally located countries in terms of music production are more likely to become popular abroad. Another way to capture the temporal process of cultural globalization is to focus on longitudinal media data. Here, the seminal study by Janssen et al. (2008) is exemplary. It focuses on the changes in the coverage given to domestic and foreign cultural items (artists, artworks, cultural products) discussed in newspapers from Germany, France, the Netherlands and the United States from 1955 to 2005. The results by Janssen et al. (2008) show that globalization in terms of the coverage of foreign cultural items had increased in the selected European newspapers but not in the United States, and that there were also remarkable differences among the different forms of art.

\section{Box 4.1 Finnish classical music nationalism}

Classical music coverage in the Finnish Helsingin Sanomat, the newspaper with the widest coverage of classical music in our data, exemplifies how articulations of the distinction and tension between national and international culture may be an essential element in cultural journalism and aesthetic evaluations. In the case of Helsingin Sanomat, and particularly concerning classical music - traditionally a 'strong' cultural field in Finland with the renowned Jean Sibelius (1865-1957) as the flagship composer of the country - this distinction seems to be the key without which it would be impossible to understand the tones and emphases of classical music coverage. In other words, the classical music coverage in Helsingin Sanomat is heavily coloured by national sentiments and the special significance of the Finnishness of music or musicians. This national aspect of Helsingin Sanomat's classical music coverage is either totally alien (e.g. The Guardian) or much less pronounced (e.g. ABC and El País) in other newspapers in our data.

The national focus of classical coverage is seen, first, from the many news articles that are published about local events from around Finland. Especially in the first decades of the research period, there were plenty of news stories on local topics, such as how a classical music school in Kuopio suffered from the need for new space and had applied for a loan from the City of Kuopio (HS/20/05/60_22). Accompanied are the many reviews of local concerts such as a concert for the fiftieth birthday of the conductor of the orchestra of the small city of Pori, a concert that 'turned out to be a distinguished art event' (HS/17/04/60_23). Second, and more importantly, the national focus is evident in articles that somehow relate Finland to an international context. These can be articles that report and quote foreign newspapers whenever Finnish composers or musicians have been covered abroad (the most important topic of this international media monitoring is Sibelius). In 1960, there was, for example, a report on how The Daily Telegraph in the UK had written about a new, contested Sibelius biography by an American 
professor (HS/03/05/60_19). There are also articles about different types of music competitions. Especially important are competitions combining the following key elements: an international competition, Finnish success and Sibelius. Finally, the articles relating Finland to an international context include articles discussing Finland with a nationalistic tone and making either explicit or implicit international comparisons.

A good example of explicit nationalist sentiments is a long report from 1960 titled 'Lively Finnish Culture by Means of Singing and Music' (HS/21/07/60_11). It is about a summer school organized by a Finnish a music education institute, in which the journalist herself had just participated. The writer describes enthusiastically not only the practices and environment of the Institute, but also Finland more generally as an exceptional country where artists and ordinary people can meet. The style is ceremonial, and the brightest star shining above everything else and making all this possible is, of course, Sibelius. The journalist describes at length the lectures given by the teaching staff, especially the chief conductor Jussi Jalas, who had known Sibelius personally and could thus 'generously sprinkle treasures to the audience from Sibelius' own goldmine':

It emerged to me [...] in a nearly visionary clarity how divinely gifted our people still are, in many ways. [...] Show me another country in this wide world that shares a similar close and inspiring proximity between its most remarkable artistic personalities and the rank and file.

(HS/21/07/60_11)

Even if the article might be an extreme case in its nationalistic pathos, the obsessive focus on Finnishness and nationalist sentiments are a continuous feature in Helsingin Sanomat's classical music coverage. Indeed, the quality of Finnish musicians and composers in an international comparison seems to be one of the major concerns of classical music critics. An article from 1970 reporting how the British media received a new Finnish-English production of Sibelius' Kullervo in London is a good example (the article summarizes reviews published in The Guardian, The Times, The Daily Telegraph and The Financial Times; HS/23/11/70_12). Another article from 1970 reports that a young Finnish pianist managed to perform well in an international Chopin competition in Warsaw and concludes: 'Our young musicians seem to more often and boldly than before participate in different international competitions. The trend is right and has to be encouraged' (HS/27/09/70_28).

Because international competitions provide a great means for objectively testing the international level of Finnish musicians, it is no wonder that competitions receive such thorough coverage, the most important being the Sibelius violin competition. In fact, the emphasis on competitions is so overwhelming that there is even one large profile article on German violinist Christian Tetzlaff titled 'To the Top Without Success in Competitions' (HS/12/09/90_B9). The main point of the article is that Tetzlaff is extraordinary, as he has made it to the 'top' without winning any major violin competitions. While 1990 is the last year in our data when the Helsingin Sanomat culture section was clearly dominated by serious highbrow content, the monitoring of Finnish musicians' success abroad continued strongly in the 2000s, as shown in articles on star conductor Esa-Pekka Salonen in 
Los Angeles (HS/11/09/10_C8) or on Simon Rattle performing Sibelius with the Berlin Philharmonic Orchestra (HS/23/05/10_C1).

Finally, a long article from 2010 summarizes the stability and change of classical music coverage in Helsingin Sanomat over the fifty-year period. The topic, the Sibelius violin competition, is most traditional, given the history of Helsingin Sanomat's classical music coverage. However, the article adopts a meta-level perspective to the competition and posits on the best Sibelius competition winner of all time. The journalist interviews the 'surprising winner', the Russian Pavel Kogan, who won the competition in 1970. Even if the topic is most traditional for classical music coverage in Helsingin Sanomat, the article arguably popularizes classical music. While classical music competitions have always been a way to attract media attention and widen audiences, this article is a sign of its times by bringing an entertainment element to a highbrow, nationalistically important art form.

\section{Cultural globalization: quantitative approach}

In this section, the key variable under scrutiny is the origin of the cultural product discussed in culture sections. It is used as an indicator of cultural globalization, whether the cultural products discussed in the culture sections of quality European newspapers originated from home or abroad. The variable consisted originally of fifteen categories: the nine categories presented in Table 4.1 and the six countries of the newspapers studied, now merged into the category 'other Europe'. In addition to this, the variable used below is also recoded into the four most significant categories, distinguishing domestic cultural products from those originating in 'other Europe', 'United States' and 'other world'. Because not all articles in our newspaper data had identifiable cultural products, the number of cases included in the analyses using the variable 'origin of the cultural product' is lower than the number of total articles $(n=8,088){ }^{3}$

Table 4.I Origins of cultural products discussed in the articles by year (percentages)

\begin{tabular}{lrrrrrrr}
\hline & 1960 & 1970 & 1980 & 1990 & 2000 & 2010 & Total \\
\hline Domestic & 48.2 & 47.8 & 52.0 & 42.6 & 46.3 & 47.5 & 47.1 \\
Other Europe & 31.8 & 31.4 & 26.6 & 29.1 & 23.5 & 21.5 & 26.2 \\
USA & 9.9 & 9.1 & 11.1 & 14.3 & 14.7 & 19.1 & 14.0 \\
Canada & 0.1 & 0.1 & 0.2 & 0.4 & 0.5 & 0.7 & 0.4 \\
Other America & 0.7 & 1.7 & 2.3 & 2.5 & 3.5 & 1.8 & 2.3 \\
Russia/Soviet Union & 3.3 & 3.6 & 3.0 & 3.3 & 1.6 & 2.3 & 2.7 \\
Asia, Australia, & 1.1 & 1.3 & 0.8 & 2.5 & 2.7 & 2.9 & 2.2 \\
$\quad$ Oceania & & & & & & & \\
Africa & 0.1 & 0.2 & 0.5 & 1.0 & 1.3 & 1.3 & 0.9 \\
Multinational & 4.9 & 4.8 & 3.4 & 4.2 & 5.9 & 2.9 & 4.4 \\
Total & 100.0 & 100.0 & 100.0 & 100.0 & 100.0 & 100.0 & 100.0 \\
(N) & $(822)$ & $(1,091)$ & $(989)$ & $(1,334)$ & $(1,985)$ & $(1,867)$ & $(8,088)$ \\
\hline
\end{tabular}


To answer the question of whether cultural globalization measured in terms of the relative proportion of foreign cultural products discussed in the studied culture sections has increased over the research period, Table 4.1 presents the origins of the cultural products according to year. It shows that the domestic products clearly dominate the scene, totalling almost half of the articles. The second largest group is 'other European' products with one-quarter of the articles, and cultural products from the United States is third with 14.0 per cent. Individually, the rest of the world stays marginal, although together they total almost the same as the US products.

The most interesting question is whether these proportions have changed over time. Concerning the possible increase in cultural globalization, the results are not very clear. The proportion of domestic cultural products remains almost identical between 1960 and 2010, meaning that there is no straightforward increase in foreign cultural products. Only in 1980 did the relative proportion of domestic cultural products surpass foreign ones (52.0 per cent coverage); in 1990 , this decreased and recovered in the 2000s to a stable level of slightly below half of the articles.

More substantial trends over time are found in cultural products originating from other Europe and the United States. The proportion of other European products decreased from 31.8 per cent in 1960 to 21.5 per cent in 2010. Meanwhile, the proportion of US cultural products almost doubled from 9.9 per cent to 19.1 per cent in the same time-frame. Considering cultural products from all other parts of the world, their article proportions tend to remain both relatively stable and marginal.

Figure 4.1 presents how newspapers published in different parts of Europe vary according to their level of globalization and whether the composition of geographical origins of cultural products discussed in their culture sections has evolved over time. We expect to find clear differences due to the characteristics of the national contexts in which the newspapers are embedded. Based on the seminal study by Janssen et al. (2008), we expect the results to be in line with at least three society-level factors: cultural centrality of the country, language and common history. We expect newspapers from culturally central countries with strong domestic cultural production (The Guardian, Le Monde) to be more selfsufficient and thus devote more attention to domestic cultural products than newspapers from more peripheral countries (see Appendix Table B.4). In other words, we assume that under the circumstances of strong and internationally successful domestic cultural production, the demand for imported cultural products would be smaller and that the level of cultural globalization measured from newspaper coverage would be lower. While size of language area should associate positively with successful national cultural production (the more widely the language of the country is spoken, the larger the markets language-dependent cultural products abroad), language matters also in the sense of shared (colonial) history and close relations that affect the import and export of cultural products. Countries and areas with common language and shared history with 


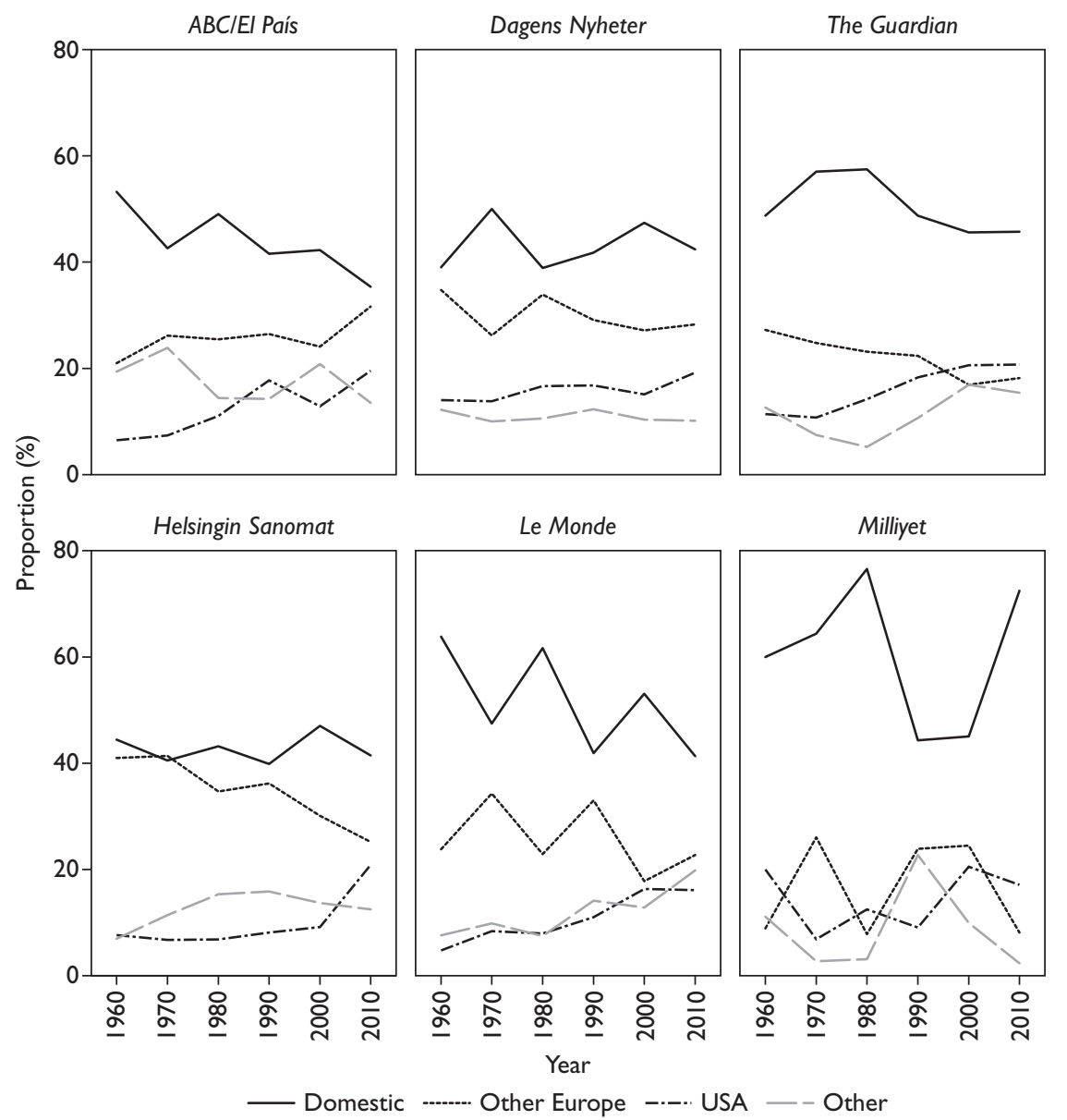

Figure 4.I Origins of cultural products discussed in the articles by year, separately on each newspaper (percentages).

old trade contacts in our case are primarily the UK with the United States, Spain with Latin America and France with Africa. Thus, we expect to see traces of these special relations in newspapers' cultural coverage.

Figure 4.1 reveals that domestic cultural products dominate the cultural coverage in our European newspapers with varying degrees and tendencies. As expected, the newspapers from the most culturally central countries cover more domestic cultural products (Le Monde with 50.8 per cent and The Guardian with 48.8 per cent) than newspapers from more peripheral countries (Helsingin Sanomat, Dagens Nyheter and ABC/El País all have around 43 per cent). However, Milliyet concentrates the most on domestic cultural products with an 
overall proportion of 62.7 per cent of all articles with identifiable cultural products. This reflects not only the relatively isolated position of Turkey from Western-dominated global cultural flows, but also the efforts the country has devoted to culture and arts as a means of building national identity. Only from 1990 to 2000 did Milliyet cover substantially less national culture, and the available space during those years was filled mostly by articles on other European cultural products. These themes will be discussed in detail in Chapter 6 (see also Box 2.3).

The proportion of domestic cultural products decreased in ABC/El País and Le Monde, while keeping its position in other newspapers. Leaving aside Milliyet, other major trends such as declining articles on other European cultural products and the rise of articles on US cultural products are well recognizable across the newspapers (most mildly in Dagens Nyheter, which shows the strongest stability in its geographical composition of cultural products discussed). The only exception is the Spanish newspapers, which show an increase in articles on other European cultural products. Thus, ABC/El País have compensated for the decreasing space devoted to domestic cultural products by increasing the space given to US and other European cultural products. Hence, the Spanish newspapers indicate a trajectory of not only increasing Americanization but also Europeanization, which in the other newspapers seem to be mutually exclusive. Similar to Milliyet, the political and national aspects of these trends in $\mathrm{ABC} / \mathrm{El}$ País are discussed in detail in Chapter 6.

While the trends (with above-mentioned exceptions) of declining proportions of articles on other European cultural products and rising proportions of articles on US cultural products are evident, the overall levels and shapes of the trends vary across the newspapers. Articles on other European cultural products range from 14.9 per cent in Milliyet to 33.7 per cent in Helsingin Sanomat. In the case of articles on US cultural products, the range of overall proportions is narrower, from 10.9 per cent in Helsingin Sanomat to 17.5 per cent in The Guardian. However, these differences across the newspapers in the case of US cultural products were even smaller in 2010 because the newspapers with the lowest overall proportions faced the most rapid and recent increase in the proportion of US cultural products. These findings can be interpreted through the fact that other European products often represent classical highbrow arts and US cultural products represent chiefly popular culture, and that new art forms become common and legitimate earlier in central than peripheral countries. This would mean that a major part of the globalization processes inspected here overlaps with the rise of popular culture and the decline of highbrow arts analysed in Chapters 2 and 3.

Overall, the rest of the world collectively covers almost the same proportion of cultural products as the United States. There are several differences among newspapers and the trends are variable because 'other world' includes a variety of locations with specific meanings for each of the newspapers and their respective countries. Connections based on language and shared history are evident. 
Besides The Guardian showing the widest coverage of US cultural products, the Spanish newspapers cover the largest overall share of cultural products from 'other world' (17.9 per cent, with Milliyet having the lowest proportion at 6.8 per cent). This is mostly due to the fact that there are three times more cultural products in ABC/El País that originate from Latin America (6.8 per cent) compared to the average proportion in the entire dataset ( 2.3 per cent). This is obviously a result of a common (colonial) history and shared language (discussed separately in Box 4.2). However, contrary to the expectations based on historical ties, Le Monde covers only very slightly more African cultural products (2 per cent) than the entire dataset ( 0.9 per cent), showing that the routes of cultural flows on the pages of quality European newspapers are far from equal. ${ }^{4}$

Table 4.1 and Figure 4.1 give strong reasons to expect that the origin of cultural products is most likely associated with art forms and cultural domains discussed in the articles. To unpack this question, we first investigate if cultural products of different art forms differ by geographical origin. Our expectation is that there are remarkable differences among the art forms, for several reasons. First, we expect that classical highbrow arts more often originate from Europe and that the rising popular culture originates primarily from the United States. However, according to the hybridization paradigm, emerging cultural forms should at some point reach domestic production (Pieterse, 2003; cf. Regev, 2013); thus, we expect to see a rise in the coverage of domestic popular culture. The other point of view is the transportability of cultural products: on one hand, mass-produced cultural objects such as music records, films and books are easily distributable. However, language dependency should mean that, for instance, abstract art or (most) classical music would be easier to transport across national and linguistic borders than language-dependent cultural products that need translation, such as theatre or books.

First, we scrutinize the differences between a classical highbrow art form, classical music, and a form of popular culture, pop-rock music. ${ }^{5}$ Figure 4.2 shows the origin of the cultural product according to the year and the music genre. The differences are clear: a clear majority ( 58 per cent) of articles on classical music discuss music products from Europe, followed by classical music articles discussing domestic and other world products, while US products represent only 3 per cent of all classical music articles. In pop-rock music, one-third of articles discuss domestic music and another third of articles discuss US music products, whereas one-quarter discuss other European products and 11 per cent discuss music products from other world.

There is a huge difference between classical music articles and pop-rock articles regarding changes over time. Classical music articles show considerable stability, whereas pop-rock articles demonstrate transformation. It is no wonder that, in the case of an emerging art form such as pop-rock, the balance of geographical origin of cultural products being discussed has changed, in contrast with a traditional art form such as classical music. The very few first articles on pop-rock discussed either US or British cultural products. During the 


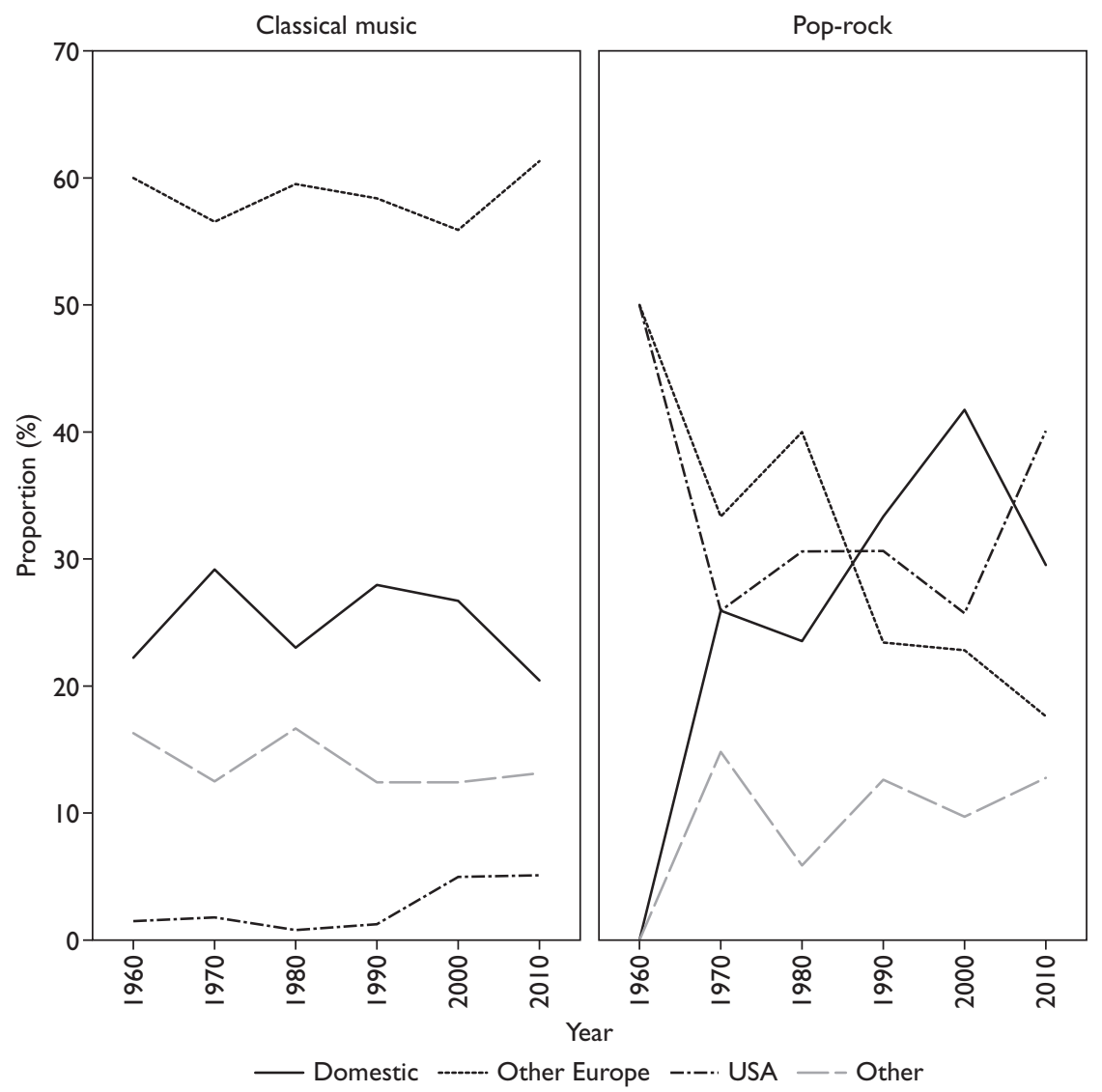

Figure 4.2 Origins of cultural products discussed in the articles by year, separately on classical music and pop-rock articles (percentages).

proliferation of pop-rock articles in 1970-1980, articles on domestic pop-rock reached the level of articles on US pop-rock, while the other European products were discussed more often. Since then, the proportion of articles on other European products has decreased, whereas domestic and, in the 2000s, US pop-rock products have been discussed increasingly often. These trends are therefore in line with both domestication (or 'poprockization' of national music; Regev, 2013) and increased Americanization of pop-rock coverage.

Four cultural domains other than music are presented in Figure 4.3: literature, theatre, the visual arts and film. The visual arts are the most abstract domain, while the others, especially literature, are more language-dependent. Literature and film are more easily distributed as copies, while theatre and the visual arts (if displayed at galleries or exhibitions) are more event- or performance-based. 


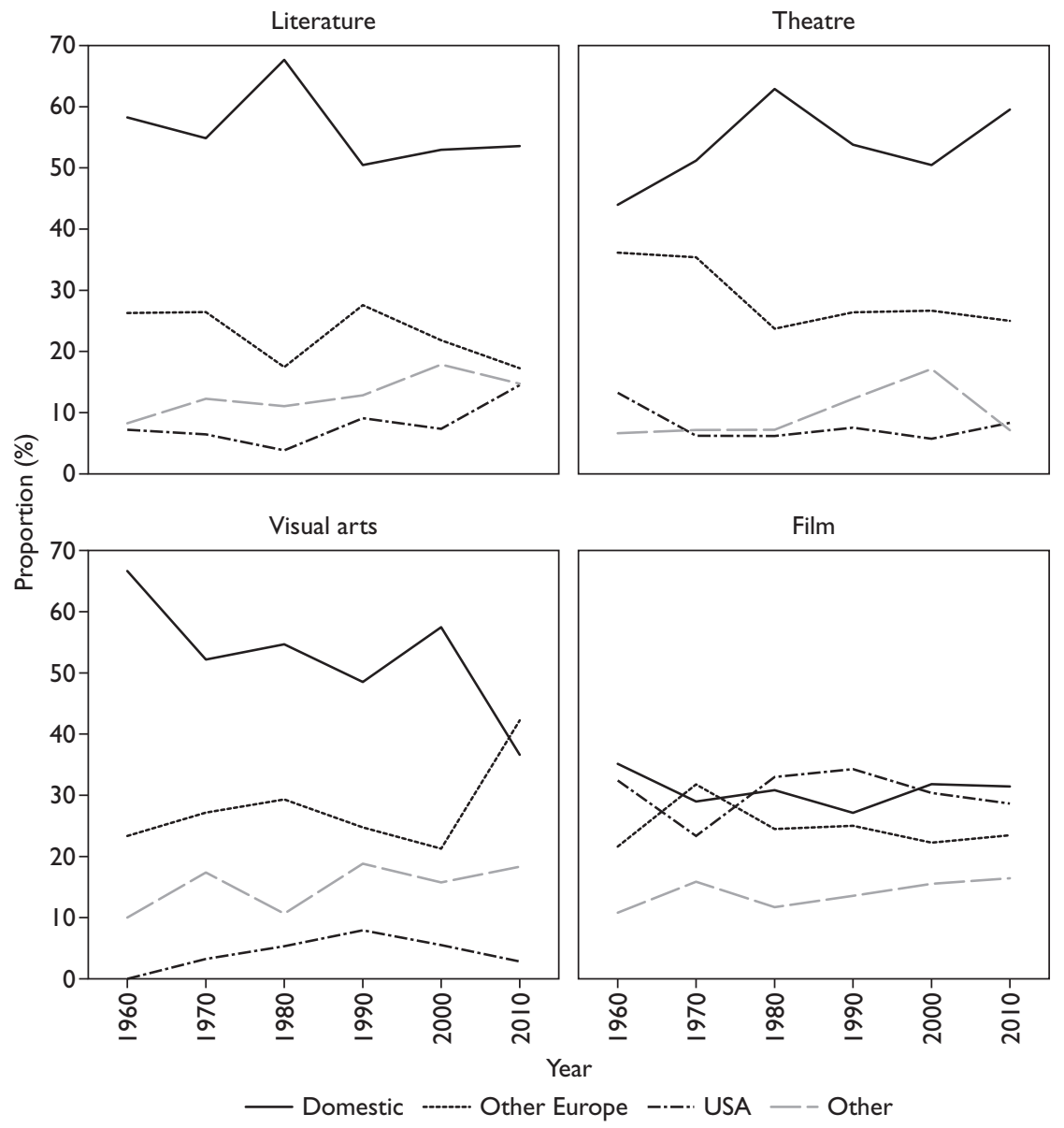

Figure 4.3 Origins of cultural products discussed in the articles by year, separately on four art forms (percentages).

Figure 4.3 reveals that literature and theatre are the most domestically dominated art forms by their cultural coverage in quality newspapers. The same is true of the visual arts, though it shows a clear recent trend towards more international coverage (2010). Of the four art forms, film is definitely the most international in its newspaper coverage. Domestic and US films are covered almost as frequently (around 30 per cent of all articles on film), followed by other European (24 per cent) and those from elsewhere in the world (15 per cent). Overall, the trends in the origin of the films discussed are stable, with domestic and US films competing with each other at the same level of coverage (cf. Crane, 2014). Other European films are slightly decreasing and other world films slightly increasing in coverage. 
In literature, the proportion of domestic cultural products is 55 per cent and overall stable (peaking in 1980). The relative proportion of other European products has decreased since 1990, while the coverage of books from the United States and other world areas have slightly increased. In total, 22 per cent of literary products covered are from other Europe, 14 per cent from other world and 9 per cent from the United States. The overall levels and trends in articles on theatre are similar. However, articles on domestically originated theatre, which have dominated theatre coverage throughout the period, clearly increase over time ( 52 per cent of all theatre articles). Articles on other European plays (31 per cent overall) decreased over time, and the space given to US or other worldproduced theatre is limited (both with 9 per cent). There was intensified interest in theatre productions from 'other world' in 1990 and 2000, but that trend weakened in 2010. Finally, in the case of articles on the visual arts, the proportion of domestic products clearly decreased (from 68 per cent in 1960 to 37 per cent in 2010, the total share of domestic products being 53 per cent). Correspondingly, the proportion of other European products (totalling 27 per cent of all visual arts articles) increased significantly in 2010. As with literature and theatre coverage, the proportion of US products in visual arts articles is only 5 per cent. 'Other world' is, however, well represented with 15 per cent of all articles on the visual arts, and the trend of discussing visual art from outside Europe or the United States has risen from 10 per cent in 1960 to 18 per cent in 2010.

Finally, we investigate highbrow/popular composition of products from different geographical origins. In Figure 4.4, cultural products are divided into highbrow arts and popular culture, and their relative proportions are presented according to year and origin. ${ }^{6}$ This demonstrates the degree to which cultural globalization trends (as understood by geographical origin of cultural products) overlap with the transformation in the balance between highbrow arts and popular culture.

In the case of articles on domestic cultural products, the total proportion of highbrow arts is 47 per cent (popular culture 53 per cent) and popular culture surpassed highbrow arts in 1980. In other European products, highbrow products dominated popular culture until the 2000s, when there was no difference between the two after a dramatic decrease in other European highbrow arts coverage and a corresponding increase in popular culture coverage. This confirms our expectation. As expected, in the case of US cultural products, articles on highbrow arts never dominated. Only 20 per cent of US products covered are highbrow, and the proportion diminished over the period. The slightest differences between highbrow arts and popular culture are in the products from other parts of the world; the situation is fifty-fifty. There is a clear decrease of highbrow culture (from 66 per cent in 1960 to 43 per cent in 2010), but the proportion of popular culture products surpassed the proportion of highbrow arts as recently as 2000 .

According to these analyses, it is clear that cultural globalization measured by origins of cultural products is not straightforward or linear. It is strongly 


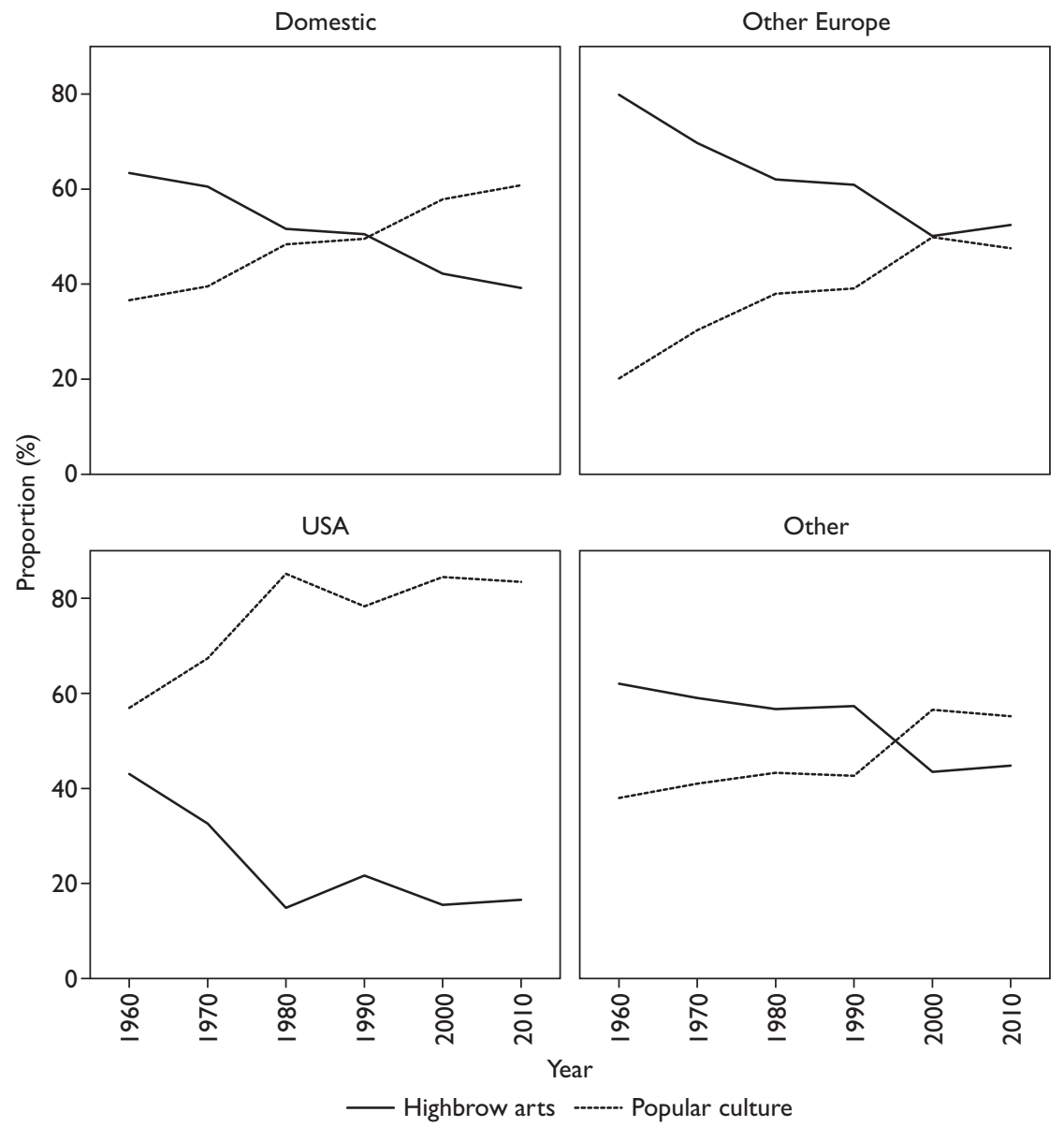

Figure 4.4 Articles on highbrow arts and popular culture by year, separately on origins of cultural products (percentages).

related to different cultural fields, particularly the division between highbrow/ popular as well as language-dependency and shared histories between specific nations. Hence, it was not enough to investigate proportions between 'domestic' and 'foreign' cultural products discussed in the newspapers; their actual geographic origins and cultural, social and historical ties are essential.

\section{Cultural globalization: qualitative approach}

The quantitative results showed the levels and trends of cultural globalization in our data. The next step is to more closely qualitatively explore newspaper 
articles to discover how foreign or international cultural products are discussed and characterized (for the various meanings and characterizations of national culture, see e.g. Chapter 6 and Box 4.1). We will concentrate on three different aspects of globalization, primarily coverage of American cultural products - the relative proportion of which doubled between 1960 and 2010. Examining articles on cultural products from 'other world' and multinational cultural coverage, both prominent signs of globalization but too small to be analysed in depth quantitatively, will further illuminate this topic.

\section{Beyond Americanization: the reception of cultural products from the United States}

As perhaps the largest qualitative analysis of this study, we conducted a close reading of all articles (over 1,000) covering cultural products from the United States. ${ }^{7}$ The aim was to analyse how US cultural products were discussed and evaluated in quality European newspapers. The two recurrent themes found were success and creativity. Besides those themes, the focus was in the evaluations made in the articles: whether US cultural products were evaluated approvingly or negatively.

The theme of success appeared in the articles in two different ways, as linked either to commercial success or popularity. Commercial success refers simply to good sales numbers or remarkable incomes: '[Charlie Sheen] is paid 1.25 million dollars per episode' (HS/05/11/10_NYT_TV5) or '[The hit collection of the Eagles] is the all-time best-selling album of the country with almost 30 million albums' (HS/23/12/10_C4). Popularity refers to artists' abilities to attract large audiences: '[Clark Gable is] one of the great magnets for the public' (DN/18/11/60_19) or '[The trombone player Ashley Slater] always aimed to reach a bigger audience' (GU/26/01/00_G2_14).

The themes of success and creativity do not exclude each other, but very often creativity is seen as a counterforce for (commercial) success in the newspapers. Creativity was represented as multifacetedness, originality and talent, going against the current, breaking rules, and sometimes being openly political. American creativity is often framed as positive, a refreshing break from stuffy, exaggeratedly established, and formal European culture: 'American music often has an optimistic and energetic note. [...] A kind of European, indented anguish does not bother the symphonies of Schuman' (HS/14/11/10_C5). Le Monde laments that: 'in France [...] the public never even heard about' popular literary genres vivid in the Anglo-Saxon world (LM/04/07/70_Livres_8). In a 1980 interview with Dagens Nyheter, after moving to Sweden, the US-born jazz pianist Steve Dobrogosz summarizes the creative power and attractiveness of his native culture, in a similar way:

Many [Swedish musicians] would benefit from working in the USA. There, they have a completely different tempo from here. There, everyone just 
wants to play and play and play ... and it's important to be the best. [...] What I perhaps miss most compared to the USA is the creativity. Almost no one here dares to experiment, to try new things.

(DN/13/08/80_13)

Besides novelty, originality and enthusiasm, American creativity also appears to rebelliously resist the establishment or political power. Inside the American cultural scene, this appears as resisting mainstream or commercial mass culture. This was already visible in the 1960s: 'In these times in which exceptionally many failures have left their mark on Broadway, theatre-goers have optimistically headed towards these small and modest theatres known as "off-Broadway", (HS/20/05/60_21). Another big production concentration worth opposing is of course Hollywood, mentioned several times as a destructive power against artistic creativity and independence: '[Hollywood Mavericks] is an essay on the outsiders who know how to use the system: filmmakers and directors who have managed to pursue their own, independent vision in the Hollywood context' (GU/06/10/90_Weekend_44).

These counter-flow artists or productions are mainly discussed approvingly in the quality European newspapers. While commercial mass productions are not usually evaluated as art, acting against them is seen as a good, valuable attribute. The main division in our data can be summarized as a difference between the 'bad' mainstream, mass-produced, commercial entertainment lacking any artistic ambitiousness, and the 'good' creative, enthusiastic counter-culture, which usually is of high artistic quality. The 'bad' American culture is often treated quite harshly:

Marc Eliot's unofficial chronicle titled Eagles: Take It to the Limit (1998) probably won't change the mental image of the group because it has been written based on old presumptions - about a populist group that was most of all some kind of business.

(HS/23/12/10_C4)

Of course, success does not always make cultural products bad. There are discussions on popularity as a reference of quality, and commercial success can be discussed in a positive way, if it is used for the right purposes, such as making art accessible for larger audiences. In the earlier years of this study, it could be enough for a piece of art to be a novelty in Europe to be 'good'. For instance, Le Monde describes Johnny Cash as 'a legendary personality to the pop audience' and 'a really popular star in the United States, as well among young people liking pop music and among the great public of American TV' (LM/12/11/70_Spectacles_2).

These themes of success and creativity and evaluations related to them remain almost the same during the fifty-year time-span of the study. There is one important change related to the acceptability of commercial success: from 1990 onwards, even very clearly commercial cultural products can reach 
legitimate status, if they are artistically qualified or have authenticity or exotic novelty for European audiences. For instance, when the television series Friends was introduced to Spain in 2000, El País mentioned neutrally that the series had 25 million viewers in the United States and that it had won several awards. However, 'the most important thing is that it has never succumbed to cheap sentimentalism or the easy temptation of excessively drawing out the scenes' (EP/03/01/00_53). Another example of very commercial but also legitimized American culture is Twin Peaks: the Director David Lynch was praised as 'the maker of such brilliant surrealistic art movies as Blue Velvet and Eraserhead', and choosing a director 'with such an original, uncommercial vision' shows that 'something's right in America' (GU/10/04/90_42).

We have seen that the newspapers' relationship with America is by no means unproblematic: the aesthetic value of US cultural products is often defined in the shadow of commercial values (cf. Box 3.2). Typically, commerciality has been an automatic sign of 'bad' culture, but in the context of a larger wave of various and overlapping legitimization processes of popular culture and the popularization of (traditional) legitimate culture, commercial success is increasingly seen as permitted. Chapter 5 will further discuss the commercial aspects of aesthetic evaluations.

\section{Distant and exotic? Cultural products from the 'other world'}

Our category of the 'other world' in our classification of areas refers to beyond the triumvirate of domestic, other European and US cultural products. According to the original coding, the cultural products and artists falling into this category originate from Canada $(n=32)$, other America $(n=184)$, Russia/Soviet Union $(n=215)$, Asia/Australia/Oceania $(n=174)$ and Africa $(n=72)$. In this section, we will present specific examples on how culture from the 'other world' was represented in newspaper coverage.

To start with a look at the art form composition of cultural products from the 'other world', the largest art forms among the Canadian cultural products discussed in the articles are popular music ( 28 per cent), literature ( 25 per cent) and film (9 per cent). The most frequently covered art forms of 'other America' (mainly Latin America; see Box 4.2) are literature (37 per cent), popular music (25 per cent) and film (12 per cent). Russian products are most often classical music (28 per cent), literature (20 per cent) and theatre (16 per cent). Products from Asia, Australia or Oceania are mainly literature (26 per cent), film (18 per cent) and popular music (18 per cent). African cultural products covered most often include popular music (40 per cent), literature ( 24 per cent) and film (19 per cent). Thus, literature, popular music and film are the most typical art forms from the 'other world' discussed in quality European newspapers.

Most coverage on cultural products from the 'other world' is in no respects exoticizing; rather, it focuses on the same features as an article on any other 


\section{Box 4.2 Connected by language and cultural ties: the case of Latin America}

When looking at the national background of artists that make it to the culture sections, it seems evident that there are substantial differences across newspapers. This is not surprising as each country has experienced different historical paths and established closer political relations to other territories due to geographical proximity, cultural affinities and common historical endeavours. In this sense, it seems logical that certain regions of the world have a more relevant presence than others in cultural coverage.

The case of Latin America is exemplary. This region, comprising Central and South America, is formed by countries that belonged (except for Brazil and some smaller countries) to the Spanish empire until the beginning of the nineteenth century. While culturally Latin America is an active region with renowned writers and musicians, cultural coverage on it has not been high in European newspapers. The only exception is Spain, which shares a common language with most of these countries. Although the independence of most Latin American countries dates back 200 years and the intensity of different trade and cultural exchanges was relatively low for most of that period, it is clear that those historical links have been significant.

Our data shows that, in most of the newspapers, there is barely coverage on Latin American culture (less than 1 per cent in most). Nevertheless, in the Spanish newspapers, coverage on Latin America reached a figure of nearly 7 per cent. In fact, there is a substantial gap between $A B C$ and El País, the coverage of the latter being much higher. Furthermore, the way Latin American culture has been covered by Spanish newspapers has changed through time, and it is not only a matter of figures. For instance, in $A B C$, Latin American countries are seen from an interesting perspective, as an old brotherhood with Spain, as a symbolic reference and the motherland (the madre patria) united by language and a common history. Most of the articles cover history or academic gatherings of Hispanists; reviews of films and musical events are rare. There is often an emphasis on the legacy of Spain and the importance of Spanish language. For instance, one article mentions the excellent impression made by Spanish scholars at an international conference of discoveries, in which they focus on different aspects of the conquest of America (see ABC/13/09/60_37). There are also references in the legacy of Spain, for instance, the struggle to keep Spanish alive in Puerto Rico (see $\left.\mathrm{ABC} / 13 / 02 / 70 \_48\right)$. However, it is also evident that cultural trade with America is not substantial; this is confirmed by a lesser coverage of Latin American cultural products, which is also the result of the situation of the country during Franco's rule (e.g. nationalism, international isolation, underdeveloped economy).

In El País, the approach is different. Since the 1980s, the newspaper has made references to the strategic importance of Spanish language and the need to consolidate the links between Spain and Latin America (see EP/14/06/80_30). The political relations of democratic Spain with Latin American countries are strengthened through a number of diplomatic initiatives and forums (Cumbres Iberoamericanas), which paved way for later trade agreements and investments. The Spanish language started to achieve a higher status, partly because of the rise 
in the number of its global speakers (due to the expansion of population in Latin American countries), and partly because of the increasing number of the Latin American immigrants to the United States. The growing influence and the development of communications has helped to shape the views of Latin America, which was then seen as a modern trade partner rather than a long-lost brother. From the 1980s onwards, Spanish companies started to invest heavily in Latin America, and soon Spain became the second biggest investor in the region after the United States. Since the 1990s, there has been an explosion of coverage related to the recording industry, with an interest in Spanish music as a possible magnet for profits.

This is reflected also in cultural field. In the 1980s, cultural exchanges increased, and Latin American artists and their contributions were reviewed more regularly. The boom and post-boom writers, films and especially pop-rock music found space in El País. The United States and its Latino community played an important role as catalysts of the investment efforts in cultural industries. What should not be underestimated is the influence of PRISA, the media conglomerate behind El Pais, and their business interests, highly representative of the discourse on Latino music that mushroomed in Spanish media at the turn of the century (see Box 5.2). In the following article, which also lists exact calculations on market expectations, we can see how their discourse is framed:

Muxxic Latina will start signing artists from September onwards, to launch later their careers from the end of this year and the beginning of 2001. This will be done from their new headquarters in Miami, which is now an important capital for business and entertainment production.

$\left(\mathrm{EP} / 07 / 07 / 00 \_42\right)$

This kind of pro-business article is a significant feature in the way music and artists from Latin America are perceived. In literature and films, however, discourses are different, highlighting classic aesthetic values and cultural commonalities, not unlike other artists from different latitudes. On both ends of the legitimacy and commerciality ladder, common language and cultural affinities play a role.

nationality would do (see e.g. LM/25/04/90_18). For Finnish Helsingin Sanomat, Russia is not only a physical neighbour (which Finland was part of until 1917) but also a cultural highbrow superpower with enormous quantities of classical theatre, literature and music; therefore, it is only natural that Russian art is frequently covered. The articles on Russian cultural products focus heavily on these classics, and usually in a canonizing tone: in a review of Chekhov's play Three Sisters, the reviewer mentions that: 'The performance is like an introduction to Chekhov and to Konstantin Stanislavski's actors' methods, born in the Moscow Art Theatre' (HS/17/12/00_B5). The coverage of Russia in The Guardian focuses similarly on almost exclusively highbrow arts: Bolshoi is titled 'one of the world's greatest ballet companies' with an 'explosive appeal' 
(GU/20/07/10_G2_19). At the same time, the rough times faced by Russian art has not been forgotten: the review on Bolshoi's visit to London in 2010 is in part a subjective reminiscence of their visit in 1986, but also a history of the turbulent times the world-famous ballet company has gone through.

Another entirely different viewpoint of the coverage of the 'other world' is coverage on African cultural products and artists. The coverage is often formally similar to that of other nationalities, but specific attention is paid to its diverging context, usually in a highly appreciative tone, as, for instance, when Dagens Nyheter laments the fact that the main act of a concert of an African artist has been cancelled, because 'it is not every day one can hear bhangra and afropop with influences of taarab in Stockholm' (DN/05/04/10_Kultur8). Another good example is a review titled 'A Liberation Carved in Stone' on a contemporary African art exhibition at the London gallery Gimpel Fils (GU/25/04/90_45). The review resembles the typical canonized way of writing, but there is a strong political dimension and a contextualization on the movement is included, probably as a polite gesture to readers potentially unfamiliar with movements inside African art. A small detail of the review reveals that ethnicity, for an 'ethnic' artist in the eyes of the majority, might be a feature demanding caution - as something which is capable of being used 'wrongly'.

The show's pieces are unlabeled and arranged in a purely aesthetic scheme that, as with previous exhibitions of African art, seems to suggest that the artist should not intrude upon the 'ethnicity' of the work. But the range of the talent in the show is impressive.

(GU/25/04/90_45)

The coverage on the 'other world' pictured here does not follow any clear pattern. This is mostly due to the definition of the category; it combines several radically different countries and socio-political contexts, some of them Western (and even Anglo-American), some very peripheral from the point of view of the average European newspaper. Still, the mere existence of the category can be considered to be a good proxy for cultural globalization, especially in the sense of Beck's (2004) 'banal cosmopolitanism'. Exotic, 'new' cultural items can serve as tokens of legitimacy, and they surely can bring about an aura of openness and tolerance to culture sections. Perhaps the most important lesson is the one exemplified by Latin America: cultural ties and affinities are key in understanding globalization, especially, the smallest streams of it.

\section{Beyond domestic and foreign: multinational cultural products}

Sometimes it is not easy to define the origin of an artist or a piece of art. Even the simple category of domestic versus foreign cultural products is not always clear, and for the actual origin of a certain product, the definition can be even more 
complicated. The code 'multinational' was used every time the cultural product or artist had roots in several countries (a typical example, in addition to children of multicultural families, were different international cooperations). In total, 353 articles were primarily discussing cultural products labelled as multinational, constituting only 4.4 per cent of all articles that were coded with the variable 'origin of the cultural product'. To investigate these multinational cultural products more closely, we chose a sample of articles on multinational cultural products from Helsingin Sanomat $(n=61)$ and The Guardian $(n=50)$ for closer reading.

First of all, there was typically no mention of the origin of a cultural product in an article; the coder looked for information on nationality and generally found at least one source defining the artist or piece of art as multinational. Almost half of the articles have no emphasis on the origin of the product. Similarly, it was common to briefly mention multinational origins. Almost onequarter of the articles under scrutiny are this kind. For instance, in 1990, The Guardian states matter-of-factly that the director 'Andrei Serban defected from Romania to the United States 20 years ago. Now, in these freer post-Ceausescu times, the Boston-based director is going back to head the country's National Theatre - a post he initially refused' (GU/14/05/90_37).

An alternative way to introduce the multinational origin of a cultural product is to relate it to the work of art. This is common in literature, for example, through emigrants situating novels in the former habitat, such as in this book review:

Pridencio de Pereda is a previously unknown author for us. He was born in New York but his parents are Spanish emigrants, and he has strong spiritual ties to his 'old' country. The novel Fiesta, which has now been published in Finnish [...] is an excellent indication about that.

(HS/17/04/60_22)

The importance of emigrant authors of multinational and mixed geographical origins in literature and art more widely stems from the fact that the ideology of modern art has particularly valued outsiders' or strangers' points of view as a means to shed new light on the ordinary and the taken for granted. An author or artist with a multinational background can benefit from a fresh perspective vis-à-vis the previous or current country. In this sense, multinationalism can be seen as a virtue of the modern artist, providing unique reflective resources that would be impossible for mere 'national' artists. This is not embodied in one artist only but also as a virtue also for a collective or an event. A good example is a review of the exhibition of Jean-Michel Alberola and Iba Ndiaye: 'Algerianborn Jean-Michel Alberola and Senegalese Iba Ndiaye symbolize for us a strange culture, something non-European. The colours of their paintings glow from the "warmth of the South", and "primitivism" is easily seen in their topics' (HS/26/01/90_B14). A typical feature of the coverage on multinational artists is the emphasis on the links between the exotic and domestic: 'As a painter 
Ndiaye is very European: he keeps drawing as a baseline for painting, and especially the traditions of impressionism and expressionism experience a new renaissance in his colourful canvases' (HS/26/01/90_B14).

Usually multinational aspects of cultural products and artists are mentioned as something positive, something that adds to the commonplace topics, something that suits well the cultural goodwill of the potentially middle-class readership of the newspapers studied. Often, what is emphasized in these discourses is the cosmopolitan air of these multinational cultural products. 'Styles from seven countries', boasts a 1960 The Guardian article covering a design exhibition in London (GU/30/03/60_6). International cooperation products are valued very highly throughout the time-span, for instance, the 1970 interview with Dmitri Tiomkin, the producer of the American-Soviet film Chaykovskiy. Tiomkin pictures the hardships of the project but praises its success: 'The cooperation was considered occasionally completely impossible. But now the filming work has been completed and we are satisfied. MOS-Film gave the best forces to the work' (HS/27/01/70_10). The tones of national pride present in some of the articles on multinational cultural products tell the same story (see also Box 4.1). This usually overlaps with discourses on cosmopolitanism. For instance, in a 1990 Helsingin Sanomat, there is a review on the exhibition of Asko Sutinen, introduced as a 'real cosmopolite':

Asko Sutinen is a real cosmopolite. He was born in Canada 35 years ago and received his art education in Australia. [...] The material for his artwork is gathered through travelling and working in Egypt and Greece, for example. The pieces of this exhibition have been painted in Finland.

(HS/31/05/90_B10)

In a similar tone of appreciation and perhaps even distinction, multinational roots can be highly acknowledged and considered almost as a guarantee of quality art. As early as the 1960s, an enthusiastic film review of the FrenchBrazilian-Italian Black Orpheus praises exotic samba music and the actors: 'And most of all: these colourful performers are truly mesmerizing in their licentiousness and the freshness of their way to put one's soul into it' (HS/15/10/60_11).

Finally, and as an important reminder that all multinational art is not necessarily considered to be positively exotic, trouble-free or even valuable, there is plenty of coverage with discussions on the post-colonial past of several multinational artists and artworks, and on the politics of multinationalism in general. In a record review on diasporic African music, several essentially political topics are raised:

There are songs of nostalgia for home, dreams of foreign riches, and reminders of the hardships [...] Daara J Family's Unite 75 and K'naan's 15 Minutes Away are both songs about money transfers, and provide a wry, pained description of what the promised land outside Africa can often be like.

(GU/11/06/10_FilmMusic_12) 
Similarly, multiculturalism can also mean clashing identities and conflicting political views. A 2010 interview on The Kominas, 'an American band, even though we sing in Punjabi', concentrated on the political and religious clashes the band members have faced rather than on their music. 'There are conservative punks or redneck punks who are hard to deal with, but the main problem we have is with anti-religious punks who cannot see any value in a religious heritage', said the spokesperson of the band. 'It breaks my heart when Muslim kids come to our shows and then read our lyrics and write back saying they just can't come to see us again' (GU/11/06/10_FilmMusic_4). 'Multinational' culture, just like the exotic culture from the 'other world', can be used as an effective frame for creating but also problematizing cultural hierarchies.

\section{Conclusion}

This chapter explored in detail the geographical diversity of cultural products discussed in quality European newspaper culture sections from the point of view of cultural globalization. Cultural globalization was measured via relative proportion of foreign cultural products discussed in the articles, but the picture is not black and white. If measured this way, domestically produced cultural products stubbornly dominate newspaper coverage in Europe and the level of cultural globalization has not really increased over the half-century research period. The latter is due to the 'foreign' category, which contains contrasting trends of the prevalence of cultural products originating from various parts of the world. Moreover, there are remarkable differences across the art forms discussed in the articles. A crucial finding combining these two aspects is that classical highbrow culture has been mostly European, whereas emerging popular culture has been heavily American. While the latter is increasing, the former is declining. When scrutinizing the newspapers in the light of the national contexts in which they are embedded, there are some clear trends: common history and shared language create a basis for connections that are still visible in cultural exchange and in the proportions of cultural coverage.

Still, the most important factor with which processes of cultural globalization seem to be associated is the art form of the cultural product. Mostly this is due to the remarkable significance of the traditional division between highbrow and popular arts, but the language-dependency and distributability of cultural products play minor roles in influencing which cultural products of different geographical origins end up being discussed in culture sections of European newspapers. In line with Janssen et al. (2008), who studied globalization of cultural coverage in Dutch, German, French and US newspapers, we find two popular and mass-produced cultural domains, film and popular music, to be international in nature. Similarly, we find also that the visual arts have become more international over the research period. On the other hand, our results regarding theatre and literature differ from Janssen et al.'s (2008): in our case, the coverage of literature was even more domestically dominating than theatre's 
coverage. These small differences could indicate the significance of different languages and national contexts on globalization more widely.

In this chapter, we paid special attention to cultural products originating from the United States and investigated how quality European newspapers write about them. The two main themes of success and creativity, while occasionally overlapping, show clear differences in how they are evaluated. Success, especially commercial success, was usually linked to negatively evaluated phenomena such as mass production and loss of artistic independence. Creativity was seen as a positive feature, connected to novelty, artistic quality and originality. Especially since the 1990s, we have seen a change of discourse in which commercial success can be covered positively if the artwork was observed through a legitimizing lens, typically if it was combined with an attitude of cultural goodwill, for instance striving for authenticity.

In the close readings of articles covering 'other world' and 'multinational' art, small categories covering cultural products from lesser-known places with few cultural links to the contexts studied, we found, besides clear traces of colonial histories, an interesting interplay of cosmopolitanism and the attraction of the exotic. Cultural products from different parts of the world are usually covered in tolerant and enthusiastic tones, and there are typically considerate contextualizations to familiarize the reader with the backgrounds. Both the examples of legitimization of commercial success in the case of coverage of American culture and the positive tones attached to imported and unfamiliar art reveal that cultural globalization as studied here has happened via the legitimization and inclusion of some selected foreign and exotic items, presented and disseminated through newspapers.

Analysing newspaper coverage of national origins of cultural products provides only a limited view on cultural globalization. Geographical mobility of cultural products and their reflection in newspaper cultural coverage is one obvious indicator of cultural globalization, but it does not illuminate how cultural influences fundamentally exist and operate or how foreign influences are adapted, adopted, domesticated and merged into national hybrids. Our approach has its advantages in terms of making globalization processes visible and empirically analysable, but, ideally, it should be complemented by views on how foreign influences are adapted and used in national contexts (cf. Regev, 2013). In the context of this book, this fundamental aspect is taken into account by showing how originally 'foreign' (Anglo-American) cultural forms have been rising and increased their legitimacy and newspaper attention. The prime example of this is the rise of pop-rock (see Chapter 2), independent of its national origin, because the music style was originally American. To some extent, this applies also to other forms of popular culture, for instance, films and television, which are now mostly domestically produced but might still represent global commercial popular culture in terms of format and style. 


\section{Notes}

1 See, for example, Giddens, 1990; 1999; Robertson, 1992; Held, McGrew, Goldblatt and Perraton, 1999; Tomlinson, 1999; and Beck, 2000a.

2 See, for example, Lizardo, 2005; Woodward, Skrbis and Bean, 2008; Savage, Wright and Gay-Cal, 2010; Pichler, 2012; Cappeliez and Johnston, 2013; Meuleman and Savage, 2013; Regev, 2013; Wright et al., 2013; and Rössel and Schroedter, 2015.

3 Moreover, the origin of the cultural product was not coded, if the article type was an announcement/list. The variable measuring the origin of the cultural product was defined as the country of origin of the first-mentioned artist or piece of art in the article; in many cases, there were several cultural products discussed in the same article, but only the first one was coded.

4 As a curiosity, in Helsingin Sanomat, 5.1 per cent of articles cover cultural products from Russia or the Soviet Union, compared to an overall proportion of 2.7 per cent in the entire dataset.

5 As the following analyses are using the highbrow/popular categories (Figures 4.2, 4.3 and 4.4), Milliyet has been excluded (see Chapter 2 and Box 2.3).

6 Again, we follow here, and in all following analyses using the distinction between highbrow arts and popular culture, Janssen et al. (2011) in our definitions (see Chapter 2).

7 See Purhonen, Lauronen and Heikkilä, 2018. The Turkish Milliyet has been excluded from this analysis. 


\section{Commercialization \\ On the commercial dimension and advertisements}

\section{Introduction}

Despite widespread arguments that cultural journalism has lost at least some of its autonomy and become part of the market economy (see Janssen, 1999; Jaakkola, 2015), previous research has not explored in detail the commercial dimensions of the cultural content in quality newspapers. This chapter does this by detecting signs of commercialization not only in articles and reviews written by cultural journalists but also in the advertisements published in culture sections.

Classical highbrow arts that have long been considered to be more prestigious than popular art forms remain heavily subsidized by national cultural policies, securing their stable position from the pressures of alleged or real commercialization (Heilbrun and Gray, 2001). While a soap opera or musical might be economically successful (cf. Scardaville, 2009), within the sphere of highbrow arts, aesthetic legitimacy has traditionally outweighed economic legitimacy. Economic and aesthetic legitimacy are usually seen as competing, mutually exclusive forces. In contrast, popular arts, such as pop music and cinema, have from their birth been associated with the pursuit of economic rather than aesthetic legitimacy. In recent years, however, several scholars have pointed out that the increasing number of reviews on popular art forms (especially in newspapers, see Janssen, 1999; Schmutz, 2009b) and their legitimizing tone (Baumann, 2007; Schmutz, 2016) has moved them closer to aesthetic legitimacy. As shown in Chapters 2 and 3, popular culture, especially pop-rock music, has gained legitimacy recently, through its increasing coverage in quality newspapers and success in developing its own system of symbolic value that has managed to stay relatively (but far from completely) autonomous from the commercial sphere.

This chapter explores the relationship between artistic and commercial valuation, connected to the complicated relationship between art and money, on the pages of our quality newspapers. The chapter opens by discussing the tension between arts and economy and the alleged commercialization of culture, treating these two questions from the perspective of cultural journalism. Next, our empirical analysis will examine to what degree cultural content, especially 
evaluations, are intertwined with commercial vocabulary and valuation, and whether there are systematic trends over time. This question is approached both quantitatively, through the examination of the explicit commercial dimension (vocabulary using economic indicators) included in the newspaper articles, and qualitatively, by close reading of articles with a commercial dimension to see how commercial content is interrelated with aesthetic evaluations. Finally, we analyse the advertisement content published in the culture sections of our newspapers. As one indicator of the increased commercialization of media outlets which has been said to be the blurring of boundaries between editorial and advertisement content (Hallin, 2005: 235), we ask whether the space given to advertisements published in culture sections is increasing and what kind of products the advertisements concern. Thereby, our analysis of commercialization will cover elements from both inside and outside the journalistic cultural content published in quality European newspapers.

\section{From the enduring tension between art and money to commercialization of culture}

Arts and money have always had a special relationship. Notwithstanding the level of vocation and passion of the artist, full-time, long-lasting artistic work requires economic resources. The relationship between economic matters and art has surely been problematic in its own ways across historical models of art patronage, but the relationship has been recognized as particularly pressing in modern times. After the nineteenth-century introduction of 'fine arts', separating arts from crafts and artists from artisans, and the building of arts markets (Shiner, 2001), funding of the arts has been channelled through three main sources: private funding (including 'old-fashioned' patronage, the non-profit sector, foundations), public funding (from local government to the state) and commercial markets (including consumers, companies and other for-profit institutions and cultural entrepreneurs) (Mulcahy, 2003). Since the birth of the modern art world, or field, the question has been articulated primarily in terms of degree of autonomy from economic goals and constraints (Bourdieu, 1996). The roots of the ideology of 'art for art's sake' and the idea that art should be autonomous from economy (as well as politics; see Chapter 6) can be traced back to the Age of Enlightenment and the aesthetics of Immanuel Kant (Gronow, 1997); since the nineteenth century, the field of art has consolidated and accomplished the relative, albeit fragile, autonomy that has characterized it ever since.

Bourdieu has been perhaps the most forceful voice in arguing that modern art rests on the idea that art and commercialism are contrasting opposites and, at the same time, in showing that the ideology of disinterestedness and 'art for art's sake' is only doxa, masking the subtle and complicated relationship between the fields of art and economy, which is continuously reworked and maintained. For Bourdieu, it is intrinsically the autonomy from commercial pursuits that defines art: 
The opposition between art and money (the 'commercial') is the generative principle of most of the judgements that, with respect to theatre, cinema, painting and literature, claim to establish the frontier between what is art and what is not, between 'bourgeois' art and 'intellectual art', between 'traditional' art and 'avant-garde' art.

(Bourdieu, 1993: 162)

The complicated relationship between money, funding, economy and the arts, and the ideology of autonomy, have been constitutive to the distinction between highbrow arts and popular culture. Highbrow arts can be defined as 'creator-oriented' and popular culture as 'audience-oriented' (Gans, 1974). Thus, for highbrow arts, funding from the third main channel, commercial markets, has traditionally been taboo, whereas the very same funding channel has characterized popular culture by definition. Bourdieu (1993) conceptualizes this by talking about two opposite fields of cultural production: 'large scale production' and 'restricted production'. The former operates in the search for profit and voluminous audiences and tries to satiate a pre-existing demand, thus also minimizing risks; the latter strives for symbolic capital, 'a kind of "economic" capital denied but recognized, and hence legitimate - a veritable credit, and capable of assuring, under certain conditions and in the long term, "economic" profits' (Bourdieu, 1993: 142). According to Bourdieu's definition (1993), the 'autonomization' process of arts refers to a development in which it is able to break away from the commercial demands and other external influences connected to large-scale production and finally to operate through its own system of symbolic valuations (see Box 5.1).

Bourdieu shows that the birth of the discourse of an ideally non-commercial 'art for art's sake' and its legitimate status is a complex historical process that was in turn linked to the inevitable clash between commercial art forms ready to cater to audience expectations and a competing 'realist current' (Bourdieu, 1993, 1996). Furthermore, the distinction between 'bestsellers with no tomorrow' and lasting classics relies on the education system that in turn consecrates and canonizes classics. What Bourdieu calls the 'pure gaze', the ability to discern and appreciate highbrow art in the 'correct' way, is inevitably connected to cultural competence and education, which again is linked to class position (Bourdieu, 1984).

The discourse on the commercialization of culture has particularly been concerned with whether the influences and demands from the commercial funding typical of popular culture would become more prominent in the highbrow arts. Different negative scenarios have been presented throughout the twentieth century, especially the latter half, and this discourse strongly overlaps with the ideas of the homogenization of culture and cultural imperialism, referred to in connection with Americanization in Chapter 4. Perhaps the most famous and extreme version of the discourse is represented by Horkheimer and Adorno (1969) with their 1944 declamation of the dismal influence of the 'culture 
industry' (mass media and popular culture), which threatens to commodify genuine art altogether.

Here, it is significant to distinguish between the idea that art and commercialism are competing opposites (an empirical generalization of the ideology of modern art) and the discussions according to which commercialization threatens culture and the arts, which can be understood as a form of cultural critique. Bourdieu's work is, perhaps paradoxically, an embodiment of both positions, as the former (and arguably more substantial) was presented in his major studies on cultural production, most importantly The Rules of Art (1996), whereas the latter was voiced in his late political essays, published in collections such as On Television (1998b). 'But what is currently happening to the universes of artistic production throughout the developed world is entirely novel and truly without precedent', Bourdieu claimed, perfectly in the spirit of shamelessly presentist cultural critics, and continued: 'the hard-won independence of cultural production and circulation from the necessities of the economy is being threatened, in its very principle, by the intrusion of commercial logic at every stage of the production and circulation of cultural goods' (Bourdieu, 2003: 67). Bourdieu's list of offenders is conventional to cultural critiques: 'Hollywood films, telenovelas, TV serials, soap operas, police series, commercial music, boulevard or Broadway theater, all purpose magazines, and best-sellers produced directly for the world market' (Bourdieu, 2003: 69).

What is of special interest here is that both questions can be posed more specifically in the case of cultural journalism to determine the nature of structural (and ideological) tension between cultural journalism and economic goals and constraints and whether cultural journalism has been (or will be) commercialized.

\section{Autonomy in peril? The commercialization of cultural journalism}

While the tension between consecrated art and commercial success has given plenty of material for one of the most essential debates in cultural sociology and especially in the context of cultural hierarchies and legitimization, the fine line separating 'real' culture and commercial culture is also timely in the context of cultural journalism (Hovden and Knapskog, 2015). Just as in the field of culture, metadiscourses on cultural journalism foster division between legitimate 'quality journalism' and 'commercial journalism'. Jaakkola (2015) places commercialization as one of the main five discursive metacritical frames of cultural journalism together with elitization, popularization, journalistification and professional 'apathization'. All these are 'representations of menace; they present potential instrumentalizations of the idea of autonomous journalism and threats to the functions of qualified cultural journalism' (Jaakkola, 2015: 54). Commercialization has also been claimed to skew news towards a more commercially oriented and trivial tone and simultaneous 'tabloidization' to popularize editorial content 
and threaten what could be considered to be quality journalism or 'real news' (Franklin, 1997; Magin, 2017).

While there are clear signs of these developments, there is no conceptual consensus about what commercialization, at least in the field of cultural journalism, really refers to or how it should be measured. While not a direct menace in the sense of a situation in which journalistic content would be difficult to separate from commercial content, at least in traditional quality news outlets (but see Hallin, 2005), some scholars have pointed to the 'blurring of boundaries' between proper hard news and content less oriented on immediate news value; in this 'soft journalism', there is an oscillation between information and entertainment, and lighter human-interest topics such as housekeeping, cooking and lifestyle (Kristensen and From, 2012). Cultural journalism is traditionally included in 'soft' news (Harries and Wahl-Jorgensen, 2007; Jaakkola, 2015). In the case of newspapers' cultural content, 'service' or 'soft journalism' typically mixes light topics with straightforward advice for cultural consumers: recommendations on cultural products and phenomena, information on cultural events and so forth. Even the fact that newspapers increasingly cover and review newly available and newsworthy cultural products (e.g. new exhibitions, movies and books) instead of classical topics can be interpreted as an indicator of service journalism (cf. Kersten and Janssen, 2017).

From the perspective of cultural legitimacy, the greatest threat set forward by the commercialization of cultural journalism is tied to the possible changes in aesthetic legitimation and artistic consecration, which in newspapers typically happens through reviewing. Many scholars have paid attention to the complicated web of influences between critics' opinions, commercial success of a cultural product and readers' tastes (sometimes realized as a concrete consumer choice). While commercial interests can be included in the motives behind different gatekeepers' decisions, scholarly findings on the topic are not entirely clear. For instance, Shrum (1991) concludes that a positive review's influence is higher in the realm of more traditional highbrow theatre reviews than for popular theatre shows. However, the gatekeeping and selecting role of cultural journalists, resulting in media attention given to different cultural items, is effective: visibility is even more important than evaluation.

Commercialization of journalism, of course, has historical motivations. For instance, in the Nordic context, the commercialization of journalism was tied to commercializing developments in the entire political sphere, which challenged radically the Nordic media model based on strong professionalism, traditionally neutral commercial press and strong state intervention (Hallin and Mancini, 2004). These developments were further emphasized by the economic recession in the 1990s, which brought about a then-unknown business ethos in editorials and challenged traditional ideological journalistic understandings. Profit was placed above journalistic legitimacy, and several publishing houses that previously had concentrated on only newspapers became parts of large media corporations and conglomerates (Hellman, 2010; see also Box 5.2 on the Spanish music industry). 
Finally, it should be kept in mind that, to a certain extent, the commercial aspect of journalism is an unavoidable fact, not only because, due to decreasing circulation numbers, newspapers have a more urgent need of advertising revenue than ever before (Picard, 2008). More importantly, journalism's structural position binds it by definition to commercial interests (Bourdieu, 1998a, 1998b, 2005; Champagne, 2005). The field of journalism is more dependent on external forces than any other field of cultural production, thus its relative autonomy from the pressures of both political and economic constraints is always very fragile; it is intrinsically subordinated to various laws of supply and demand (Bourdieu, 1998b: 75; see also Bourdieu, 2005; Champagne, 2005). Hallin summarizes that:

the distinctive media logic that has developed during the twentieth century is in fact a complex hybrid influenced by both commercial and strictly 'professional' or 'intellectual' influences; these two are in many ways in tension with one another; and the balance is shifting toward the commercial.

(Hallin, 2005: 235)

Finally, cultural journalism occupies a special structural position within journalism, oscillating between the art field and the field of 'hard' journalism, resulting in a situation in which cultural journalists are 'doubly dominated' (Hovden and Knapskog, 2015). Cultural journalism is not fully appreciated in either field because of its close relationship with both. Bourdieu (2005: 42) recognizes the special position of cultural journalists by distinguishing, homologously with the opposition between 'pure' and 'commercial' art in artistic fields, between 'the most heteronomous sectors of journalism' (most notably television) and the 'purest regions' of journalism (quality press and, particularly, Le Monde in French context). The former spreads commercial influences to the entire field of journalism, the 'purest journalists' included, which has made the field of journalism increasingly commercial, especially since the 1980s and 1990s (Bourdieu, 1998b).

\section{Box 5.1 The price of art}

In many fields of art and culture, it is typical that the monetary value and the presumed or recognized aesthetic value of an object of art are not identical, or their development does not follow each other. In many cases, the opposite might be more likely the case. For instance, the fact that a book is a bestseller, or a movie is a blockbuster, does not guarantee its high value as an object of literature or film art among connoisseurs or critics. The performance of an author or an actress who earns millions of dollars is often looked upon by the gatekeepers of culture with suspicion. On the other hand, a movie that succeeds in gathering only some thousands of spectators or a book whose readers can be counted in hundreds can often receive praise from critics and art historians or be rewarded with high cultural awards. 
For Bourdieu, the very fact that the criteria of economic success and value and the artistic success and value of a cultural object do not coincide is the best proof that aesthetic fields (such as the visual arts and other forms of 'authentic' culture) are autonomous and follow their own standards. In the heteronomous subfield of production of popular culture, actors are oriented towards external criteria, for example, sales and economic profits, whereas in the autonomous subfield of restricted production, actors have a stronger orientation towards internal criteria of evaluation (see Bourdieu, 1996).

At first glance, the field of visual arts seems to contradict this claim (cf. Velthuis, 2003). Objects of visual art - paintings, sculptures or items of design are often sold for astronomically high sums of money without losing their high aesthetic value. On the contrary, the high price paid for them can be regarded as proof of their high and unique aesthetic value.

This seems to be the case in particular of works of classical or older, wellestablished art, the creators of which have already established their cultural reputation and value both in art history and in art markets. This explains the somewhat unexpected fact that the culture sections of newspapers report openly and without question the high prices sometimes paid for individual works of art at auction, or write about the extremely high prices that art collectors or museums have paid for paintings or sculptures.

The following examples come from Dagens Nyheter. On 12 November 1970, the newspaper wrote a short report about an art auction in which various works of art had been sold for 1 million Kronas. The journalist stated that: 'there surely is loose money in this country' (DN/12/11/70_12). Similar articles were published later, with the difference that the prices had risen exorbitantly. For example, a similar article from 2010 on the most expensive items (this time Swedish Anders Zorn's paintings) at the Bukowski auction (DN/23/05/10_Kultur2) shows that this practice of cultural journalism was not restricted to earlier times.

It seems that in the case of unique and authentic objects of art, such as paintings and sculptures, the mentioning of price - if not the main or sole guarantee of their aesthetic value - does not diminish or destroy their value. The situation is different in 'heteronomous' fields of art that rely on the techniques of reproduction, often making the price of any single piece of art relatively cheap. To earn large sums of money, artists and authors must sell to large numbers of customers and find admirers among various kinds of people. This 'commodification' or 'massification' can diminish their authenticity and the aesthetic value of their work.

It is probably more common to refer to commercial success in relation to popular rather than highbrow culture. At the same time, this can raise suspicions about real aesthetic value. This is particularly true when the reviewer thinks that artists have mainly aimed at commercial success in their work. These comments can be found in Dagens Nyheter more commonly from editions of, for instance, popular music rather than visual art, such as in this contemptuous review of American singer Pat Benatar's concert: 'This is American club music. One can find thirteen such groups in a dozen in LA or NY. They are just as good as they are impersonal. Their attitude to music comes close to a car salesman's' (DN/03/11/80_20).

Thus, building on this idea of the rather blatant reporting of the prices of the visual arts and our argument concerning the differences in the relaxedness of the 
relationship between commercial success and artistic quality between classical music and pop-rock music (Chapter 3), it is possible to conclude that the question of commercialism and aesthetics is far from a simple opposition. To paraphrase Bourdieu, 'the markets of symbolic goods' might be 'economic world reversed' at the level of ideals of 'true' art, but in practice, the situation is more blurred. In most consecrated arts with their singular and unique artworks, with nothing left to prove to be recognized as legitimate art, the conflict between commercial and artistic values is more or less resolved (as shown in the case of visual art auctions). However, popular cultural products targeted to wide audiences (in fields such as pop-rock music or television) are still struggling with the pressures created by that conflict and the ideal-level opposition insofar as they are evaluated as striving for being considered to be genuine art.

\section{Commercial dimension in newspaper data: quantitative approach}

To assess the role of commercial aspects in data from newspaper culture sections, we can use a variable measuring 'commercial dimension' in a similar way as we used the variable of 'aesthetic dimension' in Chapter 3. The commercial dimension is defined as 'explicit references to money or other economic indicators'. ${ }^{1}$ Thus, the dimension includes not only references to the cheapness or expensiveness of something but also commercial success ('cash magnets', 'selling gold' or that 'something has attracted thousands of visitors'), commercial failure ('the making of a film turned out to be ruinous') or a real person's money ('the director was a millionaire'). Defined this way, by means of 'explicitly' commercial vocabulary, the commercial dimension covers topics from artistic prizes to the commercial success or failure of artists or cultural products. The obvious challenge is that, without any evaluative attribute, articles with a commercial dimension include both positively and negatively framed stories of commercial issues, from admirations of millionaire musicians to the lamentations of the economic struggles of highbrow arts. However, the code in any case provides us with the possibility to examine how profoundly present 'explicitly' commercial or money-related elements are in the journalistic content of culture sections. ${ }^{2}$

Table 5.1 shows how the commercial dimension varies in our data. The prominence of the commercial dimension increases only very slightly from the bottom level of 1960 and 1970; the vast majority of cultural content still ignoring it in the 2000s. The clearest increasing trend is in Le Monde - a fact that did not go unnoticed by Pierre Bourdieu in his frequent commentary concerning the increasing commercial elements particularly in Le Monde (see Bourdieu, 1998b). In 2010, the commercial dimension increased considerably in El País. Excluding Le Monde, the newspapers do not show clear trends. There are clear differences in the overall level of commercial content in the newspapers. Most importantly, Dagens Nyheter seems to have more explicitly commercial content 
Table 5.I Articles including commercial dimension by newspaper and year (percentages)

\begin{tabular}{lcccccccc}
\hline & 1960 & 1970 & 1980 & 1990 & 2000 & 2010 & Total & $(N)$ \\
\hline ABCIEI País & 13.7 & 9.7 & 17.4 & 22.0 & 14.3 & 25.6 & 16.6 & $(459)$ \\
Dagens Nyheter & 24.8 & 19.0 & 27.2 & 32.6 & 29.8 & 31.5 & 27.6 & $(695)$ \\
The Guardian & 5.8 & 17.2 & 19.4 & 16.1 & 17.5 & 15.4 & 15.1 & $(262)$ \\
Helsingin Sanomat & 15.0 & 16.3 & 19.8 & 17.7 & 23.3 & 15.6 & 18.0 & $(511)$ \\
Le Monde & 5.9 & 9.3 & 8.5 & 16.5 & 16.7 & 22.1 & 13.6 & $(260)$ \\
Milliyet & 1.1 & 14.1 & 2.2 & 10.8 & 6.2 & 5.6 & 6.3 & $(88)$ \\
Total & 13.6 & 13.9 & 17.0 & 20.8 & 18.2 & 17.9 & 17.3 & \\
$(\mathrm{~N})$ & $(200)$ & $(281)$ & $(261)$ & $(462)$ & $(558)$ & $(513)$ & & $(2,275)$ \\
\hline
\end{tabular}

Note

Total $N=|3| 6 \mid$, , of which 82.7 per cent $(n=10,886)$ did not include commercial dimension.

than the other papers. Perhaps even more strikingly, the Turkish Milliyet has published far fewer articles including a commercial dimension than other papers.

If the newspapers did not show particularly impressive trends when the commercial dimension is measured this way, what would the situation be like if they were scrutinized according to specific art forms? Table 5.2 shows whether the articles on art forms are dissimilar in the prevalence of commercial dimension and temporal trajectories. ${ }^{3}$

Again, there are no clear trends for specific art forms (on the contrary, the art forms show surprisingly strong stability), but the overall levels in terms of whether the articles include the commercial dimension vary significantly across

Table 5.2 Articles including commercial dimension by art form and year (percentages)

\begin{tabular}{lcccccccc}
\hline & 1960 & 1970 & 1980 & 1990 & 2000 & 2010 & Total & $(\mathrm{N})$ \\
\hline Popular music & 25.9 & 17.9 & 14.7 & 26.4 & 24.0 & 20.0 & 21.5 & $(293)$ \\
Classical music & 10.3 & 14.0 & 14.0 & 18.6 & 9.0 & 11.3 & 13.3 & $(156)$ \\
Literature & 20.5 & 15.5 & 16.3 & 16.3 & 16.4 & 17.1 & 16.9 & $(374)$ \\
Film & 12.8 & 11.7 & 18.4 & 22.7 & 26.1 & 24.1 & 21.0 & $(287)$ \\
Theatre & 11.7 & 10.7 & 16.6 & 13.5 & 20.5 & 9.3 & 13.2 & $(165)$ \\
Television & 12.2 & 9.5 & 25.0 & 25.9 & 9.9 & 15.2 & 14.7 & $(120)$ \\
Visual arts & 20.2 & 11.4 & 20.7 & 28.0 & 22.3 & 27.2 & 21.6 & $(163)$ \\
Other & 14.2 & 18.0 & 24.0 & 24.2 & 21.3 & 35.0 & 22.9 & $(567)$ \\
Total & 14.7 & 14.0 & 18.4 & 21.5 & 19.3 & 21.5 & 18.6 & \\
$(N)$ & $(195)$ & $(257)$ & $(252)$ & $(438)$ & $(521)$ & $(462)$ & & $(2,125)$ \\
\hline
\end{tabular}

Note

Total $N=|I, 4| 2$, of which $8 I .4$ per cent $(n=9,287)$ did not include commercial dimension. 
art forms. The only exception is film; articles on films began including the commercial dimension more often leading up to the 2000s; the proportion of articles on film including the commercial dimension doubled between 1960/1970 (around 12 per cent) and 2000/2010 (25 per cent). Articles on popular music, films and the visual arts include the commercial dimension most often. Articles on classical music, theatre and television include the commercial dimension least often. ${ }^{4}$

Figure 5.1 presents how commercial and aesthetic dimensions vary across European newspapers' cultural content during the years when reviews,

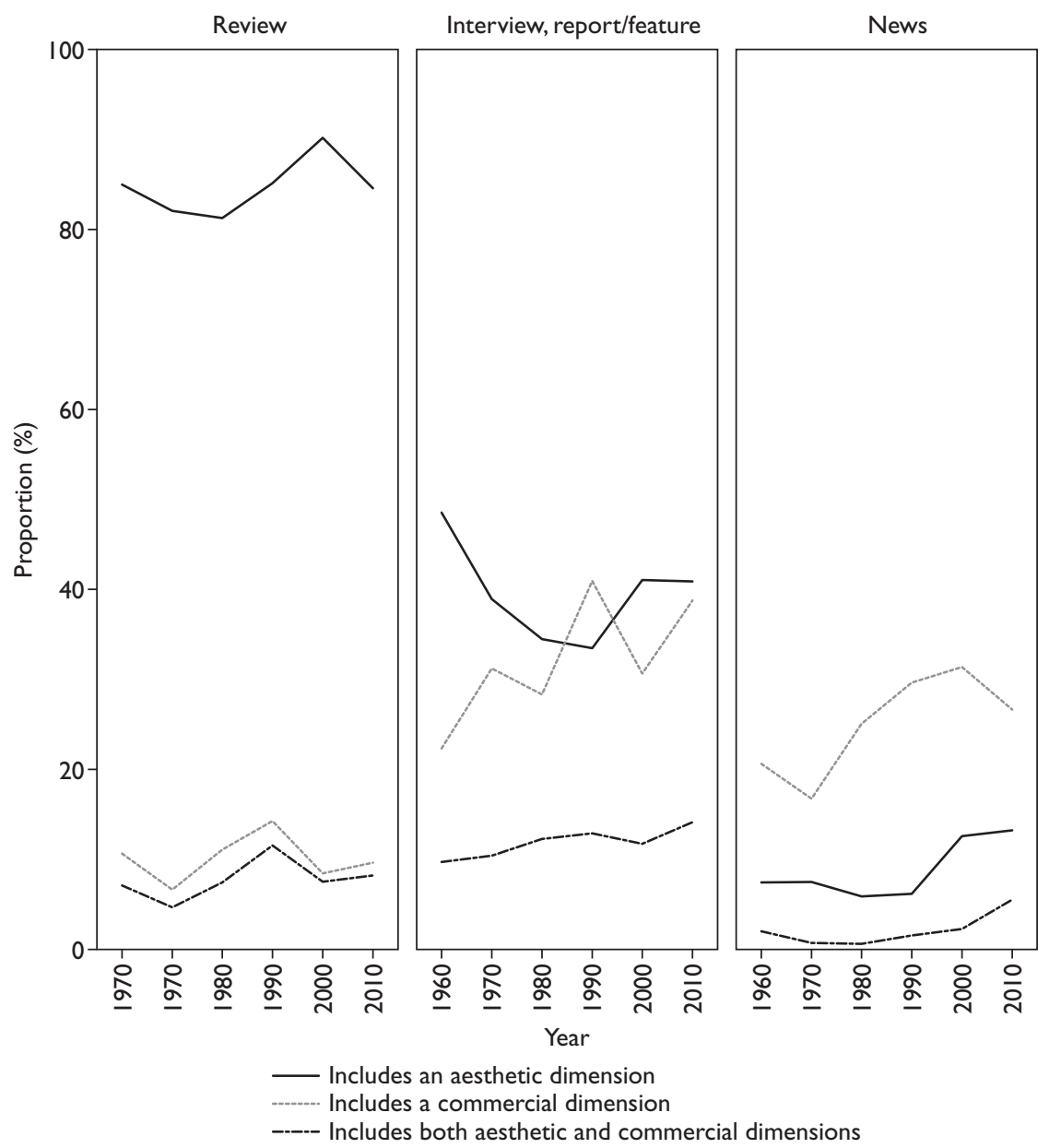

Figure 5.I Articles including aesthetic dimension, commercial dimension and both aesthetic and commercial dimensions by year, separately on main article types (percentages). 
interviews/reports and news stories are inspected separately. First, Figure 5.1 highlights the importance of article type. Reviews usually include the aesthetic dimension, interviews and reports include it sometimes and news includes it very rarely. The commercial dimension, in turn, is most present in profiles and reports as well as in news, and the trend is increasing towards the present day in both article types. Almost 40 per cent of all interviews and reports and almost 30 per cent of all news stories have included the commercial dimension since 1990 , whereas in the case of reviews, the proportion is only around 10 per cent and has remained relatively stable over the entire period. Finally, the proportion of articles including both aesthetic and commercial dimensions, arguably the most interesting articles from the point of view of how aesthetic and commercial elements (and possibly also evaluative principles) coexist and are interrelated, is expectedly the smallest category. From the main article types, this is the most prevalent in interviews and reports ( 12.2 per cent), followed by reviews ( 8.0 per cent) and news stories ( 2.2 per cent) of all news stories. While the proportion is stable in the case of reviews, in interviews and reports as well as in news, articles including both aesthetic and commercial dimensions have slightly increased. It is the articles including the explicit commercial dimension, and especially articles including it along with aesthetic evaluations, that will be analysed in more depth.

\section{The role of commercial elements in cultural coverage: qualitative approach}

Our original definition of the 'commercial dimension' led to several different manifestations of the topic in our data. In order to elucidate the content of our commercial dimension and obtain different perspectives, we formed a qualitative sample for close reading. The opposition between commercial success and consecrated art being one of the most salient and debated in contemporary cultural sociology, we chose to make a comparison between the expressions of the commercial dimension in two domains of music coverage, classical music and pop-rock, easily understood as Bourdieu's the 'two modes of cultural production, "pure" art and "commercial" art' (Bourdieu, 1993: 166). In addition, and to add another perspective from an increasingly commercializing cultural domain, we read all the cinema coverage from Le Monde. We are also keeping in mind, in line with our analyses in Chapters 2 and 3, that popular culture is in general developing around itself institutional frameworks and discourses that treat it in a similar way to the high arts and using the categories of codified, legitimated art. $^{5}$

While autonomy from commercial influences is usually understood to be one of the requirements of at least partial aesthetic legitimacy - for instance, Schmutz (2016) finds that the autonomous system of symbolic value that popular music has been able to foster has constituted its aesthetic legitimacy simultaneously with economic legitimacy - we expect to find similar dynamics 
in our data. For the qualitative analysis, we have closely read all the articles on classical music with a commercial dimension $(n=173)$ and all the articles on pop-rock with a commercial dimension $(n=206)$. All Le Monde articles on film $(\mathrm{n}=322)$ were closely read.

The qualitative analysis of this section differs from the one presented in Chapter 3 in many significant ways. While Chapter 3 concentrates on whether classical music coverage and pop-rock coverage increasingly resemble each other during the time-span studied (showing that there were signs of both popularization of the highbrow and legitimization of the popular), this chapter pays closer attention to the fundamental boundary that the 'legitimatization' discourse especially struggles with: the inevitable commercial side of (especially popular) music. The subsample used here, articles with explicit commercial dimension, is different from the subsample analysed in Chapter 3 and is used to accentuate the differences already found and bring new nuances to the discussion.

\section{Pop-rock and classical music coverage with a commercial dimension: cultural goodwill and tensions between art and money}

At first glance, classical music coverage with a commercial dimension seems to depart from an overly negative stance. Classical music institutions such as music academies are in constant financial troubles, and classical music events make perpetual losses that are later covered up by different public operators such as states and cities. Another oft-mentioned expense is the costly instruments that are discussed in many articles, usually in amazement: 'at least half a million' is the estimation of the value of a cello played in a 1990 concert by the Finnish orchestra players directed by the Polish conductor Penderecki (HS/24/02/90_ B3). Swedish opera singers are delighted when they discover that their salary will rise (DN/05/04/10_Kultur2). It is made clear that classical music is a costly domain, but these expenses are rarely questioned or further discussed.

Whenever there are many tickets sold for a classical music event, and especially when there has been a full house, it is usually mentioned in a highly positive light throughout the time-span studied. In a 1990 Le Monde article covering a three-day Bach concert, it is mentioned that the event gathered together an amazing 80,000 spectators (LM/01/02/00_34). Lack of audience and empty concert halls during 'good' concerts are highly lamented, usually not from the commercial perspective of creating economic losses but in a cultural goodwill tone that emphasizes highbrow culture as something that requires understanding and knowledge: 'There were no crowds at the unique event, there were several empty seats. I never remember our public being this incorrect!' (HS/31/05/90_B9).

From the 1990s onwards, there is a slight change in the neutral tone of commercial topics in classical music coverage: several articles regret that concert tickets are excessively expensive, and the rationale of the high price is questioned. After a concert of the Vienna Philharmonic, the dissatisfied reviewer of 
The Guardian posits, 'Yet where, you might ask, having spent $€ 60$ on a ticket, was the beef, the red meat of the musical experience?' (GU/02/11/90_37b). When the same orchestra played in Paris, the Le Monde reviewer paid attention in the same way to the exorbitant price of the tickets: 'It was enjoyable while regretting that ... the ticket price (from 180 to $700 \mathrm{~F}$ ) is inaccessible to most melomans' (LM/02/11/90_11). Clearly classical music has, since the 1990s, been losing its aura as a cultural domain totally outside of the sphere of economic exchange and becoming, at least partially, a consumable cultural good that the consumer is allowed to demand some quality from.

Money has slowly become a more visible topic in classical music coverage since the 1990s. There are articles on recording contracts and on billboard success; for instance, when Pavarotti's version of Nessun Dorma was used as the theme for FIFA's World Cup in 1990, The Guardian noted that it 'has propelled Pavarotti spectacularly up both singles and LP charts' and that the 'World Cup's most successful team' might not be Italy or West Germany, but Pavarotti himself (GU/26/06/90_37; see also Chapter 3).

In classical music coverage, in contrast to the accounts of pop-rock, the incomes or personal wealth of classical music musicians is barely even mentioned. One of the few mentions of the remuneration of artists is El País's comment that the Soviet pianist Sviatoslav Richter did not accept payment during his concert in Seville because he wanted to perform (EP/19/02/90_39). This is highlighted as a heroic fact, and it is a good example of the consecration of classical music to a level that it is, or cannot, be commercialized or is above attempts of banal economic exchange. In classical music coverage, popularity and success are treated mostly as guaranteeing artistic value rather than contradicting it (see Chapter 3); the fact that money is not emphasized fits perfectly with this discourse.

As shown in the quantitative analysis, in our newspapers, there are more pop-rock articles than classical music articles which include a commercial dimension. Apart from this numerical edge over classical music articles with a money-related aspect, the commercially oriented pop-rock coverage is by definition much more openly commercial than classical music coverage. While classical music coverage seems to dampen conversations on money and reduce them to comments on the prices of things or prizes received (see e.g. DN/11/02/10_ Kultur7), in the sphere of pop-rock, it is more common to talk about money.

Part of the prevalence of this topic is that, historically, the pursuit of economic legitimacy has been a central ideology of pop-rock music (cf. Schmutz, 2016). An apt definition comes from Le Monde in a 1970 article explanatorily titled " "Underground" y le pop-music', a short essay portraying the differences between these new music genres for the curious but uninformed reader.

Born four or five years ago, 'underground' is a voluntarily subterranean music, a music that is looking for new kinds of sonorous colours, driven by young Anglo-Saxon musicians who don't want to enter any system or to 
become commercial. [...] Some groups that for long have been situated in the frontiers of 'underground' become popular overnight (Chicago Transit Authority).

This quote is a good introduction to the conjectural dynamics of pop-rock music, a good, original or initially non-commercial enterprise that flirts with the borders of pop music but can quickly and unfortunately be sucked into the popular 'machine'. This fits Bourdieu's $(1993,1996)$ idea of the antagonistic 'opposite poles': small-scale 'real art' and originality and large-scale commerciality and the pursuit of quick economic profit. An excellent example of the limits between suitable and unsuitable commercialism and a harsh criticism of the American pop music industry (cf. Chapter 4) is an article on Wilson Phillips, the bestselling band comprising the daughters of Brian Wilson of The Beach Boys and of John and Michelle Phillips of The Mamas and the Papas. The article openly mocks the business-minded American AOR-style rock music: 'It sounds like Fleetwood Mac, Toto and Heart, though, regrettably, not at all like Aerosmith. The songs are by and large stately, medium-paced slabs of flotsam about love. Pretty awful material' (GU/31/05/90_24).

While economic success is an important topic in cultural pages, there is a much deeper level of significance underneath the surface. The most important and continuously recurrent theme found in commercially oriented pop-rock coverage is a discourse that acknowledges fully the inevitable commercial side of pop-rock music but concedes that money has only a secondary, instrumental role. In this vein, several pop musicians allude to that the profits they get from pop as merely an instrument for doing something more interesting and artistically fulfilling. For instance, members of the British instrumental rock band The Shadows, the third most successful act in the UK singles chart ever, comment in Dagens Nyheter: 'On the side of it [good record sales], we have the possibility of experimenting and doing lots of other stuff that perhaps isn't economically so giving' (DN/19/03/80_20). Muse, despite their record-breaking sales numbers and significant fan base are able to, in their own words 'still be an independent band' (EP/11/06/10_EP3_5).

These discourses have revealed that, although the implicit goals of popular cultural domains to become more popular and commercially successful, within poprock coverage, there is a widely accepted idea that making an economic fortune is not nor should be the obvious goal of anyone. According to this ideology, money is, at best, only an instrument and stepping-stone for being able to do interesting things. It is recognized as a sign of high legitimacy and artistic value to be able to operate between the commerciality and artistic value of art. Taken to the next level, artists who were thought to be able to take the best of both poles were openly praised in the articles (see also Chapter 3). These accounts of musicians that were successfully combining an openly lucrative attitude and still thought to make good music include, for instance, Kool and The Gang, one of 'those blessed 
representors of disco music that have been able to combine commerciality and music of a high standard' (HS/27/12/80_14) and Spanish pop singer Loquillo, who 'seems to be able to take rock to the casinos without losing his street spirit that saw the light in him ten years ago' (EP/14/05/90_38).

While commerciality seems to become legitimate when used in an instrumental way, in order to pursue artistically more revered values or when successfully combined with commercial success (e.g. maintaining originality and artistic values and having a high artistic level despite good sales), it is rarely received well if there is nothing more than commercial calculatedness in pop music. The 'pre-success' era of now bestselling artists is often remembered in a longing tone: 'How would their boogie potpourri sound in its original context, at a small rock club?' (HS/03/06/10_C2) asks the reviewer of Helsingin Sanomat after accusing the AC/DC concert in Finland of being too calculative, commercial, repetitive and therefore without any artistic value.

Finally, along with these legitimizing discourses of defending and accepting commerciality as an instrument for getting access to symbolically more valuable art, there has existed since the 1990s a strand of articles concentrating on the pop-rock music market (usually without referring to concrete names of musicians, though similar types of articles on music markets were published regarding classical music: e.g. GU/14/06/80_10). There is significant coverage of overt attempts to create new stars for the growing market. For instance, the new record label Muxxic Latina, launched by two mediatic megapowers in 2000, claims that it wants to be 'extremely selective when catching new talent and equipping them in order to make them flourish. Our work is not limited to recording them; we will also promote and commercialize them globally.' Attributes such as 'ability to see the market and capacity ... to capture new talents and launch them' and especially 'knowing the consumer's taste' are key factors in succeeding (EP/07/07/00_42; see also Box 4.2 on the Spanish music industry). As expected, artistic values are not discussed.

While money was more often and also more openly discussed in pop rather than classical music articles, our main finding is that commercialization is understood in radically different ways in the two different spheres of music. Classical music coverage utilizes a discreet tone when talking about money: commercial success is hardly ever expressed to be the explicit goal of classical music artists, insinuating that the value of classical music is intrinsically nonmonetary. By contrast, in pop-rock articles, money is a more common topic, and the pursuit of it is allowable at least to some extent but is viewed positively as an objective only in the discourses of interviewed entrepreneurs, not journalists. Instead, a discourse emphasizing the calculative commerciality of pop-rock is fostered, and 'true legitimacy' in this case was given to those who were able to skilfully use commercial profits received from pop music for pursuing artistically more valuable goals. Echoing the findings of Schmutz (2016), pop-rock clearly has its own sphere of symbolic value, but it is still overshadowed by commercial success, which is why overcoming this bridge is highly valued. 


\section{The case of French cinema coverage: the denial of the commercial}

Out of all the cultural domains covered, cinema was the only one that experienced profound commercialization between 1960 and 2010, and Le Monde was the only newspaper in which the commercial dimension grew notably over time. In 1960, none of Le Monde's articles on film had a commercial dimension; in 1970, 5.4 per cent did; in 1980, 8.9 per cent did; in 1990, 13.8 per cent did; in 2000, 24.4 per cent did; and in 2010, 25.9 per cent did. For this section, we read all the cinema coverage from Le Monde, without distinguishing whether it had commercial dimension.

In the 1960s, there were few cinema reviews, and evaluation was in general very scarce. The few examples show that film evaluation did not differ much from that of other art forms:

I thus saw again Le Passage Du Rhin. Yet, there was no surprise. Not a good nor a bad one [...] a solid, honest, in many ways seducing film, that was a little bit too systematic to earn my full acceptance.

(LM/10/11/60_12)

From the 1970s onwards, film reviews became longer and more detailed but did not change significantly in style. A good example is the 1980 review of American Gigolo, which could have been from any year: 'As the dark and incredibly sparkling John Travolta corresponds to the image that the American public has on "Latin lovers", he was originally supposed to incarnate the hero of this film - a man who lives from his charms' (LM/14/06/80_31). Early in the review, commercial factors are brought to discussion: 'But the box-office has its demands, and after having ended up as a victim of a stinging failure (Moment to Moment), Travolta had to give up his role to Richard Gere' (LM/14/06/80_31).

The close reading revealed a feature not observable through the quantitative data, namely, the content of the possible aesthetic dimension; without going back to the articles, we would not know whether the aesthetic evaluations would be positive, negative or something in between. In the case of the cinema coverage of Le Monde, the relationship of the film genre to the tone of the evaluation is usually extremely clear, and popular movies usually get negative reviews. For instance, a review on Michael Anderson's sci-fi mini-series Chroniques Martiennes uses harsh words: 'What is there left, in this film, of the admirable book of Ray Bradbury?' (LM/01/01/80_9). This tendency resists time: even in 2010, the evaluation aspect is essentially the same, with the difference that titles and subtitles of reviews have become longer and more explanatory and movies are given stars, from 3 ('excellent') to 0 ('to avoid').

In Le Monde, cinema has since the 1960s been accepted as highbrow culture without need for specification; for instance, famous critics are asked to write essays about it. In 1970, Le Monde wrote a lot about the originally uniquely 
French Union Générale de Cinematographie (French National Film Union) being sold to private investors. Le Monde expresses clearly and ferociously its indignation at this, fearing that film production would become less legitimate and that, in an alarming possible new spirit of commercialization, there would be fewer quality films.

In the 1980s, the legitimacy of the film sections of Le Monde was in its heyday: mostly acclaimed 'quality' directors (e.g. Mankiewicz, Fassbinder, Mizoguchi) were discussed, and several art film festivals were covered. References to Cahiers de Cinema, a highly legitimate film review, are common, and the academic writing style for cinema in Le Monde is crystallized by the use of footnotes. In general, the cinema coverage of the 1980s in Le Monde comes in many cases close to philosophical essays and highly sophisticated discussions on the interpretations of films.

The very highbrow tone of the film sections of the 1980s is further corroborated by explicit mentions that some movies, despite being worthwhile in their own genres, are popular ('If we had in Europe an equivalent for the American B class movies, Rosy la bourrasque would be a dream come true', LM/24/08/80_9). There are purely negative reviews on popular films, for instance, Quadrophenia, which is criticized in an almost moralistic tone for showing violence and drugs, and some early product placement:

In the week following the première of Quadrophenia, in England scooter sellers were out of stock, and there was not a single parka coat to be found in London. [...] The film classification board has forbidden this movie for minors in France. It was the right thing to do.

(LM/04/04/80_20)

After several truly legitimate and non-commercial decades in Le Monde film coverage, in the 1990s, more popular cinema started to appear in Le Monde: thrillers, Scorsese movies and so on. Still, the highbrow-oriented style did not change too much. While the themes and movies covered became more popular, the tone did not change, and there was a clear, implicit expectation of a cultured, non-commercially oriented reader. There was a strong demand for quality, for instance, in the following review of an American horror movie: 'In the end, we don't know if we should be thrilled that Hollywood leaves so much creative freedom to a young director or to mourn the obligation of narration and entertainment imposed to a creator who surely knows better' (LM/18/10/00_37). Phenomena such as popularization and Disneyization are heavily criticized, for instance, in this review on Disney's Tangled (2010) lamenting the fact that this film is another banalized version of a classic, now simplified for the masses: 'Among the great classics of children's literature, Raiponce (in German Rapunzel, after a popular tale by the Grimm brothers) was one of the few ones not having been integrated into Disney's repertoire.' Later in the review, the outcome is sneered at ironically: 'The result is a movie with capes and swords 
in which the blonde hair serves as a liane and a bridge, having given animators the chance to have fun with 3D. Let's hear it for "Disneyzation"!' (LM/17/11/10_23).

Finally, and as a conclusion to the qualitative close readings, it looks as if the most popular and commercially driven cultural domains, in this case cinema and pop-rock, have had to fight the hardest to gain artistic affirmation and legitimation. Motti Regev discusses the relationship between pop-rock and commerciality in the following way:

At its extreme ideal-typical form, the notion of autonomy in art relates to a situation in which creativity is performed regardless of practical, utilitarian, or any other not purely aesthetic consideration. In the case of pop-rock's aesthetic ideology this means, most importantly, autonomy from commercial interests and market demands.

(Regev, 2013: 72-74)

This captures well the aspirations of the pop-rock and cinema journalists to reward artists displaying the right kinds of attitudes towards commerciality: the importance of creativity over other aspects and the sometimes inevitable and acceptable role of money, if combined with suitable ingenuity and talent.

\section{Box 5.2 Indisputably commercial: the case of the Spanish music industry}

When looking at the commercial dimension of culture, there are interesting elements that deserve further analysis. One example is the development of an interest in the business side of art, meaning that culture sections not only highlight specific commercial elements of the artistic product (the price of assisting an event, purchasing a record, etc.), but also focus on corporate policies and industry strategies. This interest has been particularly strong in Spain, especially in the 2000s, when culture sections suddenly started publishing increasingly businessoriented coverage. Given the fact that Spain is, in economic terms and with the exception of Turkey, the country with the lowest GDP per capita of the national contexts studied, it is relevant to explore why the interest in cultural industries is so strong.

Spain has experienced a notable economic boom since its transition to a democracy in the mid-1970s and joining what is today the European Union in 1986. After a brief economic crisis in the 1990s, substantial economic reforms helped it to join the Euro in 1998. The economic growth during the 1990s (the times of 'Smiling Spain') was strong and led to a certain euphoria shared by both the neoliberal-inspired government and the biggest firms. This led to a wider interest in business news evident in El País. While El País was considered to be politically close to PSOE (the social democratic party of Spain), the outlet was part of a wider corporation called PRISA, a media conglomerate not immune to the zeitgeist of the moment, especially since it made an entry to the stock market 
and started diversifying its business interests. PRISA not only purchased several publishing companies but also invested heavily in the television sector. In the mid-1990s, it started an aggressive expansion in Latin America (see Box 4.2), and not unsurprisingly started to use the newspaper as part of its marketing strategy.

Therefore, the corporation became a source of news itself. However, it is in the field of pop-rock where the proliferation of news that emphasizes the 'economic dimension' of music is more noticeable: news in which multinationals, phonographic companies or PRISA have a leading role, as their mergers and agreements help to increase market shares, the globalization of music in Spanish and so on. For instance, a long article discusses in detail the agreement between PRISA and Universal to promote Spanish-language artists through a record company (Muxxic). The illustration includes a number of executives sitting around a table, giving a vivid impression of a business atmosphere, and the text is different from other coverage found in culture sections:

Universal owns the music corporations Decca Record Company, Deutsche Grammophon, Polydor, Universal Records and Philips, among others. The PRISA Group - present in over 20 European and American countries with a major role in the publishing industry - will hold exclusive rights to exploit and commercialize the products in Spain.

$\left(\mathrm{EP} / 07 / 07 / 00 \_42\right)$

Of course, industry interests go beyond PRISA. For instance, there is an article about how SGAE, the controversial Spanish Society of Authors and Editors, has created a foundation to expand their business operations in the world, made agreements with a television channel and developed new strategies to commercialize Spanish music internationally (EP/26/01/00_46). Purely international industries are also covered: when Apple purchased the Beatles catalogue for iTunes, not only are the details of the operation described, including the previous conflicts between the corporation and the band, but also the benefits for the consumer downloading the songs ('you can create a compilation') (EP/17/11/10_38). This emphasis is strong from the 1990s onwards, showing a clear trend towards commercialization. Even when covering a festival (EP/17/12/00_42), the amount of money donated to charity is pointed out as a success and as a natural result of a great show.

Another critical element is the Spanish language and Spanish 'branding'. There is a strong emphasis on the importance of a language that is widely spoken and a country well known because of its culture, traditions and tourism. The success of the Barcelona Olympic Games and the Seville Expo to promote a modern image of Spain is supported by additional marketing strategies. For instance, there is an article on how Mick Jagger promoted Spain through a video, mentioning who is involved (managers, companies, etc.) and discussing the profits for Spanish culture (EP/31/05/90_43). The reader gets the impression that the interest in Spain and Spanish is huge, and therefore articles end up discussing everything from the prospects of Latino artists in the Grammys following the nomination of Santana (EP/01/02/00_41) to the challenges of Spanish pop abroad. The debut album of 21 Japonesas with a British recording company is perceived as an important event (see EP/26/06/90_37), with the band members claiming that this proof that 'Spanish music is becoming something to trust in' and justifying 
how the authenticity of music can benefit from association with a multinational business.

In sum, the marketing strategy of PRISA, reinforced by a pro-business environment, led to a magnification of the business side of art in the media, particularly in the field of music. This was evident with the rising number of different contests and events, many with prizes, accompanied by public and private investments, emerging start-ups and so on (see EP/07/01/90_28). Despite the later economic crisis, this pro-business atmosphere is still present in the culture section of El País, though the misfortunes of PRISA, mostly the result of excessive debts and poor management, have minimized the presence of the conglomerate in cultural industries.

\section{Advertising as another aspect of the commercial dimension}

Apart from the editorial content of newspapers, there is a substantial amount of non-editorial content, comprising mostly commercial advertisements. Advertisers are at the heart of what Bourdieu (1984: 324) calls the 'new cultural intermediaries', central for constituting taste milieus (cf. also Featherstone, 1991). Advertisements, assigning different values to distinct cultural products and making them desirable for potential consumers, are definitely part of the general 'cultural package' of contemporary newspapers (Janssen and Verboord, 2015).

Advertisements, of course, serve to create desire in potential consumers and to ensure the purchase of the advertised goods. In modern advertising, the product is named and 'transformed into a representation' (Falk, 1997: 66) for making it look appealing. In modern capitalism, mass-produced goods have to be sold to the market, and advertising helps this happen. Sociologists, though, have found other latent functions of advertisements: advertisements are not aleatoric images of selected goods but carefully designed idealizations of desired social life (cf. Goffman, 1979). It is for this reason that advertisements constitute a good base for studying cultural and social valuations of specific contexts.

Modern advertising started around the mid-twentieth century; before that, advertisements were closer to classified advertisements or announcements, for instance making known the availability of a specific product or the possibility of seeing a specific play. It was not until the age of mass production and mass culture that advertising started to play an important role, first in newspapers and later in other mass media such as television (Bourdieu, 1996). The increasing focus on advertising is of course also linked to wider macro-level transformations, most of all a turn towards a consumption economy as an organizing principle of society. In our era of disorganized capitalism, traditional mass culture has been transformed into differentialized market segments with aesthetically competent consumer-citizens and highly individualized forms of marketing and consuming.

Although the most significant changes happening in advertising are probably taking place in the audio-visual media instead of traditional display advertising 
in 'old media' such as quality newspapers, magazines and outdoor advertising (cf. Falk, 1994), it is clear that advertisements have been and still are part of the (post-)modern flow of images. For this chapter, two randomly chosen weeks from each year and each newspaper were selected, and all proper newspaper display advertisements (so-called 'classified advertisements' were left out) appearing in the culture sections were collected for examination. The total number of culture section pages scrutinized is 1,991 , and the final advertisement data consists of 2,799 advertisements. ${ }^{6}$

For Figure 5.2, we scrutinized all the newspaper pages collected for the advertisement data and observed whether journalistic coverage or advertisement

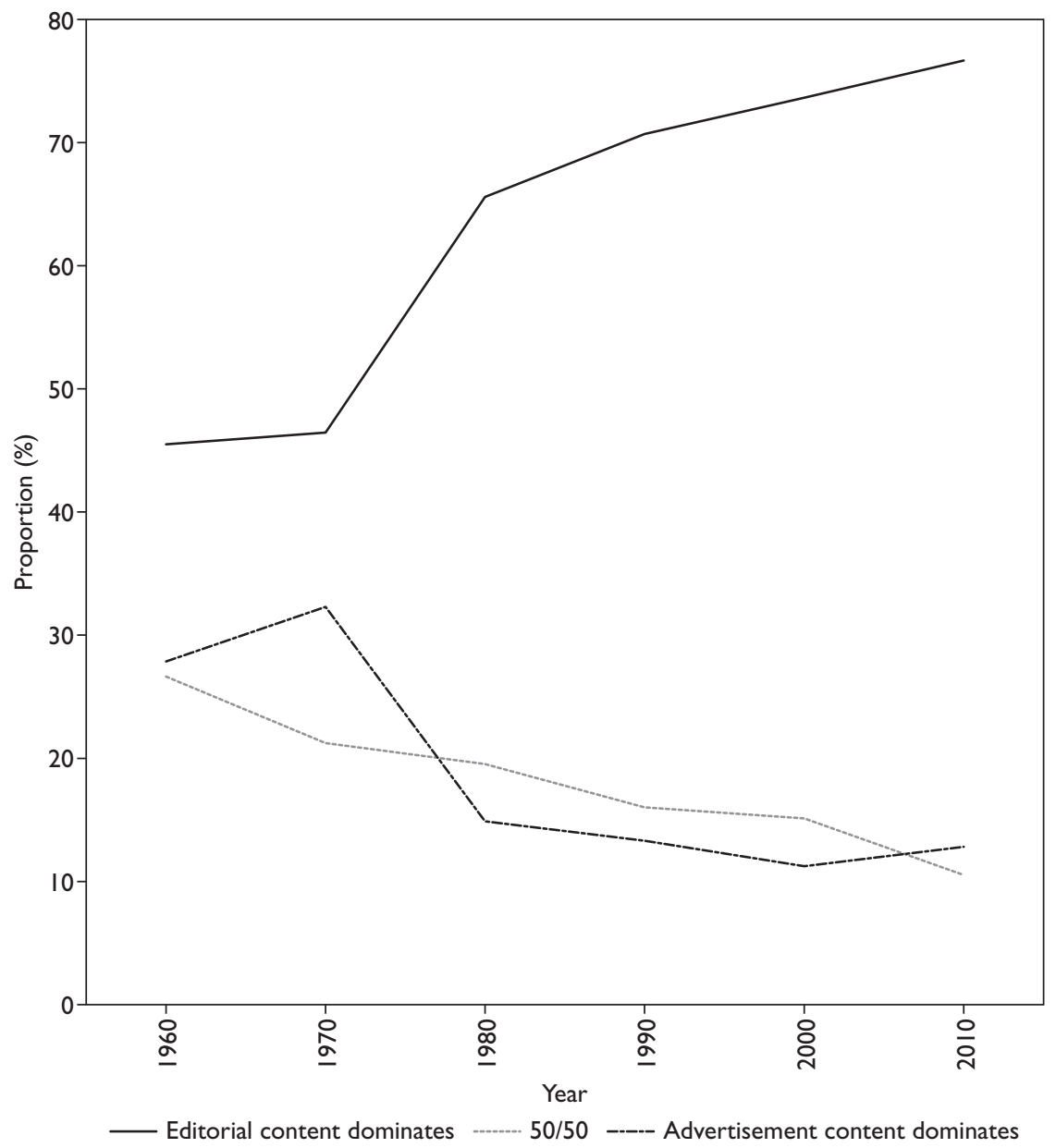

Figure 5.2 The main content of the page in culture sections by year (percentages). 
content was dominating. If the page was more than half journalistic coverage, it was coded as 'journalistic domination', and vice versa. We can see that, with the exception of 1970 , there is a clear trend of journalistic content beginning to dominate advertisements. While in 1960 less than half of the culture section pages were dominated by editorial content, in 2010 almost 70 per cent of the culture section pages did. Another interesting case are the fifty-fifty instances, in which the amounts of editorial and advertisement content are similar. While in 1960 more than a third of culture section pages were in this category, less than one-fifth were in 2010. All in all, editorial content dominates more frequently, and culture section pages have turned from advertisement-dominated towards being journalistically oriented. The result thus contradicts claims that editorial content would have been replaced or outnumbered by advertisements in culture pages (see e.g. Hallin, 2005).

Figure 5.3 shows the recoded topics of all the advertisements scrutinized. The topic was first coded into eighteen categories (see note 6 of this chapter), but then recoded into the following four: culture and education, personal wellbeing, household products/food supplies and luxury/economy. The total number of advertisements decreased between 1960 and 2010; there is thus expectedly no absolute growth in any of the categories. In relative terms, though, differences accentuate. Culture and education advertisement (comprising advertisements of cultural events, education and courses, instruments such as pianos and finally cultural objects such as books or records) is in general largest category and dominates in most years, but it gained a substantially bigger proportion between 1960 and 2010 (although facing some decrease between 2000 and 2010). Personal well-being (medicines and vitamins, clothes, cosmetics and sports and well-being) is the category that lost most ground, shrinking to less than 10 per cent in 2010 from more than 20 per cent in 1960 (facing again a large change between 2000 and 2010). Among the original variables, medicines and vitamins and cosmetics faced large decreases, starting at altogether almost 10 per cent of all advertisements in 1960 and ending up with 0.3 per cent in 2010. The household/food supplies category, including mostly advertisements on food, alcohol and cigarettes, cars and other vehicles, housewares and entertainment electronics, likewise decreased, again with a remarkable shift between 2000, marking a milestone decrease from 24 per cent to only 10 per cent, and 2010, lifting the proportion back to 19 per cent. The luxury and economy category (advertisements for expensive products such as watches or jewellery, flats and real estate, economic services, trips or employment positions) faced mild but not remarkable growth.

The main conclusion to draw is that, since the 1980s, advertisements related to culture dominate clearly, with a majority or about half of advertisements. This can be taken as a sign of consolidation of culture sections and that the majority of advertisements published in culture sections are about culturerelated products. It is increasingly rare, therefore, that the advertisements in culture sections are unrelated to the manifest themes of its journalistic content. 


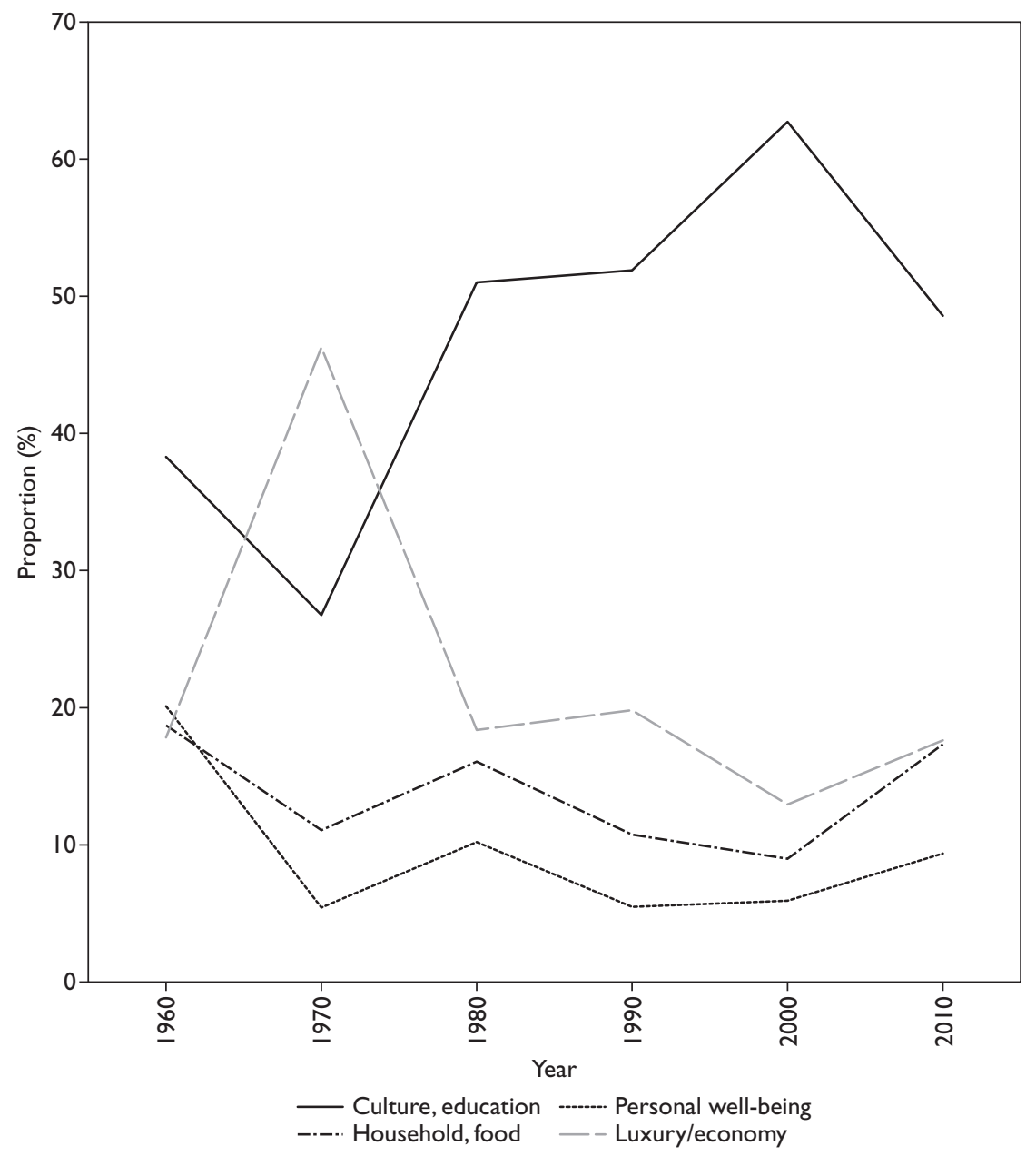

Figure 5.3 The topics of advertisements published in culture sections by year (percentages).

During the golden age of newspaper advertising, the twentieth century (Picard, 2008), newspapers were a valuable and extremely profitable advertising channel. With the decreasing circulation numbers of traditional print press and the advent of digitalization and several competing advertising media, what can be expected from the future? Berte and de Bens (2008) raise challenges but also opportunities: new possibilities are mostly connected to the plethora of new formats, the combination of mass market and smaller niche audiences, and general synergy with the Internet. 
Our key findings from the advertisement data are clear: the relative number of pages with more editorial content than advertisement content grew substantially between 1960 and 2010, and the topics of the advertisements placed in the culture sections, still a heterogeneous mass in 1960 and 1970, became influenced by the topics present on the pages, revealing that when it comes to advertisements, the cultural pages have actually become more cultural and codified.

\section{Conclusion}

In this chapter, we have focused on the fundamental tension between art and money by using our quantitative measure of commercial dimension, close readings and finally a specific dataset on advertisements and have shown that the tension is strong and lasting but that its characteristics change over time and according to the cultural domain. We have seen that between 1960 and 2010, the commercial dimension was more or less always present, growing only slightly. Out of all art forms, popular music, film and visual arts articles stand out as having more commercial mentions than other domains. Film is the only art form in which the coverage had a significant increase in the commercial dimension.

However, the quantitative analysis does not tell the whole story of the commercial dimension. This is why we constructed a qualitative sample on articles with commercial aspects; more specifically, we read all the classical music and pop-rock music coverage with commercial dimension. We found that articles from these two opposite poles, the former tied to formal and consecrated highbrow art and the other to more commercial values and less formal consecration, had somewhat different systems for talking about money. In classical music coverage, the discourses on money first tended to focus on the expenses of making it (especially in a negative tone, emphasizing the costliness of instruments and tickets, and lamenting empty audiences) and only from the 1990s onwards mentioning things such as sales figures and the possible profits for the musicians. By contrast, the mentions of economic factors in pop-rock music coverage focused much more on the openly commercial aspect of making music since the beginning. Nevertheless, the relationship of money to pop music is far from uncomplicated: openly commercial pop music projects are deemed dubious, and true artistic legitimation was offered only to the artists that had the skills to both make money and use it for 'higher' purposes. The ideal pop musician, at least from the 2000s onwards, is one for whom money means, at most, a possibility to pursue real artistic consecration.

While the quest for authentic 'aesthetic autonomy' goes hand in hand with a rejection of commercial success, cultural domains such as cinema have been able to acquire legitimacy despite the fact that they have an intrinsically commercial side to them (cf. Schmutz, 2016; see also Chapter 3). In our reading, neither classical music nor pop-rock music was free of commercial constraints: while classical music coverage shows increasingly more tolerance to openly commercial pursuits, pop-rock music and cinema coverage struggles with its 
explicit commercial nature and is very critical of openly economic interests, allowing legitimacy only to enterprises with pursuits other than commercial ones.

The results of this chapter are an essential addition to the general shift of the cultural legitimacy hierarchies we are witnessing: while highbrow arts face a decrease and popular culture an incredible increase in culture sections, this rearrangement is in no way unproblematic. Popular culture coverage, pop-rock and cinema in our reading, has to force its way through the boundaries of the legitimate, proving that it has the right attitude towards commercialization. As the commercial dimension inside the journalistic content is increasing, explicit talk of money is very much influenced by a quest for and idealization of artistic, non-commercial legitimacy and the idea that unconcealed and bold pursuit of economic profit is not desirable. At the same time, the presence of advertisements is decreasing, and the topics of advertisements are more and more often cultural products and services, content that is very close to what is already present in the cultural pages. Instead of a fierce and out-of-control commercialization, we are witnessing a trend of consolidation of the cultural pages.

On a larger scale, commercialization is essentially part of the general heterogenization or 'opening' of legitimate culture. A point of view on this is offered by Bourdieu, who points out in an interview that, as a mediator (or 'ombudsman') the journalist has to serve readers who themselves are aware of the growing importance of commercial orientations, on the plea of openness:

To those who, after the publication of an interview with a fading pop star by an insipid writer, I complain that Le Monde is 'drifting into a kind of demagogy', he can only reply, in the edition dated 18-19 January 1998, that his paper is 'committed to openness': 'These subjects, and others', he writes, 'receive extensive coverage because they shed useful light on the world around us and because, for that very reason, they interest a large section of our readership'.

(Bourdieu 1998a, 71-72)

In the end, the culture sections are obliged to remould themselves to the cultural, socio-historical, commercial and political conditions of the context: 'journalists are structurally condemned to produce - variably, depending on the period and outlet - under political and/or economic constraints' (Champagne, 2005: 50). In the next chapter, we shall see how the political context can profoundly shape newspapers and their cultural coverage.

\section{Notes}

1 However, the possible mentions of exact prices of cultural products given elsewhere than in the body text of the article were excluded. For instance, if the bibliographic reference given at the end vignette of a book review was accompanied by the official price of the book, that was not counted as a commercial dimension. But if the price 
was mentioned and commented on in the body text of the review, it was included as a measure of commercial dimension, for instance, the amounts of money mentioned in connection with artistic prizes.

2 See note 11 (Chapter 3).

3 As Table 5.2 uses art form classifications sensitive to the Western highbrow/popular distinction, Milliyet has been excluded from the analysis. This applies also to the qualitative analysis and the analysis of advertisements of this chapter.

4 At first glance, it may sound surprising that articles on television include the commercial dimension relatively rarely, but one has to remember that public service broadcasting has dominated the television markets in most of Europe, especially during the earlier decades of our research period, and commercial television has made its breakthrough only in the 1980s and 1990s (e.g. Hellman, 1999).

5 See also, for example, Baumann, 2001; van Venrooij and Schmutz, 2010; Janssen et al., 2011; Regev, 2013; Schmutz, 2016; and Varriale, 2016.

6 In the case of $A B C$ and The Guardian, we use only one $(A B C)$ and three (The Guardian) constructed weeks. All the advertisements selected for the sample were first coded into an Excel matrix and then transferred to SPSS for analysis. In total, the coding system included thirteen variables. Here we use the following variables: domination of editorial content/advertisement content and topic of the advertisement. The domination of editorial content/advertisement content was likewise coded into three categories: editorial content dominates, fifty-fifty, and advertisement content dominates. Whenever the ratio was not clear, the sizes of the sections were measured and compared. The topic of the advertisement was coded into eighteen categories: cultural events, education and courses, cultural products, medicines and vitamins, clothes, cosmetics, sports and well-being, food, alcohol and cigarettes, cars and other vehicles, home, entertainment electronics, expensive commodities, flats and real estate, economic services, trips, jobs and positions and other. 


\title{
Beyond culture
}

\author{
Politics and the role of culture in a \\ wider socio-historical context
}

\section{Introduction}

What elements shape cultural hierarchies throughout time? While studies on cultural stratification have widely emphasized the importance of the rise of new consumers of culture, whose range of taste is significantly wider due to new values that highlight the importance of openness, tolerance and omnivorousness (Peterson and Kern, 1996; Bennett et al., 2009), and the role that institutions (including newspapers) play in providing a framework to rank different cultural goods (DiMaggio, 1991; Janssen et al., 2008; Daenekindt and Roose, 2015), there has been substantially less work focused on the ideological contexts that may also help to shape such hierarchies (see, however, Cvetičanin and Popescu, 2011; Purhonen and Heikkilä, 2017). This is not strange once most of Western Europe and the United States have enjoyed liberal democracies where freedom of press was guaranteed by the nature of the political system, helping to spread ideas, fashions and tastes among different audiences of society with barely any interference from public powers (with the exception of public funding). Certainly, in democratic societies, there might be occasional public scandals that involve the banning of specific works of art (the censorship of certain films, for instance), but, in general terms, the public should find no other limits to access culture rather than market constraints and shortcomings in terms of funding. However, the zeitgeist in the political sphere might raise interest in specific cultural manifestations rather than others; public funding might be influenced by party politics and audiences of newspapers are commonly segmented by ideological lines. Newspapers and their culture sections, even in democratic societies, develop a specific editorial line and policies.

All these elements make it worthwhile to explore the interrelation between the cultural content in our European newspapers and their political background, as power relationships, party constellations, governments, public funding of art or market trends and fashions might influence notably the cultural hierarchies of a country. Moreover, politics might be even more influential in the cultural realm in environments where democracy is absent and autocratic governments follow a nationalist or ideological doctrine. After all, in most of Southern and 
Eastern Europe, the turn to democracy can be still considered a relatively recent event. Before the arrival of parliamentarism, many European countries were ruled by authoritarian governments whose approach to the cultural sphere rejected free speech and banned certain ideas and art movements, aiming at engaging populations with the core ideological beliefs of their regimes. In this sense, the famous motto of 'art is not a mirror but a hammer' was widely used by these regimes to frame and shape political views through art manifestations, the coverage of legal newspapers being relevant to this propaganda.

Therefore, views on culture and art are particularly influenced by social and political context. Models of governance, hegemonic ideologies and power relations within different societies can all shape a wide range of cultural policies and build specific cultural hierarchies where socio-geographical boundaries might be very relevant (Fishman and Lizardo, 2013). National culture is, in this sense, also the product of a specific cultural milieu where a set of national customs, practices and traditions build national artistic products, and newspapers help to establish the boundaries and features of such art. Art and the ways it is represented in the media can be an important aspect of nationbuilding and enhancing national identity (see Box 4.1). However, the role of arts reviewing and newspaper cultural coverage in the interplay between culture and politics has often been ignored (cf. Hallin and Mancini, 2004; Riegert, Roosvall and Widholm, 2015).

This chapter highlights the important connection between culture and politics through our European newspaper data. We aim to answer two main questions. First, how does cultural coverage in quality newspapers reflect political and social issues in a society? Second, how have evaluations and their aesthetic criteria employed in culture sections changed throughout time against the background of socio-political events and structures? Even more importantly, in this chapter, the core idea is to point out and track the connections between cultural coverage and the specific socio-historical context of each national case and time point, including two examples of how the political context influences the ideas of national identity. In this sense, we will explore two specific cases that have stood out in our research: Francoist Spain, whose later transition to democracy shaped drastically the views on how national identity is constructed, and Turkey, with its challenges on national identity derived from its process of Westernization. Before going into these cases, the chapter opens with an overview of the theoretical stakes of the problematic relationship between art and politics, after which comes a section analysing the articles including the explicit political dimension in our entire newspaper data.

\section{Artistic valuation and politics: a complicated relationship}

When studying different fields of cultural production and arts, sociologists have sought to understand to what extent the evaluations follow the motto of 'art for 
art's sake' (i.e. arts seem to be 'free' and relatively autonomous, organizing an individual field; see Bourdieu, 1996) or are constrained instead by some contextual realm that could be related to politics (Adams, 2005) or other aspects of art production (Becker, 1982). This is far from a new debate. As already pointed out in Chapter 5, this traces back to the Age of Enlightenment, but, at least over the last hundred years (e.g. Lukács, 1971), discussions among scholars of literature and fine arts about the possible political imprints of different art objects have become ubiquitous. It is important to distinguish between philosophical questions and the sociological approach - the latter exploring the relationship between art and politics empirically. Bourdieu, for instance, approached the relationship between art and politics with the concept of field, which allowed him to analyse and empirically define the structure and properties (positions, actors and power relations) within each field and, importantly, to pose the question of the relationship and struggles taking place between the fields (Bourdieu, 1996, 2005). The crucial stake in all fields is its relative autonomy from other fields and influences, which already brings the question of the relationship between the fields (e.g. the art field and the field of politics) to the core of the analysis. In stark contrast to the sociological approach, one position in contemporary debates in aesthetic theory is to question the fundamental starting point of art and politics as separate entities that could have a relationship in the first place (e.g. Rockhill, 2014).

However, there has been less research on the question of autonomy of the arts in newspaper cultural coverage and on whether politics might set limits or actually frame artistic evaluations (see Riegert et al., 2015). This involves unveiling the signs of such political interventions and identifying how different elements, such as censorship, expectations, ideals, norms or political correctness, might influence the way art is discussed, reviewed and selected for reviews. In non-democratic societies, censorship is the norm, but in democratic societies, ideals, cultural norms, interests, expectations and political correctness might play an important role in framing how art is reviewed (from the selection of cultural objects to the criteria to judge them). In this sense, studying the political involves exploring other dimensions that threaten the autonomy of art, in the same way as we previously examined commercialization (Chapter 5).

Moreover, as Adams (2001) claims, there has been a lack of studies examining the role of international and national political contexts of art fields. Adams $(2001,2005)$ provides a detailed review of literature that has focused not only on the nature of the state and the state's policies as a source of change in art but also on how art is expressed in authoritarian contexts, from both government and opposition perspectives. However, while artists, intermediaries and buyers can become catalysts of change, it is challenging to take these issues into consideration when looking at newspaper cultural pages. Evaluations by critics and journalists published in the media such as quality newspapers exercise a specific power of recognition, which is distinguishable from other types of recognition and creation of symbolic value, such as professional (e.g. awards) and 
popular (e.g. box office) recognition (see Bourdieu, 1993; Kersten and Bielby, 2012; Schmutz, 2016). Under these conditions of recognition, critical and popular recognition might appreciate positively any kind of critical political content that is developed under authoritarian regimes. However, those subversive pieces tend to be actually discussed in democratic periods when the change of political regime permits a re-examination of art forms (Cushman, 1995; Szemere, 2001). Moreover, not all repressed art is political; some might not even belong to the sphere of the subversive (Goldfarb, 1980). In any case, the critical point is that, in authoritarian regimes, only pro-regime art is discussed, with occasional exceptions (usually world masters whose legacy cannot be fully ignored, such as the case of Picasso, whose legacy was discussed (albeit dismissed) during the Franco years in $A B C$ ), whereas in democratic periods, repressed art is vigorously vindicated. ${ }^{1}$

Propaganda can be a tool for authoritarian states to increase their support and legitimacy (Bonnell, 1997) and strengthen support and adhesion to the state, but it also contains factors that help to hold together democratic societies. Certain forms of art can be essential to frame specific political movements, such as songs in civil rights movements (Eyerman and Jamison, 1995), and some might be even linked to nation-building. An additional question is whether politics or the political content of art is considered to be 'good' or 'bad' for cultural products when making aesthetic judgements. In other words, one can ask, first, whether a politically normative (often subversive) dimension is relevant at all to (or intertwined with) aesthetic judgements, and, second, whether it is appreciated by reviewers (whether having such dimensions elevates legitimacy and reception of the cultural product). In fact, a recent comparative research on 'quality TV' discourses in Flanders and Israel hints at the role of political content in cultural legitimation (Lavie and Dhoest, 2015). The main finding was that: 'the view of political critique as a sign of quality is much more prominent among Israeli television reviewers than among their Flemish counterparts, who seem to highlight more "universal" social themes at the expense of direct political engagement' (Lavie and Dhoest, 2015: 72). It seems that political content does affect the process of legitimation, but the question of which cultural fields or national contexts are more open to political influence is awaiting empirical attention. It is also important to note that not all politics have to do with political power, parties or ideologies, and the realm of the political might not be that obvious: there is a commercial dimension that might be intertwined with aesthetic and political remarks, and that deserves to be explored (Chapter 5). Connections with specific industries might also be political in a sense, for instance Hollywood movies and the role of the United States in the world (cf. Chapter 4). There are also dimensions of the political that might be linked to gender issues and everyday life practices, such as the presence of kids' culture (which, in our data, is more abundant in Nordic newspapers than elsewhere), and different issues of representation in society, welfare and social democracy (including cultural policy; see Box 6.1). 


\section{Political dimension in newspaper data: quantitative approach}

To assess the importance of societal and political aspects in our newspaper data, we utilize a variable measuring 'political dimension', in a similar fashion to aesthetic and commercial dimensions (Chapters 3 and 5). More precisely, the question is whether or not each article published in our culture sections includes an explicit political dimension, detectable from obviously political watchwords such as 'politics', 'society', 'power', 'equality', 'social class' or 'poverty'. The variable allows us to probe the degree to which apparently political content is intertwined with cultural content in our newspaper data. The downside is that the variable based on surface-level vocabulary does not recognize which political aspects - left or right, progressive or liberal, positive or negative, etc. - were identified as political. Moreover, in some contexts, articles can be deeply political between the lines, without using these watchwords. ${ }^{2}$

Table 6.1 shows how the proportion of articles with explicit political dimension changes over time across the newspapers. The first thing to notice is that only about one-quarter of all articles in our data include a political dimension, and that this overall share remains relatively stable through time. However, there are substantial differences in political prevalence between the newspapers. Most importantly, Dagens Nyheter and The Guardian stand out for having the most articles with a political dimension. That The Guardian is also 'political' in its culture section is hardly surprising, as the UK is characterized by strong 'party-press parallelism' and thus British quality papers, The Guardian being one of the best examples, 'have distinct political identities' (Hallin and Mancini, 2004: 212-213). ${ }^{3}$ The case of Dagens Nyheter is perhaps more unanticipated, and it is discussed separately in Box 6.1. As for the other newspapers, Le Monde shows the clearest increase in the proportion of articles including a political dimension. What is particularly interesting, however, is that both of our cases of

Table 6.I Articles including political dimension by newspaper and year (percentages)

\begin{tabular}{lcccccccc}
\hline & 1960 & 1970 & 1980 & 1990 & 2000 & 2010 & Total & $(\mathrm{N})$ \\
\hline ABC/EI País & 15.9 & 8.8 & 26.0 & 18.9 & 14.3 & 22.3 & 16.6 & $(459)$ \\
Dagens Nyheter & 54.4 & 45.0 & 53.4 & 46.7 & 53.8 & 49.3 & 50.0 & $(1,262)$ \\
The Guardian & 38.8 & 49.0 & 49.3 & 26.3 & 44.5 & 41.0 & 39.3 & $(684)$ \\
Helsingin Sanomat & 10.3 & 14.0 & 17.4 & 19.6 & 15.9 & 15.9 & 15.7 & $(444)$ \\
Le Monde & 14.5 & 16.1 & 19.3 & 20.7 & 21.8 & 28.6 & 20.4 & $(390)$ \\
Milliyet & 18.4 & 9.4 & 6.7 & 23.8 & 22.7 & 6.8 & 12.3 & $(171)$ \\
Total & 27.7 & 22.8 & 28.8 & 26.3 & 25.6 & 25.7 & 25.9 & \\
$(\mathrm{~N})$ & $(406)$ & $(459)$ & $(443)$ & $(583)$ & $(782)$ & $(737)$ & & $(3,410)$ \\
\hline
\end{tabular}

Note

Total $N=|3| 6 \mid$, , of which $74 . \mid$ per cent $(n=9,75 \mid)$ did not include political dimension. 
special interest in this chapter, the newspapers from Spain and Turkey, show very modest levels of articles including political dimensions. Therefore, a qualitative approach focusing more closely on these two cases and revealing the politics behind the surface vocabulary is particularly warranted.

Before going into the case studies, however, it is worth investigating how the proportion of political dimension varies across different art forms. ${ }^{4}$ Table 6.2 shows some important differences. Not surprisingly, literature stands out as having the most articles including a political dimension, ${ }^{5}$ whereas music, especially classical music but also popular music, is much less often discussed in political terms. Articles on television became less political in the 2000s, whereas in the case of theatre (see Box 2.2) and the visual arts, the use of political dimensions sharply increased in 2010.

It has been suggested that art, particularly the visual arts, would have experienced a paradigm shift from 'modern' to 'contemporary' (Heinich, 2014), and one of the key parts of this change would have been the 'social turn' of art (Bishop, 2012). The 'social turn' refers to the increased expectation that art should be socially and politically relevant, engage in dialogue with society, and that artists should be similarly willing to create 'activist', 'collaboratory' or 'participatory' art. ${ }^{6}$ Perhaps the rise in articles including a political dimension in the visual arts and theatre has to do with this 'inside-art' development. Still, we must recognize not only the limits of our variable, political dimension, but also that our data concerns newspapers' representations of art, not art itself. However, it is still interesting to see that if our newspaper culture section articles are divided into highbrow arts and popular culture (cf. Chapter 2 and 3 ), the result is that the proportion of articles on political dimension increases in the case of highbrow articles and decreases in the case of popular culture articles (Figure 6.1). This can be tentatively interpreted as supporting a

Table 6.2 Articles including political dimension by art form and year (percentages)

\begin{tabular}{lcccccccc}
\hline & 1960 & 1970 & 1980 & 1990 & 2000 & 2010 & Total & $(\mathrm{N})$ \\
\hline Popular music & 29.6 & 16.1 & 18.6 & 13.8 & 16.0 & 15.3 & 16.0 & $(218)$ \\
Classical music & 13.0 & 7.4 & 8.9 & 8.3 & 13.0 & 13.8 & 10.4 & $(122)$ \\
Literature & 45.2 & 32.0 & 36.2 & 39.2 & 35.7 & 44.9 & 39.2 & $(868)$ \\
Film & 30.1 & 22.8 & 33.8 & 22.3 & 23.3 & 30.9 & 26.3 & $(360)$ \\
Theatre & 16.3 & 26.5 & 31.1 & 27.1 & 32.5 & 47.2 & 27.4 & $(342)$ \\
Television & 29.3 & 35.8 & 70.8 & 28.7 & 14.2 & 16.6 & 24.1 & $(196)$ \\
Visual arts & 18.2 & 5.7 & 17.4 & 19.6 & 17.5 & 32.5 & 18.0 & $(136)$ \\
Other & 40.7 & 30.7 & 44.1 & 37.9 & 34.4 & 41.9 & 37.7 & $(934)$ \\
Total & 29.1 & 23.8 & 31.3 & 26.8 & 25.8 & 31.9 & 27.8 & \\
(N) & $(385)$ & $(438)$ & $(429)$ & $(544)$ & $(695)$ & $(685)$ & & $(3,176)$ \\
\hline
\end{tabular}

Note

Total $N=|I, 4| 2$, of which 72.2 per cent $(n=8,236)$ did not include political dimension. 


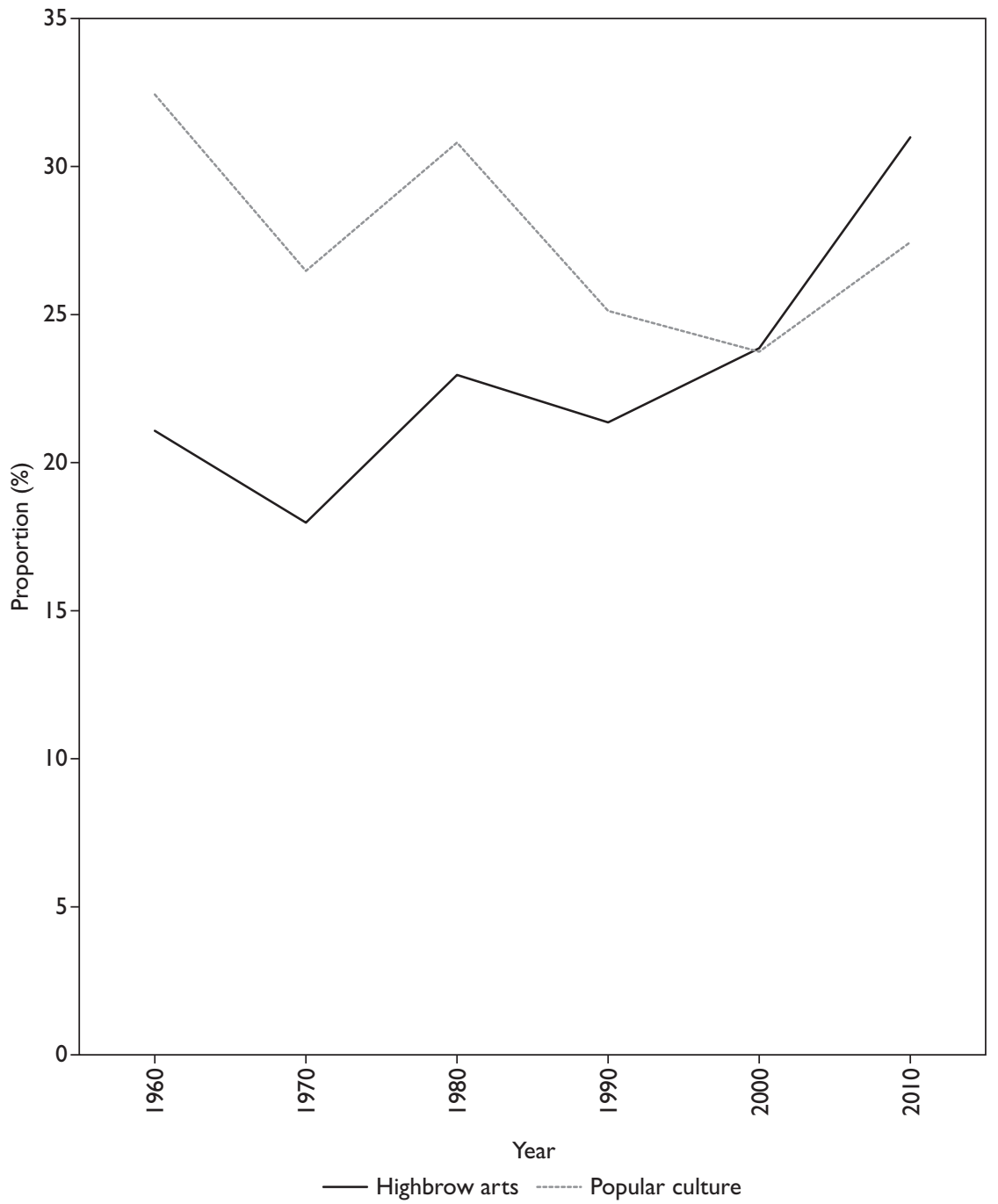

Figure 6.I Articles on highbrow arts and popular culture including political dimension by year (percentages).

paradigm shift and the 'social turn' of art, because the shift has been thought to characterize primarily 'serious' fine arts and not popular culture.

Finally, Figure 6.2 shows how the proportions of articles (reviews, interviews/ reports and news stories) including a political dimension, both aesthetic and political dimensions, and both commercial and political dimensions evolve over time. First, it demonstrates the significance of article type. A political 


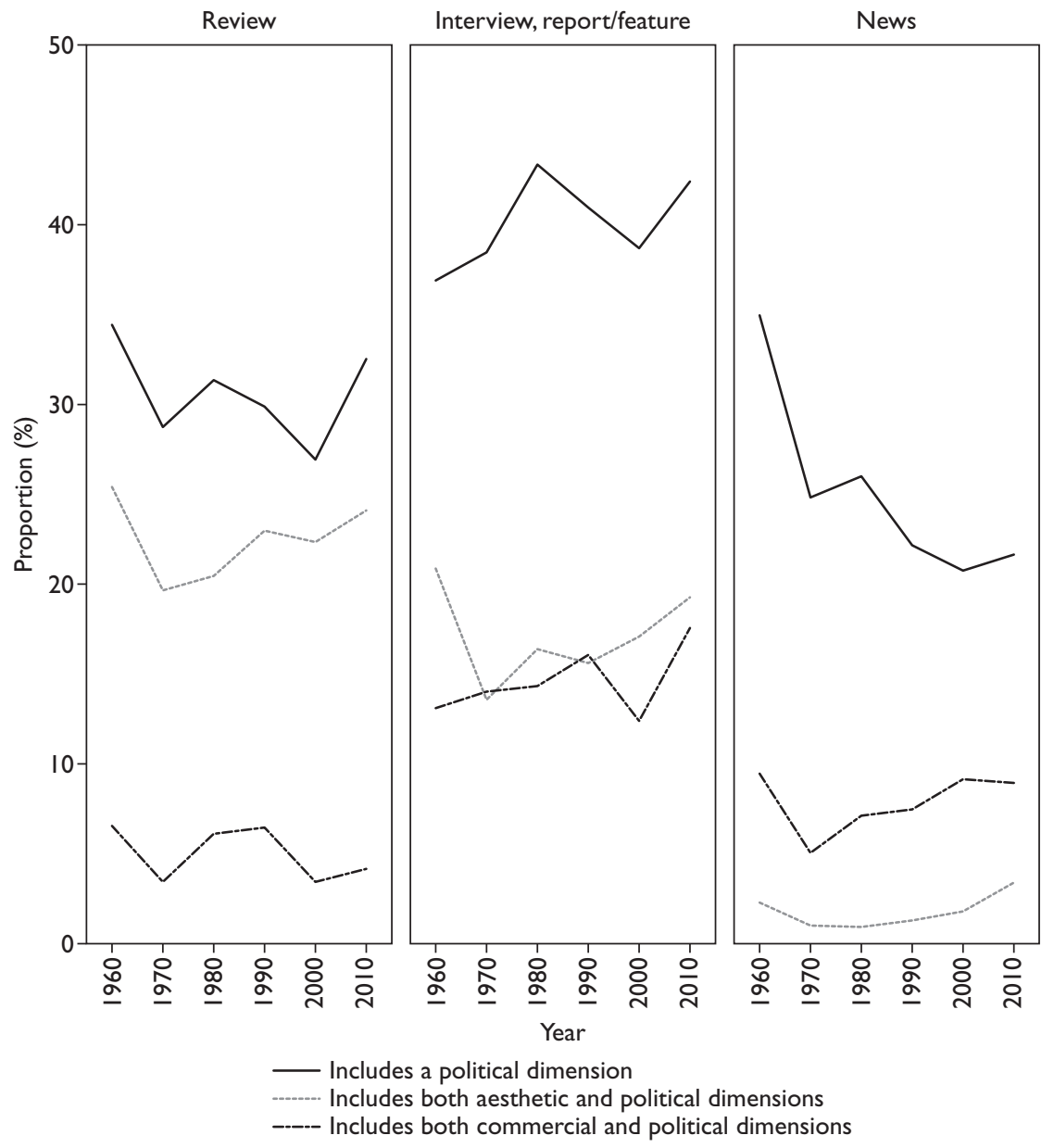

Figure 6.2 Articles including political dimension, both aesthetic and political dimensions and both commercial and political dimensions by year, separately on main article types (percentages).

dimension is most present in interviews and reports, and less so in reviews and, especially, news. Moreover, the political dimension seems to increase in the case of interviews and reports but decrease in the case of news. Second, the political dimension appears with the aesthetic dimension more than the commercial dimension in reviews. However, in interviews and reports, there is almost no difference between the articles including political and aesthetic dimensions versus political and commercial dimensions. In news, where both combinations are rare, articles including both political and commercial dimensions are more common than articles having both political and aesthetic dimensions. 
Because reviews often include explicit aesthetic evaluations (and thus our variable of aesthetic dimension), it follows that the combination of aesthetic and political dimensions is more frequent than the combination of commercial and political dimensions. News can be considered to be the most neutral and journalistically oriented article type (Jaakkola, 2015), and the declining trend of political dimension is in line with that. From the same point of view, it is no wonder that the most normatively charged (and perhaps most dangerous) combination of an article being both aesthetically and politically normative is the least common.

\section{Box 6.1 Meanwhile, in Sweden: cultural policy and politics in Dagens Nyheter}

Reports, news and reviews in the cultural pages of a newspaper can obviously have several diverging aspects of the 'political'. They can range from openly political proclamations to evaluations of cultural events with a more or less clear political dimension, from news and commentaries on cultural politics to reports on the political repression of authors, journalists and artists in authoritarian states. The dimension coded as political in our study can thus include various aspects of the political.

Sweden is often regarded as one of the most democratic and egalitarian societies in the world. Perhaps surprisingly, its daily newspaper, Dagens Nyheter, publishes in its culture sections more articles with a political dimension than any other newspaper analysed. In contrast to the Spanish newspaper ABC under Franco's times, or the Turkish Milliyet, which both had clear conservative-nationalistic agendas loyal to the government, Dagens Nyheter's political involvement is radically different. In addition to some actual issues of the cultural policy of Sweden, Dagens Nyheter gives plenty of space to reviews of more or less directly political cultural events and pays attention to the political repression of third world artists and authors.

The culture sections of Dagens Nyheter thus offer good examples of politically relevant cultural journalism. Based on the material at our disposal, it is difficult to say how typical such reports or comments were in other Swedish newspapers. However, the publicly announced political stance of Dagens Nyheter, which is regarded as a liberal paper without any direct party affiliations, varied from 1960 to 2010 (Hadenius, 2002): for a long time it was 'liberal' (1924-1973), from 1974 to 1998 'independent' and since 1998 it has been 'independent liberal'. On the one hand, Dagens Nyheter has been characterized as a pronouncedly political and socially conscious newspaper against the overall Swedish media environment, especially in the 1960s and 1970s (Hadenius, 2002). On the other hand, Dagens Nyheter has been classified as only very mildly centre-left in the political spectrum of the Swedish media (Hallin and Mancini, 2004: 182).

Some articles took up the economic consequences of the cultural policy of the Swedish state. A longer article published in 1960 reported on changes that had taken place in the financial compensation Swedish authors received based on the loans of their books in Swedish libraries, a compensatory system built to support 
the authors of both fiction and non-fiction (DN/14/11/60_6). The recent reform of the system had, according to this article, led to a situation in which authors who had published their first book during the ongoing year could not get any library grants. The same issue was taken up again twenty years later (DN/14/01/80_4).

The political 'news of the world' in the Dagens Nyheter culture sections typically has a progressive and tolerant tone. For instance, the newspaper announced a series of fifty authors facing political repression according to the International PEN Club (DN/08/11/10_Kultur4), and the first repressed author presented was Anna Politkovskaya, the journalist murdered shortly before in Moscow. Another good example of the politically open-minded tone of the newspaper is the coverage of the opening of the first Bosnian opera (DN/22/04/00_B4), published along with an opera review. While not a directly political event, it had a clear political relevance (in Bosnia, and via the immigrant population from the area, also in Sweden). The political dimension comes up in the explanation of its context: this was the first-ever opera in Bosnia, the story of which obviously had a clear nationalistic and even potentially anti-Islamic message. The reader is expected to understand without explanation what makes Bosnia at the time of the publication of the article so special and interesting:

The spiritual life at Sarajevo has experienced somewhat of a buzz under the last couple of weeks. [...] The critical point of the poem is directed against old traditions, but includes even some cautious critique of Islam as well as hints to a class conflict.

(DN/22/04/00_B4)

The common reports in Dagens Nyheter about cultural products, books, art exhibitions or theatre performances with a feminist or sexual political message can be taken up as yet another example of the political relevance of cultural journalism. Cultural events with identity politics, and in particular gender politics, seem to have received increasing attention in Dagens Nyheter's cultural pages. Different politically oriented events are strongly linked to culture: the big exhibition arranged in connection with The Stockholm Pride is covered, and the curator's interview reflects well the tolerant spirit of Dagens Nyheter:

More and more queer art has come into being during the last decades which the big institutions do not dare to present. We want to show as many as possible to open them a way to the regular world of art.

(DN/20/07/10_Kultur2)

As early as the 1990s, there was news about the lack of female artists at a big international exhibition of the Stockholm Museum of Modern Art, which gave cause to a storm of protests from female artists. On the same page, there is an article on the exhibition of the openly political Guerrilla Girls: 'Guerrilla Girls Strike! Female Artists in the Struggle Against Racism and Sexism' (DN/28/10/90_B4).

As these examples prove, the culture sections of Dagens Nyheter promote various politically oriented news, reviews and cultural activities. In stark contrast to the politics found on the pages of $A B C$ and Milliyet, and their issues of 
repression, censorship and brutal building of national identity by means of writing and representing culture and the arts, the strong progressive and liberal political orientation in Dagens Nyheter shows that cultural journalism is always intrinsically linked to its socio-political context.

\section{Spanish and Turkish national identities in the making: political contexts}

The focus now turns to two countries where the influence of politics might be particularly interesting and deserving of attention. As shown in Table 6.1, a total of 459 articles with a political dimension come from El País and ABC and 171 come from Milliyet. These articles comprise the subsamples we will analyse qualitatively below.

To make sense of the interaction between the political and cultural fields, we need to outline some key features of political affairs before and around the period under study. It should be considered that Spain is, by European standards, still a relatively young democracy: the first free elections within the current democratic period took place in June 1977, so the country has just recently celebrated its fortieth anniversary as a democratic country. Before that, Spain experienced hard times. From 1936 to 1939, civil war took place after a period of increased political polarization and economic hardship (Carr, 1971). The conflict, in which a left-wing republican government (with limited support from the USSR and international volunteers) tried to resist rebel army forces supported by Italian and German fascists, ended with the collapse of the previously short-lived republic and the establishment of a right-wing dictatorship. From 1939 to 1975, the country was ruled by Francisco Franco, whose authoritarian rule emphasized traditional values and a national Catholic ideology, repressing liberal and leftist ideas (Payne, 1987). The fascist regime made wide use of censorship. However, some press plurality was still allowed, linked to different groups that supported the regime and whose political ideas differed substantially (fascists, right-wing Christians, monarchists, etc.). This was evident in the existence of different newspapers with distinctive editorial lines (Ya, El Alcázar, ABC).

Since the 1960s, the country has experienced a process of economic modernization and growth, and soon a growing discontent erupted in the streets, with young people demanding democracy and freedom. During those years, the regime also softened the censorship rules, but control over the media was still strong. In the beginning of the 1970s, new demands emerged, and demonstrations and strikes were common all over the country. After the death of Franco, the dictatorship collapsed and different political groups negotiated a transition to a parliamentary democracy, where the king would be the official head of state. During the late 1970s, the transition to democracy was paved through free elections, legalization of political parties and a constitution (see Carr, 1980; 
Payne, 1987; Foweraker, 1989). Among the reforms, freedom of press was established and new newspapers were founded, El País being the most successful in terms of sales and influence, to the point of being considered to be the primary example of 'reference press' (Imbert and Vidal-Beneyto, 1986). After the transition to democracy, Spain quickly became a modern democracy, joining the EEC (later EU) in 1986 and the Eurozone in 1998, and providing a fresh image after organizing successful events, such as the Barcelona Olympic Games in 1992, and becoming the eighth largest economy in the world by the turn of the century. The economic euphoria and the consolidation of several global companies led to an increasing shift towards pro-market policies, led by both the social-democratic PSOE and the conservative PP (who have held all cabinet positions since 1982). However, certain tensions always remained, linked to national articulation (in areas with a strong national identity such as Basque or Catalonia), corruption and an imbalanced economy (Alonso and Fernández Rodríguez, 2008; Royo, 2013). From 2008 onwards, the country has suffered a deep economic crisis due to the end of a housing market bubble (López and Rodríguez, 2011). Since then, the country has experienced a period of social unrest with the emergence of critical views on the quality of Spanish democracy (the 15-M movement, particularly; Sampedro and Lobera, 2015) and the recent return of territorial tensions in regions such as Catalonia.

Box 2.3 on Turkey in Chapter 2 provides essential information about how Turkey differs from the rest of our newspapers in terms of the topics we discuss. Turkey is a young democracy that has been unstable since the establishment of the new Republic. After the Republic was founded in 1923, the only available political party was the one established and supported by the factions who had led the Independence War following the demise of the Ottoman Republic. This party, led by the founding figure Mustafa Kemal, initiated a large-scale modernization project, which aimed to Westernize all aspects of life, including production and consumption (Feroz, 2002; Lewis, 1961). A second political party competed in the elections for the first time in 1946, and the founding party, RPP, lost the elections for the first time in 1950 to the Democrat Party (DP) that advocated a more liberal policy both in economy and politics. However, due to various reasons (Feroz, 1977), the military organized a coup in 1960 to take power out of the hands of the DP. Under military rule, the leading figures of the party were hanged in 1961. It is in this period that our sample's coverage begins. Since the establishment of the new Republic, Turkey has experienced two overt coups $(1960,1980)$, two soft coups $(1971,1997)$ and three failed coups $(1962,1963,2016){ }^{?}$

The 1980s in Turkey was a period of intense transformation, leading to major changes in the way journalism and the publishing sectors operated. The liberalization process resulted in a shift in the ownership and sponsorship profiles as well as the legal and institutional frameworks, within which newspapers worked. Especially after the 1970s, the press began to integrate into corporate business as big capital owners heavily invested in the sector. The relationship between 
newspapers and politicians became more complicated due to media owners' desires to increase their chances in competitive biddings and government incentives. They also manipulated editorials to increase their profits by advertising or publishing indirect content favouring their corporate firms (most notably banks). The coup that took place on 12 September 1980 and the economic restructuring that followed further challenged the independence of journalism from the political field. After the coup, the military directly and indirectly controlled what was covered in newspapers. Several were closed down and many journalists were jailed. Turkey began to facilitate its integration in the world economy at the expense of social welfare policies (Önder, 2017). At the same time, new regulations increased the price of papers directly and put pressure on production conditions.

Direct and indirect censorship affected how newspaper sections were organized and how news was delivered during this period. To avoid confrontation on risky topics, editors added a separate section on the economy and increased the space for international politics. They also began to put more emphasis on the characteristics of protagonists, such as lifestyle choices, clothing and so forth, rather than the news story itself. To keep circulation numbers high and avoid censorship, many newspapers chose to increase the erotic content in their news stories and visuals (Dündar, 2016). It was typical to present announcements and news on cultural events with photos marked by sexual aesthetics. In the 1980s, the labour-intensive cultural content in Milliyet began to diminish even further. Moreover, cultural news was moved to a separate sheet aimed at covering lifestyle issues and 'magazine news' (personal stories on artists). All these transformations led to a change in the understanding of which elements (personal versus artistic) and forms of culture and arts (apolitical versus critical) were to be presented to the readers. Culture had begun to be delivered as the 'culture of entertainment', which inevitably changed the habits and expectations of popular readership in relation to cultural journalism.

The complex relationship between politics and journalism continued under Erdoğan's conservative 'democratic' rule. Press freedom was supressed under the Justice and Development Party (JDP) government in 2007-2010 and onwards through the effective use of state power, commercial forces and self-censorship (Yesil, 2014). For instance, one of the biggest press corporations in Turkey, Doğan News Agency, who used to own Milliyet, was charged with a record tax fine in 2009, raising issues around indirect political pressure. In the context of increasing conservatism, culture and its coverage has become one of the most contested domains. The rise of the JDP is often seen as a period when religious factions began to find ways to accumulate economic capital and create a new middle class and bourgeoisie parallel to their secular counterparts. There is plenty of research demonstrating how this accumulation generated new styles of consumption (Göle, 1999; White, 1999) facilitated by a consumption market for religious consumers introducing the 'Islamic' version of many services and products (e.g. summer resorts, restaurants, clothing). However, conservative 
factions failed to claim authority over culture and arts, which generated tensions around the production, distribution and demonstration of established arts. As briefly described in Box 2.3, these Western arts received public funding in the early years of the Republic through the policies put forward by secularist and pro-Westernization cadres and have never got across to pious factions. This political atmosphere and conspiracies regarding the systematic devaluation of traditions enabled JDP to create a strong anti-intellectualist attitude ridiculing and/or explicitly interfering with the events of established arts. The so-called cultural journalism of newspapers that are known to be pro-Islamist and progovernment reinforced the tension by provocatively informing on traditions and cultural events 'harmful to the Turkish culture'. For instance, the worldrenowned female Turkish pianist İdil Biret's concert at Topkapı Palace was announced in an Islamist newspaper by highlighting the fact that its sponsor was a wine producer and that wine was planned to be distributed in the 'holy' palace. The concert was then attacked by fifty men, who finished their demonstration by performing Namaz (prayers). Many examples, ranging from breaking artists' public exhibitions to cancelling concerts, can be given to demonstrate the hostility shown towards intellectuals and artists. There are no studies on how this political climate affected cultural journalism in quality newspapers; the scope of the pressure a two-decade-old, one-party rule had on cultural editors is open for speculation.

What is common in these two cases, compared to the rest of the European newspapers in our data, is that the political spheres have suffered undemocratic interventions. Our initial review of the articles suggested that cultural coverage was affected by these shifts more in these two cases, especially in relation to how national culture is defined and framed. We also identified a dramatic change over time in the way national culture is perceived, in parallel with the changes taking place in the political sphere. The next section will unpack this theme by drawing on our extensive close reading of articles with explicit political content.

\section{Continuity and change}

\section{Spain: from unicity to pluralism}

The key issue on which we will focus on in this chapter is the way national identity is framed, perceived and built. It is compelling to explore particularly $\mathrm{ABC}$ as it is the newspaper that coexisted with Francoism. In the case of El Pais, it is especially of interest to focus on the 1980s, when most topics of democracy emerged.

In $A B C$, the idea of Spain as an abstract, deep and almost religious concept or entity (with a very strong political intention) is present in many articles of the culture sections. Articles emphasize the view of Spain as a country and culture unified around the Spanish language, with little attention to the specific 
cultures of certain regions (Catalonia, Basque). Most emphasis is on nationalism, unity and the glory of an imperial past, with the word 'Spain' used in a very political sense, the spiritual (Catholic) reserve of Europe. Even foreign scholars focus on the true ethos of Spain, which according to Giscard d'Estaing (whose son was later to become a French prime minister) leaned on 'honour and cavalry, making Spain the spiritual reserve of Europe' and the traditional values 'that differ a lot from the current youth values, as young people seem to have no goal or direction' (ABC/07/11/70_77). In some of these articles, it is easy to grasp details of the dictatorship's organizing bodies and supporters, and their emphasis on nationalism, tradition, religion and old values. Bureaucratic bodies (including the army), the Movimiento Nacional (the only political organization during Franco's regime) and the Church were key actors. For instance, in a meeting of scientific journals, there was one workshop on 'journals with an ideological orientation' chaired by a priest. In the 1970s, polemical films on the Church were mentioned (ABC/23/04/70_88). Priests colonized the cultural sphere as well as different regime members (professors, officials, politicians), sending a clear message of what Spain is and should be.

As in any other nationalistic regime, references to a glorious past are omnipresent. There are many references to cultural articles that deal with Spanish history and military epics. The history of Spain is usually presented as glorious, from the Reconquista (see mentions of Middle Ages Christian hero El Cid; ABC/07/11/70_77) to the Spanish empire, and the praising of Franco. There are many references to America and the conquest, with many conferences organized around the topic (ABC/15/10/60_66). The newspaper occasionally advocates imperialism, not only through these laudatory views on the Spanish empire but also by justifying imperialism and colonialism. For instance, in an incredibly racist article about the Congo (ABC/09/07/60_42), the author, the Francoist Joaquín Arrarás, justifies the colonial domination by Belgium because it brought 'civilization'. There are also references to the legacy of Spain: one article covers a memorial organized in the Philippines around one scholar in the field of history (ABC/10/11/60_65), and another covers the struggle to keep Spanish alive in Puerto Rico (ABC/13/02/70_47).

Authoritarian rule is supported by different writers and reviewers. Criticism of democracy appears often. In a meeting of an international institute in Italy (ABC/07/09/60_35), the keynote speaker, a Spanish professor, gives a talk in which he emphasizes the need to combine freedom with authority, because freedom without authority represents something 'corrosive, hallucinatory, with cannibal effects on the self'. In general, right-wing authors are widely celebrated. A book by Neculai Totu, a Romanian soldier who joined Franco's army in the Spanish Civil War, is praised, and the author is considered to be a 'patriot who came to defend God, Spain and Romania' (ABC/02/12/70_63). Moreover, in $\mathrm{ABC}$, it is not uncommon to find materials written by far-right authors whose work would be considered to be unworthy of a culture section in contemporary times. For instance, in a section called 'Art and Artists' (ABC/01/03/60_42), 
$A B C$ published an open letter by the obscure ex-policeman and far-right writer Mauricio Carlavilla (a well-known anti-Semite, anti-masonry and anticommunist author) in which he humbly apologizes to an aristocratic family for offending the memory of their late father. According to the letter, the writer 'only wanted to express some criticism of the public persona of the count of Romanones in his book AntiEspaña 1959 (Anti-Spain 1959)'. The writer offers to omit the passages related to this person in a gesture of submission that seems paradigmatic of the authoritarian culture of the time.

A counterpoint to Spain is the USSR, recurrently presented as the essence of an evil government. There are several articles that discredit the repressive policies of the communist regime and emphasize dissidents such as Solzhenitsyn $\left(\mathrm{ABC} / 13 / 10 / 70 \_51\right)$. One interesting note is the careful treatment of cultural news linked to the United States, a very important political ally. News emphasizing cooperation appears, sometimes linked to military issues. For instance, in an event where a keynote speaker discusses trade unionism in the United States (ABC/01/03/70_43), there is a certain subtlety in the description of the role of American trade unions, emphasizing that they are actually very dependent on the state (a sort of subordinate body of state for industrial relations) and trying to link their role to the only Spanish trade union of the time, Sindicato Vertical (free trade unions had been banned since the Civil War), which was part of the regime and cornerstone of the corporative state.

Politics is mostly approached unconventionally, never discussing real issues. For instance, there are reviews of books that directly tackle the issue of politics, but atypically. It is common that those publications are historical books in which the current state of affairs in Spanish politics was never to be discussed, setting politics far away in time. In 1970, however, there was a bit of an opening. Some conflicting issues, such as protests by some associations (screenwriters, exhibitors) are covered $\left(\mathrm{ABC} / 13 / 02 / 70 \_74\right)$, and even critical plays such as Castañuela 70 ( $\left.\mathrm{ABC} / 23 / 08 / 70 \_51\right)$, which was banned later, are viewed positively.

With the transition to democracy, the landscape changes completely, particularly regarding national identity. El País demonstrates a drastic change. Selfcriticism regarding national identity appears, and the legacy of the colonial past is discussed critically. For instance, in 1980, the director of El País, participating in a symposium, mentioned how badly Spain managed the former colony of Equatorial Guinea, exploiting its resources ruthlessly and with no interest in developing cultural activities (EP/10/12/80_35). However, there is a sort of national pride when trying to clean the image of Spaniards, breaking from the archaic image portrayed by other Europeans in plays or operas such as Bizet's Carmen, which is translated into Spanish in a 'modernized' version (EP/14/06/80_33). One interesting point here is how debates about national culture, for instance bullfighting, emerge in a different way, showing the growing struggles that tauromaquia face due to government attempts to forbid these events (EP/06/10/90_38). This new perspective is shown by focusing on 
different events and perceptions of Spanish history. Opposing the view of the Reconquista, Arab influence in the country is seen with a more positive perspective. Thus, we see news such as an international workshop in praise of the translator of Don Quixote into Arabic (EP/10/12/80_37). Occasionally, there are references to the strategic importance of Spanish and the need to strengthen the links between Spain and Latin America (see Box 4.2), Spanish having a higher status as a world language and emphasizing its importance continuously, even if the discourse is now framed on the possibility of higher economic profits than on political domination (see support to the Brazilian policy of introducing Spanish as compulsory language in education, EP/18/06/00_34).

A critical issue here is the emergence of new analyses of the Spanish Civil War, the post-war and the Franco period. Therefore, new problems are examined (for instance the issue of the exiled, EP/07/09/80_26) and some profiles of writers and other artists are rehabilitated (EP/26/09/80_32). There is a complete turnaround, and now attention is focused on the artists repressed or banned by Francoism, while popular writers during the Franco years are often ignored. The transition to democracy has been studied since its beginning, and there are commentaries and articles on political issues related to art, such as the recovery of heritage requisitioned by Franco's authorities being slowly devolved to their original owners (EP/24/07/80_25).

Moreover, national identity loses its homogeneity, and new issues are raised, such as the role of different national cultures with Spain (for instance, how to develop knowledge of Euskara among the Basque population, EP/19/03/80_30a). Another example is the article noting that 'there has been the production of the first 100 per cent Andalusian film' (EP/14/06/80_32). Occasionally, controversies emerge regarding the role of Basque or Catalonia in Spain and mutual attacks between nationalist views. For instance, in 2000, a conflict between different academic institutions regarding the names of places in bilingual regions was covered in depth (EP/29/04/00_41), and in 2010 there was a report on how political parties vote in Catalonia on the abolition of bullfighting $\left(\mathrm{EP} / 20 / 07 / 10 \_46\right)$. In general, inner politics dominate, with emphases on sectarianism from one side or the other heavily affecting cultural policies (EP/19/03/80_31). This is a key point as the cultural scene is gradually inflected with politics, showing an ideologically divided country, far from the monolithic Spain of Franco.

One surprising branch of news concerns the struggles and conflicts in different associations and public institutions. These conflicts range from internal disputes in associations regarding statutes (e.g. EP/01/08/80_21) to trade unions or lobbies claiming new policies or better working conditions for their sectors (EP/01/08/80_23). Particularly important are the struggles of Spanish cinema, which feels threatened by US cinema and its power of distribution (EP/25/04/90_35). In general, it is easy to notice the opening of the country in political terms; for instance, previously banned books are being published (e.g. the biography of Lenin; see EP/19/03/80_30b). In a 1980 El País, there is, for instance, 
a full-page discussion on a book on socialism and its possibilities in Spain (EP/12/04/80_26). However, occasionally it is possible to find interventions from public powers to censor certain events or books. For instance, the authorities 'kidnapped' one book by Galician authors because of its offensive comments on the Spanish police (EP/26/09/80_31a), and one television programme was cancelled amid accusations of political censorship (EP/07/09/80_29). The political profile of artists is openly mentioned and many of the artists, particularly musicians, interviewed or covered otherwise in 1980 tend to have progressive leftist views (such as the folksinger Víctor Manuel, EP/19/03/80_33; or Leo Ferré, EP/26/09/80_35).

International politics are examined through new lenses, and that affects the world of culture. For example, one article examines how Chilean police enforce repressive policies to downplay the anniversary of the leftist poet Pablo Neruda (EP/26/09/80_31b). In general, much attention is given to artists who were exiled because of right-wing dictatorships, such as Manuel Puig (EP/25/04/90_37a), and leftist figures such as Sandino (EP/19/02/90_62). There is a critique of dictatorships and excesses; views of the USSR are not positive either, particularly regarding the Stalinist period and later, showing the political contradictions of the regime, albeit distantly (EP/30/10/80_37), or themes such as the role of utopia in the end of the century (EP/01/08/90_19). In any case, by the 1990s, there were plenty of articles in El País about the perceived collapse of the Soviet empire, with news such as the rejection by Solzhenitsyn of the Soviet Union passport and the collapse of dictatorships in Latin America.

In later years, new political issues were raised such as feminism and racism (covered widely when reviewing the films of Spike Lee, EP/01/08/90_18). There is a growing attention to new phenomena such as jihadism, especially since the fatwa to Salman Rushdie (e.g. EP/18/08/90_48). There are also discussions about legislation and, particularly, coverage on the privatization process of the media, which widely affects culture (EP/25/04/90_37b), whether art should be profitable and the role of the state in preserving culture (EP/06/10/90_33; see also Chapter 5). There are even hints of consumer criticism, for instance, when Snoopy is presented as a symbol of consumer society (EP/11/02/10_44).

\section{Turkey: constructing and preserving a national culture}

Before focusing on how the same theme has played out in the Turkish context, it is worth noting that there is a substantial difference between the sample sizes of each country. While Spanish newspapers devoted considerable space for cultural events and news across the time-span covered, Milliyet's coverage remained limited, especially in the earlier decades of our data. However, Milliyet began to publish a separate art supplement in 1972, in which a wide range of cultural and artistic events were covered. Several named journalists and authors published regular columns in this Milliyet Sanat (Milliyet Art), whereas such labourintensive cultural journalism was not to be found in the main newspaper. Milliyet Sanat began to be sold separately from the main newspaper after 1980. 
Within the scope of this research, and following our decision to include only those supplements not sold separately from the core newspaper (see Box 7.1 on supplements), these monthly supplements were not included, and the focus remained on the main newspaper, which targets a larger readership. The editorial decision Milliyet took regarding how to deliver a large part of 'serious' cultural content as separate from the main newspaper reveals the (assumed or existing) gap between the types of readers that are different in terms of their interests in culture. Leaving much of the serious cultural journalism and content out of the main newspaper meant that only those who already had the economic and cultural capital to access the rich content of the supplement, perhaps resulting in the accentuation of the distinction between different readers later in time.

In 1960, the main newspaper was six pages long. There was not a section titled 'Culture', but the announcements and commentaries on cultural events were consistently published on page four. However, nearly half of this page in Milliyet was filled with cartoons and advertisements of various household items. On some days of the week, a small column by a journalist was published, but in general, it was more common to publish direct extracts from books and short stories. On most of the 1960 dates, the main piece on this 'cultural page' was an extract from the speech Atatürk, the founding leader, delivered in 1927 at the second congress of Republican People Party (see e.g. MIL/11/03/60_4). This Speech ('Nutuk') explains the events that took place between the start of the war and the establishment of the Republic and defined the official historical view of the foundation of the Republic (Alaranta, 2008). It was published as a book and was widely referred to as a source with high symbolic value by the secular and republican factions of society. Some thirty-three years after its delivery, sections from this book were being published regularly in Milliyet. Considering the lack of alternative cultural content, this choice demonstrates cultural intermediaries' willingness to reinforce the feelings of national belonging through cultural products in that time period.

Our data covers the period around the military coup of 1960. It seems as if the political events surrounding the military's takeover influenced the choices of topics by editors and cultural journalists. Considering that censorship was actively applied in other fields of social life, we can also assume that it had an impact on how cultural products are evaluated. For instance, after giving brief information about a regularly organized local festival, the reviewer suggests that the performance of this year exceeded expectations thanks to the 'military which encouraged the development of national arts and science from the first minutes of its "gentlemanly coup"' (MIL/09/07/60_4). The choice of words to define the coup is not arbitrary; the military defined the intervention as an attempt to restore national unity until conditions necessary for democratic politics were developed. In fact, the day the coup took place (27 May) was named a national holiday to celebrate 'liberty and constitution' until the constitution changed in 1982 with another coup. We found that pieces on culture published in that period were in line with this discourse on the 'coup bringing liberty and 
national unity' in circulation. For instance, one author makes a strong point about the power of theatre to reinforce national unity and belonging (MIL/13/09/60_4) by giving specific cases as references from the West. More direct censorship is also traceable through cultural news, which seems to go through self-censorship before publication. For instance, in one comment, an author reports on the closure of theatres because of the upcoming military coup (MIL/03/05/60_4). However, he does not follow up on the impact of military control in the rest of the article and instead gives an historical account of theatre and its changing status in society.

In 1970, the political content that we identified in culture news still emphasizes national culture, albeit less strongly. Political issues came up in the extracts editors selected from one the most prominent novelists of the time, Kemal Tahir, who is known to represent the authenticity of the Turkish social structure and its people (MIL/30/03/70_6). There are also articles reflecting institutional attempts to create a 'national' field of culture. For instance, an article published in 1970 reports how one new popular song managed to pass the strict censorship test that assessed whether songs fit into the criteria of Turkish music. The article suggests it was given permission after musical experts assured the censoring committee that the song was not under influence of Indian and Arabic rhythms (MIL/13/10/70_6).

Compared to other decades, the number of articles having political or social content was dramatically low in 1980 . This period in Turkey is known to be a period of 'opening' to the outside world due to the new policies implemented by the centre-right neoliberal party rule. Especially after the 1980 coup, and with the effects of the social turmoil preceding the intervention, this period is argued to be marked by a process of de-politicization. In line with this atmosphere, culture news was pushed to the entertainment supplement called Yaşam ('Life') for a period of time. The news was reduced to singers' family quarrels ('My husband has not slapped me'; MIL/07/09/80_Yaşam_1) and the reporting began to include graphic content, despite the lack of context for its use (e.g. MIL/24/08/80_13). This shift in the way culture is portrayed is in line with the political and economic background of the period. Interestingly enough, there were also some articles negatively evaluating the quality of TRT (Turkish Radio and Television), the only television channel available at the time. For instance, a columnist criticized the broadcast policy of TRT at length for its overdependency on international products and for its incapacity to overcome bureaucratic regulations working against the production of good-quality local shows (MIL/26/09/80_4).

Milliyet's culture and art coverage in 1990 was significantly different from the rest of the sample, which has already been shown by the volatile changes in 'serious' cultural coverage from this period (Chapter 2) and growing internationalization (Chapter 4). In this period, the newspaper began to devote a specific page to culture news and employed reviewers and well-known literary figures to regularly write columns. The reporting of international events began 
to be taken very seriously; in fact, this is the only decade in our sample in which elaborate reviews and news on cultural events abroad were included. Interestingly, the cultural products chosen to be reviewed and the artists interviewed often had a critical political element. For instance, an interview published in 1990 questions whether the art world had done enough to unpack the repercussions of the 1980 coup in a critical manner (MIL/02/11/90_10). Another reports positively on a national production of a play by a Czech writer, especially for the emphasis it put on the negative effects of war and the military system (MIL/06/12/90_12). Significant space was given to cultural events and artworks highlighting gender inequality embedded in the national culture. The macho character of Turkish intellectuals was chosen as the topic of an interview, again written with a strong critical tone (MIL/07/01/90_10). Another long article covered the successful story of a Turkish play on the oppression of women, which took place at a French theatre festival (MIL/18/08/90_12). Compared to previous decades in our sample, coverage of international cultural events in 1990 also leaned into artwork and topics with political content. Events concerning former Soviet figures (e.g. the Leon Trotsky Museum, MIL/24/08/90_10a) and other Western artists of political significance in their own national contexts (e.g. Federico García Lorca, MIL/24/08/90_10b) found ample space in this period's culture pages.

Interestingly, in the 2000s, the theme of national identity and belonging returned to the agenda with highly different content than in earlier decades. In the culture section of Milliyet, we came across a number of articles and reviews of cultural events that highlighted the ethno-cultural plurality of the country. Especially in the field of music, concerts explicitly aiming to bridge cultures and the ones in which Armenian and Kurdish tones were articulated to the repertoire, were reported positively (e.g. MIL/18/09/00_14). In a similar vein, a relatively long article reports on the new plays staged fully in Kurdish and asks with a positive tone, 'What is happening to the Turkish theatre?' (MIL/16/02/10_5). There is also a long article on a concert by Kurdish-Turkish left-wing folk (protest) band Grup Yorum, whose members had been arrested and albums had been banned several times since their establishment in 1985 (MIL/14/06/10_4). In previous decades, there were hardly any reviews or news on cultural products reflecting ethno-religious diversity in the country. This may be due to the rise in such ethnically eclectic cultural products with the politically more tolerant climate that came with the 'Democratic Initiative' (Kurdish-Roma-Armenian opening) period started by Erdoğan in 2009. This so-called opening seems to have facilitated the organization and reporting of cultural events aiming to 'bridge cultures'. It would be interesting to see how the situation changed after this initiative, as the general promises on democratization have generally failed.

In 2010, a substantial part of cultural coverage in Milliyet consisted of news and announcements of television products. Political and social content appeared especially in pieces on national soap operas. This is expected given their share in domestic and international markets. Turkey has become a major television 
series exporter to the regional market, reaching audiences in seventy-five countries and generating a drama production with revenue of US $\$ 200$ million (Alankuş and Yanardağoğlu, 2016). Some suggest that the success comes from a so-called 'neo-Ottoman cool' stemming from the JDP and Erdoğan's attempt at combining Islam with democracy. However, robust empirical research demonstrates that flexibility in adaptation to neoliberal market demands in the industry, rather than aspirations for neo-cultural imperialism, made Turkey the main soap opera exporter in the region (Alankuş and Yanardağoğlu, 2016). In fact, with a length of 180 minutes (including advertisements) and cross-cutting different socio-economic statuses (Arun, 2015), soap operas occupy a central place in the national television field as well as culture sections of the main newspapers. In the 2000s, political content often appeared in more detail in the coverage of a peculiar television soap opera genre, which can be directly translated from Turkish as 'mafia shows' (e.g. MIL/15/05/00_23). In such shows, the screenwriters make direct references to the domestic and international political developments and update their plots when significant new political issues unfold in real life. Such shows have a strong male character, who fights against internal and external enemies in the context of an inefficient legal system. For instance, an article titled 'Polat will save Palestine' introduces the topic of a new spin-off movie and explains how the latest episode, implying US and Israeli involvement in terrorist operations in Turkey, attracted attention (MIL/17/01/10_ Cadde_1). Newspaper articles with a social and political dimension also reflect the rise of ruling conservative politicians' concerns over traditional and religious values. For instance, a ruling conservative JDP member of parliament maligned television shows in which problematic family structures and male violence is problematized for revealing and facilitating the dark and pervert character of human beings (MIL/17/11/10_5).

\section{Conclusion}

In this chapter, we have explored the relevance of the political dimension in the cultural coverage of quality European newspapers, presenting politics, broadly conceived, as an element that might not only threaten the autonomy of the arts in specific contexts (particularly authoritarian) but also have an impact on reviews and aesthetic evaluations. The political dimension frames the impact of politics in articles on culture and widely influences views on culture and art. We showed via our newspaper data that a political dimension included in articles published in culture sections vary significantly across newspapers located in different parts of Europe, as well as between the art forms discussed, with some of them being politicized recently as a reflection of the alleged social turn in the art world (the visual arts and theatre, in particular). Furthermore, we showed the relevance of the type of the article for the inclusion of explicit political vocabulary, which our measurement was able to capture. Political dimension, which sometimes appears in combination with aesthetic and commercial 
vocabularies, is overall a stable element; there is no sign of a clear trend towards the politicization of culture and the arts in European newspapers.

To be able to go deeper into the nature of the political and how it influences cultural content and aesthetic valuations, two historical cases were selected for closer analysis: Spain and Turkey, the only two countries that have substantially altered their political regimes during our research period, with the former experiencing a transition from a fascist-inspired dictatorship to a full democracy and the latter swinging from democracy to authoritarianism throughout the half-century from 1960 to 2010 . The main question was how these extraordinary historical periods were reflected on the cultural pages of the leading quality newspapers of both countries. To understand the weight of politics in the culture sections of ABC, El País and Milliyet, we selected the issue of national culture. Our focus on the cases of Spain and Turkey was not supposed to indicate that politics would be a relevant aspect in cultural valuation and hierarchies represented in newspapers only in such extreme national cases. However, extreme cases make it easier to see the significance of politics, which otherwise might remain invisible and would be taken for granted when studying newspapers of stable democracies.

To sum up the results of our analysis of the two cases, in the early decades of our data, the articles in which we could identify political and social content touched upon culture in a tone clearly destined for elevating the feelings of belonging and national identification. In the most recent decades, however, we noticed that events highlighting the ethnic plurality and national identities of different regions began to find a legitimate space in the cultural pages. This, of course, does not necessarily mean that the cultural field became more pluralistic and that cultural products would have lost their capacity to reinforce a monolithic national identity. For instance, in the Spanish case, during Francoism there was an emphasis on uniformity and in the post-Franco era on pluralism, but still the obsession with Spanish as an almost universal language remains. However, it demonstrates how political background can increase and decrease the chances of a cultural product being recognized by cultural intermediaries and therefore be included in newspaper coverage.

In both cases, the newspaper cultural coverage clearly reflected the political processes of the country, showing what is considered worthy of journalistic attention and how products are properly evaluated in specific historical time points. In this sense, our analysis of the Spanish and Turkish cases reveals the characteristics of Hallin and Mancini's (2004) 'polarized pluralist model' in a clear way. As discussed in Chapter 2, due to little autonomy on the part of journalists and strong constraints and state pressure, the national contexts fitting to this model exhibit the most unstable trajectories. This chapter unravelled how exactly the changes in the political sphere affected the content of cultural coverage produced under these volatile conditions. Moreover, it showed how newspapers went through different periods in which their cultural coverage was evaluated vis-à-vis their capacity to build a national identity. Overall, the focus 
on national identity has changed throughout time (exclusive nationalism versus plurality of identities) with respect to the political changes taking place in that period.

\section{Notes}

1 While these points are relevant in our study, as will be highlighted throughout the chapter, it is not our focus to discuss only the status of censored art. We are not covering exclusively cultural products that have subversive political elements; articles with pro-establishment views have been also added into the category of the political. In this we do not only include patriotic content but also other approximations to politics that might be subtler, for instance pro-business views, that in some cases flourish particularly in democratic periods, such as in El País.

2 See note 11, Chapter 3.

3 Hallin and Mancini (2004: 213) report that, in 1997, as many as 67 per cent of the readers of The Guardian supported Labour, whereas only 7 per cent supported the Conservative Party.

4 As Table 6.2 and Figure 6.1 use art form classifications sensitive to the Western highbrow/popular distinction, Milliyet has been excluded from the analysis.

5 The fact that the category of 'other' in Table 6.2. has a substantial proportion of articles including a political dimension is expected because the category includes articles on society, philosophy and science and, most importantly, cultural policy.

6 For Heinich $(1998,2014)$, the paradigm shift is more profound than implied by the idea of socially engaged, 'participatory' art. Rather, she refers to the change in which artwork has come to receive meaning primarily vis-à-vis surrounding society and not by making references to other artworks, such as those in the 'modern' paradigm, or directly representing the world, as with art in the 'classic' paradigm. See also Roose, Roose and Daenekindt, 2018.

7 For more details, see Gürsoy, 2017. 
Part III

The place and space of culture 


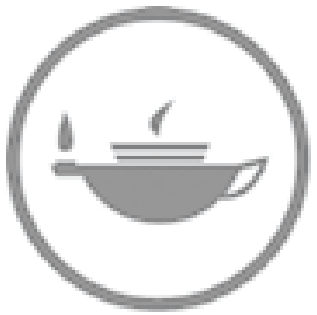

Taylor \& Francis Taylor \& Francis Group

http://taylorandfrancis.com 


\section{Packaging of culture \\ On the 'crisis' of cultural journalism and journalistic popularization}

\section{Introduction}

Since the 1960s, newspapers have shifted from public institutions to commercially oriented media institutions (Kristensen, 2010). If it is the case, as already discussed in Chapter 5, that 'the journalistic field is losing more and more of its autonomy' because 'the weight of the economy within the field is constantly growing' (Bourdieu, 2005: 42), it is evident that this structural change has also affected the presentation and packaging of published material, pushing newspapers to compete in terms of both form and content. In the current context of economic competition, there is an ongoing struggle in newspapers to make themselves attractive for the reader: these strategies can materialize as a more personal, 'human-interest' orientation, an informal and linguistically less challenging style, different narrative forms or writing, longer stories and increasing attention to visual attractiveness (Verboord and Janssen, 2015).

Indeed, as a specific case of the more general discourse on the crisis of journalism (e.g. Alexander, Breese and Luengo, 2016), which is mostly concerned about the printed press and its shrinking circulations and revenues that create more competition, the crisis of cultural journalism, too, has been discussed in detail recently. The advocates of the crisis argue that serious cultural journalism is given increasingly less space and importance in newspapers. Accordingly, it is claimed that the journalistic means used in reporting about arts and culture have popularized, that the content and topics of cultural journalism have become too popular and commercialized, that the boundary between editorial and advertisement content has become increasingly blurred and especially that traditional aesthetic-normative criticism has lost space and quality on the printed page. ${ }^{1}$ There has been a multitude of fundamental changes, which communication researchers have been able to demonstrate more objectively than the indicators of the normative crisis itself, in how cultural journalism is organized at the editorial level of newspapers and in cultural journalists' professional identities. Most importantly, there has been a decreasing specialization of cultural journalism, manifested in how the role of cultural journalists has started to resemble that of ordinary news journalists (Kristensen and Riegert, 2017) or 
how the professional identity of cultural journalists has changed from 'aesthetes' to 'reporters' (Hellman and Jaakkola, 2012).

Paying special attention to transformations within the cultural pages, the role of culture sections within full editions of newspapers and a variety of journalistic means through which the cultural content is packaged, this chapter will explore whether these supposed trends in the crisis of cultural journalism and journalistic popularization resonate with our quality European newspapers. While the main interest of this book has not been to study cultural journalism as such but rather to explore the changing cultural hierarchies and engage in key discussions of cultural sociology by analysing newspapers, the perspective of this chapter is arguably closer to the level of cultural journalism than is the rest of the book.

After a brief introduction to the crisis discourse, we will concentrate on the space allotted to cultural journalism through the years and the place culture sections have been given. In doing this, we use our newspaper data in slightly different formats, as 'issue data' $(n=585)$ and 'full edition data' $(n=30)$, than in other chapters, in which the unit of analysis is the article. ${ }^{2}$ After examining the space and place of culture sections, we see how the newspapers change over time in terms of the packaging of cultural content (e.g. article type, size and illustrations). After assessing these and other possible indicators of journalistic popularization and crisis, we conclude by discussing cover stories in our newspapers' culture sections. Clearly identifiable, typically long and illustrated cover stories, which have become increasingly omnipresent in newspapers, signal increased journalistic and popular orientations, and provide an opportunity to summarize many of our main findings.

\section{Changing cultural journalism}

Cultural journalism has often been characterized as a field in a state of constant oscillation: it always balances 'between the journalistic paradigm and the aesthetic paradigm' (Hellman, Larsen, Riegert, Widholm and Nygaard, 2017: 130). Cultural journalists have been considered to be cultural intermediaries (Bourdieu, 1993), efficiently filtering newspaper content and creating symbolic value for the evaluation and hierarchization of culture. Unlike several other journalistic fields, there is no formal education or title for a cultural journalism; in fact, cultural journalists are often linked to the art world or are artists themselves (Jaakkola, Hellman, Koljonen and Väliverronen, 2015; Janssen, 1997). There is also no objective way of authenticating the veracity or validity of cultural journalists' or reviewers' opinions (van Rees, 1989). In this context, it is not surprising that the professionalization of cultural journalism is still underway (Jaakkola, 2014).

Recently, there have been debates on an alleged crisis of cultural journalism, and there is consensus that significant changes have taken place in the field of cultural journalism. Jaakkola's (2014) analysis based on Scandinavian academic research and public debates yields five frames for the crisis: elitization, popularization, commercialization, journalistification and professional apathy, all of them perceived threats to the artistic and professional autonomy of cultural 
journalism. Elitization refers to a view in which cultural journalism caters mainly for cultural elites, consolidating existing cultural hierarchies and giving excessive dominance to the aesthetic paradigm. Popularization refers to the expansion and shifting of legitimacy boundaries for topics in culture sections, whether through the simple inclusion of popular themes, a popularly oriented concept of quality of art or through a legitimization process of popular content (cf. Baumann, 2007; Schmutz et al., 2010). Commercialization refers to the growing proximity of cultural journalism and cultural industries, threatening to influence journalistic neutrality and reduce criticism of consumer advice or straightforward marketing (see Chapter 5). Journalistification refers to the normalization of cultural journalism, increasingly obliged to resemble other sections of the newspaper, which is directly linked to worsening work conditions for cultural journalists, continuous demands for shorter and more news-oriented articles and the introduction of cultural journalism to a new kind of market logic (Hellman and Jaakkola, 2012; Hellman et al., 2017). Finally, the professional apathy discourse refers to the perceived incapability of cultural journalists to fight against macro-level phenomena such as the loss of traditional gatekeeper roles. The underlying problem was seen as an unwillingness to change and carry out the fundamental ethical role of the journalist.

Alongside this discursive crisis, there exists a normative crisis that in general laments the worsening conditions and quality of contemporary journalism (cf. Carroll, 2009; Elkins, 2003; McDonald, 2007). One of the central worries is linked to the vision of the reviewer as a reference instead of an authority; in this scenario, he becomes just another 'consumer reporter [...] who records his or her likes or dislikes so that readers can use them to predict what shows, or books, or films they will like or dislike' (Carroll, 2009: 8). In a context of decreasing circulation numbers of Western quality newspapers (cf. Brink Lund, Raeymaeckers and Trappel, 2011; Weibull and Nilsson, 2010), the Internet is becoming a substantial competitor to and replacement for traditional print media (McChesney, 2011; Verboord, 2014), which has led to numerous fears regarding the loss of traditional, authoritative and evaluation-based reviewing: 'The critic-as-instructor, as objective judge and expert, has yielded to the critic who shares personal reactions and subjective enthusiasm. If anyone can be a critic, there is hardly any need for specialized and devoted professionals' (McDonald, 2007: 5).

While scholarly findings on the normative crisis are ambivalent, there have been tremendous general, macro-level changes in newsrooms and journalism. Besides changes in professional values and working practices, the status of culture departments has been transformed: relatively autonomous arts sections in the 2000s tied into more structured and centrally led newspaper routines (Jaakkola et al., 2015). From an organizational perspective, cultural departments are now located closer to other departments and encouraged to produce more news content; reviews are more frequently outsourced to freelancers (Jaakkola, 2014).

At the same time, research has found, as shown by the findings presented earlier, that the volume of arts and culture coverage has grown throughout 
Western countries. ${ }^{3}$ While a big proportion of the growth points towards increasing popular culture coverage, the way popular culture is written about is approaching discourses and categories previously reserved for highbrow culture (Chapter 3; see also e.g. van Venrooij and Schmutz, 2010; van Venrooij, 2011). Moreover, a multitude of interrelated trends has given rise to increased cultural heterogeneity, the opening of legitimate culture and the erosion of the hierarchical boundary between high and popular culture (see Chapter 2). If the readers of quality newspapers are becoming more eclectic in their product and format consumption, it is reasonable to expect that not only the content of newspaper culture sections but also the formats and ways of presenting culture and the arts will become more heterogeneous and popular.

Finally, journalistic popularization and the 'crisis' of cultural journalism relate to the key themes of this book because the question is of cultural legitimacy of cultural journalism itself. In the case of our quality newspapers, critics' and cultural journalists' capacity to act as influential cultural intermediaries and attributors of symbolic value has been reinforced by institutionalized media: the quality newspapers and their prestige (van Rees, 1987; Bourdieu, 1993; Verboord, 2014). According to Champagne, journalism's 'immanent power of consecration - the power to say who and what is important, and what we should think about important things and people - is based on its own legitimacy, which journalists have collectively accumulated in the course of history' (2005: 58). Thus, if people decreasingly trust in newspapers and cease to consider cultural journalists and critics to be aesthetic authorities, or even reliable advisors, then cultural journalism loses its position as a cultural mediator and tastemaker.

\section{The space of culture}

The topics covered in culture sections have already passed several gatekeepers and filters before ending up being published. ${ }^{4}$ While thus far we have examined in detail which art forms and cultural domains are given space in our quality European newspapers, an interesting question in its own right is how much space newspapers have given to arts and culture in the larger context of the newspaper issue. We have seen already (particularly in Table 1.2) that the number of articles in culture sections increased considerably from 1960 to 2010 (with a drop between 2000 and 2010, probably due to the recession and cuts in advertising revenue). Was there similar growth throughout newspapers, and how much space was cultural content allocated?

We examined the newspapers in their entirety using issue data $(n=585)$. We studied both the core content of the newspapers (the fixed, primary part of the newspaper comprising established sections with little variability) and their supplements (referring to the often weekly specialized publications inside the main publications but with a secondary role) and their interrelations (for more details about supplements, see Box 7.1). 


\section{Box 7.1 Choosing lifestyles: the emergence of cultural supplements}

Newspaper supplements refer to publications that have a secondary role vis-à-vis a main publication. Some supplements are physically part of the main newspaper or magazine (e.g. The Guardian's G2 or El País's Babelia) and are either separate, small volumes found inside the newspaper, usually following the newspaper's pagination, or editorially marked and separated from the rest of the content. Other supplements are spin-offs that carry the name of the main newspaper but are independent publications sold separately. Supplements typically specialize in areas considered to be soft news, 'infotainment' or entertainment, covering culture, arts, sports, leisure, health, home improvement and so on.

The cultural supplements linked to the newspapers used in our study cover various cultural domains (see Appendix Table B.1). Only daily or weekly cultural supplements published alongside the core newspaper at no extra charge were included in the data. All the newspapers have cultural supplements, excepting Dagens Nyheter, which has no supplements. Some supplements focus on only one cultural domain (such as The Guardian's Film $\mathbb{E}$ Music or Le Monde's Le monde des livres), but, especially from the turn of the millennium onwards, the supplements are microcosms of culture, covering various topics from the highly legitimate to the very popular (e.g. G2 of The Guardian, MP3 of El País, or NYT of Helsingin Sanomat). In the 2000s, it became clear that supplements are the perfect outlet for service journalism, informing consumers about cultural events (such as Listings in The Guardian, itemizing hundreds of concerts, exhibitions and clubs) or products (The Guardian's The Editor, humorously offering pieces such as 'The Digested Read' (GUFri280100_TE_16), which makes tempting suggestions to occupied readers: 'Too busy to read the hot books? Let us read them for you.'

While some supplements started to appear early (in the case of the famous Times Literary Supplement in 1902), the number of the cultural supplements and the proportion of cultural content in them did not grow until the 1990s. This is linked to the growth of consumer society and wealth in general: supplements have primarily been forums for displaying and discussing the expanding cultural supply. In an era of declining newspaper circulation and diminishing revenues, supplements are a perfect solution for offering advertisers readily tailored audience segments. In some cases, supplements have brought in enough new advertisement revenue to increase editorial coverage.

Supplementation has been one of the most remarkable mediatic changes of the last few decades (Weibull and Nilsson, 2010). Many tendencies of supplements reflect recent changes in journalism, serving the tastes of the increasingly educated and wealthy audiences with a need for quick, concrete consumer advice (such as information on new cultural items and events) and informative lifestyle content. Their topics and style reflect the blooming subjectivization of media in general. In a context of tough mediatic competition with a permanent struggle to cater to the rapidly changing tastes of reader, attractive supplements are a way of branding individual newspapers (cf. Kristensen, 2010).

While an important outlet for diverse kinds of culture, the various supplements included in the study have not directly served as a means for introducing new cultural domains to newspapers: most cultural domains covered by the supplements 
coexisted in the core newspapers long before supplementation. Contrary to expectations, supplements do not concentrate solely on popular culture: especially in Le Monde and El País, several highbrow cultural domains are mainly covered in supplements (e.g. Le monde des livres and Babelia, supplements focusing on highbrow literature covered mainly through reviews and essays). In most of the supplements focusing on events, traditional highbrow events such as classical music concerts and visual arts exhibitions are listed together with different popular music concerts and club gigs.

In the context of the rise of popular culture, supplements have eased the circulation of information on consumption possibilities, but their main role has been and remains emphasizing the individualization and consumption aspect of culture and oiling the wheels of consumer society. They have also eased readers' choices, especially through specialized supplements: instead of a fixed arrangement of cultural items found in culture sections, the reader can concentrate on the interesting supplement that fits best his or her lifestyle and tastes.

What will be the future of newspaper supplementation? With scenarios of rapid digitalization and financially struggling newspapers, will supplements become even more flooded with advertisements, losing more ground as journalistically interesting outlets of distinguished topics? Or will they manage to find footing and retain their specialization? Amid challenges to traditional institutionalized print newspapers from quick digitalization, modified reading habits and highly differentiated audiences, supplements might well prove to be a durable format.

Figure 7.1 shows visible growth in volume for all content of the newspapers, especially from 1980 onwards; however, growth decreased between 2000 and 2010. Still, between 1960 and 2010, newspaper issues more than doubled their pagination from less than forty pages in 1960 to almost 100 pages in 2010. Cultural coverage growth was even more remarkable. The overall space devoted to culture almost tripled from approximately three pages per edition in 1960 to approximately nine pages per edition in 2010. However, the trend is not linear; it spiked between 1960 and 1970 and again between 1980 and 2000. While Verboord and Janssen (2015) reported that the size of the Dutch, German, French and US newspapers they examined increased between 1955 and 2005, our data (which extends five years further) shows a decrease in the size of full newspapers, likely a trend that will be even more pronounced as the rapid digitalization of media continues.

The more interesting trend is the growth of cultural coverage in culturerelated supplements. In 1960 and 1970, there was practically no coverage in supplements, and in 1980 and 1990, only a fraction of all cultural coverage was in supplements, accompanied by general growth in core newspapers. A peak year for supplements was 2000: nearly half of all coverage was in supplements. The shift towards supplements began earlier in cultural coverage than in general content (there was some cultural content in the supplements in 1970 and 1980, but when observing all content, almost all coverage is in the core newspaper) 

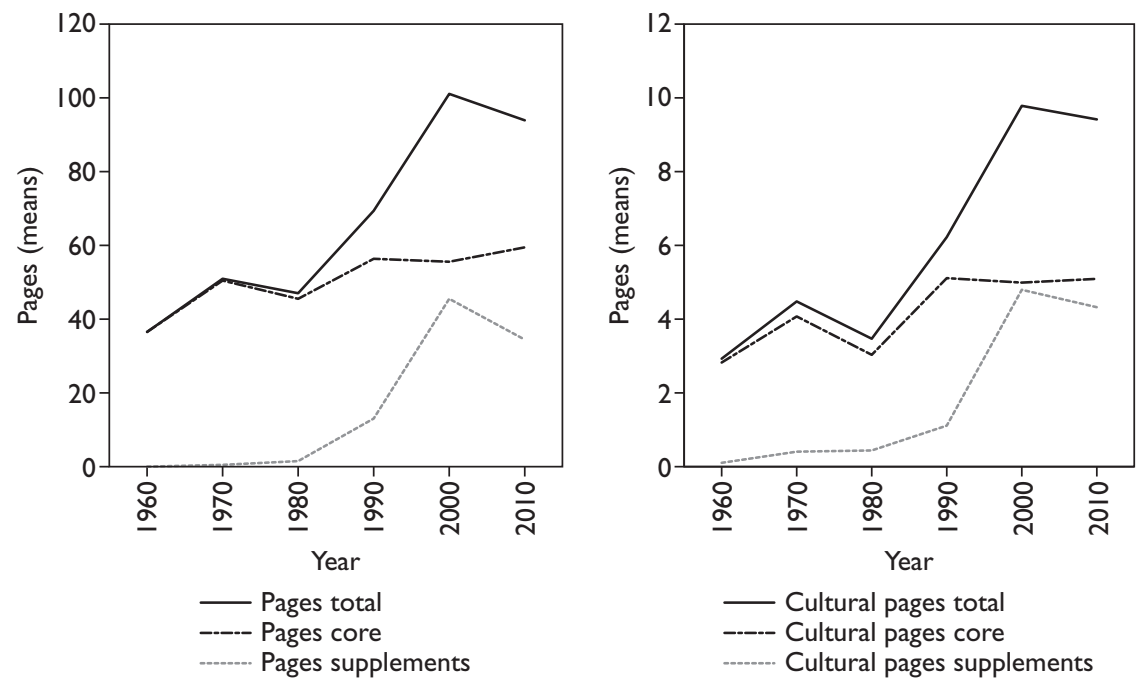

Figure 7.l Pages per issue (means) by year and whether the content has been published in 'core' newspaper or supplement, separately on the entire issue (left) and sections devoted to culture (right).

but happened more slowly. In 2010, the total volume of all newspaper content declined, but the loss of pages occurred only in supplements. Cultural coverage did not resist the declining trend, but its loss of content in supplements was not as significant as the loss of overall content.

\section{The place of culture}

Newspapers have always published coverage of cultural topics, but culture sections were established only in the 1950s (Hurri, 1993; Jaakkola, 2015). Thus, the consolidation of culture sections is a recent phenomenon, which we encountered when collecting data: in the early editions of 1960, some cultural coverage was difficult to discern simply because specific news, sports or culture sections were not established. For instance, Helsingin Sanomat has news on culture, politics, weather and birthdays of important people on the same page in year 1960. ${ }^{5}$

Increasing leisure time, growing wealth, a strong increase in the supply of cultural products, increasing public and private financial support for the arts and a growing number of intermediaries throughout Western countries were influential factors behind the expansion of cultural coverage in newspapers (Verboord and Janssen, 2015). Besides growth in the amount of newspaper coverage on culture and the arts, there has been an important diversification in the supply (although, as seen in Chapter 2, cultural coverage still tends to focus on the most canonical forms of art: literature, music, theatre and the visual arts). 
This has led to consolidated culture sections with explicit vignettes signalling the topics covered.

Our point of departure is the idea that the hierarchy of topics inside a newspaper is indicative of the hierarchy of those topics in a given society. In other words, we assume that if a given section is placed in the beginning of a newspaper, it is granted more symbolic value than a section placed in the middle or at the very end of the paper, and we interpret shifts in the placement of sections as reflecting shifts in hierarchies (Stegert, 1998). To better understand the symbolic value that culture sections have had in different years, we investigate in detail the placement of culture sections within newspapers. Empirically, the question of place is twofold: at what end of the newspaper has the culture section been located in different years, and what has been its location in relation to other important sections?

To answer the first question, we divided the core newspapers into four parts according to the full pagination using our issue data $(n=585)$. Then, we inspected in which of these quarters the culture sections started. ${ }^{6}$ Figure 7.2 shows that the locations of the culture section have been far from stable. In 1960, all culture sections (with the exception of Le Monde, in which the culture section is in the third quarter) are firmly located around the second quarters of the newspapers. In 1960, newspapers contained approximately thirty-five pages, meaning that the culture sections typically started well before page 10, again excepting Le Monde. This trend was strong until 1980. The Guardian (followed by Le Monde) was the first newspaper to move its culture section further away, close to the last quarter of the newspaper. In all the newspapers (except Dagens Nyheter, which kept its culture section between the first and second quarter throughout the period), the culture sections moved towards the ends of the newspapers over time. Thus, in 2010, the culture sections of El País, Helsingin Sanomat, Le Monde and The Guardian were located in the third or fourth quarters of the newspapers. Here we do not pay attention to the larger processes behind this trend (technological changes, changes in layouts, illustrations etc.), but on a larger scale, there is a trend of the culture sections moving slowly towards the ends of newspapers.

How, then, were the culture sections located in relation to other important sections? To examine this, we used our full edition data $(n=30)$ to determine the exact positions of the culture sections. We first separated the clusters of national news ( $\mathrm{n})$, international news (i), culture (c) and sports (s), all established and recognizable parts of the newspapers. For other sections, such as economics or employment, we chose to observe closer the interplay of sport and culture, sport - with the exception of some specific elite sports - traditionally being linked to popular culture and culture (as the arts) to the highbrow culture. We identified the clusters via a simple close reading of each edition, interpreting several subsequent pages about the same topic as constituting a section.

Table 7.1 shows that most of the newspapers have been loyal to their own internal structures throughout the years, with few or no changes in the locations 


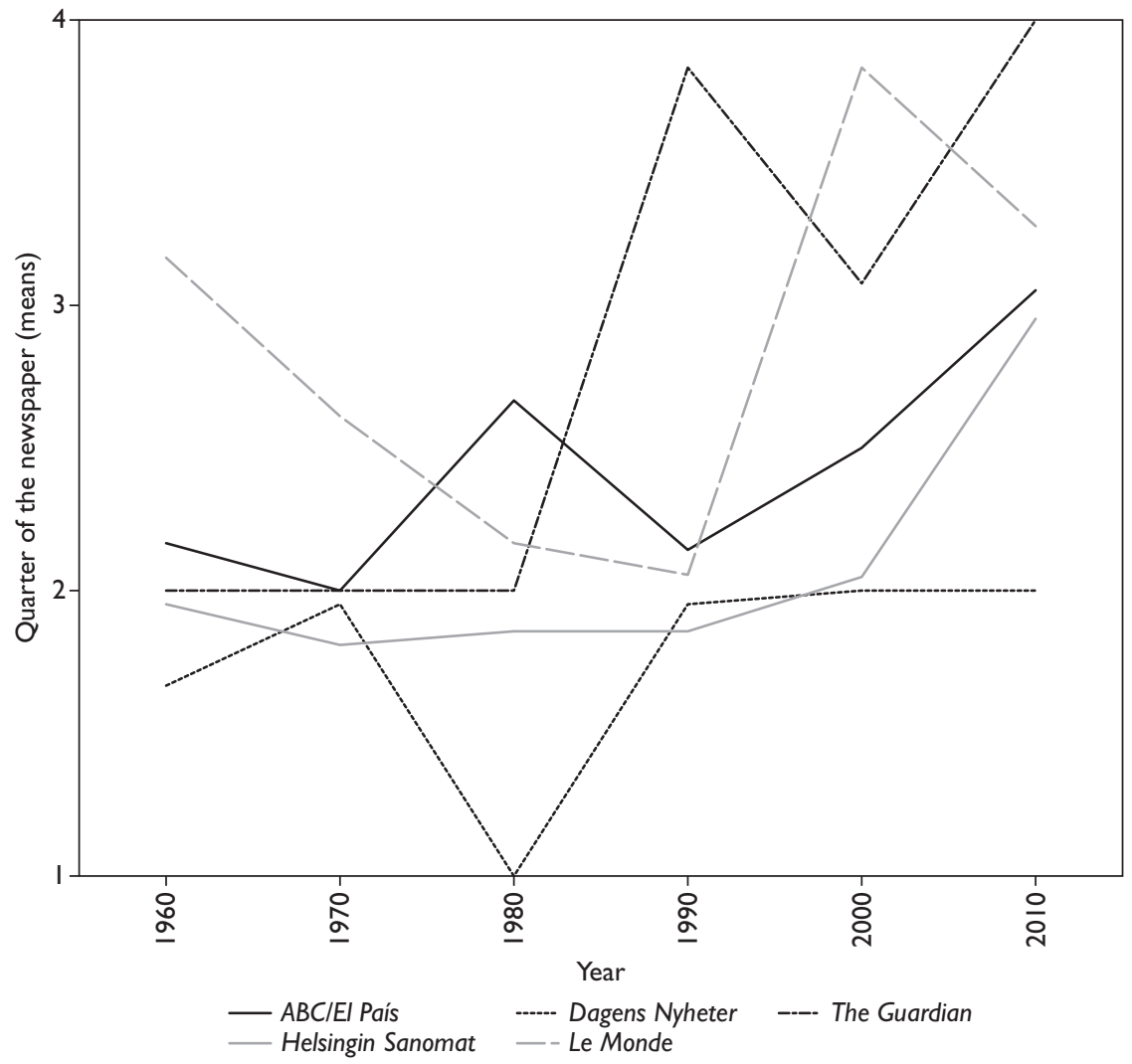

Figure 7.2 The quarter of the first cultural page by year and newspaper (means).

Table 7.I The locations of culture sections in newspapers by newspaper and year

\begin{tabular}{lllllll}
\hline & 1960 & 1970 & 1980 & 1990 & 2000 & 2010 \\
\hline ABCIEI País & $\mathrm{i}-\mathrm{n}-\mathrm{s}-\mathrm{c}$ & $\mathrm{i}-\mathrm{n}-\mathrm{s}-\mathrm{c}$ & $\mathrm{i}-\mathrm{n}-\mathrm{c}-\mathrm{s}$ & $\mathrm{i}-\mathrm{n}-\mathrm{c}-\mathrm{s}$ & $\mathrm{i}-\mathrm{n}-\mathrm{c}-\mathrm{s}$ & $\mathrm{i}-\mathrm{n}-\mathrm{c}-\mathrm{s}$ \\
Dagens Nyheter & $\mathrm{n}-\mathrm{i}-\mathrm{c}-\mathrm{s}$ & $\mathrm{n}-\mathrm{i}-\mathrm{c}-\mathrm{s}$ & $\mathrm{n}-\mathrm{i}-\mathrm{c}-\mathrm{s}$ & $\mathrm{n}-\mathrm{i}-\mathrm{c}-\mathrm{s}$ & $\mathrm{n}-\mathrm{i}-\mathrm{c}-\mathrm{s}$ & $\mathrm{i}-\mathrm{n}-\mathrm{c}-\mathrm{s}$ \\
The Guardian & $\mathrm{n}-\mathrm{s}-\mathrm{c}-\mathrm{i}$ & $\mathrm{i}-\mathrm{n}-\mathrm{c}-\mathrm{s}$ & $\mathrm{n}-\mathrm{i}-\mathrm{c}-\mathrm{s}$ & $\mathrm{n}-\mathrm{i}-\mathrm{s}-\mathrm{c}$ & $\mathrm{n}-\mathrm{i}-\mathrm{c}-\mathrm{s}$ & $\mathrm{n}-\mathrm{i}-\mathrm{c}-\mathrm{s}$ \\
Helsingin Sanomat & $\mathrm{n}-\mathrm{c}-\mathrm{i}-\mathrm{s}$ & $\mathrm{n}-\mathrm{c}-\mathrm{i}-\mathrm{s}$ & $\mathrm{n}-\mathrm{c}-\mathrm{i}-\mathrm{s}$ & $\mathrm{n}-\mathrm{c}-\mathrm{i}-\mathrm{s}$ & $\mathrm{n}-\mathrm{c}-\mathrm{i}-\mathrm{s}$ & $\mathrm{n}-\mathrm{i}-\mathrm{s}-\mathrm{c}$ \\
Le Monde & $\mathrm{i}-\mathrm{n}-\mathrm{s}-\mathrm{c}$ & $\mathrm{i}-\mathrm{n}-\mathrm{c}-\mathrm{s}$ & $\mathrm{i}-\mathrm{n}-\mathrm{s}-\mathrm{c}$ & $\mathrm{i}-\mathrm{n}-\mathrm{s}-\mathrm{c}$ & $\mathrm{i}-\mathrm{n}-\mathrm{s}-\mathrm{c}$ & $\mathrm{i}-\mathrm{n}-\mathrm{c}$ \\
\hline
\end{tabular}

Notes

$\mathrm{c}=$ culture section; $\mathrm{i}=$ international news section; $\mathrm{n}=$ national news section; $\mathrm{s}=$ sports section. 
of these four key sections. For instance, Helsingin Sanomat and Dagens Nyheter maintained the exactly same structure between 1960 and 2000; in 2010, Dagens Nyheter changed the internal sequence of national and international news, keeping the culture section untouched, while Helsingin Sanomat moved it from immediately after the national news to the last position after all other sections, including sport. In general, the newspapers have maintained their own internal hierarchies: Le Monde and the Spanish newspapers always used international news as their cover stories, whereas the two Nordic newspapers started with a section on national news (except for Dagens Nyheter in 2010, when it began opening with international news). In 2010, the Sunday edition of Le Monde did not have any sports section, locating sport in a supplement from the previous day. It should be noted that we are studying only Sunday (or weekend, in the case of newspaper with no Sunday issue) sections. It could be that Sunday editions (with larger circulations and more established readerships) are more conservative and less prone to change than weekday editions.

\section{The packaging of culture}

In this section, we return to our main newspaper data (with the article as the unit of analysis) and examine a crucial aspect of packaging cultural content, namely, how our quality European newspapers' culture sections have evolved over time regarding published article types. In addition to article type, we will focus on article size.

Our variable for the type of the article, the significance of which we have demonstrated in previous chapters (see Chapters 3, 5 and 6), includes nine categories, the most relevant being review, interview, report/feature and news (see all categories in Table 7.2). ${ }^{7}$ Table 7.2 shows overall stability regarding the

Table 7.2 Type of article by year (percentages)

\begin{tabular}{lrrrrrrr}
\hline & 1960 & 1970 & 1980 & 1990 & 2000 & 2010 & Total \\
\hline Review & 25.3 & 20.4 & 34.6 & 30.5 & 31.6 & 32.1 & 29.4 \\
News & 24.1 & 34.7 & 21.4 & 17.7 & 20.2 & 19.6 & 22.4 \\
$\begin{array}{l}\text { Announcement/ } \\
\quad \text { list }\end{array}$ & 19.4 & 22.7 & 14.2 & 20.7 & 17.2 & 19.8 & 19.1 \\
$\begin{array}{l}\text { Report/feature } \\
\text { Commentary }\end{array}$ & 12.5 & 8.2 & 15.3 & 15.6 & 14.1 & 10.0 & 12.5 \\
$\quad$ text & 5.0 & 3.3 & 6.4 & 7.5 & 6.8 & 7.8 & 6.4 \\
$\begin{array}{l}\text { Interview } \\
\text { Preview }\end{array}$ & 1.7 & 2.9 & 4.1 & 4.6 & 5.5 & 6.4 & 4.6 \\
$\begin{array}{l}\text { Artistic text/ } \\
\quad \text { fiction }\end{array}$ & 6.7 & 6.7 & 3.0 & 2.7 & 3.6 & 2.2 & 3.9 \\
Other & 5.1 & 0.8 & 0.7 & 0.5 & 0.3 & 0.8 & 1.1 \\
$\begin{array}{l}\text { Total } \\
\text { (N) }\end{array}$ & 0.2 & 0.4 & 0.4 & 0.3 & 0.6 & 1.4 & 0.6 \\
\hline
\end{tabular}


proportions of different types of articles in our newspaper coverage. Since 1980, reviews have been clearly the most common article type at about one-third of all articles. ${ }^{8}$ Similarly, since 1980 , the proportion of the second-most-common article type, news stories, has remained stable at around 20 per cent. Thus, reviews and news seem to be counterparts, together accounting for about half of all articles in culture sections.

The third most ubiquitous article type is announcements/lists, ${ }^{9}$ about 20 per cent of all articles, showing no clear trend. From all other smaller article types, only two have clear trends: interviews, which increased from 1.7 per cent to 6.4 per cent of all articles and previews, which showed an opposite trajectory.

Article size is another crucial feature that characterizes cultural content published in newspapers. We interpret that a decrease in the length of articles covering culture (cf. Janssen et al., 2008; Jaakkola, 2015) would refer to more fragmented culture sections. Table 7.3 shows how article size has varied over time. Our article size variable measures size in relation to newspaper pages and has six categories, ranging from multiple pages to 'very small' (referring to an article of ten lines or less). Article size measured this way encompasses both text and illustrations.

The main result shown in Table 7.3 is that the relative number of small articles decreased and the number of half-page, full-page and multiple-page articles increased (though in the 2000s, the proportion was still moderate). The relative proportion of mid-sized articles was more or less stable.

As article type and size are most likely related, adjusting the proportions of article types presented in Table 7.2 by article sizes will reflect actual newspaper coverage better than numbers based on relative counts of articles. Table 7.4 shows size-adjusted proportions of the four main article types.

Reviews show hardly any difference. The situation is radically different for news coverage, which is much smaller than the number of articles indicates: the overall proportion of news drops from 22.4 per cent (calculated by number of articles) to 12.7 per cent (calculated by size-adjusted proportion). For both reports/features and interviews, coverage is much larger than the number of articles indicates. Report/feature coverage has been (with the exception of

Table 7.3 Sizes of articles by year (percentages)

\begin{tabular}{lrrrrrrr}
\hline & 1960 & 1970 & 1980 & 1990 & 2000 & 2010 & Total \\
\hline Very small & 14.7 & 15.2 & 8.1 & 8.1 & 5.6 & 15.6 & 11.0 \\
Smaller & 61.7 & 57.7 & 53.0 & 46.1 & 44.1 & 42.9 & 49.3 \\
Quarter page & 13.2 & 15.5 & 22.8 & 25.0 & 25.2 & 17.8 & 20.5 \\
Half page & 6.0 & 5.0 & 12.6 & 17.2 & 16.8 & 12.8 & 12.5 \\
Full page & 1.9 & 0.9 & 1.8 & 2.2 & 4.8 & 4.9 & 3.1 \\
Multiple page & 2.5 & 5.7 & 1.7 & 1.3 & 3.4 & 5.9 & 3.7 \\
Total & 100.0 & 100.0 & 100.0 & 100.0 & 100.0 & 100.0 & 100.0 \\
$(\mathrm{~N})$ & $(1,467)$ & $(2,015)$ & $(1,538)$ & $(2,219)$ & $(3,058)$ & $(2,864)$ & $(13,161)$ \\
\hline
\end{tabular}


Table 7.4 Coverage (size-adjusted proportion) of main article types by year (percentages)

\begin{tabular}{lrrrrrrr}
\hline & 1960 & 1970 & 1980 & 1990 & 2000 & 2010 & Total \\
\hline Review & 26.1 & 20.3 & 37.0 & 31.8 & 26.7 & 30.2 & 28.5 \\
News & 15.1 & 23.4 & 12.6 & 10.5 & 9.9 & 10.4 & 12.7 \\
Report/feature & 22.4 & 9.5 & 22.1 & 23.2 & 21.4 & 18.9 & 19.6 \\
Interview & 3.7 & 5.2 & 8.1 & 7.4 & 11.7 & 15.1 & 9.9 \\
\hline
\end{tabular}

1970 ) around 20 per cent of all coverage (the number of articles indicates only 12.5 per cent), and interview coverage rose to 15 per cent in 2010, meaning that overall coverage doubled compared to the proportion based on the number of articles.

We can thus see that news stories are often briefer than average articles, whereas reports/features and interviews are substantially longer. Regarding reports/features and interviews, the differences between the numbers of articles and coverage were particularly significant in the 2000s, meaning that they have been especially long only recently. The length of reviews, on the other hand, has been surprisingly stable. These results support our decision to emphasize the role of interviews and reports/features (see Chapter 3), and to treat reports/ features and interviews as a combined category of article type contrasting both news and reviews. Furthermore, the turn towards longer articles and an increase in the coverage of interviews and reports/features in the 2000s suggest that there has been a trend towards personalized styles of writing, which can be seen as linked to the changing professional ethos of cultural journalism oriented towards emotional appeal, human-interest aspects and storytelling (cf. Kristensen, 2010; Akola et al., 2015).

To summarize these tendencies and relationships, Figure 7.3 shows how our newspapers differ from each other regarding the prevalence of the main article types when using size-adjusted proportions, and how those proportions evolve over time. El País is the most stable of the newspapers and particularly focuses on publishing interviews and reports/features. The Guardian and Le Monde have given primacy to reviews and published very few news stories about culture. In Dagens Nyheter and Helsingin Sanomat, the three main article types are closer to each other: they have significantly published cultural news, especially in 1960-1970, but eventually the coverage of news has declined (in Helsingin Sanomat to almost none). Finally, Milliyet is the only newspaper that has published predominantly news (in 1970-1990), but even Milliyet demonstrates the major trend that is shared by all the newspapers: interviews and reports/features have received increasing space, especially in the 2000s. Mostly this has happened at the cost of news reporting, not reviewing (except in The Guardian). 


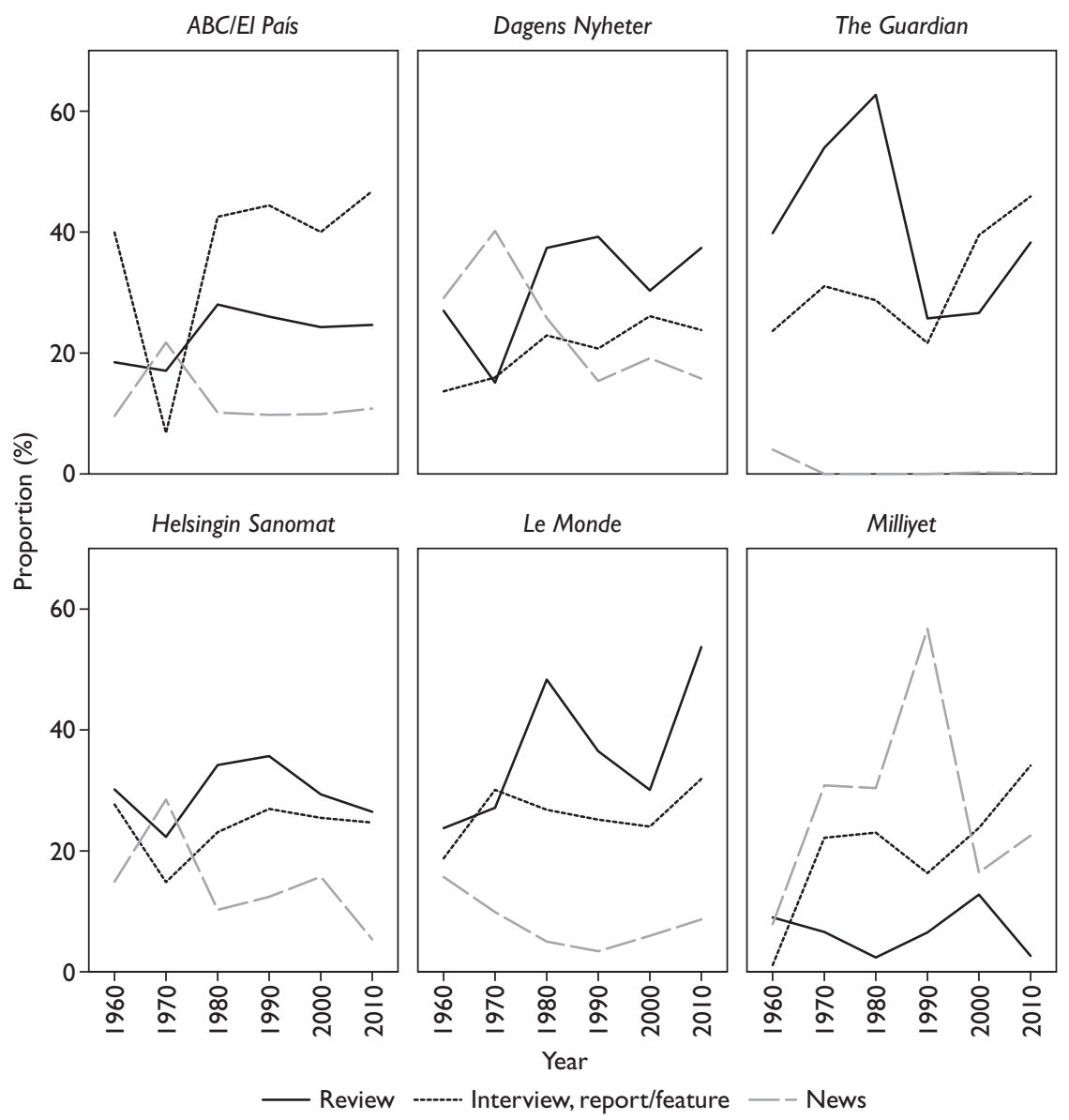

Figure 7.3 Size-adjusted proportions of main article types of all articles by year, separately on each newspaper (percentages).

\section{Is there a 'crisis'?}

Article type and size are arguable two major characteristics that determine how content in newspaper culture sections is packaged. However, there are also many other possible indicators for the crisis of cultural journalism that might measure journalistic popularization more directly than article type or size can. To answer more thoroughly whether the discourse of the crisis is well grounded in the case of our quality European newspapers, Table 7.5 presents trends over the years according to eight indicators of possibly increased popularization. The indicators touch upon visualization, personification and literary or linguistic level. 
The first three indicators measure visualization: whether the article is illustrated in the first place, whether the illustrations are large and whether the illustrations present pictures (photographs or drawings) of the artists. We expect that a strong visualization of culture (Hartley, 1992) is a central feature of the modern newspaper, competing for audiences through visual attractiveness (Verboord and Janssen, 2015). Visual media outlets with large pictures are easily scanned without the need to immerse oneself in reading. Besides possible pictures of artists, also two other indicators measure personification: whether the author of the article is mentioned (versus anonymity); and whether the article has been written using a first person point of view (a subjective dimension). These indicators of personalization increase 'emotional appeal, storytelling, debate and entertainment' (Jaakkola et al., 2015: 10). Finally, indicators of literary or linguistic level measure how challenging the text of the article is in literary terms: whether the article includes '-isms' (e.g. surrealism, impressionism), whether the article includes more than ten cultural references (e.g. proper nouns of cultural products, artists' names, brands), and whether the first paragraph is longer than fifteen lines. These indicators are linked to the crisis of cultural journalism discourse, and their strong decrease would suggest that there is a rupture in traditional legitimate newspaper writing (cf. Carroll, 2009; Elkins, 2003; McDonald, 2007).

The results of Table 7.5 strongly support the trend of the popularization of journalistic means used in presenting art and culture via increased visualization. The growth of the relative number of illustrated articles is dramatic: while in 1960 only one-quarter of articles were illustrated, over two-thirds were in 2010. This echoes the conclusions of Verboord and Janssen (2015) on their Dutch, German, French and US newspapers. In addition to increased visualization, the results support, with the exception of the subjective tone of texts, which did not increase, the personification of journalism, both by artists being presented in pictures and by naming journalists. However, no indicators of literary level show impressive or systematic trends over time. -Isms have not become more ubiquitous since the peak-year 1980; only in 1960 and 1970 were there fewer-isms in articles than ever since. The same is true with many cultural references, which have no clear trend after 1980, but 1960 and 1970 show fewer cultural references than other years. In the case of long first paragraphs, the change over time is even less systematic.

To summarize, we can observe clear trends towards an idea of visually appealing (long, illustrated) culture sections with a slight tendency towards humaninterest or personal/storytelling-oriented articles, in line with our previous analysis (e.g. Chapter 3). Moreover, we already know that articles are increasingly discussing popular culture over highbrow arts (Chapter 2 ). This may point towards a crisis of cultural journalism, but it could also be interpreted as a solidification of culture sections: resisting obvious commercialization (Chapter 5) and political pressures (Chapter 6), and still covering traditional highbrow cultural domains and being almost stubbornly dominated by national culture (even if 


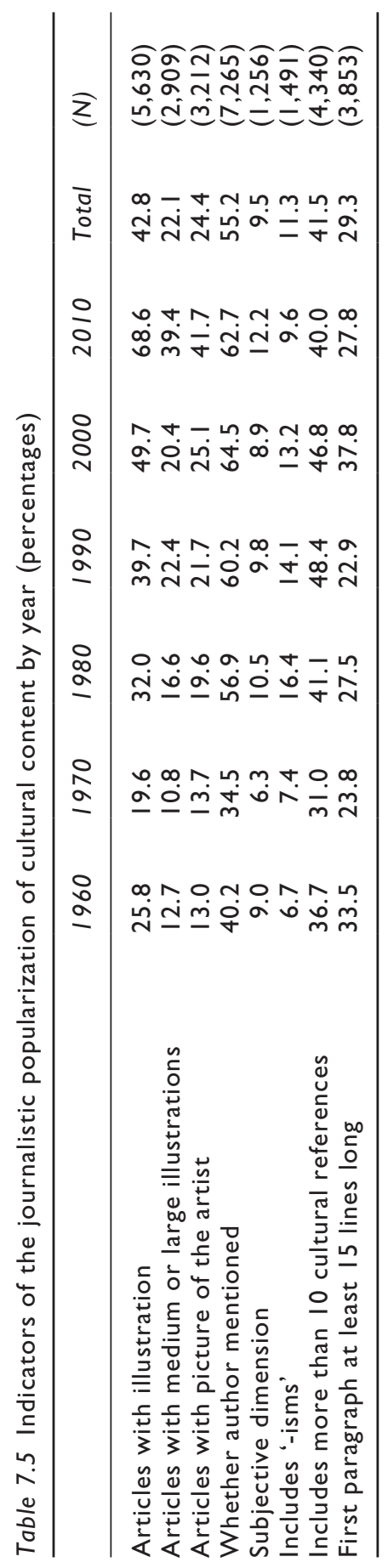


the influence of American culture may be on the rise; Chapter 4), the newspapers take on cultural trends and do their best to survive in a rapidly changing mediatic landscape.

The key question is whether articles on popular culture and highbrow arts are similar or different in terms of journalistic means of representing and packaging culture. The result is essentially that trends in packaging cultural content apply to both highbrow and popular culture. This is shown in Figure 7.4. If broken down by article type, there are few differences in the proportion of long, illustrated articles between highbrow and popular culture articles.

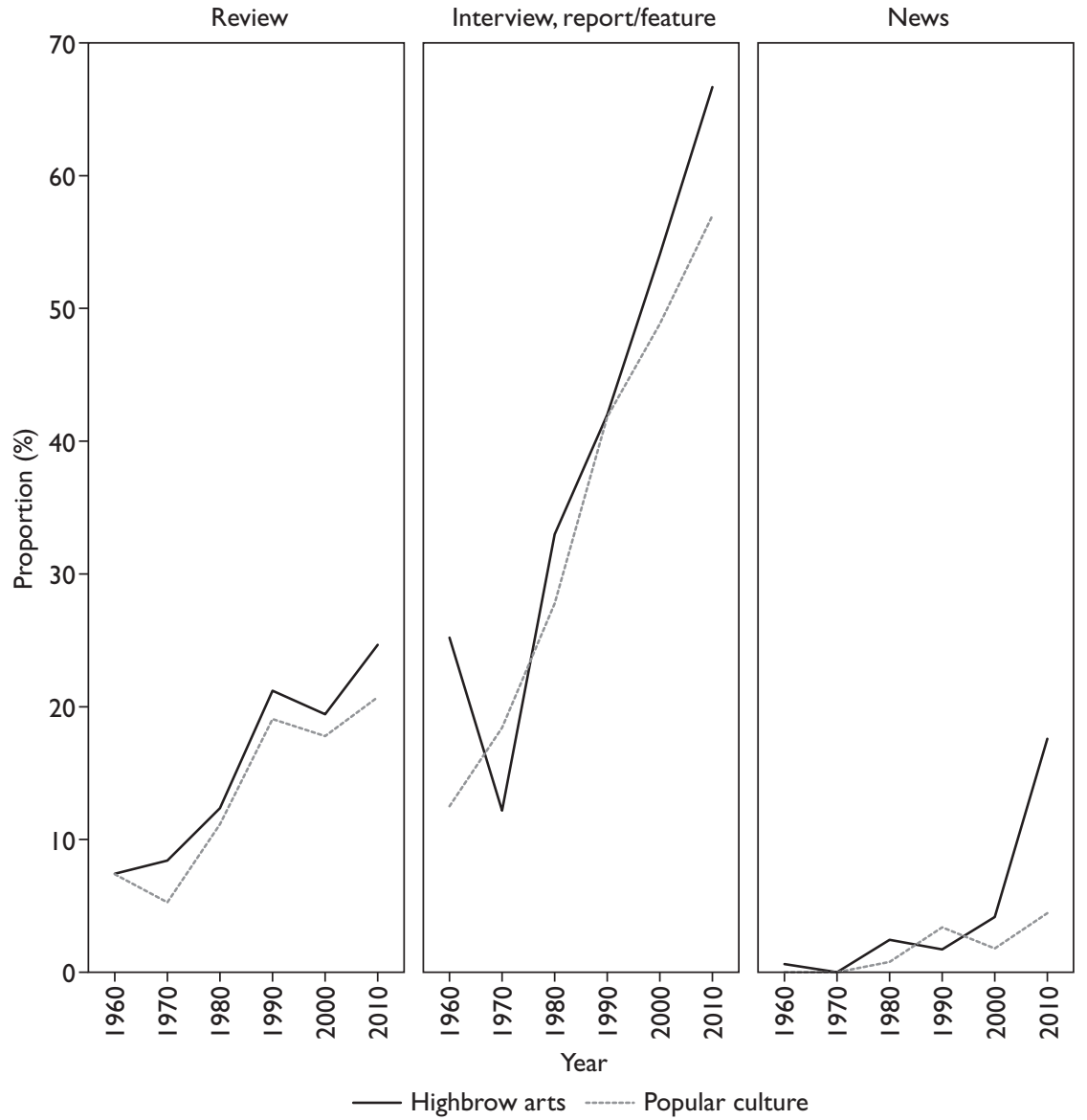

Figure 7.4 At least half-page long and illustrated articles on highbrow arts and popular culture by year, separately on main article types (percentages). 


\section{Culture cover stories}

The culture sections are not newspapers in their own right, but as they do usually have some organizational journalistic independence, and sometimes even their own layouts and visual images, they can be thought to form a kind of unity inside the wider newspaper frame. In this vein, the first and usually largest article of the culture section can be considered to be its cover story, a status that signals that a specific topic has made it to the news agenda (Luostarinen and Uskali, 2006: 182-183).

Because our analyses of previous chapters have indirectly suggested the importance of cultural cover stories (those long, often illustrated articles including journalistic orientations or human-interest elements) has grown over the years, we decided to scrutinize cover stories more systematically. Cover stories becoming increasingly important would be a sign of growing journalistification (and journalistic popularization). Fortunately, cover stories were detectable from the statistical matrix by combining information from variables indicating page numbers for articles in culture sections, locations of articles on newspaper pages and article sizes. Cover stories constitute the first articles on the first page of each culture section that are at least half a page long, namely, articles that fill the upper half of the first page in culture sections.

Table 7.6 shows how cover stories have been distributed across newspapers and art forms over the years. It also presents other key characteristics of cover stories. The most significant finding is in the first row of Table 7.6, which shows how the absolute number of cultural cover stories varies across the years. The number of clearly identifiable cultural cover stories increased considerably after 1970, ending at ninety-one in 2010 (the theoretical maximum in each year being ninety-nine). This is strong evidence showing how cultural cover stories have become the norm in the context of packaging of cultural content in quality European newspapers. There are some differences between newspapers, however. The Spanish ABC had a proper cover story in all except one issue in 1960 but very rarely in 1970. El País has had a cover story in every issue since 1990. Similarly, Dagens Nyheter has had cover stories from 1980 onwards, except not always in the last year. ${ }^{10}$ The Guardian has had a clearly identifiable cover story the least often, the cover story becoming standard only in 2010. Cover stories have been the norm in Helsingin Sanomat since 1990 and in Le Monde, since 2000.

When the proportions of cultural cover stories are viewed according to the main art forms, the results differ from art forms' relative sizes in terms of entire cultural coverage (see Chapter 2). This is significant, since a cover story attracts more readers, influence and prestige than regular articles. Literature has received the most cover story coverage of the art forms, followed by film, theatre, the visual arts (which almost doubled its proportion in comparison to all articles) and popular music. It is noteworthy that classical music has had surprisingly few cover stories, less than half of its proportion of total number of articles. 


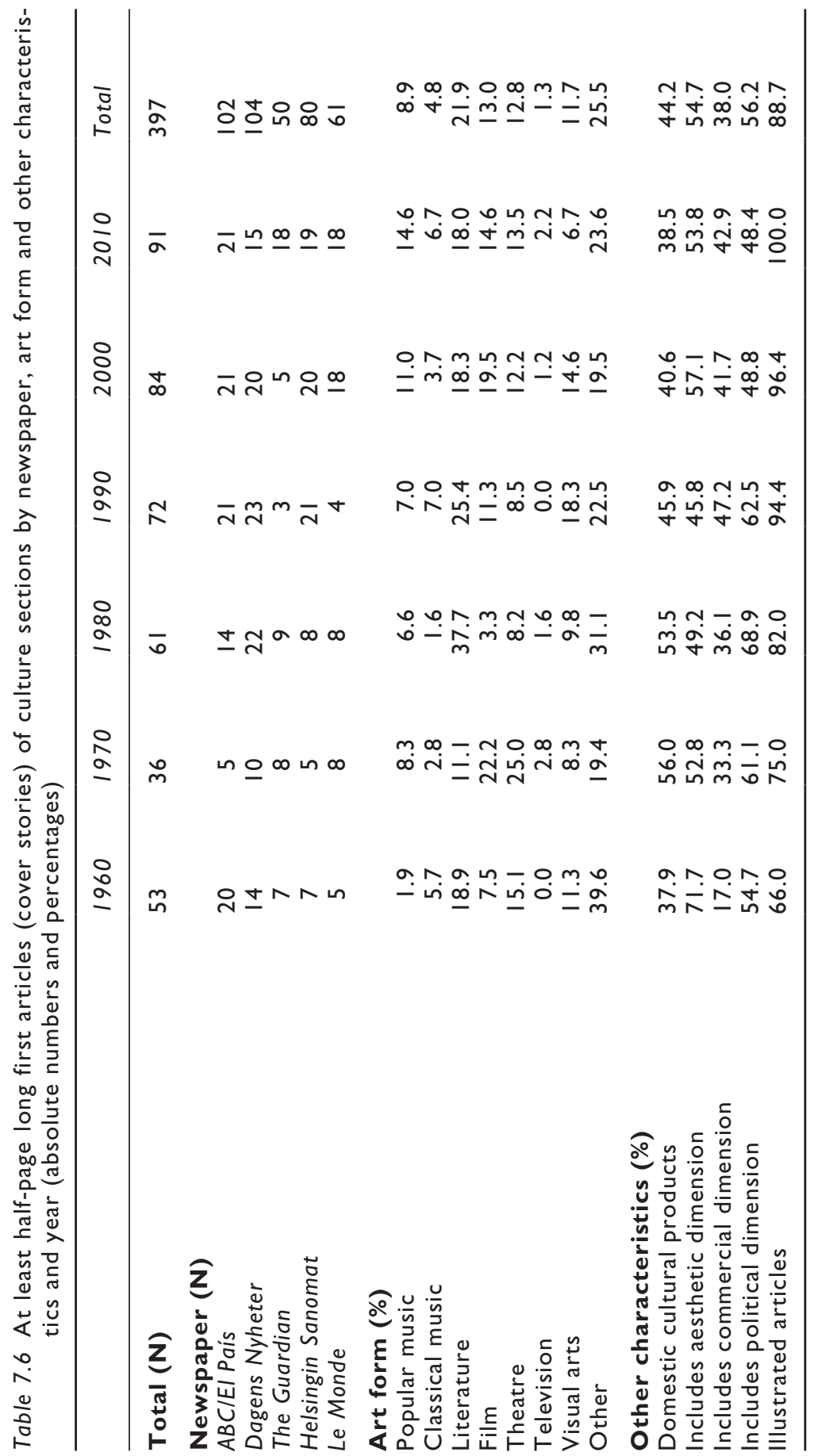


Television is the most extreme case with only 1.3 per cent of all cover stories, compared to 7 per cent of all articles (cf. Box 3.2). ${ }^{11}$

The general popularity of literature cover stories may be because literature coverage can be conveniently tied around both a human-interest topic (the author) and the cultural product. For instance, the Helsingin Sanomat article 'A Californian Boy meets Virginia Woolf' (HS/24/08/00_B8) is a colourful and appealing article on Michael Cunningham upon his publication of The Hours. First there is an author interview accompanied by a large colour picture of him laughing, apparently during the interview, followed by a review of The Hours by a well-known Finnish academic and translator of Virginia Woolf.

That film, theatre and the visual arts are all well pronounced in terms of cover stories is more intuitively explained: they are visually attractive products, and there usually are ample press pictures of films, shows, paintings or other pieces of visual art for newsrooms to use. In 1970, theatre was the most common topic for cover stories (e.g. DN/12/11/70_10), but in the 2000s, there were still plenty of cover story articles on theatre, contrasting sharply to theatre's actual coverage in the data (a radical decrease since 1970). For instance, in 2010, half of The Guardian's cover stories (nine out of eighteen) focused on theatre, typically accompanied by pictures of the play and an allusive title such as 'Little Method to the Madness in this Light Asylum Yarn' (GU/11/09/10_36) or 'Delightfully Dotty Conchords Prove They're Too Good to be Bad' (GU/12/05/10_36).

Cover stories on popular music experienced a sharp increase over the years, following the trend of general cultural coverage. In 2010, popular music was as common for cover story material as film, surpassed only by literature. Popular music cover stories were typically visually oriented articles on pop stars. For instance, in a 2010 edition of Dagens Nyheter, the first page of the culture section opened with a nearly full-page picture of Axl Rose of Guns N' Roses and one word serving as a title: 'Magnetic' (DN/14/06/10_Kultur1).

Finally, Table 7.6 shows other characteristics of cover stories, each relating to the key variables used in the analyses presented earlier: the proportion of domestic cultural products discussed in articles (Chapter 4); whether articles include an explicit aesthetic dimension (Chapter 3), commercial dimension (Chapter 5) or political dimension (Chapter 6); and whether articles are illustrated. Cultural cover stories show tremendous differences compared to total article coverage while accentuating some key trends. The proportion of domestic cultural products decreased after 1970, and cover stories were slightly more often about foreign cultural products than were regular articles. The difference between cover stories and regular articles is more substantial in the case of other indicators. An aesthetic dimension (i.e. direct vocabulary with which aesthetically normative judgements are made) is generally more common, especially in early cover stories. Both commercial dimensions (i.e. direct vocabulary using economic indicators) and political dimensions (i.e. direct vocabulary using politically charged watchwords) are twice more typical in cover stories of culture than in regular articles. Lastly, the proportion of cover stories including 
illustrations was high already in 1960, with two-thirds of cover stories being illustrated (which is 2.5 times more often than in regular articles). The proportion rose steadily to reach 100 per cent in 2010.

The prevalence of different cultural domains in these cover stories is indicative of their status, but more than anything, they are a sign of the intensive visual orientation of cultural journalism. For instance, the fact that culture sections are consolidating in general can be seen as the growth of pages with clear cover stories, which serves as a cue and persuasion for the reader to continue reading.

\section{Conclusion}

In this chapter, we have traced the trajectories of the space and place of culture sections, examined in detail the changes in the packaging of cultural content, observed possible indicators of journalistic popularization of culture sections and finally examined the often long and illustrated lead articles of the culture sections of our quality European newspapers.

We have seen that the space allotted for culture expanded radically between 1960 and 2010, supplementation being an important phenomenon from 1990 onwards and especially in the 2000s, when the growth of cultural coverage was mainly concentrated in these specialized forums. The place of culture sections shifted between 1960 and 2010, moving closer to the ends of newspapers. At the same time, individual newspapers have retained their own structures: in terms of the internal order of national, international, culture and sports sections, many newspapers are surprisingly similar from 1960 to 2010. The relative proportion of reviews and interviews grew. Large articles took over space from small ones. When scrutinizing the size-adjusted proportions, reviews remained stable; report/feature articles and interviews received much more concrete space in newspapers than their actual amount would indicate. When observing indicators of popularization, we noticed that culture sections did face a shift towards more visually attractive or eye-catching topics from popular culture domains, and some indicators of the personal element in the texts grew as well.

The case of cover stories complements our main findings: emergent popular culture such as television is rarely featured in the first articles of culture sections, which favour highbrow cultural domains such as literature, theatre and the visual arts. Again, the trend took place within highbrow arts (cf. Chapters 2 and 3). Cover stories also showed that popularization is essentially channelled by journalistic ways of presenting and representing culture and art in culture sections. Finally, cover stories, being longer than other articles, combine aesthetic, commercial and political dimensions more often than average articles (cf. Chapters 3, 5 and 6) with both highbrow and popular culture coverage (cf. Chapter 3).

Newspaper cultural coverage has expanded between 1960 and 2010, along with the increasing length of newspapers in general, but cultural coverage alone 
has faced more spectacular growth (which also means that culture's relative share within newspapers has grown). Furthermore, a large part of the growth is due to the enormous impact of cultural supplements launched in the 1990s and strengthened throughout the 2000s. Our findings echo other scholarly findings on increasing cultural coverage, growing popularization, increased visual attractiveness and, in general, increased willingness to purvey coverage for the needs of a new kind of eclectic reader-consumer that is interested in being updated about the growing and differentiating supply of cultural flows (Verboord and Janssen, 2015). On the journalistic level, we are certainly witnessing a change towards a journalistic paradigm (Hellman and Jaakkola, 2012): while we do not see an increase in direct news content, we do trace a shift towards new journalistic representational forms such as listings, star ratings and visual elements.

Contemporary cultural journalism is situated 'in a continuum between art, popular culture, lifestyle and consumption' (Kristensen, 2010: 69). The same could be said about the culture sections in newspapers. Several partly overlapping trends have all had an influence, producing a shift towards popularization and a strong move towards visualization. The development of different information technologies and a growing competitive media market have also had an impact. It might be better to speak of a crisis of journalism (challenges to traditional printed press as a whole) rather than a crisis of cultural journalism, which is only responding to the numerous challenges around it.

\section{Notes}

1 See, for example, Bourdieu, 1998b, 2005; Elkins, 2003; Hallin, 2005; Carroll, 2009; for a review, see Jaakkola, 2015; and Heikkilä et al., 2017.

2 For details concerning issue data and full edition data, see Appendix A. Milliyet is not included in these additional datasets because its structure has been unclear, especially in the early years, and culture sections were generally not easily identifiable. Between 1960 and 1980, cultural content of a daily paper was dispersed among several untitled pages. Moreover, in certain periods, the cultural content was reported in a daily supplement, which sometimes took the form of an entertainment magazine (Yaşam) or a separate twin newspaper (Milliyet 2000) (see Appendix Table B.1). Hence, there is no comparable way of estimating how Milliyet's cultural content was related with other sections of the newspaper.

3 See, for example, Janssen, 1999; Straw, 2005; Weibull and Nilsson, 2010; Janssen et al., 2011; Jaakkola, 2015; and Kristensen and Riegert, 2017.

4 Cultural journalists and critics are just one part of a much larger chain of different cultural mediators at varying levels. For instance, Janssen and Verboord (2015) distinguish gatekeeping, co-creating (or editing), connecting/networking, selling/marketing, distributing, censoring/protecting/supporting and 'evaluating, classifying and meaning making' (Janssen and Verboord, 2015: 441-442) as different forms of mediating culture. Each can be thought to have a role in the process of deciding which cultural products receive attention in the media.

5 See, for example, Helsingin Sanomat, 11 January 1960, p. 6. Echoing the finding that the 1960s marks an important moment for newspaper sections, Verboord and Janssen (2015) conclude that, as of 1955, several of their European newspapers (including Le Monde) did not have any clear sections, unlike their American counterparts. 
6 From 1990 onwards, the core parts of Helsingin Sanomat and Dagens Nyheter have been divided into four sections corresponding to the first four letters of the alphabet; in these cases, the location of the first page of the culture section was not calculated from the full pagination but directly from its position in these sections (A, B, C or D).

7 In our codebook, we followed the definition of article types from an earlier project (Janssen et al., 2008, 2011; Verboord and Janssen, 2015). A review is categorized as a 'substantial report on witnessed or experienced product that is explicitly mentioned (e.g. books, films, concerts) that generally contains both descriptive and evaluative elements'. An interview focuses 'on a conversation with an artist or an art related person'. The report/feature is defined as an 'article that provides background information on an artist, product or discipline (incl. portraits, obituaries, reportages, and personal profiles)'. Finally, a news story is an article in which 'a topical event is signalled and described (i.e. breaking news)'.

8 Apart from their lasting relative stability as an article type, our previous qualitative analysis of highbrow reviews (Heikkilä and Gronow, 2018) has shown that reviews have remained similar over the period from 1960 to 2010 when inspected through basic components of art reviews: descriptive, analytical, entertainment, instruction and evaluative elements (Shrum, 1991).

9 An announcement/list is defined as 'short information about (the appearance/availability of) a new product. Generally, announcements contain only a little descriptive information; usually in a special section carrying brief information about new books, exhibitions, movies, etc.'.

10 Dagens Nyheter numbers exceeding the theoretical maximum (twenty-one) are due to cases in which there are two articles on the first page of the culture section that continue onto the following page.

11 Inside the substantial category of 'other', cultural policy was the largest topic (6.6 per cent), followed by science, society and philosophy ( 5.9 per cent) and architecture (3.3 per cent). 


\section{Chapter 8}

\section{Conclusion}

\section{Epilogue: the death of a philosopher-celebrity}

French philosopher and author Jean-Paul Sartre, the leading proponent of existentialism and a politically active intellectual, died on Tuesday 15 April 1980. Even though Sartre's physical condition had been worsening for years and he had been living mostly outside the spotlight, not having been active in philosophical debates in the 1970s, the death of a famous philosopher sparked enormous media attention (e.g. Cohen-Solal, 1987). As with John Lennon, who died later that same year, our newspaper data includes Thursday 17 April 1980, two days after Sartre's death and the most plausible time for extensive journalistic coverage of it.

Le Monde, the natural home court of Sartre, published seven full pages on Sartre in its culture section on Thursday 17 April 1980 (pp. 13-20). The compilation of several large and smaller articles, under the title 'La mort de JeanPaul Sartre', is so enormous that it resembles an extra supplement. There are long and serious essays about his philosophy and his importance abroad (e.g. LM/17/04/80_14a), but a prominent part of the coverage is for easier digestion. First, several layout techniques indicate a lightness in style, such as humorous cartoons and small text boxes on different 'highlight' topics. These short texts present, for instance, information about the massive sales numbers of Sartre's books, besides listings of his works (e.g. LM/17/04/80_15a). In addition, there are sections such as 'Quotes on Sartre' in which other literati such as Albert Camus, Maurice Blanchot and J.M.G. Le Clézio discuss Sartre; another section has short aphorisms taken from Sartre's work (LM/17/04/80_14b).

Second, the life of Sartre is replayed in its entirety under the headline 'The Passionate History of a Committed Intellectual' (LM/17/04/80_17), and important milestones (the marriage of his parents, meeting Simone de Beauvoir, refusing the Nobel Prize, travels, publications, political troubles, hospitalization) are listed with short explanations. Finally, and as a good example of the features of popularization of traditional legitimate culture, there is a large article on the first page of the Sartre coverage titled 'I Never Read Him' (LM/17/04/80_13). The article comprises testimonies of Parisian university students of the time, 
barely aware of the death of the distinguished philosopher. One of them was told by her parents that Sartre founded a journal ('Les Temps ... whatever it was ... modernes, that's it') and heard from the radio that Sartre was at some point a member of the communist party. The point of the article is to show, rather crudely, how distant and irrelevant Sartre was for young students of the time. The coverage of Sartre's death in Le Monde is extensive and respectful, but there are clearly aspects of popularization of traditional legitimate culture, in both content and, especially, format.

Of the other newspapers, the Spanish El País, perhaps culturally closest to France, had three full pages on Sartre at the beginning of the culture section on 17 April 1980. The first article is something of a traditional obituary (EP/17/04/80_27), but El País also pays attention to such human-interest aspects as the exact time of death and speculations on the funeral. Moreover, and unlike coverage on Sartre in the other newspapers, there is a mention of Sartre's adoptive daughter Arlette Elkaïm-Sartre and even a short note on how she, as a young university student, originally came to know the famous philosopher after failing a class and asking for advice. On the second page, there are two comprehensive essays on the philosophy of Sartre (EP/17/04/80_28a and 28b) and, finally, on the third page, a long interview with Sartre, originally published in Le Nouvel Observateur (EP/17/04/80_29).

The other newspapers published much less on Sartre's death. In Finland, Helsingin Sanomat had one quarter-page translated obituary (originally published in the New York Times), which is very traditional in style (HS/17/04/80_20). The Swedish Dagens Nyheter had one obituary-style article (the first article in the culture section), written by the newspaper's own journalist, titled 'The Man of Constant Reassessment' (DN/17/04/80_4). It resembles that of Helsingin Sanomat, more conservative in format and more focused on Sartre's professional life than were Le Monde and El País. Interestingly, The Guardian published nothing on Sartre on 17 April 1980 in its culture section, but elsewhere in the newspaper there was an obituary titled 'Intransigent Road to a Lonely End: Jean-Paul Sartre, France's Greatest 20th Century Philosopher, Died Without Public Fanfare. Walter Schwarz in Paris Reports on the Final Ironies'. Similar to the main article in Le Monde, The Guardian emphasizes that Sartre was, in fact, already out of date, that 'in the end he had ceased to appear relevant to the young'. The article on Sartre's death in Milliyet is the smallest, and, as in The Guardian, it was published alongside general topics.

While the death of John Lennon, with which we began, is a fascinating example of the legitimization of popular culture, showing how a rock star is treated in the media as a genius and a true artist, the newspaper coverage of Sartre's death illuminates the ways in which traditional highbrow culture becomes popularized, displaying how a 'serious' philosopher is treated like a show business celebrity. In line with the more general picture of the process of popularization of highbrow culture created by earlier analyses, the popularizing tendencies in the coverage of Sartre's death are not as straightforward or conspicuous, as 
with the case of legitimization of popular culture (and Lennon). However, the traditional ways of writing about a 'serious' philosopher and author are complemented by popularizing characterizations and, particularly, several journalistic means that are used when reporting about the event. In the quest for easy reading and human interest, the coverage of a highly legitimate figure ${ }^{1}$ has features that could be considered loans from a lighter type of writing: the use of typographically separated text sequences, illustrations, crystallizations and entertaining commentaries.

However, this is merely one side of the story since only Le Monde and El País showed these lighter tones in the Sartre coverage, while the other newspapers utilized a more traditional, unrisky obituary style. Of course, the media reception of Sartre's death can also be seen as a continuation of Sartre's position as a particular kind of public intellectual, who had been a regular commentator on diverse social and political issues for decades in different quality media outlets in France, including Le Monde (cf. Boschetti, 1988; Baert, 2015). That Sartre's career as a philosopher and intellectual epitomized a rare combination of highbrow and popular elements, however, does not diminish the significance of how elements of high and popular coexisted in media reception of his death. Rather, it is only logical, just as with Lennon, that his life and career embodied the same elements that characterized media reception of his death. ${ }^{2}$ Furthermore, the Sartre case is a good example of the capability of culture sections to transform when needed; in particular, Le Monde's huge section on the topic shows the flexibility and potential for almost endless expansion of culture sections.

\section{Enter culture, exit arts?}

Paul DiMaggio wrote already in 1991 that 'scholars have found it difficult to characterize change in expressive culture at the societal level' (DiMaggio, 1991: 133). While the following quarter-century witnessed a proliferation of cultural sociological research touching on the question, the characterization is still accurate, and it has been one of the motivations behind this book to contribute to the systematic study of 'change in expressive culture at the societal level'. The problems faced by sociological research on the question stem from the scarcity of suitable longitudinal data sources that would allow study of cultural change over several decades, and from the tendency of focusing on a single art form, cultural field or even more restricted cases. Our response to these challenges has been, first, to draw on quality European newspaper data, reflective of dominant cultural classifications and what is considered to be legitimate culture, which has given us the ability to study cultural change in Europe over the latter half of the twentieth century. The virtue of using such data, including critical discourse and evaluations of culture and the arts, is that they 'make stratification into a cultural hierarchy explicit and public' (Blank, 2007: 18). Second, our research setting has allowed us to address and discuss multiple key questions in the sociology of culture: the heterogenization, legitimization/popularization, 
globalization and commercialization of culture, as well as the changing link between culture and politics and the packaging of reporting on culture and the arts. Empirically, we have done this by touching upon several art forms and the ways in which and the degrees to which they have been granted newspaper attention.

A major argument of this book is referred to in its main title. Enter Culture, Exit Arts? captures one of the key issues of the post-1960s cultural transformation: the expansion of 'culture' at the expense of 'arts', the culture concept being more heterogeneous, multifaceted, open and relativist than arts, which is more uniform, authoritative, fixed and universal. To put it plainly, we have witnessed the following trajectory of culture from 1960 to 2010: at first, cultural content was scarce (and 'culture' and 'arts' undifferentiated) and in some newspapers, there were no easily identifiable culture sections. There then started the gradual expansion of cultural content, published under clearly identified and explicitly labelled culture sections. Finally, in the 2000s, culture was almost everywhere, and arts became only one part of it. ${ }^{3}$

Furthermore, the main title indicates that the difference between culture and the arts is not only due to the content, art forms or topics covered, but also that the tone and the styles of writing, discourses, ways of valuating and evaluating, exhibited in the articles has changed. Only using both quantitative and qualitative approaches in the analysis has made it possible to fully recognize this. We detected a clear tendency in the 2000s that something extraordinary (or 'extra art') was needed to justify publishing long articles in the culture pages of our newspapers; this applies equally to highbrow and popular culture. Humaninterest orientations have overshadowed 'art for art's sake' in cultural journalism. Or, to use the conceptual distinction by Raymond Williams (1981) about the two meanings of the concept of culture, the anthropological meaning of the concept of culture as the 'whole way of life' is increasingly informing the way cultural journalists write about culture and the arts, which is replacing, at least partly, the traditional perspective, of culture as the arts.

This trajectory of cultural content, and the changing relationship between culture and arts, also suggests that the period during which there have been proper and easily identifiable culture sections focusing on culture as the arts, something that grew into one of the essential and definitional parts of quality European newspapers, was actually brief and historically specific. It could be roughly said that it lasted from the 1960s (first fully appearing in our ten-year interval data in 1970) to the end of the millennium. In the 2000s, journalistification and popularization of both the topics of cultural coverage and the ways of writing about them were moulding the institution of culture sections (and the culture departments of newspapers) as something new and different. Combining these trends with the crisis of journalism (Alexander et al., 2016) and the challenge posed by online, peer-produced criticism to the traditional criticism of the printed press (Verboord, 2010, 2014) means that the characteristics of quality newspapers' culture sections are currently undergoing transformation. 


\section{Transformation and stability}

We have provided new insights to facilitate the understanding of cultural transformation since the 1960s. Most prominently, we have suggested a two-way conceptualization of processes of legitimization of popular culture and popularization of classical highbrow culture, of which legitimization has been widely recognized and discussed by previous research (e.g. Baumann, 2007; Regev, 2013; Schmutz, 2016), whereas popularization has usually gone unrecognized and neglected. Thus, in a similar vein as studies on legitimization have detected 'real-world' effects of legitimizing discourses of popular culture (e.g. by focusing on how symbolic value has been institutionalized and built in the form of prizes, higher education curricula or public funding), it remains to be an exciting topic for future research to systematically investigate in different contexts whether and how the popularized discourses on traditional highbrow arts have had an influence outside of the evaluative discourses themselves, by tracing the 'deinstitutionalization' of highbrow arts' legitimacy (cf. DiMaggio, 1991; Daenekindt and Roose, 2015).

The transformation of cultural hierarchies characterized by the rise and legitimization of popular culture and the decline and popularization of highbrow arts is accompanied by cultural globalization, commercialization and the changing nature of the culture/politics link - all additional dimensions of the transformation. Consider, for example, the case of the globalization of culture, or the geographical flow of cultural objects, which we were able to analyse by measuring the national origin of cultural products discussed in culture sections (Janssen et al., 2008). The simple division between foreign and domestic cultural products does not work because the category of 'foreign' masks how strongly the geographical mobility of cultural objects overlaps with the contrasting trajectories of rising (heavily Anglo-American) popular culture coverage and declining (mainly European) classical highbrow culture coverage. Thus, using the unspecific category of 'foreign' would not only produce no clear increase in globalization but it would also lose sight of the intertwined nature of the processes of globalization and the transformation in the relationship between popular culture and highbrow arts.

Moreover, and as another example, we have followed recent contributions of 'post-Bourdieusian' studies of (e)valuation (e.g. Lamont, 2012; Beljean, Chong and Lamont, 2016) by showing the limits of Bourdieu's (1993, 1996) model of two clear-cut systems, the fields of 'large-scale production' and 'restricted production' (of which the first would operate mostly under the logic of commercial valuation and the second would follow the ideology of 'art for art's sake'). This model continues to be valuable heuristically and as an ideal-typical categorization (cf. Baumann, 2007: 174-175), but it does not hold empirically in the 2000s, when the boundaries between popular and highbrow culture had largely fallen. Rather, it seems that in fields of 'large-scale production' such as pop-rock music (that are also young art forms establishing their status as 'art' only recently 
after legitimization) there are clear tendencies to focus on artistic value and downplay the commercial aspects. Similarly, in the established fields that have the most unquestionable status of art, there seem to be no strong pressures to avoid commercial valuation of emphasis on the 'art for art's sake' ideology anymore. It is a task for future research to continue studying the relationship between artistic and commercial valuation in both established highbrow and emerging popular art forms since it seems, to paraphrase Bourdieu (1993), that the field of art as the 'economic world reversed' might have taken a further twist.

However, it would be misleading to highlight only changes when summarizing the results of this study. Even if we have shown important changes in cultural classifications (the most salient ones concerning the rise and legitimization of popular culture and the decline and popularization of highbrow arts, and the changes in the layout and packaging of cultural content) another set of results indicates substantial stability. The most established art forms continue to dominate cultural coverage in quality European newspapers, whereas coverage given to entirely new art forms has remained only marginal. Where music, of the two most widely covered art forms, exemplifies a major transformation, literature represents stability. Reviews of highbrow arts and the evaluative criteria used have changed only limitedly. The coverage of highbrow arts has declined only relatively, while more or less keeping its position in absolute terms. The coverage of national culture continues to dominate the coverage of international culture in all of our European newspapers. There is no evidence of unambiguously increasing commercialization or politicization of culture. All these features underlining continuity are important not only in their own right, but also because they create the context against which changes have been discerned. Without a certain stability in the overall context, it would be even harder to assess which changes are the most important, ultimately rendering analysis over time unfeasible.

Finally, the results of this study concerning variation across our newspapers located in different parts of Europe forcefully show the power and problems of cross-cultural comparisons of this kind. Regarding the most important themes (the rise of popular culture, the relative decline of highbrow arts coverage, cultural globalization, commercialization and how cultural content has been packaged in culture sections), we mostly found consistent trends across our newspapers, except Milliyet. Legitimate culture in Turkey has historically been very different from that of core Europe countries (making it, for instance, meaningless to talk about the decline in the status of Western highbrow arts), and the polarized pluralist media model (Hallin and Mancini, 2004) with limited journalistic autonomy from political and economic pressures has enabled the volatile trends revealed in Chapter 2 and made the case of Milliyet exceptional. Without doubt, the story and design of this book could have been much more straightforward by not including Milliyet in the first place. However, by including it, we have been able to show the geographical and 
cultural limits of many of the cultural trends that have been very European and Western in nature.

Of course, there have been differences among the rest of our newspapers. Overall, the results suggest that Dagens Nyheter and El País represent more progressive or liberal newspapers attentive to new influences early on, whereas Le Monde and Helsingin Sanomat represent conservative newspapers that have been latecomers to new tendencies (however, both of them have changed rapidly during recent decades). The Guardian falls somewhere in between these two camps, showing tendencies of both early opening (such as the clearly earlier loosening of boundaries between popular and classical music compared to Helsingin Sanomat, Chapter 3) and a certain amount of conservativeness (such as continuing to publish wide coverage on highbrow arts, Chapter 2). While all variations across the newspapers have not been systematically in line with the expectations derived from society-level dimensions along which the countries in which the newspapers are published differ from each other (such as size and global position of the country, media system model or cultural policy regime), some key differences can be seen as grounded in these. This is shown, for example, by the already mentioned difference in the timing of the opening of the content of legitimate culture (such as how The Guardian is different from Helsingin Sanomat, which is in line with all three dimensions, the UK being a global centre and characterized by a liberal media system model and cultural policy compared to Finland's position as a small, peripheral country with a strong Nordic media system model and state-driven cultural policy). A further example is the difference in the dominant position of domestic cultural coverage (large and central countries being the most self-sufficient, as reflected in The Guardian and Le Monde) and how shared languages and colonial histories are shown in cultural coverage given to products originating from other parts of the world (such as Latin America in the Spanish newspapers or the United States in The Guardian). Another example is the political transformations in Spain and Turkey, how they have been reflected in cultural coverage and the ways in which culture and art have been used to construct national identities.

Overall, we have found studying cultural change through quality European newspapers ideal in terms of both their capacity to reflect cultural legitimacy and its changes over time and the challenges and problems that are inevitably highlighted when conducting such study. Thus, to acknowledge the problematic side, in the following section we will discuss theoretical and methodological themes or dilemmas that we believe are important for cultural sociology and the study of cultural change. Rather than aiming to solve them, we only want to introduce them as, after the analyses of this book, we are well placed to discuss them from the point of view of this study. 


\section{Problems in comparative research and studying cultural change}

Problems in comparative cultural sociology have been widely discussed in recent years, both from the perspective of cultural consumption (e.g. Katz-Gerro, 2011) and cultural mediation and production (e.g. Livingstone, 2003). It is widely acknowledged that comparative research, whether cross-cultural or crosstemporal, is necessary in order to shed light on a particular empirical phenomenon under investigation; the question is whether the comparisons are made explicitly and using systematic data from multiple cases. Similarly, sociologists tend to agree that, in practice, comparative research is highly problematic (Kohn, 1989; Jowell, 1998). Thus, comparative research can be seen as an 'impossible yet necessary' (Livingstone, 2003) research practice, something which is better conducted explicitly rather than implicitly. Our methodological approach, a mixed methods study combining quantitative and qualitative analysis based on a multilingual text corpus from the cultural institution of quality European newspaper culture sections from six countries covering a fifty-year period, has been motivated by this spirit, aiming to show both the fruitfulness and challenges of the approach in analysing cultural change.

As mentioned in Chapter 1, the purpose of this book was not to explain why the studied cultural transformation happened. Instead, we examined the inner dynamics, relationships and dimensions of the cultural change, rather than reducing cultural dynamics into some superior level. Of course, we have been interested in how the timing and thoroughness of cultural transformation varies according to cultural and geographical location, and which art forms and domains are more stable and which are changing most rapidly, but the associations found do not imply proper causal relationships.

From the point of view of data and the research design of this study, the reasons to avoid the question of causal explanation are obvious. There have been three main structural levels behind the observed changes in cultural hierarchies (cf. Janssen et al., 2011): society-level factors concerning dimensions such as country size and global location as well as cultural policy and media system models, field-level factors concerning different art worlds and cultural domains and organizational factors concerning specific newspapers. ${ }^{4}$ The problem is that all three levels may change and become mixed, meaning that all levels have the potential to influence the changes observed in the newspaper data. Our analysis has been informed by some data from all these levels, which are independent from the newspapers. This is a necessary requirement when assessing their influence on the trends in newspaper data, but it is a nearly impossible task to precisely determine the role of each level. A more ambitious treatment of the subject would have obviously meant using more information on newspapers' editorial departments, policies and practices at the level of journalistic work; information on the trajectories and resources of separate art worlds and fields of culture in each national setting; and 
information on the myriad characteristics of countries in which the newspapers are embedded.

The paradox of such newspaper data is that newspaper culture sections are sensitive to different trends and changes in how culture is valued and evaluated (which is the reason to study culture sections in the first place); however, this sensitivity can simultaneously lead to muddled results if there are large-scale and rapid transformations occurring in the newspapers' socio-political environments. On the other hand, the entire premise of studying cultural change through newspaper culture sections rests on the idea that the status and role of newspapers as institutions are relatively stable. Otherwise, it would be impossible to use newspapers as a fixed point of departure enabling the investigation of large, long-term processes that have been of interest to us and cultural sociology more widely, such as heterogenization, legitimization/popularization, globalization and commercialization of culture. The Turkish Milliyet exemplifies the social sensitivity of newspaper data in the first sense, whereas the other newspapers represent the relative stability of the institution, allowing us to show how the expansion of the sphere of legitimate culture (and the two sides of the process, legitimization of popular culture and popularization of highbrow arts) has taken place in Europe since the 1960s, without being reducible to societal-, field- or newspaper-level factors.

So far, the most convincing framework for a structural explanation of the post-1960s cultural change comes from DiMaggio (1987) to substantiate his thesis that the trend has been towards more differentiated, less hierarchical, less universal and weaker cultural classifications. ${ }^{5}$ Going through the dimensions of differentiation, hierarchy, universality and boundary strength, DiMaggio presents propositions about which structural features of society either facilitate or prevent cultural change (DiMaggio, 1987: 446-449). For instance, cultural differentiation should be increased by 'social heterogeneity and status diversity', 'range of social networks', the complexity of 'role structure' and 'access to higher education', and decreased by 'structural consolidation' (DiMaggio, 1987: 446). The dimension of hierarchy should increase, in turn, along more consolidated 'status parameters', greater 'social inequality', 'more humanistic and less technical' systems of education and a more 'internally stratified formal education system', and decrease along 'more intergroup sociable interaction' and greater 'access to higher education' (DiMaggio, 1987: 446-447). These are examples of the 'external' structural factors that should be capable of explaining change in cultural classification systems. ${ }^{6}$

DiMaggio's (1987) framework of cultural classifications and how social structural features may explain them has the clear advantage that it is specific in its propositions and empirically ascertainable. Thus, it represents a significant improvement compared to the less specific attempts to explain post-1960s cultural changes with even wider processes (such as 'post-industrialization' or 'modernization', or other broad macro-level sociological narratives) that clearly include not only economic and social structural but also cultural dimensions. 
Indeed, while DiMaggio's (1987) framework has been highly influential in cultural sociology and facilitated the systematic study of cultural change, there are very few studies that would have tried to perform causal analysis on cultural change using longitudinal data following his suggestions. The closest examples are studies by Janssen et al. $(2008,2011)$ analysing changes in cultural coverage in Dutch, French, German and American newspapers from 1955 to 2005. However, these studies are similar to ours in that they have faced the same challenges of distinguishing between the influence of societal-level factors (whether based on DiMaggio's propositions or other literature) and field-level factors (most importantly, factors related to the newspapers themselves) (see Janssen et al., 2011: 160; and the concluding discussion in Chapter 2). In fact, DiMaggio's framework has been used in previous literature predominantly to provide hypotheses to cross-national comparisons rather than providing hypotheses to analyse how cultural classifications have changed (e.g. van Venrooij and Schmutz, 2010).

There are, however, also more general and foundational problems linked to the explanation of cultural change that are not reducible to our own research design. These problems are intimately related with varying views on what is 'culture' in the first place, whether it can be separated from other substances in the world, such as 'material' and 'social', and what is meant by 'explanation'. While our intention here is not to go further into the methodological or ontological debates on these matters (see e.g. Reed, 2011), it is sufficient to remark that, in general, contemporary cultural sociology has mostly rejected the explanatory frameworks of historical materialism ('base/superstructure') and other simplistic models, according to which culture is something superficial that must be explained by more profound structures. One reason for this lies in the prevalence of the stance according to which culture is not considered as a property or quality of things (material objects, structures), but as something that is constitutive of those things. From this perspective, the question of 'explaining' culture by something else is inherently incorrect (Schudson, 1989). ${ }^{\text {? }}$

One additional layer making explaining cultural change complicated is that cultural dynamics may have autonomous logic. The most notable example of this argument is Stanley Lieberson's (2000) study of how fashions in given names change over time. He shows and argues that the case can be generalized into cultural change more widely, that 'internal mechanisms - once set in motion - will generate new preferences indefinitely without the addition of any external influences', which makes it possible that 'fashion will change [...] without the operation of any external social or cultural shifts' (Lieberson, 2000: xiv). Thus, from this perspective, fashions may change autonomously from external social structures by referring to previous fashions only. However, it is noteworthy that Lieberson does not suggest that external factors would always be insignificant; on the contrary, he points out that they are not always required for cultural change, which is an unorthodox view in sociology. ${ }^{8}$ Recently, new interests have arisen around unravelling this possibility of 'autonomous aesthetic 
logics' in different fields of culture, the starting point being that: 'people follow existing tastes, but may try to move just beyond this in search of originality and novelty. This leads to relatively autonomous patterns of stylistic change, propelled by the logics of the aesthetic system itself' (van der Laan and Kuipers, 2016: 66).

In any case, if the view that culture cannot be something secondary that can be explained by social or material structures is taken to the extreme, explaining cultural change becomes impossible. Most sociologists still agree that, while culture is intimately related to the material and social, and even if their relationships and explanations of cultural change are complex, explaining culture is neither wrong nor impossible if it is done situationally, by taking into account the context and circumstances of the phenomenon in question. Thus, the critique of base/superstructure models has concentrated more on their universalistic tendencies than attempts to explain culture and treat it as separable from other substances.

Overall, sociologists have not recently been particularly interested in presenting causal explanations for cultural change. ${ }^{9}$ One reason could be Bourdieu's dominant position in cultural sociology and his famous reluctance to conduct conventional causal analysis (e.g. Bourdieu, 1984). Within the limits of this study, aiming at causal explanations would not only have been too challenging but also probably led to unfounded conclusions because of the multiplicity of the dimensions involved, the multifaceted nature of causal relationships and the constant changes to every aspect under study. This could be why so few studies have even tried to perform causal analyses on cultural change. However, perhaps these reasons are fair enough. Theoretically informed documentation and descriptions of temporal changes in a way that takes into account its multiple dimensions, at which we have aimed in this study, might be a good enough start for sociologically understanding cultural change.

In this vein, our study also exemplifies the view that sociologists should make use of more broad and open-minded longitudinal media and institutional sources to better understand how cultural hierarchies and distinctions have changed. School curricula (e.g. Daenekindt and Roose, 2015), pop-charts (e.g. Verboord and Brandellero, 2018), elite catalogues (e.g. Denord, Lagneau-Ymonet and Thine, 2011) and explorations of the cultural environment using digital datasets (Bail, 2014) are all examples of imaginative and useful ways to analyse cultural hierarchies and distinctions longitudinally. Even if the availability of goodquality longitudinal datasets on topics such as cultural participation and tastes improve in the future, sociologists interested in cultural change will have to use a variety of data sources other than (usually cross-sectional) interviews and surveys. It is our hope that this study of cultural change through the institution of the culture sections in quality European newspapers will be extended to other institutions and organizations creating, distributing and legitimating cultural classifications and hierarchies. 


\section{Notes}

1 If considered against the key indicators of high cultural legitimacy (e.g. higher education curricula, prizes, public recognitions; see Chapter 2), it is fair to say that Sartre was indeed a highly legitimate figure in France.

2 Indeed, Sartre's life and career could be used even more broadly to exemplify the main themes of this book, in a similar fashion as we introduced those themes by addressing the life and career by John Lennon in Chapter 1. One could consider, for instance, global elements (the influences from German philosophy and Sartre's famous trip to America after the Second World War), commercial elements (Les mains sales [Dirty Hands] being his most-sold book with almost 2 million copies, at least in 1980, as mentioned in Le Monde on 17 April 1980; LM/17/04/80_15b) or political elements in Sartre's work (his relationship to the communist party and the stigma of being the 'apologist' of the regimes of Stalin and Mao, which arguably was one reason why remembrances and characterizations of Sartre were not free from antipathy).

3 More or less similar trajectories have been identified in other countries than the ones included in our study; see, for example, Straw (2005: 191-194), for the evolution of newspaper cultural coverage in Canada.

4 One could say that the first level is the most interesting from the perspective of macrosociology and stratification, the second level from the perspective of sociology of art and culture and the third level from the viewpoint of media and journalism studies. Moreover, cultural policy studies are mostly interested in the interrelation between the first and second levels, whereas studies of media systems touch upon the first and the third levels.

5 Another canonical example would be the discussion by Peterson and Kern (1996: 904-906) on the reasons behind 'the historic shift from snobbishness to omnivorousness', by referring to 'structural change', 'value change', 'art-world change', 'generational politics' and 'status group politics'.

6 Besides 'external' factors and propositions connected to them, DiMaggio details also 'internal' propositions concerning the relationships between the dimensions of cultural classifications themselves, for instance, that degrees of cultural differentiation and hierarchy should be negatively associated (DiMaggio, 1987: 448). While the 'internal' propositions appear indisputable, the propositions regarding external explanatory factors are empirical in nature. One could ask whether the external factors are really independent and easily separable from the cultural classifications they aim to explain. For instance, cultural differentiation could be seen as one constituent of what is understood as 'social heterogeneity'.

7 This stance is exemplified in different 'both and' solutions to the binaries between structure and agency, material and symbolic or objectivism and subjectivism, a tendency most famously reflected in Bourdieu's (1984) notion of habitus. Despite Bourdieu's efforts to find a middle ground and emphasize the fact that structures are (also) culturally constituted, it has been customary to consider him as a structural reductionist, presenting yet another version of base/superstructure models, but operating with a vocabulary of homology, correspondence and structural similarity rather than causality (see e.g. Santoro and Solaroli, 2016).

8 On the other hand, the view that fashions (or the sphere of culture more widely) are not always reducible to 'material' or 'structural' causes but rather are 'self-dynamic processes' can be traced back to the sociology of Georg Simmel and even earlier understandings of how fashions and tastes change (see Gronow, 1997: 74-101).

9 Notable exceptions include Baumann's (2007) identification of explaining factors of legitimization of Hollywood films in the United States, and Fishman and Lizardo's (2013) explanation of divergent trajectories of omnivorous taste patterns in Spain and Portugal after democratization. 


\section{Appendices}

\section{Appendix A: collecting and coding newspaper data}

The main data used for this study comprises the culture sections of major quality European daily newspapers between 1960 and 2010: Helsingin Sanomat (Finland), Le Monde (France), ABC (1960-1970) and El País (1980-2010) (Spain), Dagens Nyheter (Sweden), Milliyet (Turkey) and The Guardian (the UK). The data was collected in 2013-2014 and coded after developing the coding system in 2014-2015. Below, we describe these processes in detail.

Representative yearly samples of the newspapers were collected using tenyear intervals, from the volumes of 1960, 1970, 1980, 1990, 2000 and 2010. To eliminate the seasonal variation of coverage of culture and arts in newspapers, each year was divided into thirds (January to April, May to August and September to December) and a stratified sampling procedure was used to select random dates to form one full week for each third of each selected year. According to this method of 'constructed weeks', two weeks per year should be sufficient to avoid problems and achieve representative samples for each year (Riffe, Aust and Lacy, 1993); to play it safe, we collected three constructed weeks per year. Thus, the full sample includes eighteen or twenty-one editions per year and per newspaper, depending on whether the newspaper appeared six or seven days a week. Dagens Nyheter, Helsingin Sanomat and Milliyet were published seven days a week and Le Monde and The Guardian six days a week throughout the period, whereas ABC in 1960-1970 and El País in 1980 were published six days a week, and El País in 1990-2010 was published seven days a week. This results in 711 newspaper editions in the sample.

After determining the sample, data was collected in the form of concrete pages of newspaper culture sections. The editions of Le Monde, Dagens Nyheter and The Guardian were collected from the National Library of Finland directly from microfilms, scanning the selected culture section pages into digital files. The editions of Helsingin Sanomat were collected in the Päivälehti Archives (maintained by the Helsingin Sanomat Foundation in Helsinki) and saved as digital files readily scanned and digitalized by the archive. Similarly, the editions of $A B C$ and El País were collected from readily scanned and digitalized pages at 
the department of journalism at the Complutense University of Madrid. The editions of Milliyet were collected from the National Library of Turkey and the Library of the Faculty of Communication in Ankara University, by photographing physical copies of the newspapers.

The coding system was designed following the example of previous studies (mostly Janssen et al., 2008, 2011; see also Schmutz et al., 2010; Verboord and Janssen, 2015), but with some differences in methodological choices and theoretical frameworks informing the study (see Chapters 1 and 2). The unit for coding was an individual article found in the culture sections of the pre-defined dates. The data included all the journalistic content of the culture sections of these dates: articles, lists and non-commercial announcements (advertisements and other commercial or non-journalistic content were excluded). After designing an initial coding system with a much more restricted variety of variables than in the final codebook, a test coding was organized by two members of the research team in spring 2014 using only Helsingin Sanomat and The Guardian from 1970, 1990 and 2010. The data generated from the test coding was used in one publication (Purhonen et al., 2015).

After completing the final coding system, including forty-nine variables, six external coders, all MA-level students at the University of Helsinki, were recruited to help the core research team with coding. In total, the coding team included eleven people. In August 2014, a two-week training period was organized for the full coding team, introducing the twenty-four-page codebook, clarifying unclear issues and explaining the use of ATLAS.ti software used for the coding. After the initial training period, in which only a part of all material was coded, the coding was carried out in a series of workshops lasting up to five days each, organized between August 2014 and June 2015 (with the exception of the coding of Milliyet, finished in November 2015). Subsequently, the ATLAS.ti matrixes were transferred to Excel and SPSS. The final data for the quantitative content analysis includes 13,161 articles.

Of the forty-nine original variables in the main newspaper data, twenty variables are used in the analyses of this book. Two are the main independent variables, year and newspaper, which were added directly to the data, meaning that eighteen of the used variables were produced in the coding process. Standard inter-coder reliability (ICR) tests were conducted at the end of the initial coding workshop. The overall agreement percentage of the eighteen variables is 86.0 per cent, qualifying as good (Neuendorf, 2002: 145), and Krippendorff's alpha level is 0.74 , qualifying as acceptable (Krippendorff, 2004a: 241). The reliability expectedly varied somewhat between variables. Luckily, for the most important variables, such as primary cultural area (84.7 per cent and 0.84$)$, musical subgenre (91.3 per cent and 0.81 ), origin of the cultural product (77.3 per cent and 0.74), article type ( 80.7 per cent and 0.72 ), article size ( 77.3 per cent and 0.83) and article illustration (95.3 per cent and 0.93), both the agreement percentage and Krippendorff's alpha are at a satisfying level. In addition, there is a group of formal variables (such as size of illustrations), which typically 
have a higher ICR than the most important variables, but their role in the wider context of analyses in this book is modest (they are mostly used in Chapter 7). There is another set of variables with lower-than-average ICR, the lowest reliability characterizing the dimension variables: aesthetic, commercial and political dimensions (see note 11, Chapter 3). However, no variables are used in this book that would have qualified below the acceptable level in terms of both agreement percentage (threshold 0.70; Neuendorf, 2002) and Krippendorff's alpha (threshold 0.67; Krippendorff, 2004a).

Moreover, additional ways to improve variables' ICRs were employed. The coding was organized systematically in the format of collective workshops (i.e. several coders working at the same time in the same space), which made it possible to resolve points of potential disagreement by discussing them on the spot. Furthermore, an important means for increasing ICR has been recoding and merging original categories for the actual analyses (see Krippendorff, 2004b: 430). To put it simply: even if the ICR of our variable on primary cultural area is high enough, when reclassified into a binary variable separating highbrow arts and popular culture, the reliability of the variable will obviously be even higher.

The coding procedure was particularly designed to produce a final dataset that allowed free movement between ATLAS.ti and SPSS from the individual coded articles to the full statistical matrix. This was especially useful when combining qualitative and quantitative analysis tools. For instance, one can examine how interesting variables found in one article are distributed or interconnected on the scale of the full data, or alternatively travel from the statistical matrix back to the individual articles and focus more carefully on delimited topics of interest for close reading. The materials used for the qualitative analyses of this book were constructed in the latter way, composing suitable 'reading packs' on, for instance, film or jazz in Le Monde, or classical music and pop-rock music in The Guardian and Helsingin Sanomat, by choosing the articles coded with these variables.

Apart from the main data, several other parallel datasets were constructed from the original newspaper data (Milliyet is not included in any of these). First, a specific issue dataset (in which the unit of analysis is an individual newspaper issue) was formed by the members of the core team out of the data on all the individual newspaper issues. The variables saved from the data in this format included the newspaper, the year, the date, the weekday, the total number of pages, the page number of the first pages covering culture, the total number of pages covering culture, the number of supplement pages in total and the number of cultural pages in supplements. The issue data $(n=585)$ was especially designed to pointing out the exact location of the culture sections in different time points. Similarly, and to add information on the placement of culture sections in relation to other topics covered by the newspapers, full edition data was collected, consisting of the full pagination of one weekend issue of each newspaper for each time point $(n=30)$. Reading these full editions made it easy to see how culture sections have related to the other sections in the newspapers. 
The issue data and full edition data are used in Chapter 7 (see also Heikkilä et al., 2017).

Advertisements were excluded from the main newspaper dataset focusing on journalistic content only. However, in 2015, after designing a coding system of thirteen variables, a separate dataset was coded from the advertisement content included in the pages of main newspaper data by a research assistant under the supervision of the core research group. The variables of the advertisement data included, for example, the size of the advertisement, the domination of editorial content/advertisement content per page, the topic of the advertisement and the advertisement's illustrations. From the main newspaper data, two randomly constructed weeks from each year and each newspaper were selected, except for $A B C$ (only one constructed week) and The Guardian (three constructed weeks). These exceptions were made because $A B C$ included clearly more and The Guardian clearly fewer advertisements than other newspapers. Balancing the data across the newspapers was possible as the intent was not to compare differences in prevalence of newspaper advertisements. All the advertisements selected for the sample were coded into an Excel matrix and then transferred to SPSS for analysis. As a result, the data includes 2,799 advertisements published in the culture sections between 1960 and 2010 concerning two constructed weeks per year and newspaper (with the above-mentioned exceptions of $A B C$ and The Guardian). Besides this, advertisement data is also analysable when the unit of analysis is not an individual advertisement but the page of the culture section $(n=1,991)$. The advertisement dataset is used in Chapter 5 .

In 2019, the main newspaper dataset (in its statistical form, accompanied with the codebook) will be deposited in the Finnish Social Science Data Archive (FSD), from which the data will be freely available to interested students and researchers.

The obvious challenges encountered in manual data collection and coding were not unfamiliar to this research project. Collecting and coding data is slow, expensive and laborious. The challenges of working on multilingual text data add another layer to the process: there is a need for language skills and deep contextual and historical knowledge, and the research outcomes require laststage translations of the materials. The new computational methods of text analysis and data mining make these laborious, manual data collection and coding methods obsolete (see DiMaggio et al., 2013). However, for this research, it was important to use pre-defined key variables (because they were already defined in previous research and theories, such as the art form or the national origin of the cultural product), preserve the original layout of the cultural pages (rather than using only digitalized text files) and employ a hermeneutic understanding of the processes behind cultural changes and the possibilities of moving fluently between close reading and statistical analysis. Therefore, the 'old-fashioned', manual approach was the best choice. 


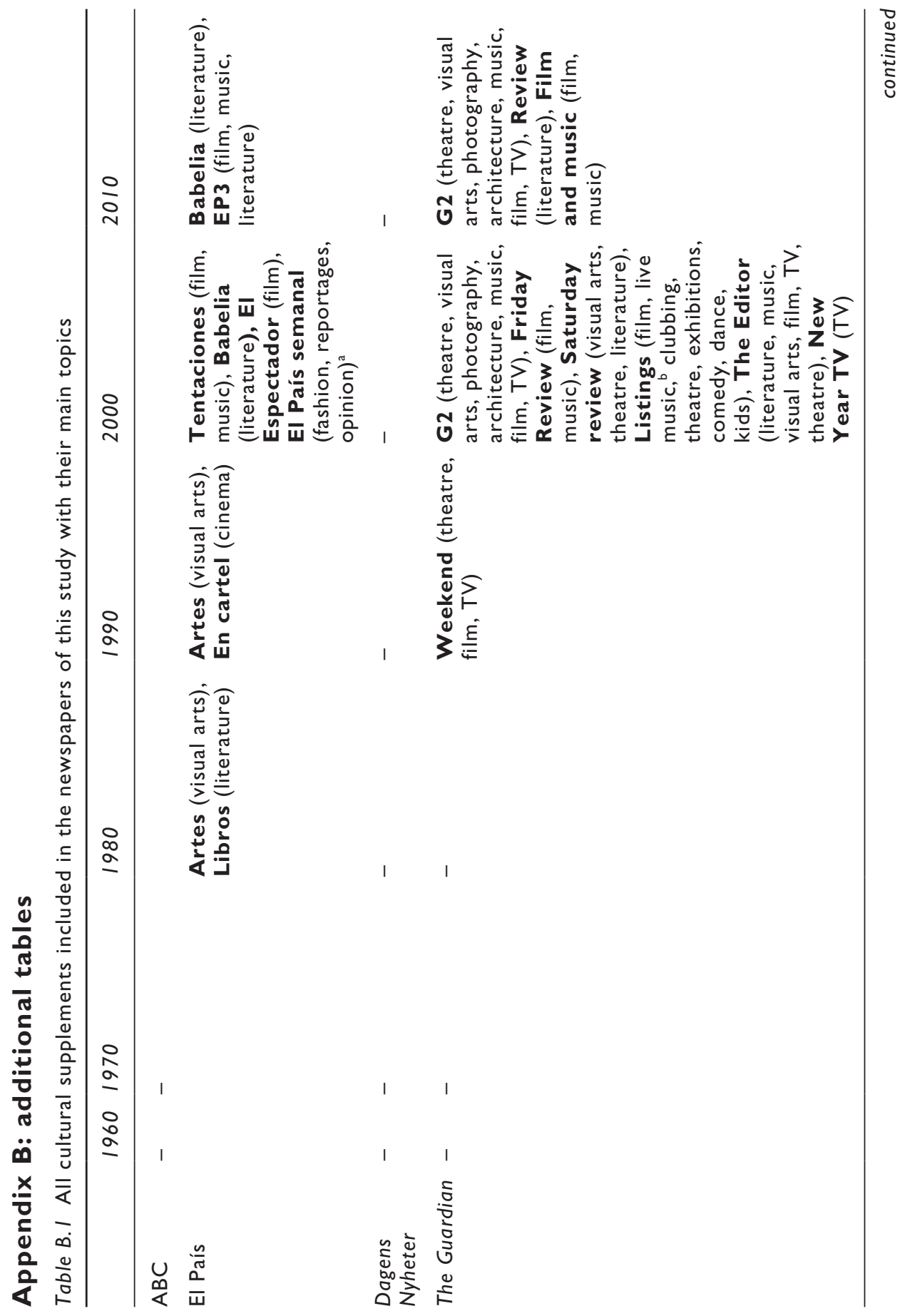




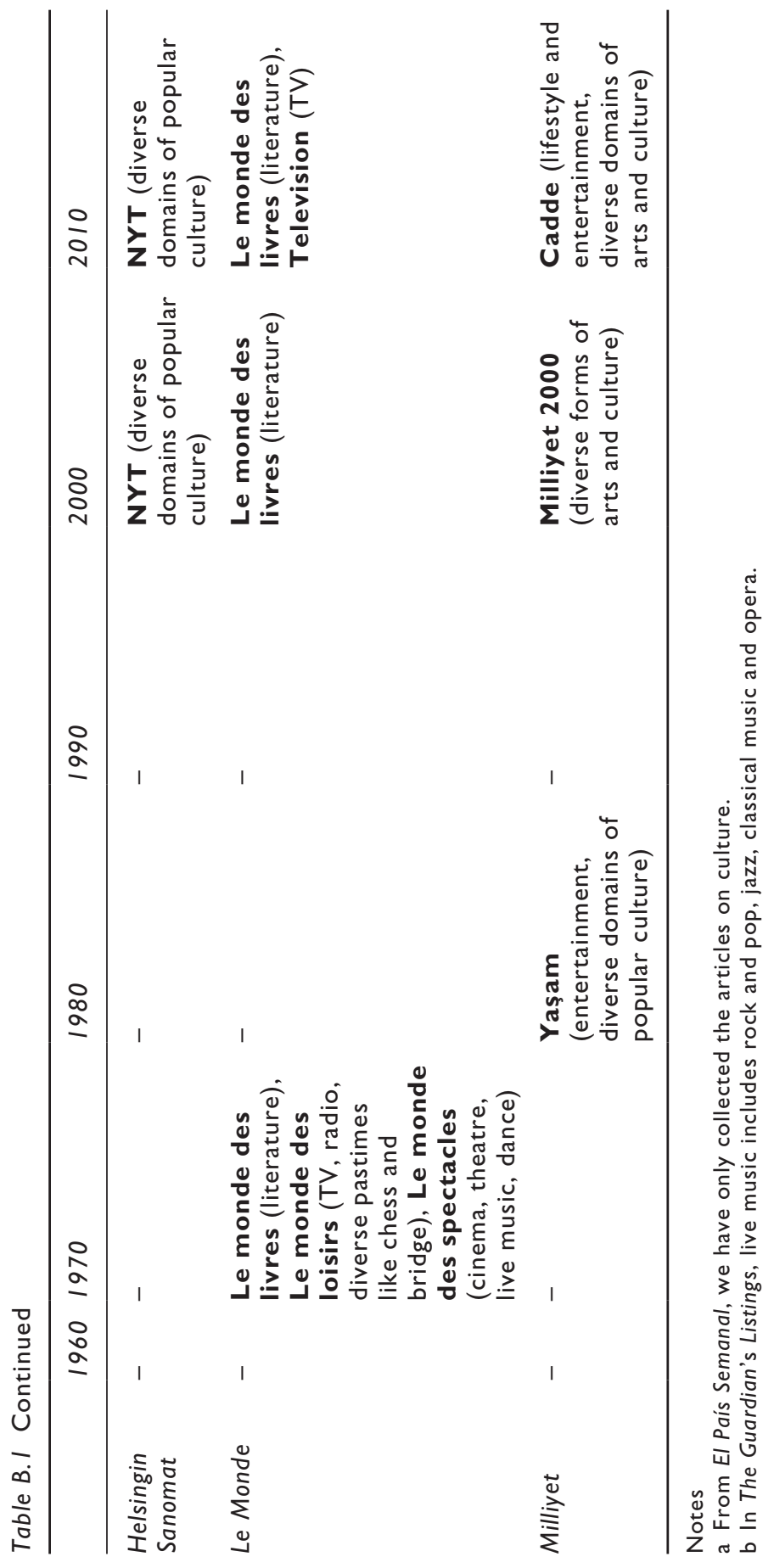




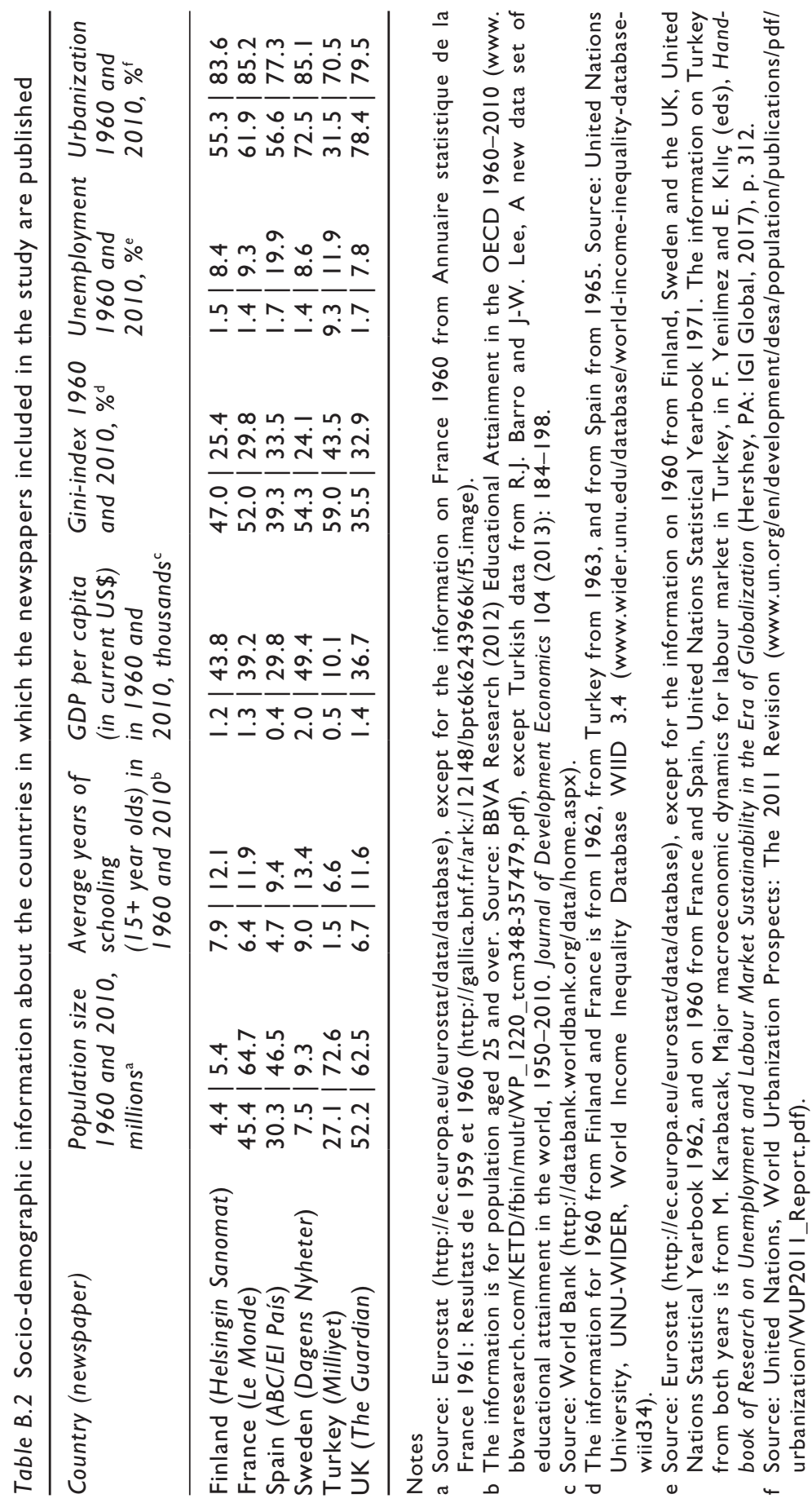




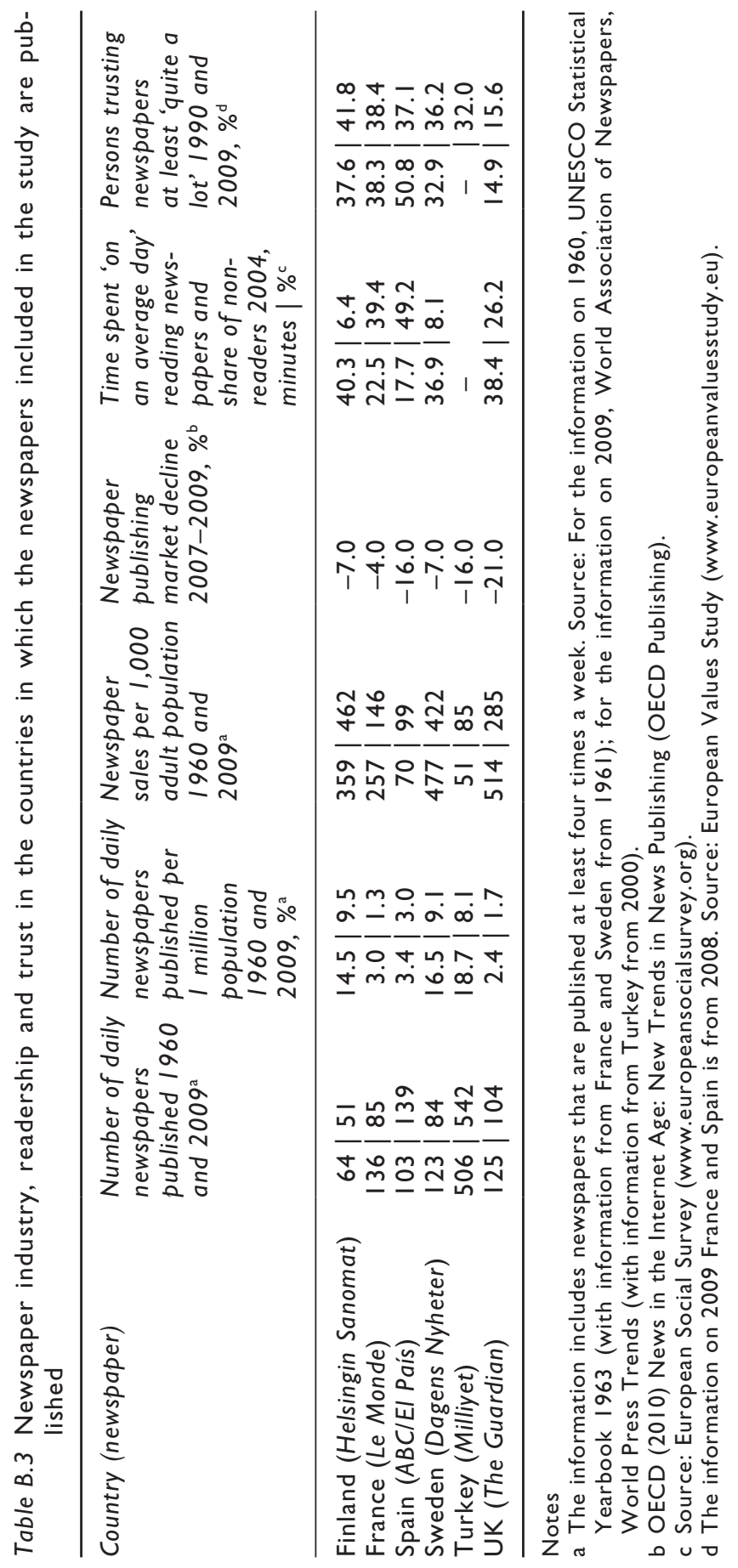




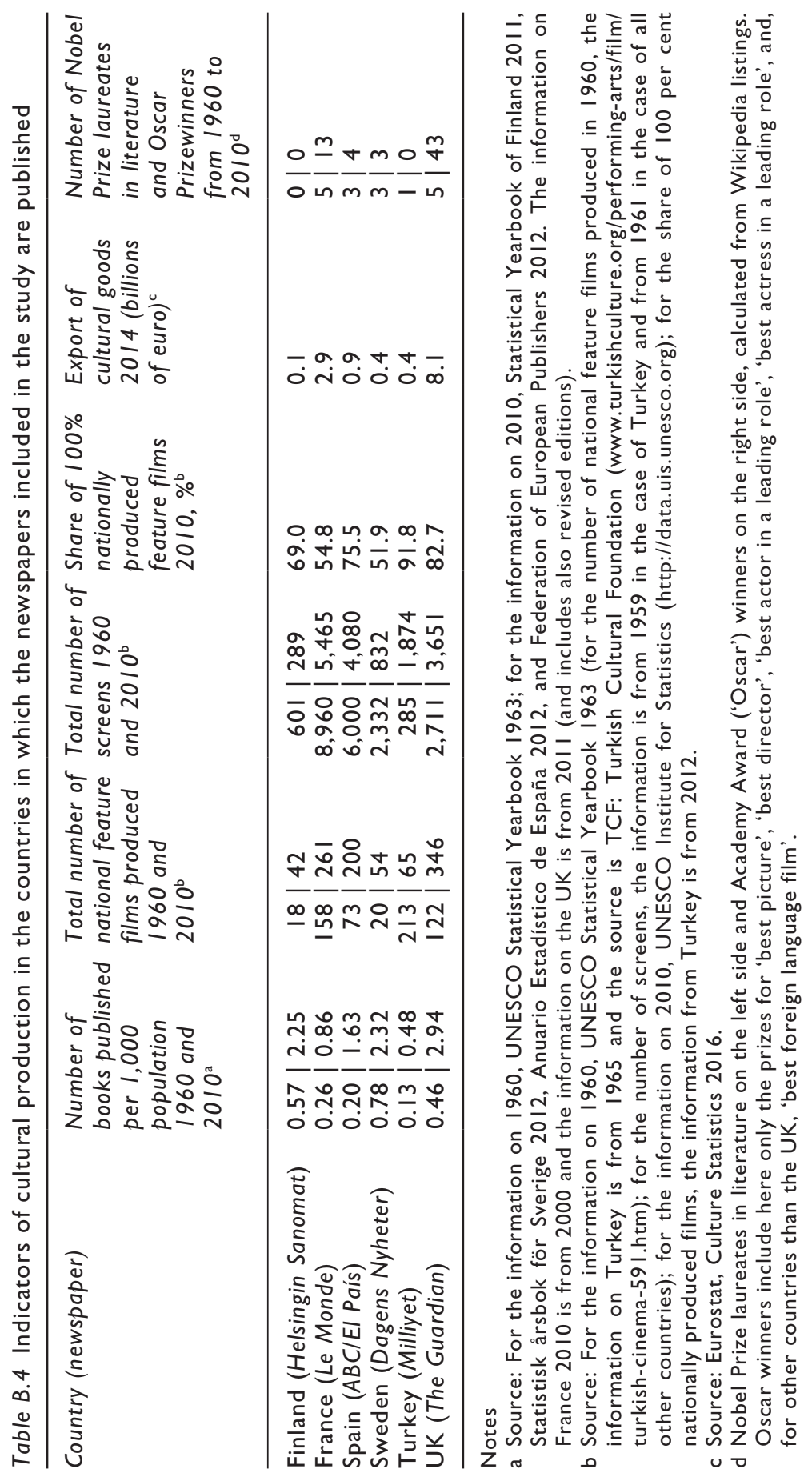




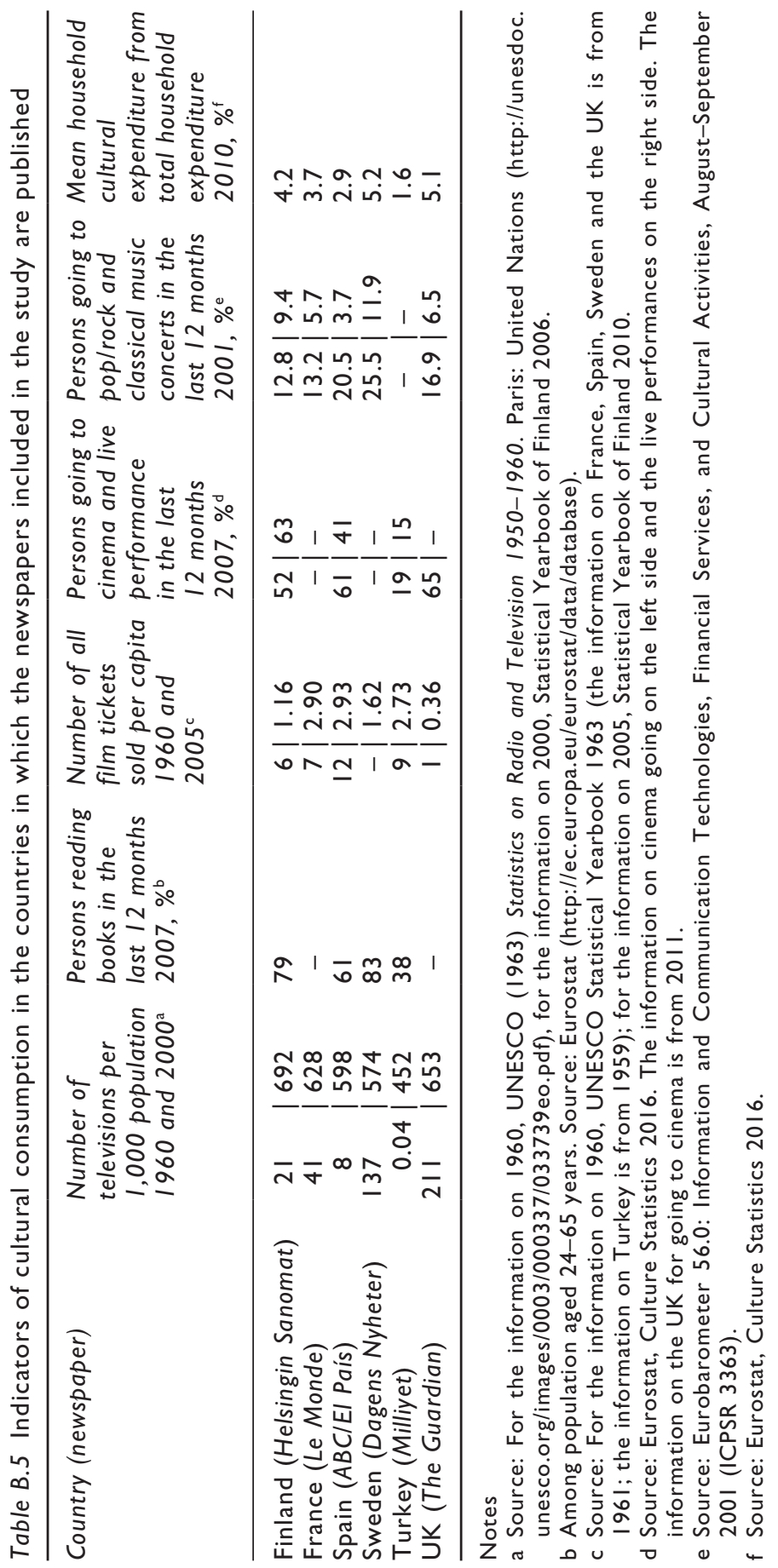




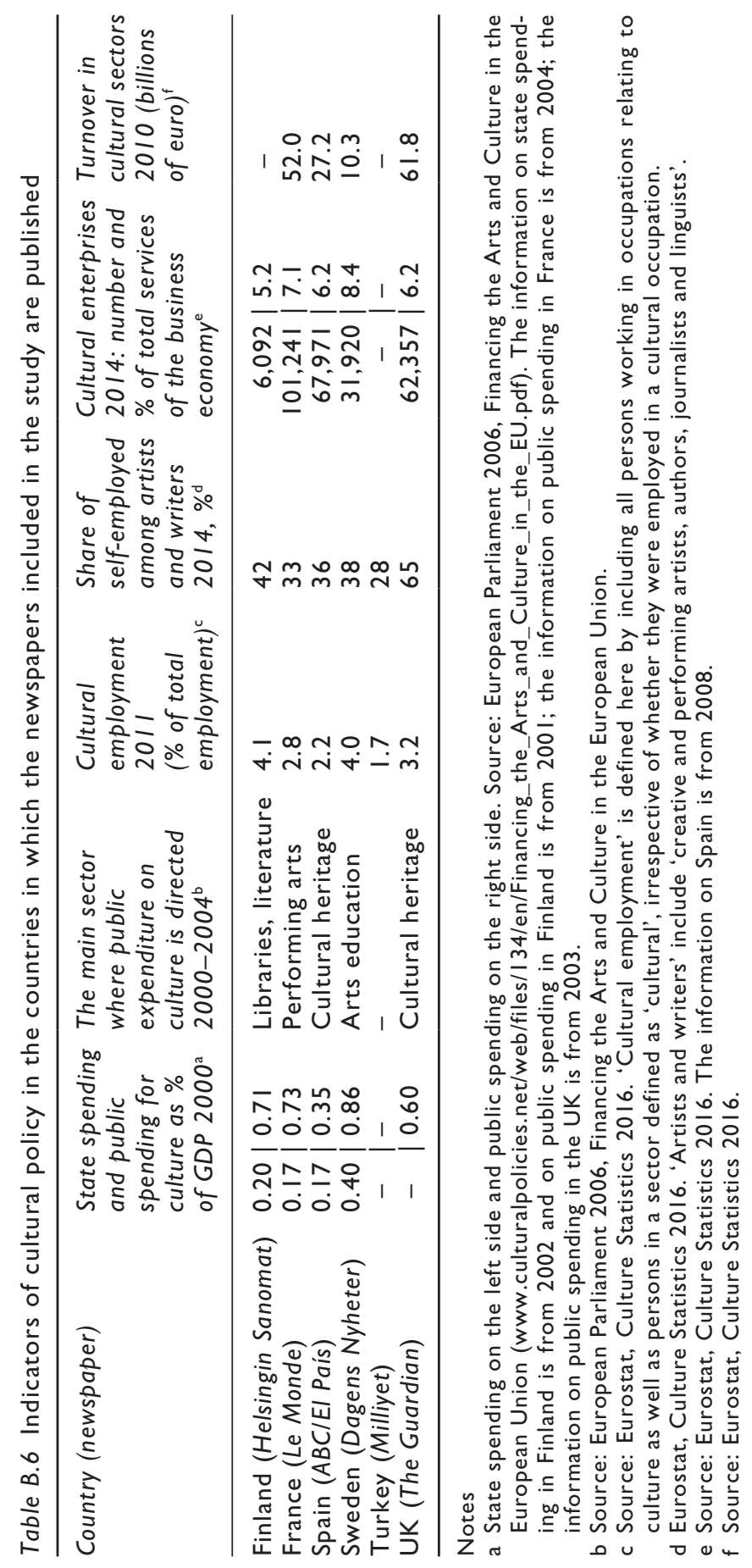




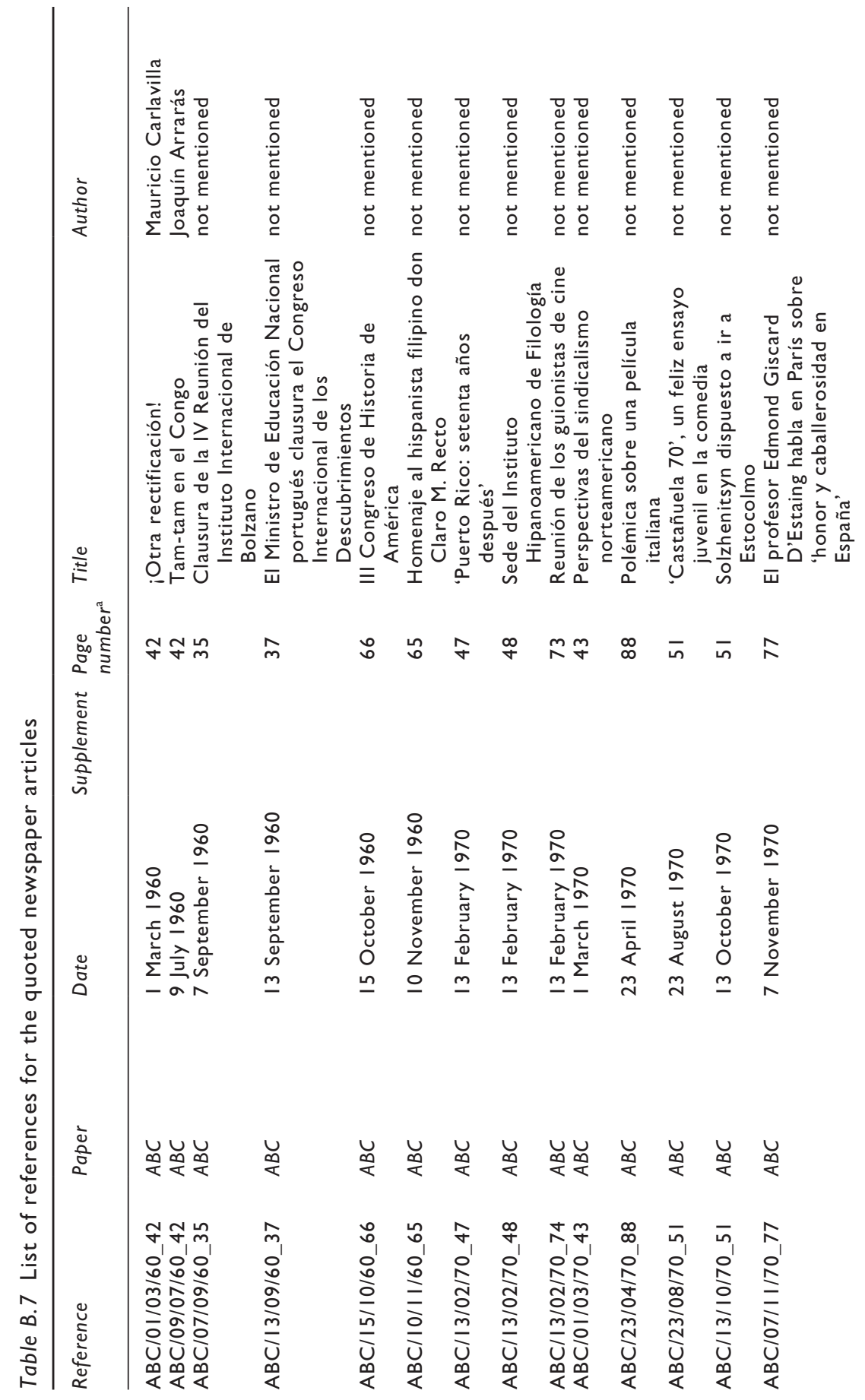




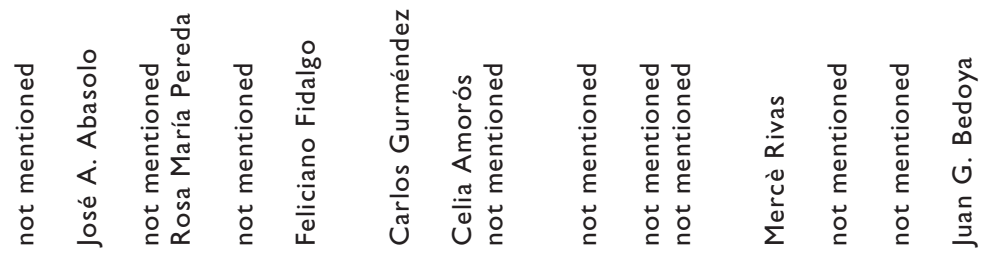

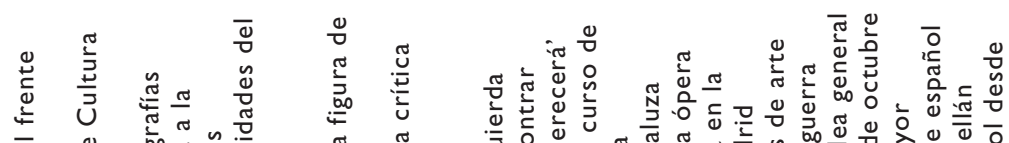

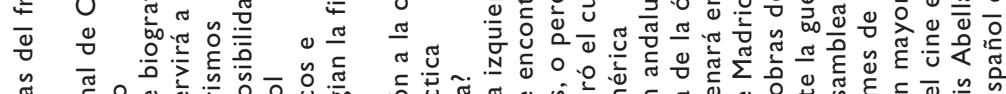

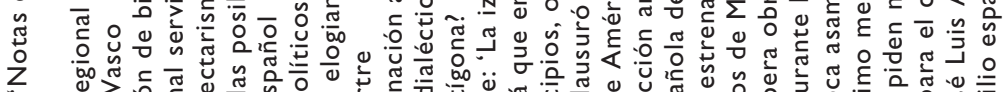
苛

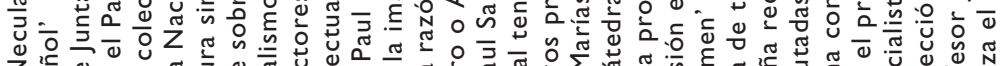

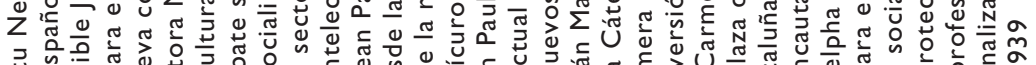

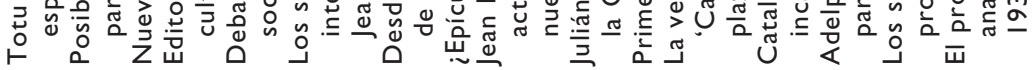

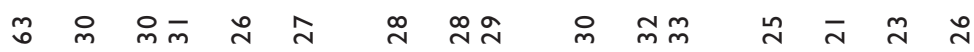

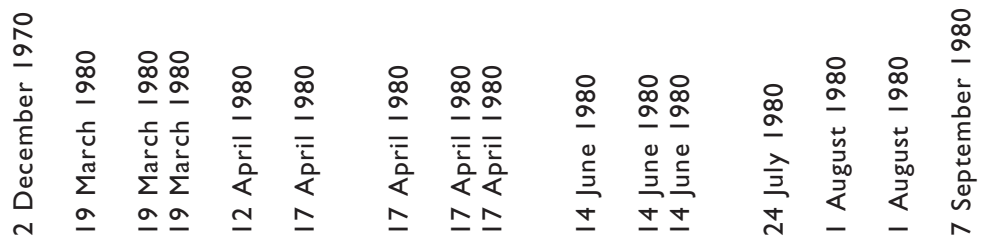

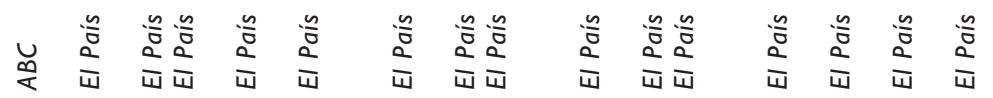

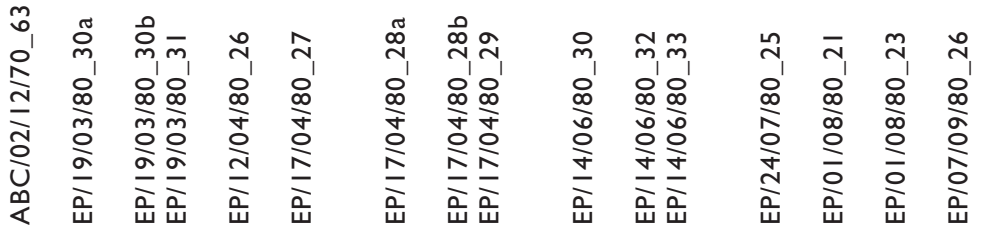




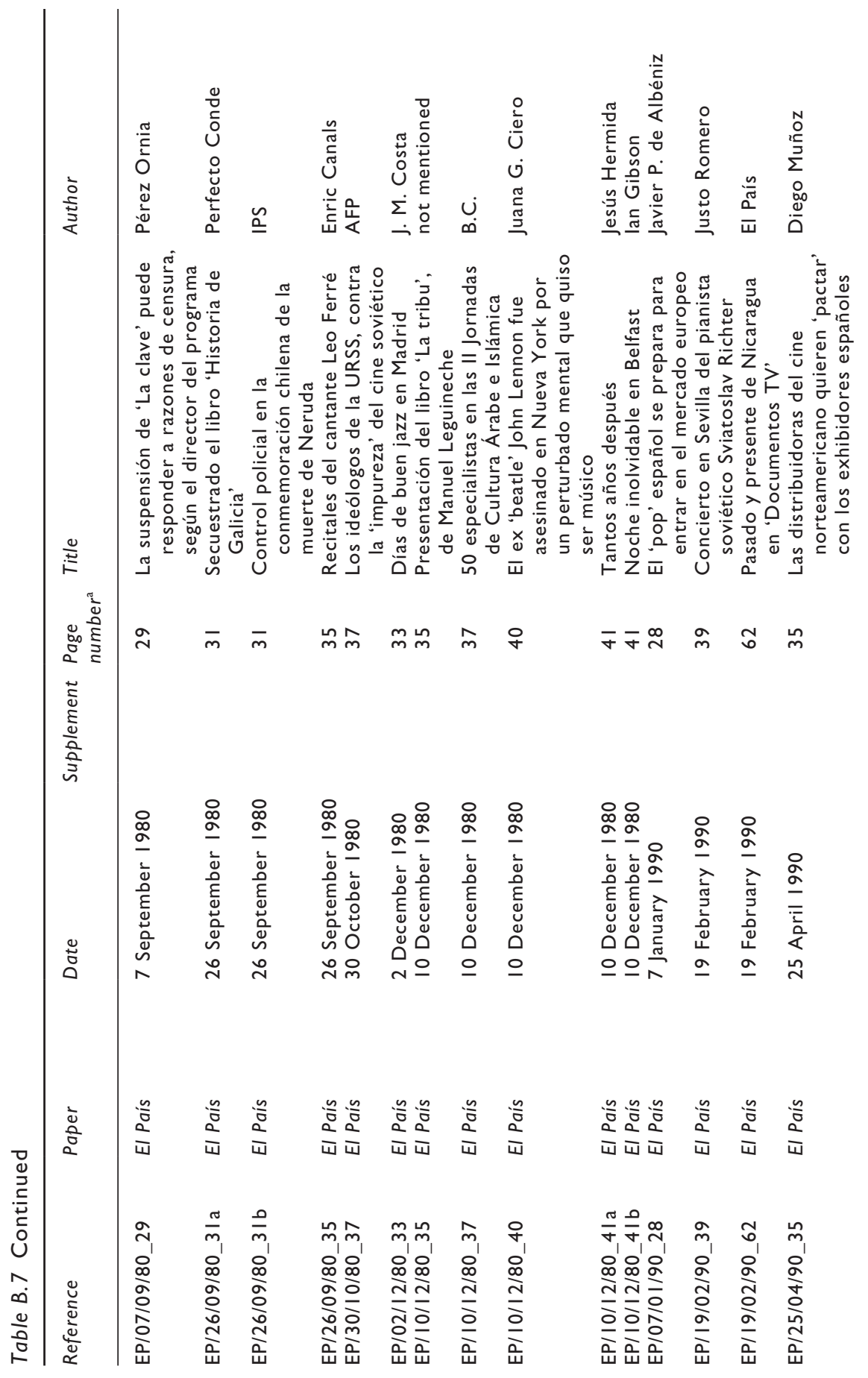




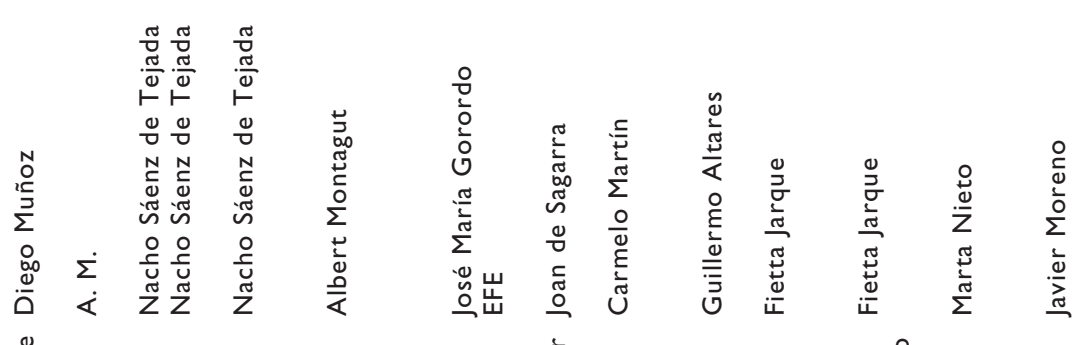

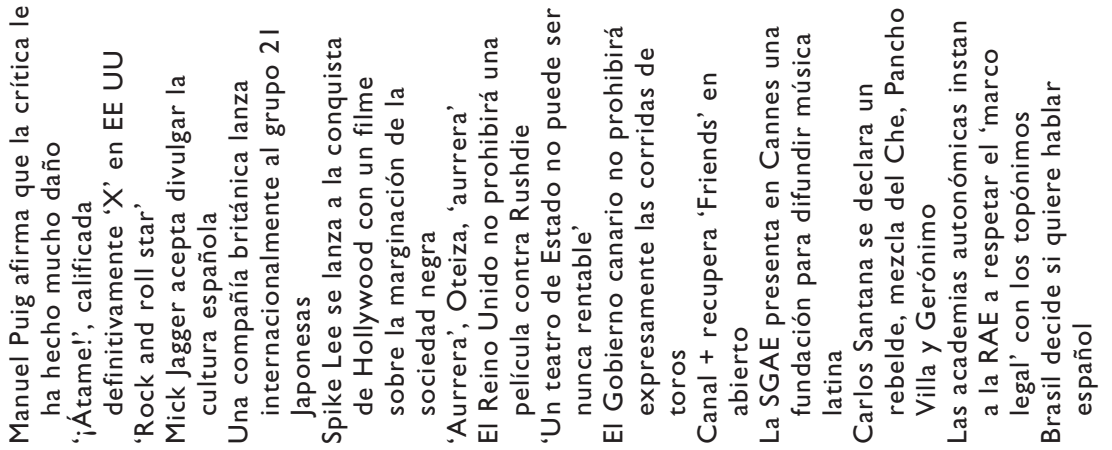

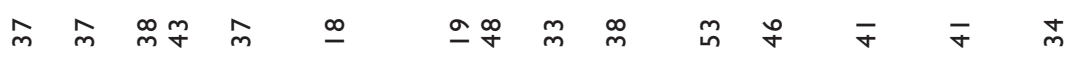

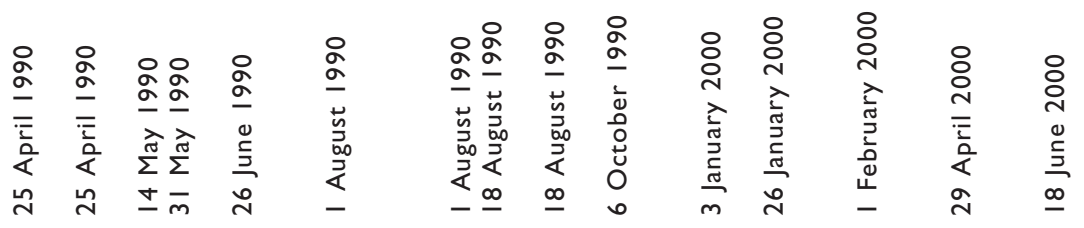

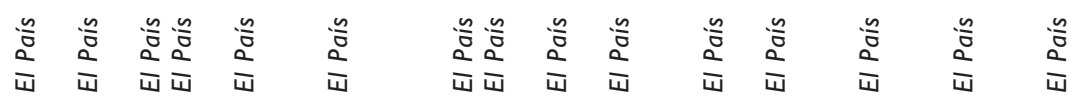

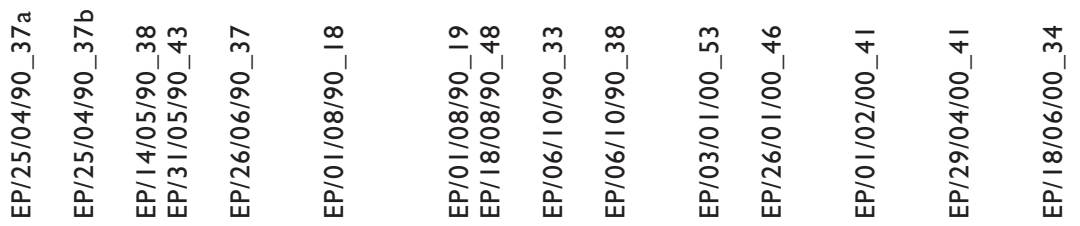




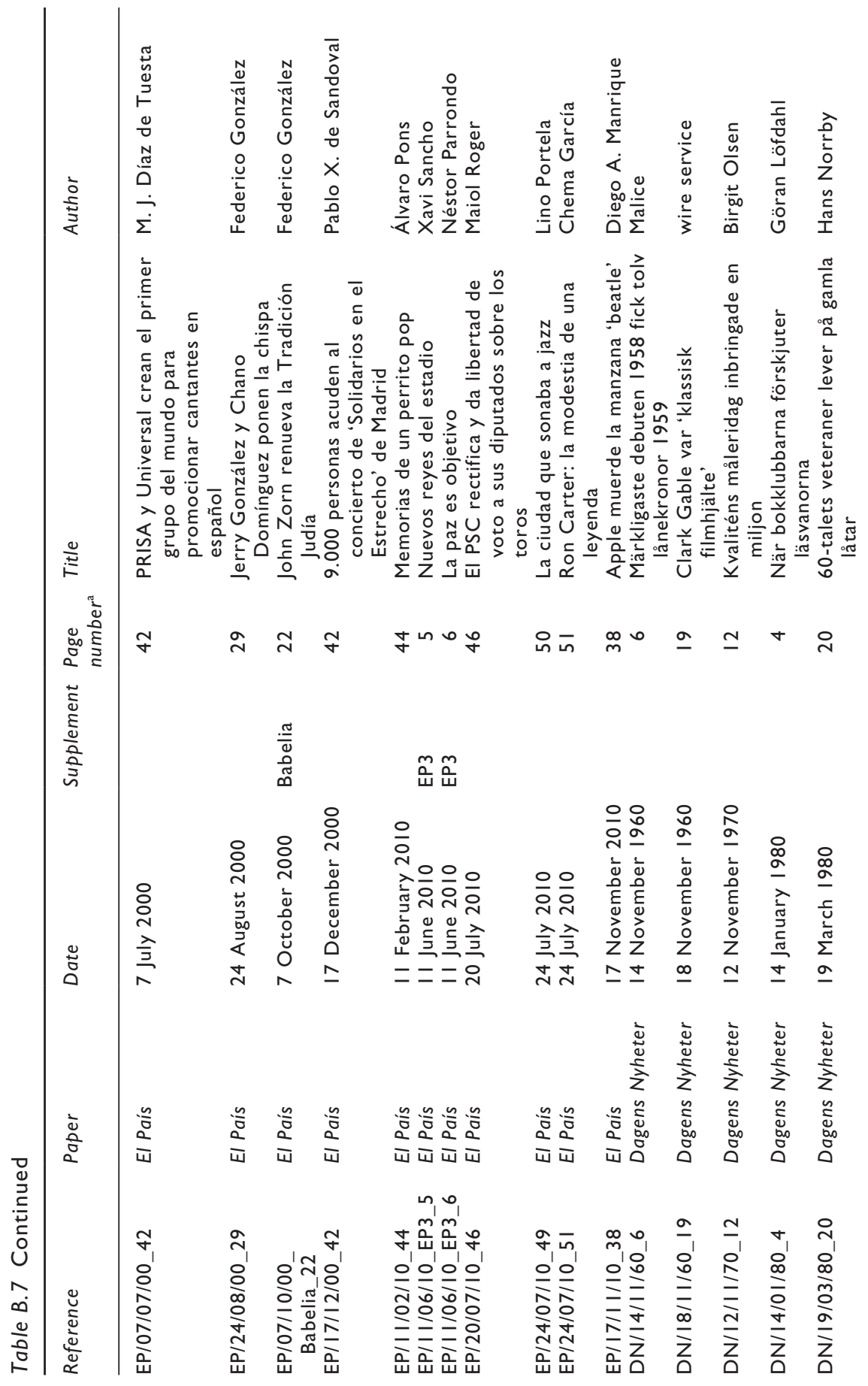




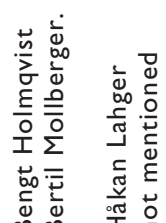
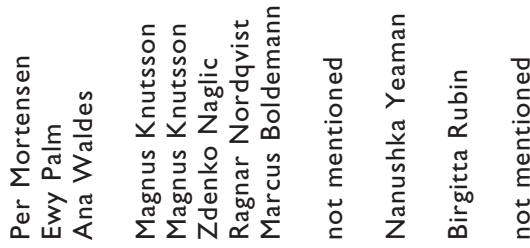

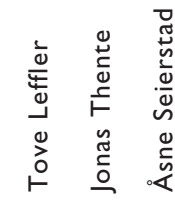

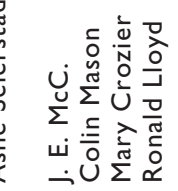

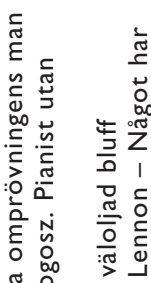

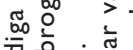

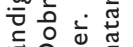

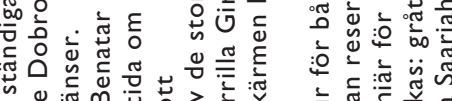

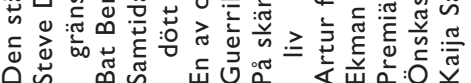

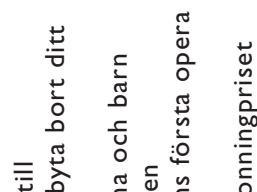

$\frac{0 \pi}{n} \frac{\pi}{20}$

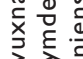

$\pi$

o

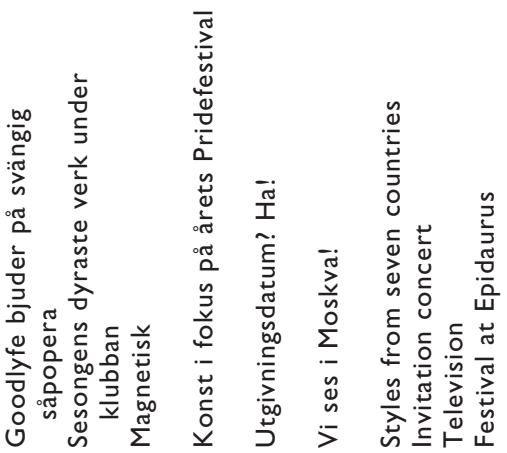

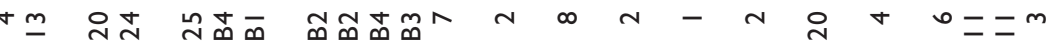

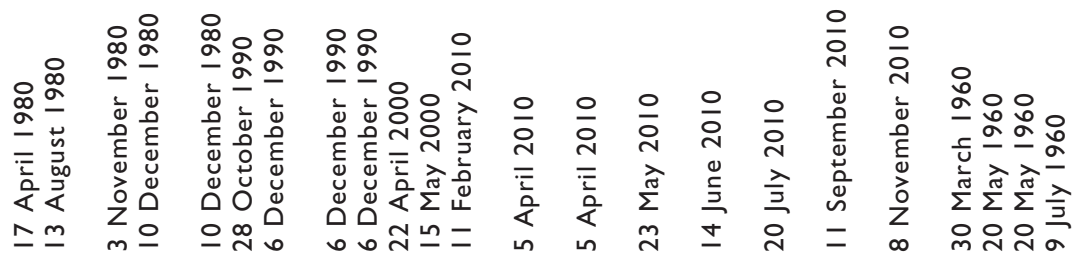

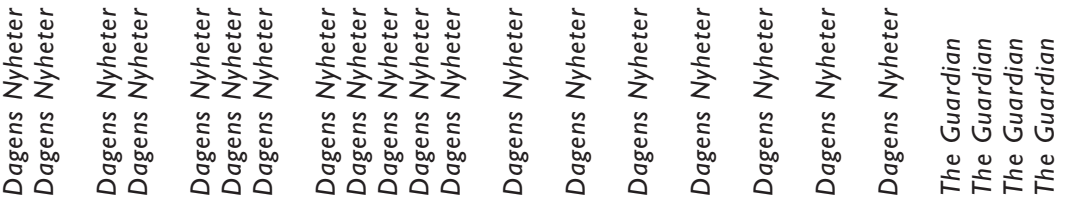

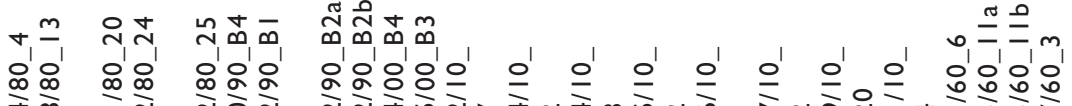

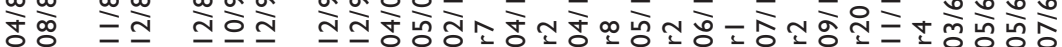

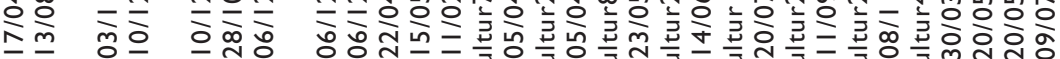

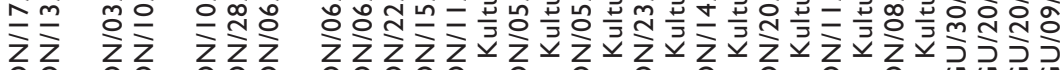




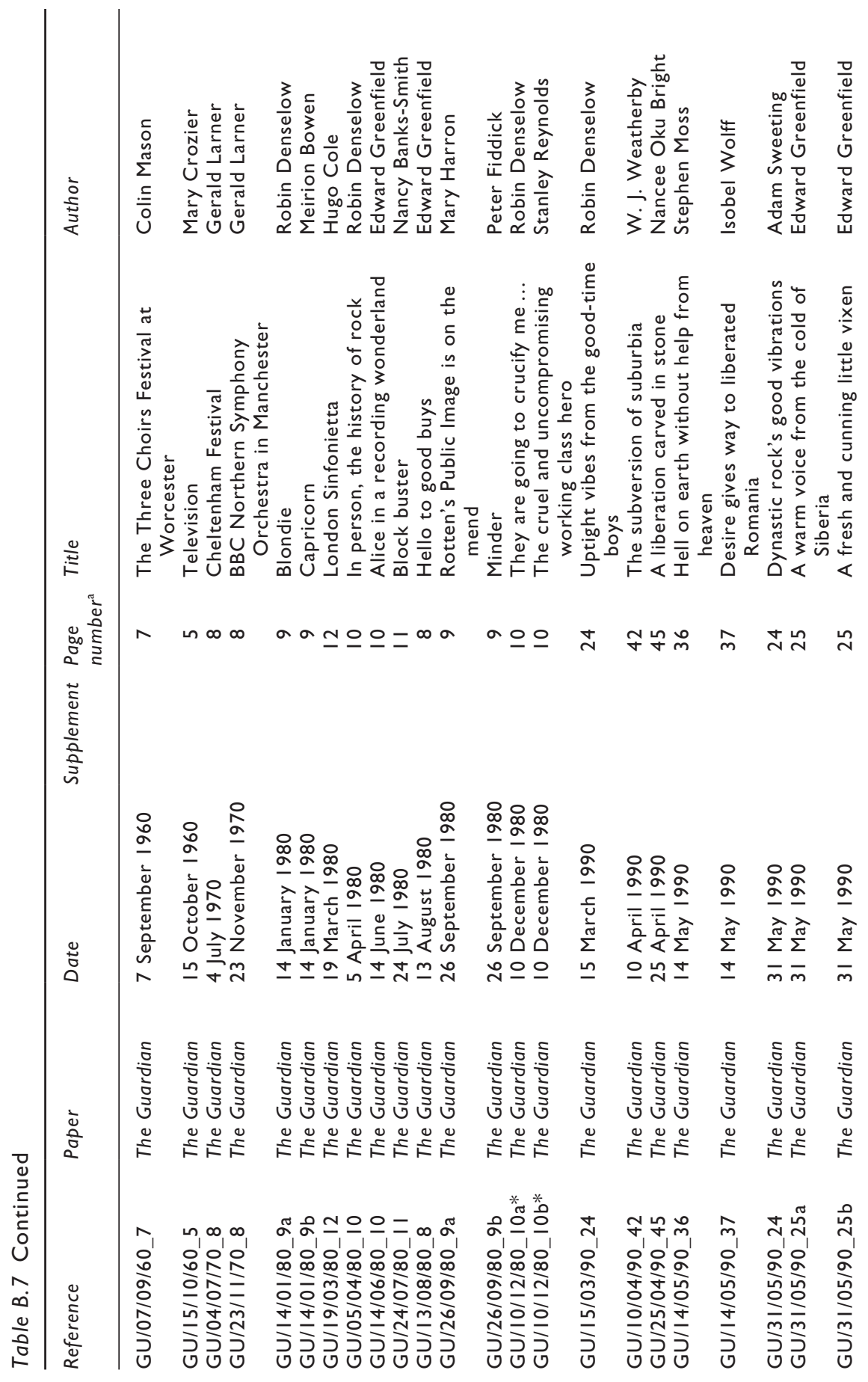




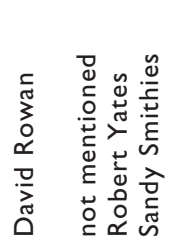

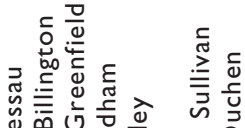

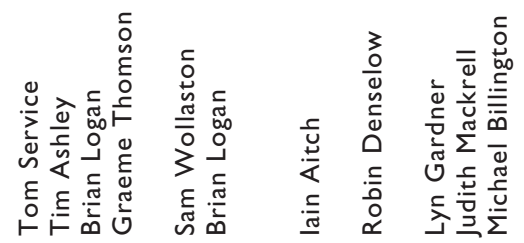

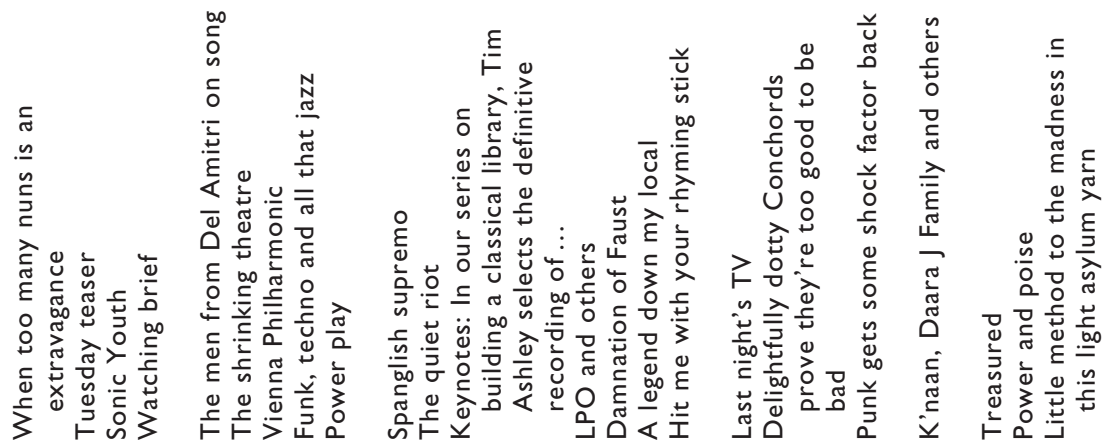

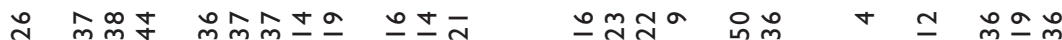

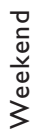

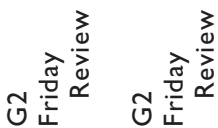

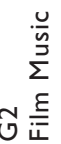
$\stackrel{\frac{u}{n}}{\frac{u}{n}} \frac{\bar{n}}{\Sigma}$

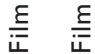
ণิ

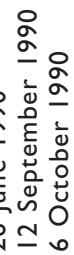

응ㅇㅇㅇ

응ㅇㅇㅇㅇㅇ

๘㐫㐫

है है

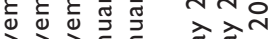

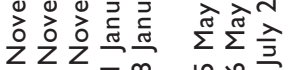

N $\sim \bar{N}$

느느무

융ㅇㅇ응

궁휴은

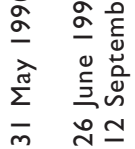

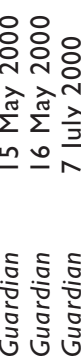

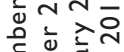

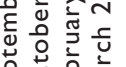

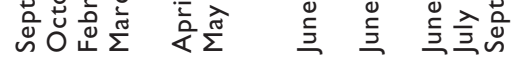

뜨ニ 호 =

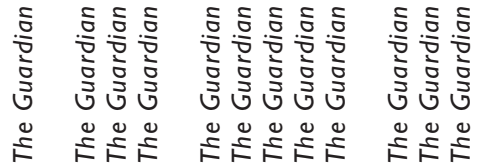

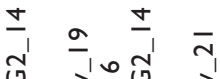

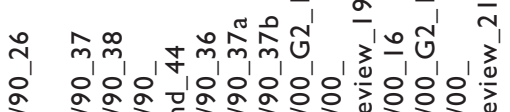

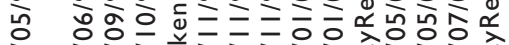

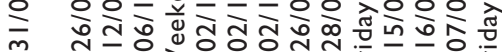

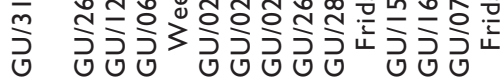

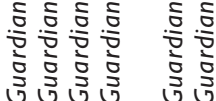

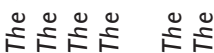

ส

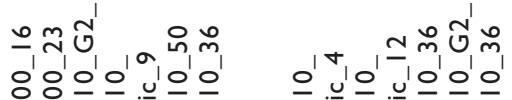

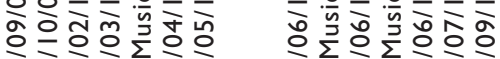

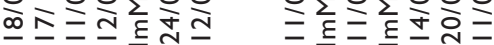

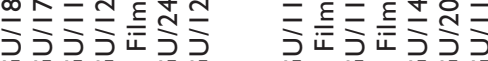




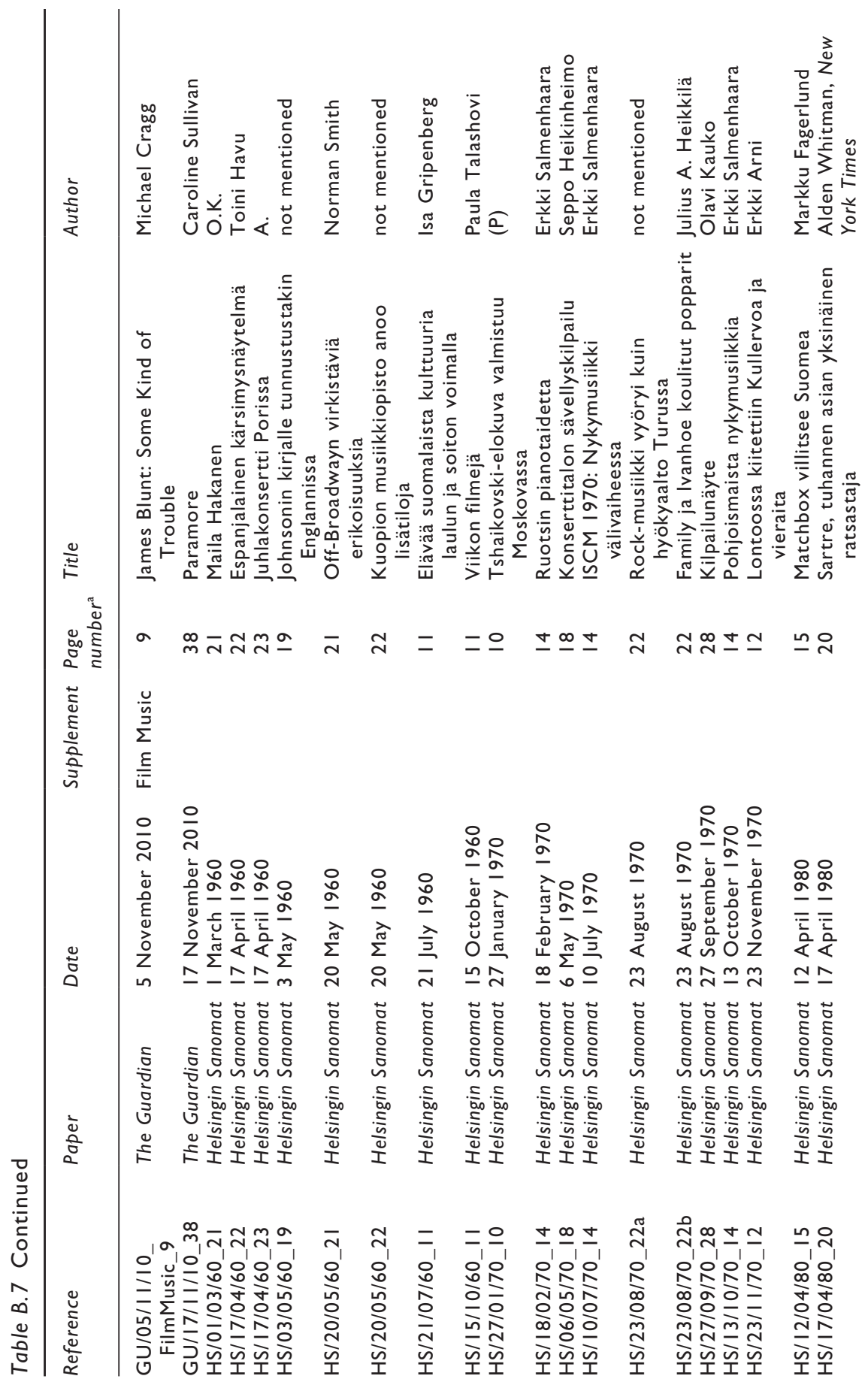




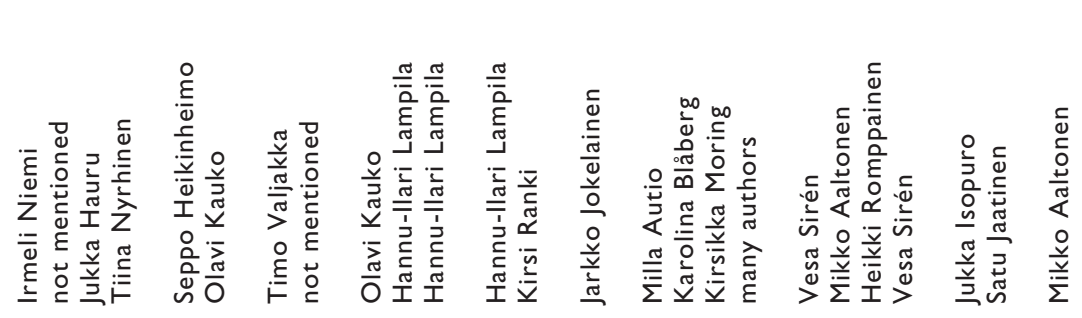

:

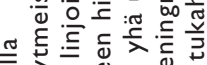

贾

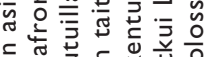

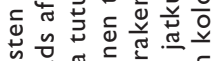

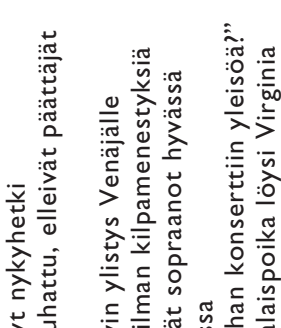

离.

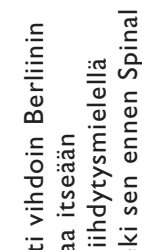

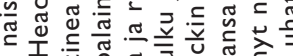

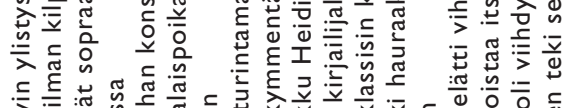

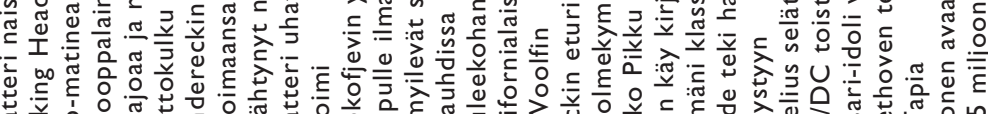

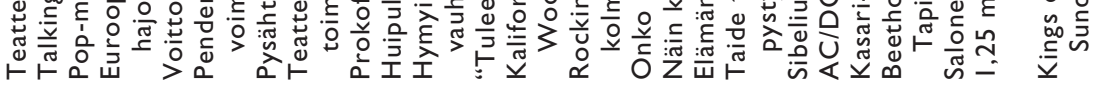

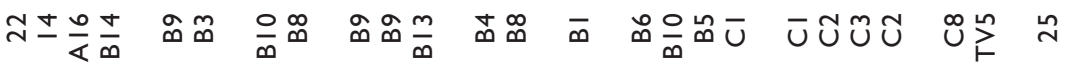

용

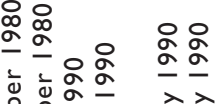

入入

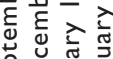

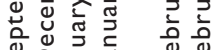

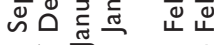

ํำกำ

몬

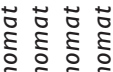

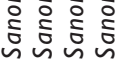

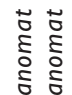

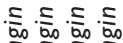

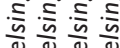

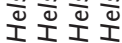

เ⿳亠口冋丁

음

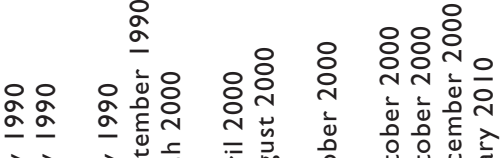

은

そ

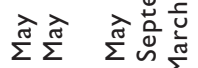

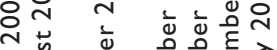

ㅎㄻㄹㅠ 응응유윰

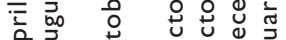

О Оับ

느느눙

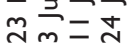

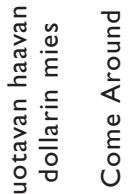

芒

을

m $\bar{m}$ 도

임ㅎㅁ

눙

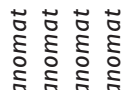

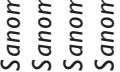

ธิ

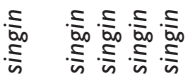

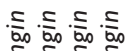

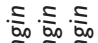

凶n

.

$\frac{\pi}{2} \frac{\pi}{2}$

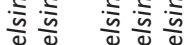

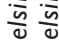

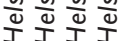

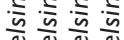

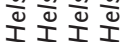

응웅유

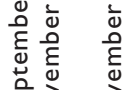

范雚 Z

สำ눙

サ̊̊

$\bar{U} \cup \mathcal{U}$

잉야양요양

응ㅇㅇㅇ

흥츠흥

సิํํㅇ

ㄴํㅇㄴํㅇ

능 ㅎํㅇ के

응응

ㅇํㅇㅇㅇ잉

응이임

ư

오송융

원

স্ণ

응ㅇㅇㅇ

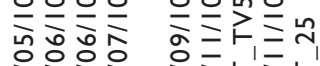

으으노응

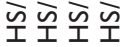

mল m청

엉 홍 츠흐츠유

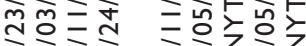

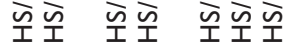

또노

जิ

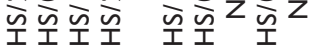




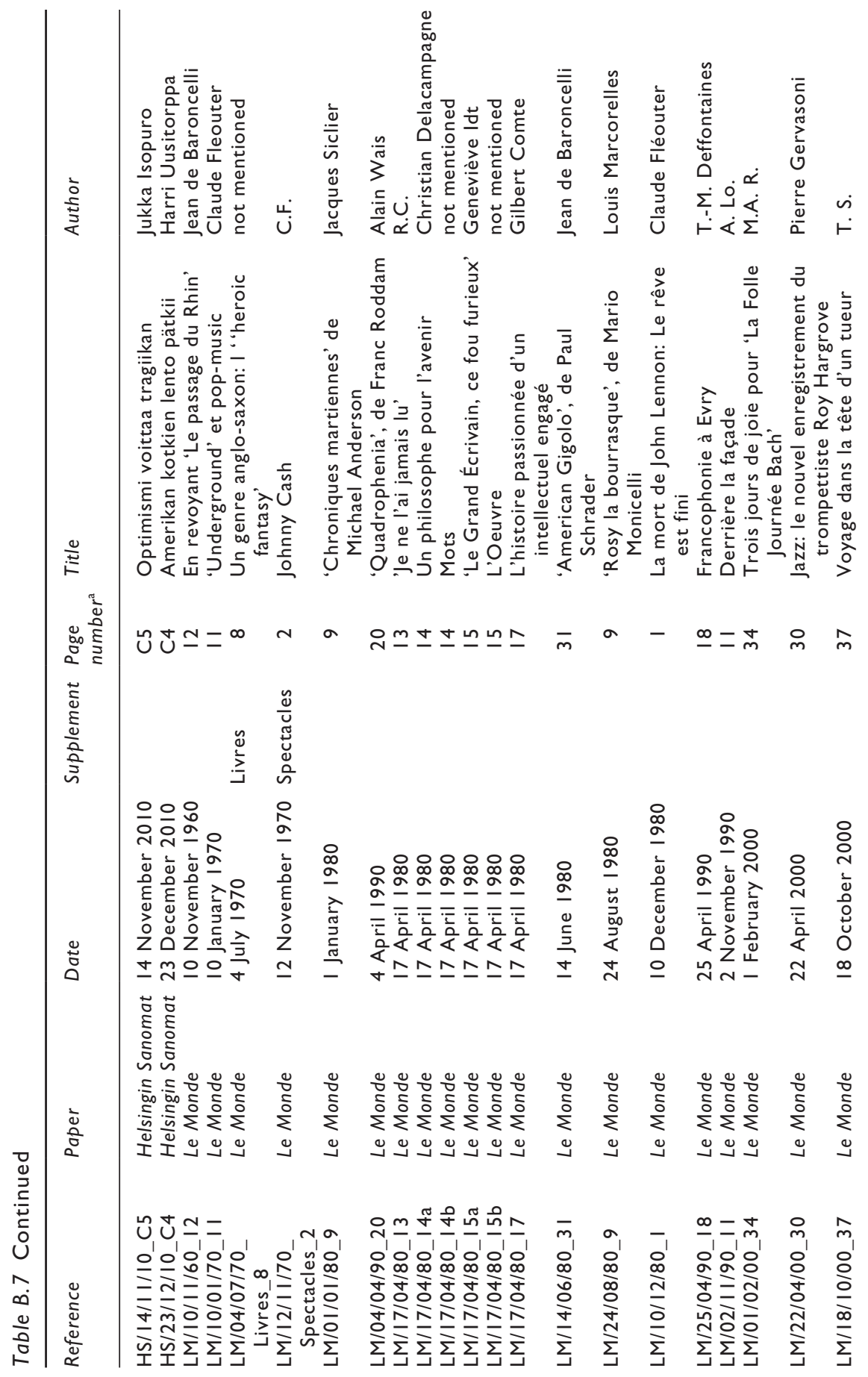



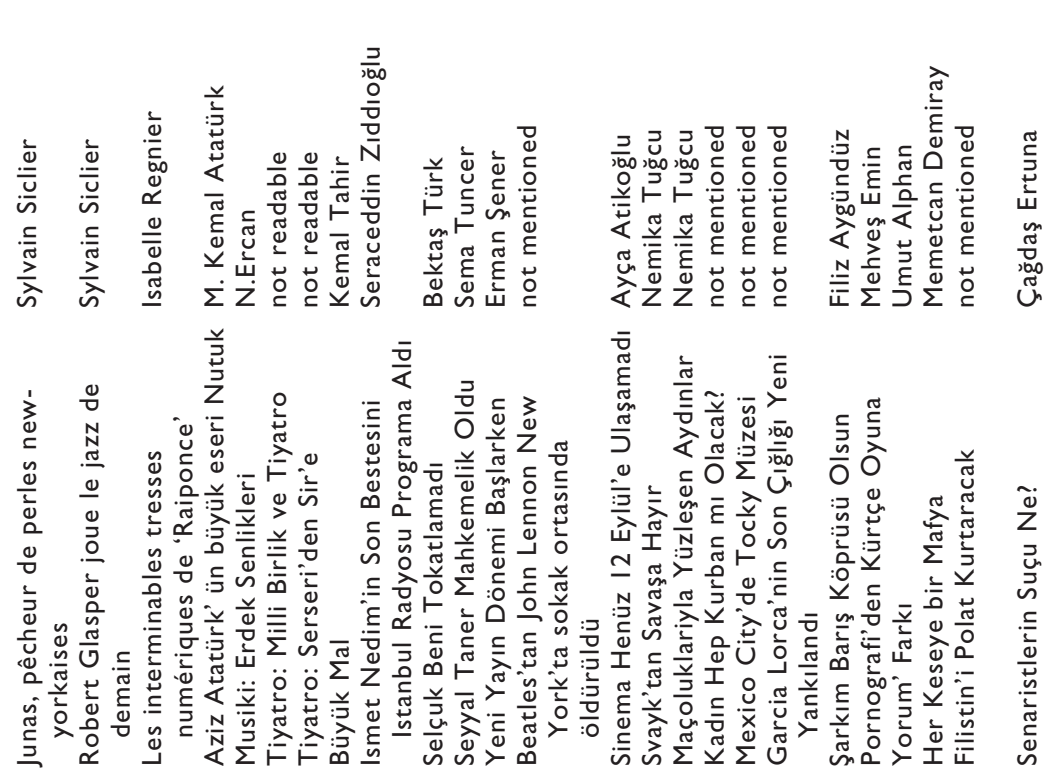

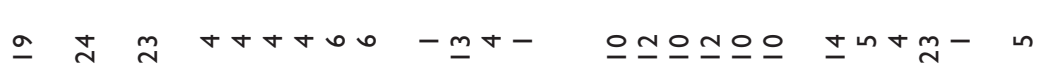<smiles>C=C=CC1CC1</smiles>

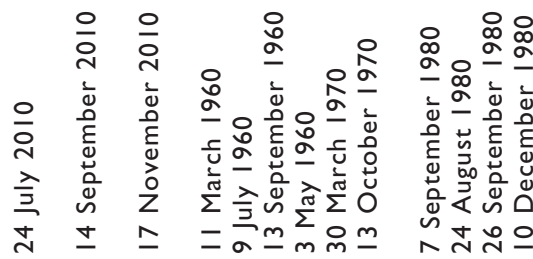
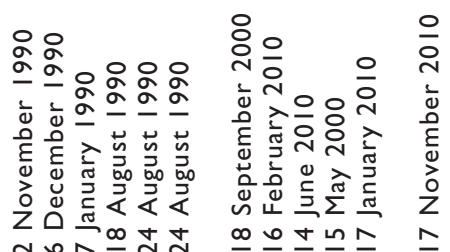

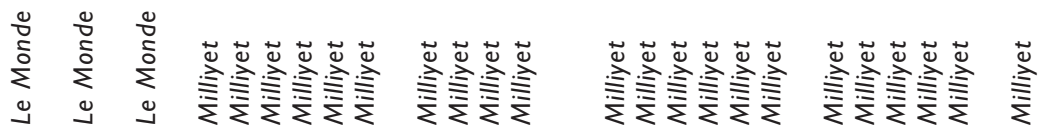

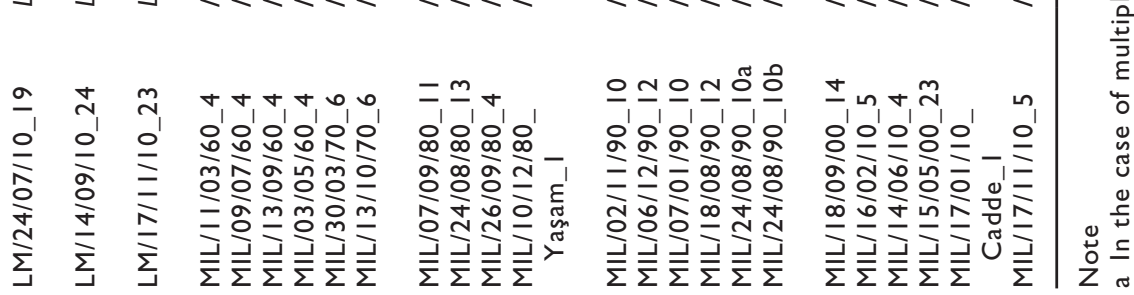




\section{References}

Abramson, A. (2002) The History of Television: 1942 to 2000. Jefferson, NC: McFarland. ACE (1998) International Data on Public Spending on the Arts in Eleven Countries. London: Arts Council of England.

Achterberg, P., Heilbron, J., Houtman, D. and Aupers, S. (2001) A cultural globalization of popular music? American, Dutch, French, and German popular music charts (1965 to 2006). American Behavioral Scientist 55(5): 589-608.

Adakl1, G. (2009) The process of neo-liberalization and the transformation of the Turkish media sector in the context of the new media architecture. In J. Harrison and B. Wessels (eds), Mediating Europe: New Media, Mass Communications and the European Public Sphere. New York: Berghahn Books, 286-318.

Adams, J. (2001) The makings of political art. Qualitative Sociology 24(3): 311-348.

Adams, J. (2005) When art loses its sting: The evolution of protest art in authoritarian contexts. Sociological Perspectives 48(4): 531-558.

Alankuş, S. and Yanardağoğlu, E. (2016) Vacillation in Turkey's popular global TV exports: Toward a more complex understanding of distribution. International Journal of Communication 10: 3615-3631.

Alaranta, T. (2008) Mustafa Kemal Atatürk's six-day speech of 1927: Defining the official historical view of the foundation of the Turkish Republic. Turkish Studies 9(1): 115-129.

Alexander, J.C., Breese, E.B. and Luengo, M. (eds) (2016) The Crisis of Journalism Reconsidered: Democratic Culture, Professional Codes and Digital Future. New York: Cambridge University Press.

Allen, M.P. and Lincoln, A.E. (2004) Critical discourse and the cultural consecration of American films. Social Forces 82(3): 871-894.

Alonso, L.E. and Fernández Rodríguez, C.J. (2008) Emploi et précarité des jeunes: le cas de l'Espagne. Travail et Emploi 115: 71-80.

Appadurai, A. (1996) Modernity at Large: Cultural Dimensions of Globalization. Minneapolis, MN: University of Minnesota Press.

Arun, Ö. (2015) Kültürel Hepçiller: Ne Seçkin ne Sıradan, Sadece Olağan! Türkiye Televizyonunda İzleyici Beğenilerinin Analizi. Toplum ve Bilim 133: 247-280.

Baert, B. (2015) The Existential Moment: The Rise of Sartre as a Public Intellectual. Cambridge: Polity Press.

Bail, C.A. (2014) The cultural environment: Measuring culture with big data. Theory and Society 43(3-4): 465-482.

Barro, R.J. and Lee, J-W. (2013) A new data set of educational attainment in the world, 1950-2010. Journal of Development Economics 104(C): 184-198. 
Baumann, S. (2001) Intellectualization and art world development: Film in the United States. American Sociological Review 66(3): 404-426.

Baumann, S. (2007) Hollywood Highbrow: From Entertainment to Art. Princeton, NJ: Princeton University Press.

Beck, U. (2000a) What is Globalization? Cambridge: Polity Press.

Beck, U. (2000b) The cosmopolitan perspective: Sociology of the second age of modernity. British Journal of Sociology 51(1): 79-105.

Beck, U. (2004) Cosmopolitical realism: On the distinction between cosmopolitanism in philosophy and the social sciences. Global Networks 4(2): 131-156.

Becker, H.S. (1982) Art Worlds. Berkeley, CA: University of California Press.

Bekhuis, H., Lubbers, M. and Ultee, W. (2014) A macro-sociological study into the changes in the popularity of domestic, European, and American pop music in Western Countries. European Sociological Review 30(2): 180-193.

Bekhuis, H., Meuleman, R. and Lubbers, M. (2013) Globalization and support for national cultural protectionism from a cross-national perspective. European Sociological Review 29(5): 1040-1052.

Belge, M. (1996) Kültür: Cumhuriyet Dönemi Türkiye Ansiklopedisi, İletişim Yayınları 5: 1287-1304.

Beljean, S., Chong, P. and Lamont, M. (2016) A post-Bourdieusian sociology of valuation and evaluation for the field of cultural production. In L. Hanquinet and M. Savage (eds), Routledge International Handbook of the Sociology of Art and Culture. London: Routledge, 38-48.

Bennett, A. (2016) Popular music and cultural sociology. In D. Inglis and A-M. Almila (eds), The Sage Handbook of Cultural Sociology. London: Sage, 527-537.

Bennett, T., Savage, M., Silva, E., Warde, A., Gayo-Cal, M. and Wright, D. (2009) Culture, Class, Distinction. London: Routledge.

Berkers, P., Janssen, S. and Verboord, M. (2014) Assimilation into the literary mainstream? The classification of ethnic minority authors in newspaper reviews in the United States, the Netherlands and Germany. Cultural Sociology 8(1): 25-44.

Berte, K. and de Bens, E. (2008) Newspapers go for advertising! Challenges and opportunities in a changing media environment. Journalism Studies 9(5): 692-703.

Bishop, C. (2012) Artificial Hells: Participatory Arts and the Politics of Spectatorship. London: Verso.

Blank, G. (2007) Critics, Ratings, and Society: The Sociology of Reviews. Lanham, MD: Rowman \& Littlefield.

Bonet, L. and Négrier, E. (2010) Cultural policy in Spain: Processes and dialectics. Cultural Trends 19(1-2): 41-52.

Bonnell, V. (1997) Iconography of Power. Berkeley, CA: University of California Press.

Boschetti, A. (1988) The Intellectual Enterprise: Sartre and Les Temps Modernes. Evanston, IL: Northwestern University Press.

Bourdieu, P. (1984) Distinction: A Social Critique of the Judgement of Taste. Cambridge, MA: Harvard University Press.

Bourdieu, P. (1993) The Field of Cultural Production: Essays on Art and Literature. London: Polity Press.

Bourdieu, P. (1996) The Rules of Art. London: Polity Press.

Bourdieu, P. (1998a) Acts of Resistance: Against the Tyranny of the Market. New York: New Press.

Bourdieu, P. (1998b) On Television. New York: New Press. 
Bourdieu, P. (2003) Culture is in danger. In P. Bourdieu, Firing Back: Against the Tyranny of the Market 2. New York: New Press, 66-81.

Bourdieu, P. (2005) The political field, the social science field and the journalistic field. In R. Benson and E. Neveu (eds), Bourdieu and the Journalistic Field. Cambridge: Polity Press, 29-47.

Brennan, M. (2017) When Genres Collide: Down Beat, Rolling Stone, and the Struggle between Jazz and Rock. New York: Bloomsbury Academic.

Brink Lund, A., Raeymaeckers, K. and Trappel, J. (2011) Newspapers: Adapting and experimenting. In J. Trappel, W.A. Meier, L. D'Haenens, J. Steemers and B. Thomass (eds), Media in Europe Today. Bristol: Intellect, 45-59.

Bryman, A. (2004) The Disneyization of Society. London: Sage.

Burke, P. (2009) Popular Culture in Early Modern Europe, 3rd edn. Farnham: Ashgate.

Çapl1, B. and Dündar, C. (1995) 80'den 2000'lere Televizyon. Cumhuriyet Dönemi Türkiye Ansiklopedisi 15: 1376-1386.

Cappeliez, S. and Johnston, J. (2013) From meat and potatoes to 'real-deal' rotis: Exploring everyday culinary cosmopolitanism. Poetics 41: 433-455.

Carr, R. (ed.) (1971) The Republic and the Civil War in Spain. London: Macmillan.

Carr, R. (1980) Modern Spain: 1875-1980. Oxford: Oxford University Press.

Carroll, N. (2009) On Criticism. New York: Routledge.

Champagne, P. (2005) The 'double dependency': The journalistic field between politics and markets. In R. Benson and E. Neveu (eds), Bourdieu and the Journalistic Field. Cambridge: Polity Press, 48-63.

Chan, T.W. (ed.) (2010) Social Status and Cultural Consumption. Cambridge: Cambridge University Press.

Cohen-Solal, A. (1987) Sartre: A Life. New York: Pantheon Books.

Coulangeon, P. (2017) Cultural openness as an emerging form of cultural capital in contemporary France. Cultural Sociology 11(2): 145-164.

Council of Europe (2016) Compendium of Cultural Policies and Trends in Europe, 17th edn. www.culturalpolicies.net/web/index.php (accessed 28 May 2017).

Crane, D. (2002) Culture and globalization. In D. Crane, N. Kawashima and K. Kawasaki (eds), Global Culture: Media, Arts, Policy, and Globalization. New York: Routledge $1-28$.

Crane, D. (2014) Cultural globalization and the dominance of the American film industry: Cultural policies, national film industries, and transnational film. International Journal of Cultural Policy 20(4): 365-382.

Cushman, T. (1995) Notes from Underground: Rock Music Counterculture in Russia. Albany, NY: State University of New York Press.

Cvetičanin, P. and Popescu, M. (2011) The art of making classes in Serbia: Another particular case of the possible. Poetics 39: 444-468.

Daenekindt, S. and Roose, H. (2015) De-institutionalization of high culture? Realized curricula in secondary education in Flanders, 1930-2000. Cultural Sociology 9(4): $515-533$.

Daloz, J-P (2010) The Sociology of Elite Distinction. Basingstoke: Palgrave Macmillan.

Davara Torrego, F.J. (2005) Los periódicos españoles en el tardo franquismo: Consecuencias de la nueva ley de prensa. Revista Comunicación y Hombre 1: 131-147.

De Graaf, N.D., De Graaf, P.M. and Kraaykamp, G. (2000) Parental cultural capital and educational attainment in the Netherlands: A refinement of the cultural capital perspective. Sociology of Education 73(2): 92-111. 
DeNora, T. (1995) Beethoven and the Construction of Genius. Berkeley, CA: University of California Press.

Denord, F., Lagneau-Ymonet, P. and Thine, S. (2011) Le champ du pouvoir en France. Actes de la recherche en sciences sociales 190(5): 24-57.

DiMaggio, P. (1982a) Cultural capital and school success: The impact of status group participation on the grades of U.S. high school students. American Sociological Review 47(2): 189-201.

DiMaggio, P. (1982b) Cultural entrepreneurship in nineteenth-century Boston: The creation of an organizational base for high culture in America. Media, Culture $\mathcal{E}$ Society 4(1): 33-50.

DiMaggio, P. (1987) Classification in art. American Sociological Review 52(4): 440-455.

DiMaggio, P. (1991) Social structure, institutions, and cultural goods: The case of the United States. In P. Bourdieu and J.S. Coleman (eds), Social Theory for a Changing Society. Boulder, CO: Westview Press, 133-155.

DiMaggio, P. (1992) Cultural boundaries and structural change: The extension of the high culture model to theater, opera, and the dance, 1900-1940. In M. Lamont and M. Fournier (eds), Cultivating Differences: Symbolic Boundaries and the Making of Inequality. Chicago, IL: University of Chicago Press, 21-57.

DiMaggio, P. (2012) Sociological perspectives on the face-to-face enactment of class distinction. In S.T. Fiske and H. Markus (eds), Facing Social Class. New York: Russell Sage Foundation, 15-38.

DiMaggio, P. and Mukhtar, T. (2004) Arts participation as cultural capital in the United States, 1982-2002: Signs of decline? Poetics 32: 169-194.

DiMaggio, P., Nag, M. and Blei, D. (2013) Exploiting affinities between topic modeling and the sociological perspective on culture: Application to newspaper coverage of U.S. government arts funding. Poetics 41: 570-606.

DiMaggio, P. and Useem, M. (1978) Social class and arts consumption. Theory and Society 5(2): 141-161.

Donnat, O. (2011) Pratiques culturelles, 1973-2008: Dynamiques générationnelles et pesanteurs sociales. Culture études 7(7): 1-36.

Dündar, L. (2016) 12 Eylül 1980 Darbesinin basına etkileri. TARIHIN PEŞINDE - The Pursuit of History: International Periodical for History and Social Research 16: 125-154.

van Eijck, K. (2001) Social differentiation in musical taste patterns. Social Forces 79(3): $1163-1184$.

van Eijck, K. and Knulst, W. (2005) No more need for snobbism: Highbrow cultural participation in a taste democracy. European Sociological Review 21(5): 513-528.

Elkins, J. (2003) What Happened to Art Criticism? Chicago, IL: Prickly Paradigm Press.

Elliot, A. (1999) The Mourning of John Lennon. Berkeley, CA: University of California Press.

Eveno, P. (2004) Histoire du Journal Le Monde, 1994-2004. Paris: Albin Michel.

Eyerman, R. and Jamison, A. (1995) Social movements and cultural transformation: Popular music in the 1960s. Media, Culture EF Society 17(3): 449-468.

Falk, P. (1994) The Consuming Body. London: Sage.

Falk, P. (1997) The Benetton-Toscani effect: Testing the limits of conventional advertising. In M. Nava, A. Blake, I. MacRury and B. Richards (eds), Buy This Book: Studies in Advertising and Consumption. London: Routledge, 64-86.

Featherstone, M. (1991) Postmodernism and Consumer Culture. London: Sage.

Feroz, A. (1977) The Turkish Experiment in Democracy, 1950-1975. London: Hurst. 
Feroz, A. (2002) The Making of Modern Turkey. London: Routledge.

Fishman, R.M. and Lizardo, O. (2013) How macro-historical change shapes cultural taste: Legacies of democratization in Spain and Portugal. American Sociological Review 78(2): 213-239.

Fogo, F. (1994) I Read the News Today: The Social Drama of John Lennon's Death. Lanham, MD: Rowman \& Littlefield.

Foweraker, J. (1989) Making Democracy in Spain. Cambridge: Cambridge University Press.

Franklin, B. (1997) Newszak and News Media. London: Arnold.

Friedman, S., Savage, M., Hanquinet, L. and Miles, A. (2015) Cultural sociology and new forms of distinction (Introduction to the special issue). Poetics 53: 1-8.

Frith, S. (1978) The Sociology of Rock. London: Constable.

Frith, S. (1981) Sound Effects: Youth, Leisure and the Politics of Rock ' $n$ ' Roll. New York: Pantheon.

Frith, S. (1996) Performing Rites: On the Value of Popular Music. Cambridge, MA: Harvard University Press.

Gans, H. (1974) Popular Culture and High Culture: An Analysis and Evaluation of Taste. New York: Basic Books.

Ganzeboom, H. (1982) Explaining differential participation in high-cultural activities: A confrontation of information-processing and status-seeking theories. In W. Raub (ed.), Theoretical Models and Empirical Analyses. Utrecht: E.S. Publications, 186-205.

Ger, G. (2017) Consumption in the web of local and global relations of dominance and belonging. In M. Keller, B. Halkier, T.-A. Wilska and M. Truninger (eds), Routledge Handbook on Consumption. London: Routledge, 121-135.

Giddens, A. (1990) Consequences of Modernity. Cambridge: Polity Press.

Giddens, A. (1999) Runaway World: How Globalization is Reshaping Our Lives. London: Profile Books.

Goffman, E. (1951) Symbols of class status. British Journal of Sociology 2: 294-304.

Goffman, E. (1979) Gender Advertisements. New York: Harper \& Row.

Goldfarb, J. (1980) The Persistence of Freedom: The Sociological Implications of Polish Student Theater. Boulder, CO: Westview Press.

Göle, N. (1999) İslamin yeni kamusal yüzleri. Istanbul: Metis.

Gronow, J. (1997) The Sociology of Taste. London: Routledge.

Gronow, J. and Southerton, D. (2010) Leisure and consumption in Europe. In S. Immerfall and G. Therborn (eds), Handbook of European Societies. New York: Springer, 355-384.

Gürsoy, Y. (2017) Between Military Rule and Democracy: Regime Consolidation in Greece, Turkey, and Beyond. Ann Arbor, MI: University of Michigan Press.

Gustafsson, K.E. and Rydén, P. (2010) A History of the Press in Sweden. Gothenburg: Nordicom.

Hadenius, S. (2002) Dagens Nyheters historia: Tidningen och makten, 1864-2000. Stockholm: Bokförlaget DN.

Hahn, H.P. (2012) Circulating objects and the power of hybridization as a localizing strategy. In P.W. Stockhammer (ed.), Conceptualizing Cultural Hybridization: A Transdisciplinary Approach. Heidelberg: Springer, 27-42.

Hallin, D.C. (2005) Field theory, differentiation theory, and comparative media research. In R. Benson and E. Neveu (eds), Bourdieu and the Journalistic Field. Cambridge: Polity Press, 224-243. 
Hallin, D.C. and Mancini, P. (2004) Comparing Media Systems: Three Models of Media and. Politics. Cambridge: Cambridge University Press.

Hallin, D.C. and Mancini, P. (eds) (2012) Comparing Media Systems Beyond the Western World. Cambridge: Cambridge University Press.

Harries, G. and Wahl-Jorgensen, K. (2007) The culture of arts journalists: Elitists, saviors or manic depressives? Journalism: Theory, Practice and Criticism 8(6): 619-639.

Hartley, J. (1992) The Politics of Pictures. London: Routledge.

Hebdige, D. (1979) Subculture: The Meaning of Style. London: Methuen.

Heikkilä, R. and Gronow, J. (2018) Stability and change in the style and standards of European newspapers' arts reviews, 1960-2010. Journalism Practice 12(5): 624-639.

Heikkilä, R., Lauronen, T. and Purhonen, S. (2017) The crisis of cultural journalism revisited: The space and place of culture in quality European Newspapers from 1960 to 2010. European Journal of Cultural Studies. DOI: 10.1177/1367549416682970.

Heilbrun, J. and Gray, C. (2001) The Economics of Art and Culture. Cambridge: Cambridge University Press.

Heinich, N. (1998) Le Triple jeu de l'art contemporain: Sociologie des arts plastiques. Paris: Minuit.

Heinich, N. (2014) Le paradigme de l'art contemporain: Structures d'une révolution artistique. Paris: Gallimard.

Heinich, N. and Shapiro, R. (eds) (2012) De l'artification: Enquêtes sur le passage à l'art. Paris: Éditions de l'École des Hautes Études en Sciences Sociales.

Held, D., McGrew, A., Goldblatt, D. and Perraton, J. (1999) Global Transformations: Politics, Economics and Culture. Stanford, CA: Stanford University Press.

Hellman, H. (1999) From Companions to Competitors: The Changing Broadcasting Markets and Television Programming in Finland. Tampere: Tampere University Press.

Hellman, H. (2010) Liberal turn in media policy: The case of Finland's digital television. International Journal of Digital Television 1(2): 193-213.

Hellman, H. and Jaakkola, M. (2012) From aesthetes to reporters: The paradigm shift in arts journalism in Finland. Journalism: Theory, Practice and Criticism 13(6): 783-801.

Hellman, H., Larsen, L.O., Riegert, K., Widholm, A. and Nygaard, S. (2017) What is cultural news good for? In N.N. Kristensen and K. Riegert (eds), Cultural Journalism in the Nordic Countries. Gothenburg: Nordicon, 111-133.

Hesmondhalgh, D. (2006) Bourdieu, the media and cultural production. Media, Culture Eु Society 28(2): 211-231.

Hesmondhalgh, D. (2007) The Cultural Industries, 2nd edn. London: Sage.

Hirsch, P. (1972) Processing fads and fashions: An organization-set analysis of cultural industry systems. American Journal of Sociology 77(4): 639-659.

Hopper, P. (2007) Understanding Cultural Globalization. Malden: Polity Press.

Horkheimer, M. and Adorno, T.W. (1969) Dialectic of Enlightenment. New York: Continuum.

Hovden, J.F. and Knapskog, K. (2015) Doubly dominated: Cultural journalists in the fields of journalism and culture. Journalism Practice 9(6): 791-810.

Huntington, S.P. (1993) The clash of civilizations? Foreign Affairs 72(3): 22-49.

Hurri, M. (1993) Kulttuuriosasto: Symboliset taistelut, sukupolvikonflikti ja sananvapaus viiden pääkaupunkilehden kulttuuritoimituksissa 1945-80. Tampere: Acta Universitatis Tamperensis 389 .

Imbert, G. and Vidal-Beneyto, J. (eds) (1986) 'El País' o la referencia dominante. Barcelona: Mitre. 
Jaakkola, M. (2014) Outsourcing views, developing news. Journalism Studies 16(3): 383-402.

Jaakkola, M. (2015) The Contested Autonomy of Arts and Journalism: Change and Continuity in the Dual Professionalism of Cultural Journalism. Tampere: Acta Universitatis Tamperensis 2072.

Jaakkola, M., Hellman, H., Koljonen, K. and Väliverronen, J. (2015) Liquid modern journalism with a difference: The changing professional ethos of cultural journalism. Journalism Practice 9(6): 811-828.

Janssen, S. (1997) Reviewing as social practice: Institutional constraints on critics' attention for contemporary fiction. Poetics 24(5): 275-297.

Janssen, S. (1999) Art journalism and cultural change: The coverage of the arts in Dutch newspapers 1965-1990. Poetics 26(5): 329-348.

Janssen, S., Kuipers, G. and Verboord, M. (2008) Cultural globalization and arts journalism: The international orientation of arts and culture coverage in Dutch, French, German, and the U.S. newspapers, 1955 to 2005. American Sociological Review 73(5): 719-740.

Janssen, S. and Verboord, M. (2015) Cultural mediators and gatekeepers. In J.D. Wright (ed.), International Encyclopedia of the Social $\mathcal{B}$ Behavioral Sciences. Amsterdam: Elsevier, 440-446.

Janssen, S., Verboord, M. and Kuipers, G. (2011) Comparing cultural classification: High and popular arts in European and U.S. elite newspapers. Kölner Zeitschrift für Soziologie und Sozialpsychologie 63(51): 139-168.

Johnson, C., Dowd, T.J. and Ridgeway, C.L. (2006) Legitimacy as a social process. Annual Review of Sociology 32: 53-78.

Johnson, M. (2006) The Dead Beat: Lost Souls, Lucky Stiffs, and the Perverse Pleasures of Obituaries. New York: HarperCollins.

Johnston, J. and Baumann, S. (2007) Democracy versus distinction: A study of omnivorousness in gourmet food writing. American Journal of Sociology 113(1): 165-204.

Jones, S. and Jensen, J. (eds) (2005) Afterlife as Afterimage: Understanding Posthumous Fame. New York: Peter Lang.

Jowell, R. (1998) How comparative is comparative research? American Behavioral Scientist 42(2): 168-177.

Karabacak, M. (2017) Major macroeconomic dynamics for labour market in Turkey. In F. Yenilmez and E. Kiliç (eds), Handbook of Research on Unemployment and Labour Market Sustainability in the Era of Globalization. Hershey, PA: IGI Global.

Karademir Hazır, I. and Purhonen, S. (2017) Kültürel Açılım, Hepçillik ve Seçkin Sanatın Düşüşü: Türkiye-Avrupa Karşılaştırması. İLEF Dergisi 4(1): 29-58.

Karademir Hazır, I. and Warde, A. (2016) The cultural omnivore thesis: Methodological aspects of the debate. In L. Hanquinet and M. Savage (eds), Routledge International Handbook of the Sociology of Art and Culture. London: Routledge, 77-89.

Karpik, L. (2010) Valuing the Unique: The Economics of Singularities. Princeton, NJ: Princeton University Press.

Katz-Gerro, T. (2002) Highbrow cultural consumption and class distinction in Italy, Israel, West Germany, Sweden, and the United States. Social Forces 81(1): 207-229.

Katz-Gerro, T. (2011) Cross-national cultural consumption research: Inspirations and disillusions. Kölner Zeitschrift für Soziologie und Sozialpsychologie 63: 339-360.

Katz-Gerro, T. (2015) Introduction: Cultural policy and the public funding on of culture in an international perspective. Poetics 49(1): 1-4. 
Kelly, M., Mazzoleni, G. and McQuail, D. (eds) (2014) The Media in Europe: The Euromedia Handbook. London: Sage.

Kendall, G., Woodward, I. and Skrbis, Z. (2009) The Sociology of Cosmopolitanism. Basingstoke: Palgrave Macmillan.

Kersten, A. and Bielby, D.D. (2012) Film discourse on the praised and acclaimed: Reviewing criteria in the United States and United Kingdom. The International Journal of Media and Culture 10(3): 183-200.

Kersten, A. and Janssen, S. (2017) Trends in cultural journalism: The development of film coverage in cross-national perspective, 1955-2005. Journalism Practice 11(7): 840-856.

Klamer, A., Petrova, L. and Mignosa, A. (2006) Financing the Arts and Culture in the EU. Brussels: Directorate General Internal Policies of the Union, European Parliament.

Kohn, M.L. (ed.) (1989) Cross-National Research in Sociology. Newbury Park, CA: Sage.

Korhonen, K. (2002) New music of Finland. In J.D. White (ed.), New Music of the Nordic Countries. Hillsdale, NY: Pendragon Press, 121-286.

Kowert, R. (2015) Video Games and Social Competence. New York: Routledge.

Krippendorff, K. (2004a) Content Analysis: An Introduction to its Methodology, 2nd edn. Thousand Oaks, CA: Sage.

Krippendorff, K. (2004b) Reliability in content analysis: Some common misconceptions and recommendations. Human Communication Research 30(3): 411-433.

Kristensen, N.N. (2010) Cultural journalism in the Danish printed press: A history of decline or increasing media institutional profiling? Northern Lights 8(1): 69-92.

Kristensen, N.N. and From, U. (2012) Lifestyle journalism: Blurring boundaries. Journalism Practice 6(1): 26-41.

Kristensen, N.N. and Riegert, K. (eds) (2017) Cultural Journalism in the Nordic Countries. Gothenburg: Nordicom.

Kroes, R. (1996) If You've Seen One, You've Seen the Mall: European and American Mass Culture. Urbana, IL: University of Illinois Press.

van der Laan, E. and Kuipers, G. (2016) How aesthetic logics shape a cultural field: Differentiation and consolidation in the transnational field of fashion images, 1982-2011. Poetics 56: 64-84.

Lahire, B. (2011) The Plural Actor. Cambridge: Polity.

Lamont, M. (1992) Money, Morals, and Manners: The Culture of the French and the American Upper-Middle Class. Chicago, IL: The University of Chicago Press.

Lamont, M. (2012) Toward a comparative sociology of valuation and evaluation. Annual Review of Sociology 38: 201-221.

Lamont, M. and Lareau, A. (1988) Cultural capital: Allusions, gaps and glissandos in recent theoretical developments. Sociological Theory 6(2): 153-168.

Lamont, M. and Molnár, V. (2002) The study of boundaries in the social sciences. Annual Review of Sociology 28: 167-195.

Lamont, M. and Thévenot, L. (eds) (2000) Rethinking Comparative Cultural Sociology: Repertoires of Evaluation in France and the United States. Cambridge: Cambridge University Press.

Lauronen, T., Heikkilä, R. and Purhonen, S. (2018) Cultural globalization on the printed page: Stability and change in the proportion of foreign cultural products in European quality newspapers, 1960-2010. Acta Sociologica. DOI: 10.1177/0001 699318780977.

Lavie, N. and Dhoest, A. (2015) 'Quality television' in the making: The cases of Flanders and Israel. Poetics 52: 64-74. 
Leguina, A., Arancibia-Carvajal, S. and Widdop, P. (2017) Musical preferences and technologies: Contemporary material and symbolic distinctions criticized. Journal of Consumer Culture 17(2): 242-264.

Lena, J.C. and Peterson, R.A. (2008) Classification as culture: Types and trajectories of music genres. American Sociological Review 73(5): 697-718.

Levine, L.W. (1988) Highbrow/Lowbrow: The Emergence of Cultural Hierarchy in America. Cambridge, MA: Harvard University Press.

Lewis, B. (1961) The Emergence of Modern Turkey. Oxford: Oxford University Press.

Lewis, G.B. and Rushton, M. (2007) Understanding state spending on the arts: 1976-1999. State and Local Government Review 39(2): 107-114.

Lieberson, S. (2000) A Matter of Taste: How Names, Fashions, and Culture Change. New Haven, CT: Yale University Press.

Lindberg, U., Guđtmundsson, G., Michelsen, M. and Weisethaunet, H. (2005) Rock Criticism from the Beginning: Amusers, Bruisers, and Cool-Headed Cruisers. New York: Peter Lang.

Livingstone, S. (2003) On the Challenges of Cross-National Comparative Media Research. European Journal of Communication 18(4): 477-500.

Lizardo, O. (2005) Can cultural capital theory be reconsidered in the light of world polity institutionalism? Evidence from Spain. Poetics 33(2): 81-110.

Lizardo, O. (2010) Culture and stratification. In J.R. Hall, L. Grindstaff and M. Lo (eds), Handbook of Cultural Sociology. New York: Routledge, 305-315.

Lizardo, O. and Skiles, S. (2012) Reconceptualizing and theorizing 'omnivorousness': Genetic and relational mechanisms. Sociological Theory 30(4): 263-282.

Lizardo, O. and Skiles, S. (2016) Cultural objects as prisms: Perceived audience composition of musical genres as a resource for symbolic exclusion. Socius: Sociological Research for a Dynamic World 2. DOI: 10.1177/2378023116641695.

Looseley, D. (2011) Notions of popular culture in cultural policy: A comparative history of France and Britain. International Journal of Cultural Policy 17(4): 365-379.

Lopes, P. (2002) The Rise of Jazz Art World. Cambridge: Cambridge University Press.

López, I. and Rodríguez, E. (2011) The Spanish model. New Left Review 69: 6-29.

Lukács, G. (1971) The Theory of the Novel. Cambridge, MA: MIT Press.

Luostarinen, H. and Uskali, T. (2006) Suomalainen journalismi ja yhteiskunnan muutos. In R. Heiskala and E. Luhtakallio (eds), Uusi jako. Miten Suomesta tuli kilpailukykyyhteiskunta? Helsinki: Gaudeamus, 179-201.

Lynes, R. (1955) The Tastemakers: The Shaping of American Popular Taste. New York: Harper \& Brothers.

McChesney, R.W. (2011) The crisis of journalism and the Internet. In G. Meikle and G. Redden (eds), News Online: Transformations and Continuities. London: Palgrave Macmillan, 53-68.

McDonald, R. (2007) The Death of the Critic. London: Continuum.

McFall, L. (2014) The problem of cultural intermediaries in the economy of qualities. In J. Smith Maguire and J. Matthews (eds), The Cultural Intermediaries Reader. London: Sage, 42-51.

McLuhan, M. (1962) The Gutenberg Galaxy: The Making of Typographic Man. Toronto: University of Toronto Press.

Madden, C. (2005) Indicators for arts and cultural policy: A global perspective. Cultural Trends 14(3): 217-247. 
Magin, M. (2017) Attention, please! Structural influences on tabloidization of campaign coverage in German and Austrian elite newspapers (1949-2009). Journalism. DOI: $10.1177 / 1464884917707843$.

Martin, B. (1981) A Sociology of Contemporary Cultural Change. Oxford: Blackwell.

Marwick, Arthur (1998) The Sixties: Cultural Revolution in Britain, France, Italy, and the United States, c.1958-c.1974. Oxford: Oxford University Press.

Marx, K. (1973) Grundrisse: Foundations of the Critique of Political Economy (Rough Draft). Harmondsworth: Penguin.

Matthews, J. and Smith Maguire, J. (2014) Introduction: Thinking with cultural intermediaries. In J. Smith Maguire and J. Matthews (eds), The Cultural Intermediaries Reader. London: Sage, 1-11.

Mattlar, M. (2015) 'Ei mitä hyvänsä rilutusta': Populaarimusiikin tie legitiimiksi kulttuuriksi Helsingin Sanomissa 1950-1982. Helsinki: Japa.

Meuleman, R. and Savage, M. (2013) A field analysis of cosmopolitan taste: Lessons from the Netherlands. Cultural Sociology 7(2): 230-256.

Meyer, J.W., Boli, J., Thomas, G.M. and Ramirez, F.O. (1997) World society and the nation-state. American Journal of Sociology 103(1): 144-181.

Moore, A.F. (1997) The Beatles: Sgt. Pepper's Lonely Hearts Club Band. Cambridge: Cambridge University Press.

Mulcahy, K.V. (2003) Comparing cultural patronage: Traditions and trends. In V.B. Morris and D.B. Pankratz (eds), The Arts in a New Millennium: Research and the Arts Sector. Westport, CT: Praeger Publishers, 95-108.

Negus, K. (2002) The work of cultural intermediaries and the enduring distance between production and consumption. Cultural Studies 16(4): 501-515.

Neuendorf, K.A. (2002) The Content Analysis Guidebook. Thousand Oaks, CA: Sage.

Norman, P. (2008) John Lennon: The Life. New York: HarperCollins.

Ollivier, M. (2008) Modes of openness to cultural diversity: Humanist, populist, practical, and indifferent. Poetics 36(2-3): 120-147.

Ollivier, M., Gauthier, G. and Truong, A.H. (2009) Cultural classifications and social divisions: A symmetrical approach. Poetics 37(5-7): 456-473.

Olmos, V. (2002) Historia del ABC: Cien años clave en la historia de España. Barcelona: Plaza y Janés.

Önder, N. (2017) The Economic Transformation of Turkey: Neoliberalism and State Intervention. London: I.B. Tauris.

Parker, F. (2013) An art world for art games. The Journal of the Canadian Game Studies Association 7(11): 41-60.

Payne, S. (1987) The Franco Regime, 1936-1975. Madison, WI: University of Wisconsin Press.

Peterson, R.A. (1977) Where the two cultures meet: Popular culture. Journal of Popular Culture 11(2): 385-400.

Peterson, R.A. (1992) Understanding audience segmentation: From elite and mass to omnivore and univore. Poetics 21(4): 243-282.

Peterson, R.A. (1997) The rise and fall of highbrow snobbery as status marker. Poetics 25(2-3): 75-92.

Peterson, R.A. (2005) Problems in comparative research: The example of omnivorousness. Poetics 33(5): 257-282.

Peterson, R.A. and Kern, R.M. (1996) Changing highbrow taste: From snob to omnivore. American Sociological Review 61(5): 900-907. 
Peterson, R.A. and Rossman, G. (2007) Changing arts audiences: Capitalizing on omnivorousness. In B. Ivey and S. Tepper (eds), Engaging Art: The Next Great Transformation of America's Cultural Life. New York: Routledge, 307-342.

Picard, R.G. (2008) Shifts in newspaper advertising expenditures and their implications for the future of newspapers. Journalism Studies 9(5): 704-716.

Pichler, F. (2012) Cosmopolitanism in a global perspective: An international comparison of open-minded orientations and identity in relation to globalization. International Sociology 27(1): 21-50.

Pieterse, J.N. (2003) Globalization $\mathcal{B}$ Culture: Global Mélange. London: Rowman \& Littlefield.

Prieur, A. and Savage, M. (2011) Updating cultural capital theory: A discussion based on studies in Denmark and Britain. Poetics 39(6): 566-580.

Prieur, A. and Savage, M. (2013) Emerging forms of cultural capital. European Societies 15(2): 246-267.

Purhonen, S., Gronow, J. and Rahkonen, K. (2011) Highbrow culture in Finland: Knowledge, taste and participation. Acta Sociologica 54(4): 385-402.

Purhonen, S. and Heikkilä, R. (2017) Food, music and politics: The interweaving of culinary taste patterns, 'highbrow' musical taste and conservative attitudes in Finland. Social Science Information 56(1): 74-97.

Purhonen, S., Heikkilä, R. and Karademir Hazır, I. (2017) The grand opening? The transformation of the content of culture sections in European newspapers, 1960-2010. Poetics 62: 29-42.

Purhonen, S., Lauronen, T. and Heikkilä, R. (2015) Into the great wide open? A comparative study of the contents of newspaper culture sections in the UK and Finland, 1970-2010. Research on Finnish Society 8: 5-18.

Purhonen, S., Lauronen, T. and Heikkilä, R. (2018) Between legitimization and popularization: The rise and reception of U.S. cultural products in culture sections of quality European newspapers, 1960-2010. Unpublished manuscript.

Purhonen, S. and Wright, D. (2013) Methodological issues in national-comparative research on cultural tastes: The case of cultural capital in the UK and Finland. Cultural Sociology 7(2): 257-273.

Rancière, J. (2004) The Politics of Aesthetics. London: Continuum.

Rankin, B., Ergin, M. and Goksen, F. (2014) A cultural map of Turkey. Cultural Sociology 8(2): 159-179.

Reed, I.A. (2011) Interpretation and Social Knowledge: On the Use of Theory in the Human Sciences. Chicago, IL: University of Chicago Press.

van Rees, K. (1987) How reviewers reach consensus on the value of literary works. Poetics 16: 275-293.

van Rees, K. (1989) The institutional foundation of a critic's connoisseurship. Poetics 18: 179-198.

van Rees, K., Vermunt, J. and Verboord, M. (1999) Cultural classifications under discussion: Latent class analysis of highbrow and lowbrow reading. Poetics 26: 349-365.

Regev, M. (1994) Producing artistic value: The case of rock music. The Sociological Quarterly 35(1): 85-102.

Regev, M. (2013) Pop-Rock Music: Aesthetic Cosmopolitanism in Late Modernity. London: Polity Press.

Riegert, K., Roosvall, A. and Widholm, A. (2015) The political in cultural journalism. Journalism Practice 9(6): 773-390. 
Riffe, D., Aust, C.F. and Lacy, S.R. (1993) The effectiveness of random, consecutive day and constructed week sampling in newspaper content analysis. Journalism Eु Mass Communication Quarterly 70(1): 133-139.

Ritzer, G. and Jurgenson, N. (2010) Production, consumption, prosumption: The nature of capitalism in the age of the digital 'prosumer'. Journal of Consumer Culture 10(1): 13-36.

Ritzer, G. and Stillman, T. (2003) Assessing McDonaldization, Americanization and globalization. In U. Beck, N. Sznaider and R. Winter (eds), Global America? The Cultural Consequences of Globalization. Liverpool: Liverpool University Press, 31-48.

Robertson, R. (1992) Globalization: Social Theory and Global Culture. London: Sage.

Rockhill, G. (2014) Radical History and the Politics of Art. New York: Columbia University Press.

Roose, H. and Daenekindt, S. (2015) Trends in cultural participation. In J. Wright (ed.), International Encyclopedia of Social and Behavioral Sciences, Vol. 5. Oxford: Elsevier, 447-452.

Roose, H., Roose, W. and Daenekindt, S. (2018) Trends in contemporary art discourse: Using topic models to analyze 25 years of professional art criticism. Cultural Sociology. DOI: $10.1177 / 1749975518764861$.

Rossman, G. and Peterson, R.A. (2015) The instability of omnivorous cultural taste over time. Poetics 52: 139-153.

Royo, S. (2013) Lessons from the Economic Crisis in Spain. New York: Palgrave.

Roy, W.G. and Dowd, T.J. (2010) What is sociological about music? Annual Review of Sociology 36: 183-203.

Rössel, J. and Schroedter, J.H. (2015) Cosmopolitan cultural consumption: Preferences and practices in a heterogeneous, urban population in Switzerland. Poetics 50: 80-95.

Sampedro, V. and Lobera, J. (2015) The Spanish 15-M Movement: A consensual dissent? Journal of Spanish Cultural Studies 15(1-2): 61-80.

Santoro, M. and Solaroli, M. (2016) Contesting culture: Bourdieu and the strong program in cultural sociology. In L. Hanquinet and M. Savage (eds), Routledge International Handbook of the Sociology of Art and Culture. London: Routledge, 49-76.

Savage, J. (2001) England's Dreaming: Anarchy, Sex Pistols, Punk Rock and Beyond, 2nd edn. New York: St. Martin's Griffin.

Savage, M. (2009) Contemporary sociology and the challenge of descriptive assemblage. European Journal of Social Theory 12(1): 155-177.

Savage, M. and Burrows, R. (2007) The coming crisis of empirical sociology. Sociology 41(5): 885-899.

Savage, M., Cunningham, N., Devine, F., Friedman, S., Laurison, D., McKenzie, L., et al. (2015) Social Class in the 21st Century. London: Pelican.

Savage, M., Wright, D. and Gay-Cal, M. (2010) Cosmopolitan nationalism and the cultural reach of the white British. Nations and Nationalism 16(4): 598-615.

Scardaville, M. (2009) High art, no art: The economic and aesthetic legitimacy of U.S. soap operas. Poetics 37: 366-382.

Schmutz, V. (2005) Retrospective cultural consecration in popular music: Rolling Stone's greatest albums of all time. American Behavioral Scientist 48(11): 1510-1523.

Schmutz, V. (2009a) The Classification and Consecration of Popular Music: Critical Discourse and Cultural Hierarchy. Rotterdam: ERMeCC, Erasmus Research Centre for Media, Communication and Culture. 
Schmutz, V. (2009b) Social and symbolic boundaries in newspaper coverage of music, 1955-2005: Gender and genre in the US, France, Germany, and the Netherlands. Poetics 37: 298-314.

Schmutz, V. (2016) Commercialization and consecration: Media attention to popular music in the U.S. and the Netherlands, 1975-2005. Poetics 59: 82-95.

Schmutz, V., van Venrooij, A., Janssen, S. and Verboord, M. (2010) Change and continuity in newspaper coverage of popular music since 1955: Evidence from the United States, France, Germany, and the Netherlands. Popular Music and Society 33(4): 501-515.

Schrauf, R.W. (2016) Mixed Methods: Interviews, Surveys, and Cross-Cultural Comparisons. Cambridge: Cambridge University Press.

Schudson, M. (1989) How culture works: Perspectives from media studies on the efficacy of symbols. Theory and Society 18(2): 153-180.

Schuster, M. (2007) Comparing participation in the arts and culture. In B. Ivey and S. Tepper (eds), Engaging Art: The Next Great Transformation of America's Cultural Life. New York: Routledge, 49-84.

Seabrook, J. (2015) The Song Machine: Inside the Hit Factory. New York: W. \& W. Norton.

Şenyapılı, Ö. (1971) 1970’lerin Başında Sayılarla Türk Basını (1950-1970 Yılları Arasındaki Gelişme, Sayısal Analiz, Genel Tutumlar ve Durum). Amme İdaresi Dergisi 4(4).

Shaw, W.M.K. (2011) Ottoman Painting: Reflections of Western Art from the Ottoman Empire to the Turkish Republic. London: I.B. Tauris.

Shiner, L. (2001) The Invention of Art: A Cultural History. Chicago, IL: University of Chicago Press.

Shor, F. (2010) Dying Empire: U.S. Imperialism and Global Resistance. New York: Routledge.

Shrum, W. (1991) Critics and publics: Cultural mediation in highbrow and popular performing arts. American Journal of Sociology 97(2): 347-375.

Simmel, G. (1904) Fashion. International Quarterly 10(1): 130-155.

Small, M.L., Harding, D.J. and Lamont, M. (2010) Reconsidering culture and poverty. Annals of the American Academy of Political and Social Science 629(1): 6-27.

Smith Maguire, J. (2014) Bourdieu on cultural intermediaries. In J. Smith Maguire and J. Matthews (eds), The Cultural Intermediaries Reader. London: Sage, 15-24.

Smith Maguire, J. and Matthews, J. (eds) (2014), The Cultural Intermediaries Reader. London: Sage.

Stegert, G. (1998) Feuilleton für alle: Strategien im Kulturjournalismus der Presse. Tübingen: Max Niemeyer Verlag.

Straw, W. (2005) Pathways of cultural movement. In S. Jeannotte, M. Gattinger, C. Andrews and W. Straw (eds), Accounting for Culture: Thinking through Cultural Citizenship. Ottawa: University of Ottawa Press, 183-197.

Szemere, A. (2001) Up from the Underground: The Culture of Rock Music in Postsocialist Hungary. University Park, PA: Pennsylvania State University Press.

Taylor, G. (1993) Changing Faces: A History of the Guardian 1956-1988. London: Fourth Estate.

Throsby, D. (2010) The Economics of Cultural Policy. Cambridge: Cambridge University Press.

Tomlinson, J. (1991) Cultural Imperialism: A Critical Introduction. London: Pinter. 
Tomlinson, J. (1999) Globalization of Culture. Cambridge: Polity Press.

Tommila, P., Ekman-Salokangas, U., Aalto, E-L. and Salokangas, R. (eds) (1988) Suomen lehdistön historia 5: Hakuteos Aamulehti-Kotka Nyheter. Sanoma- ja paikallislehdistö 1771-1985. Kuopio: Kustannuskiila.

Topuz, H. (2003) II. Mahmut'tan Holdinglere Türk Basm Tarihi. Remzi Kitabevi.

Trigg, A.B. (2001) Veblen, Bourdieu, and conspicuous consumption. Journal of Economic Issues 35(1): 99-115.

Varriale, S. (2016) Globalization, Music and Cultures of Distinction: The Rise of Pop Music Criticism in Italy. Basingstoke: Palgrave Macmillan.

Veblen, T. (1899) The Theory of the Leisure Class. New York: Macmillan.

Velthuis, O. (2003) Symbolic meanings of prices: Constructing the value of contemporary art in Amsterdam and New York galleries. Theory and Society 32(2): $181-215$.

van Venrooij, A. (2009) Classifications in Popular Music: Discourses and Meaning Structures in American, Dutch and German Popular Music Reviews. Rotterdam: ERMeCC, Erasmus Research Centre for Media, Communication and Culture.

van Venrooij, A. (2011) Classifying popular music in the United States and the Netherlands. American Behavioral Scientist 55(5): 609-623.

van Venrooij, A. and Schmutz, V. (2010) The Evaluation of popular music in the United States, Germany and the Netherlands: A comparison of the use of high art and popular aesthetic criteria. Cultural Sociology 4(3): 395-421.

Verboord, M. (2010) The legitimacy of book critics in the age of the internet and omnivorousness: Expert critics, internet critics and peer critics in Flanders and the Netherlands. European Sociological Review 26(6): 623-637.

Verboord, M. (2011) Market logic and cultural consecration in French, German and American bestseller lists, 1970-2007. Poetics 39: 290-315.

Verboord, M. (2014) The impact of peer-produced criticism on cultural evaluation: A multilevel analysis of discourse employment in online and offline film reviews. New Media E⿱ Society 16(6): 921-940.

Verboord, M. and Brandellero, A. (2018) The globalization of popular music, 1960-2010: A multilevel analysis of music flows. Communication Research 45(4): 603-627.

Verboord, M. and Janssen, S. (2015) Arts journalism and its packaging in France, Germany, The Netherlands and The United States, 1955-2005. Journalism Practice 9(6): 829-852.

Verboord, M., Kuipers, G. and Janssen, S. (2015) Institutional recognition in the transnational literary field, 1955-2005. Cultural Sociology 9(3): 447-465.

Warde, A. (1992) Notes on the relationship between production and consumption. In R. Burrows and C. Marsh (eds), Consumption and Class: Divisions and Change. London: Macmillan, 15-31.

Warde, A. (2015) The Sociology of consumption: Its recent development. Annual Review of Sociology 41: 117-134.

Weber, M. (1978) Economy and Society. Berkeley, CA: University of California Press.

Weibull, L. and Nilsson, $\AA$. (2010) Four decades of European newspapers: Structure and content. In J. Gripsrud and L. Weibull (eds), Media, Markets Eु Public Spheres. Bristol: Intellect, 39-70.

White, J. (1999) Islamic chic. In C. Keyder (ed.), Istanbul: Between the Global and Local. New York: Rowman \& Littlefield, 77-91.

Wiener, J. (1984) Come Together: John Lennon in His Time. New York: Random House. 
Wilensky, H.L. (1964) Mass society and mass culture: Interdependence or independence? American Sociological Review 29(2): 173-197.

Williams, R. (1981) Culture. London: Fontana Press.

Woodward, I., Skrbis, Z. and Bean, C. (2008) Attitudes towards globalization and cosmopolitanism: Cultural diversity, personal consumption and the national economy. The British Journal of Sociology 59(2): 207-226.

Wouters, C. (2007) Informalization. London: Sage.

Wright, D. (2011) Making tastes for everything: Omnivorousness and cultural abundance. Journal for Cultural Research 15(4): 355-371.

Wright, D. (2015) Understanding Cultural Taste: Sensation, Skill and Sensibility. Basingstoke: Palgrave Macmillan.

Wright, D., Heikkilä, R. and Purhonen, S. (2013) Comparing 'cosmopolitanism': Taste, nation and global culture in Finland and the UK. Comparative Sociology 12(3): 330-360.

Yeşil, B. (2014) Press censorship in Turkey: Networks of state power, commercial pressures, and self-censorship. Communication, Culture EF Critique 7(2): 154-173. 


\section{Index}

Page numbers in bold denote tables, those in italics denote figures.

ABC (Spanish newspaper) 6, 12-13, 15, $34,39,42,46,53,65,105-107,115$, 152, 157-159, 209, 212; aesthetic dimension of 69; 'Art and Artists' section 163; basic information about 14; classical music and pop-rock articles 45; commercial dimension of 131; cultural areas discussed in 38; culture section of 163 ; film, radio, small emerging art forms articles 40, 41; idea of Spain in 162-166; literary fiction and non-fiction articles 43; origins of cultural products 105 ; political dimension of 153 ; sizeadjusted proportions of main article 187; theatre and the visual arts articles 50

AC/DC 137

Adorno, Theodor 125

advertisements 124, 180; advent of 142; aesthetic autonomy 146; classified 143; commercial aspects of 142-146; culture and education 144; journalistic content of 144; in mid-twentieth century 142; related to culture dominate 144; topics published in culture sections 145

Aerosmith 136

aesthetic cosmopolitanism 30, 57

aesthetic legitimation 30, 123, 127, 133

African art, exhibitions of 117

African cultural products and artists 107, 114,117

Age of Enlightenment 124, 151

Alberola, Jean-Michel 118

American club music 129

American creativity 112-113
American culture, influence of 81,100 , 113-115, 121, 190

American Gigolo (film) 138

'Americanization' of culture 98-100, 106, 108, 112-114, 125

Anatolian rock (musical genre) 55

Anderson, Laurie 77

Anderson, Michael 138

Anglo-American rock music 55

AntiEspaña 1959 (book) 164

anti-religious punks 120

art coverage: highbrow 33; history of 66;

Milliyet's 168

art-economy relationship 124

art for art's sake 124-125, 150-151, 200-202

art forms 152; commercial dimension by 131 ; political dimension by 154 ; specific differences 47

articles published in culture sections: aesthetic dimension in 68-70; by art form and year 70; highbrow versus popular categories 69 ; by newspaper and year 69

artification, process of 30

artistic classification systems, idea of

$$
11-12
$$

artistic production 11, 126

artistic value of art 136; politics and 150-152

art-money relationship 123, 146; on commercialization of culture 124-126;

cultural goodwill and tensions 134-137

arts markets, building of 124

arts reviewing, role of 150

ATLAS.ti (software) 19, 210-211 
'authentic' culture 129

'autonomization' process of arts 125

autonomous journalism, idea of 33, 126

autonomous status of the arts 30

'avant-garde' art 125

Bach, Johann Sebastian 83, 134

'banal' cosmopolitanism 100, 117

Barbieri, Gato 66

Baumann, Shyon 21n5, 36, 62, 208n9

BBC Young Musicians competition 82

Beach Boys, The 136

Beatles, The 2-4, 141

Beckett, Samuel 83

Beck, Ulrich 100, 117

Beethoven, Ludwig van 76

Benatar, Pat 129

Biret, Idil 162

Black Orpheus (film) 119

Black Orpheus (jazz standard) 66

Blondie's concert in Hammersmith, review of 79

Blue Velvet (art movie) 114

Blunt, James 88

Bolshoi Theatre, The 116-117

Bourdieu, Pierre 5, 9-11, 27-28, 57n2, 124-126, 128-130, 133, 136, 142, 147. 151, 201-202, 207, 208n7; on cultural capital 11, 28; on cultural legitimacy 63-64, 91n 4

bourgeois: art 125; public 64; taste 64

Bradbury, Ray 138

Broadway theater 113, 126

Bruckner, Anton 83

bullfighting 58n9, 164; abolition of 165

bull worshipping $58 \mathrm{n} 9$

Cahiers de Cinema (film) 139

Call of Duty (computer game) 37

Carlavilla, Mauricio 164

Cash, Johnny 79, 113

censorship, of newspaper 54-55, 149, 151, 159, 161, 166-168

Chaykovskiy (American-Soviet film) 119

Chekhov, Anton 116

Cheltenham Festival 83

Chopin, Frédéric 86, 102

choral singing 83

Chroniques Martiennes (sci-fi mini-series) 138

cinema, artistic legitimation of 36

clash of civilizations 99

classical music 62; aesthetic dimension of
74 ; articles by year 73 ; artistic quality and aesthetic evaluations of 87-89; coverage of $82,134-137$; criteria used in evaluations of 67; in The Guardian 82-85; in Helsingin Sanomat 82, 85-87, 101-103; versus light music 85 ; 'list culture' rating 84; personification of 84 ; popularization of 82 ; reviews of 71,75 , 84

classified advertisements 142-143

close reading, process of $18-19,28,62,75$, $78,90,93,112,121,124,133,138,146$, $162,182,211,212$

commercial art 125, 128, 133

commercialization of culture $30,66,123$; advertisements 142-146; cultural journalism and 126-130; discourse on 125; French cinema 138-142; of newspaper data 130-133; qualitative approach to 133-142; quantitative approach to 130-133; Spanish music industry 140-142; tension between art and money 124-126

commercial journalism 126

computer games 34, 36-37, 64; Conquest

of Camelot 36; Peacemaker 37

conservative art, principles of 56

content of elite culture 29

convergence, idea of $62,75,99$

Cortázar, Julio 65

cosmopolitan attitudes and preferences 29 counter-flow artists 113

cover stories 191-194; Guardian, The 193; half-page long first articles 192;

popularity of 193; on popular music 193 critic-as-instructor 177

cross-cultural differences 13

Crozier, Mary 80

cultural capital: concept of 11, 28; content of elite culture 29; emerging forms of 29; fine arts as a form of 29; in older age group 30

cultural capitalization 99

cultural change: comparative research and studying 204-207; study through newspapers 9-10

cultural classifications, role of media in 9 cultural consumption 11-12, 100, 204, 218

cultural coverage of newspapers, analysis of 34

cultural declassification, trend towards 53 cultural economy 11 
cultural globalization 57, 120; concept of 99; of domestic and foreign culture 98; Finnish classical music nationalism 101-103; language dependency and 107; measured from newspaper coverage 104; multidimensionality of 99 ; origins of cultural products and 103, 104; perspectives on 99-103; popularization of highbrow arts and 201; process of 98, 101; qualitative approach to 111-120; quantitative approach to 103-111; of US culture 100

cultural hierarchies $17,27,126,176$; transformation of 13,201

cultural imperialism 99, 125, 170

cultural industries 11-12, 97, 116, 125-126, 140, 142, 177

cultural intermediaries $11,64,142,167$, $171,176,178$; concept of $9-10$

cultural journalism 123, 126, 167; changing 176-178; commercialization of 126-130; content and topics of 175; crisis of 175-176, 178, 187-190; essential element of 101; ideals of 77; of newspapers 162; Nordic media model of 34, 127, 203; normalization of 177 ; practice of 129 ; specialization of 175 ; visual orientation of 194

cultural journalists 11, 49; on 'bourgeois' principles of legitimacy 64; professional identity of 176 ; reporters 176 ; role of 9 ; see also journalism

cultural legitimacy: versus aesthetic legitimation 30; Bourdieu's understanding of 63; 'bourgeois' principles of 64; concept of 62, 63-68; differences in 64; heterogenization of 28 ; of pop-rock music 75,78 ; principle of 64; quantitative approach to 71-75; theoretical perspectives of 28-31; 'trickle-down' mechanism of 63, 67 cultural news 161, 164, 168, 186 cultural omnivore: concept of 29; rise of 63

'cultural package' of contemporary newspapers 142

cultural participation, in highbrow activities 29, 207

cultural policy $12,33-34,56,57 \mathrm{n} 4,58 \mathrm{n} 6$, 152, 157, 203-204, 208n4, 219

cultural popularization: of classical music 82; concept of 63-68; process of 64; quantitative approach to $71-75$ cultural production 5, 9-10, 12, 32, 64, 104, 125-126, 128, 133, 150, 217

cultural products: African 117; American 112-114; beyond domestic and foreign 117-120; classical highbrow arts 106; composition of 114; coverage in The Guardian 107; demand for imported 104; European 106; hybridization paradigm 107; language-dependent 104; legitimate status of 114; mass-produced cultural objects 107; multinational aspects of 117-120; origins of 103, 104, 107,118 ; from the 'other world' 114-117; Russian 116; in Spanish newspapers 107; transportability of 107 cultural references 18,188 cultural sociology 17-18, 27, 126, 133, 203-204, 206, 207

cultural stratification 22n13, 63, 149; consumption/production divide 10-12; consumption side of 11

cultural supplements, emergence of 179-180

cultural taste, sociology of 28

cultural transformation: comparative dimensions and expectations 31-34; hierarchies of 13; legitimation of popular culture 30; notion of 201-203; socio-political limits of 54-56

culture of entertainment 161

Cunningham, Michael 193

Dagens Nyheter (Swedish newspaper) 2, 6, 12, 34, 36, 46-47, 49, 56, 106, 112, 117, 129-130, 136, 153, 179, 182, 184, 186, 191, 193, 203, 209; aesthetic dimension of 69; approximate openness of 53; basic information about 14 ; breakdown of the data by year 16; classical music and pop-rock articles 45; commercial dimension of 131 ; cultural areas discussed in 38; cultural policy and politics in 157-159; cultural policy in 39; culture sections of 157 ; film, radio, small emerging art forms articles 40; highbrow arts coverage 51 ; literary fiction and non-fiction articles 42, 43; locations of culture sections in 183 ; news of the world 158; obituary- style article 198; origins of cultural products 105; political dimension of 153 ; political leanings of 15 ; size-adjusted proportions of main article 187 ; 
Dagens Nyheter (Swedish newspaper) continued society, policy and media articles 41 ; theatre and the visual arts articles 50

Daily Telegraph, The 101-102

de-hierarchization of culture 63

Democratic Initiative 169

d'Estaing, Giscard 163

DiMaggio, Paul 9, 11-12, 199, 205-206, $208 n 6$

disco music 137

Disney's Tangled (2010) 139

Dobrogosz, Steve 112

Dogan News Agency, Turkey 161

Donna (Dario Fo and Franca Rame) 48

Eagles: Take It to the Limit (1998) 113

economic capital 125, 161

electronic dance music, genres of 43, 44

Eliot, Marc 113; Eagles: Take It to the Limit (1998) 113

Elkaïm-Sartre, Arlette 198

El País (Spanish newspaper) 2, 6, 12, 20n2, 34-37, 39, 41-42, 45-46, 49, 56, 66, 101, 106-107, 114-116, 115-116, 130, 135, 140, 142, 159-160, 162, 164, 166, 171, 179-180, 186, 191, 198, 203, 209; aesthetic dimension of 69 ; approximate openness of 53 ; basic information about 14 ; breakdown of the data by year 16 ; classical music and pop-rock articles 45; commercial dimension of 131 ; cultural areas discussed in 38 ; film, radio, small emerging art forms articles 40; founding of 15 ; highbrow arts articles $\mathbf{5 1}$; literary fiction and non-fiction articles 43; origins of cultural products 105 ; political dimension by 153 ; size-adjusted proportions of 187; theatre and the visual arts articles 50; topics of democracy 162 emerging arts 39, 40, 107

Enter Culture, Exit Arts? 199-200

entertainment, culture of 161

Eraserhead (art movie) 114

established arts: dominance of 34-41; literature and music 41-46; transformations inside 41-46

ethno-cultural plurality 169

European newspapers 4, 103, 120-121, 178, 187, 202-203, 207; coverage of culture in 27 ; culture sections of 12,17 ; quality of 15

evaluation-based reviewing 177
Fassbinder, Rainer Werner 139

FIFA World Cup 135

film articles, in newspapers 39, 70, 109

film industry 32; Hollywood 113

Financial Times, The 102

fine arts 124; concept of 46; decline of 29; as a form of cultural capital 29

Finnish classical music nationalism 101-103

Fleetwood Mac 136

Fogo, Fred 21n4

Francoism 162, 165, 171

freedom of press 160-161; in Turkey 161

free speech 150

French cinema coverage, case of 138-142

French National Film Union 139

French theatre festival 169

French Union Générale de Cinematographie see French National Film Union

Friends (television series) 114

Gable, Clark 112

general musical conception 83

Gere, Richard 138

Gerhard, Roberto 83

Gimpel Fils (London gallery) 117

global cultural system 12, 32, 34

globalization of culture see cultural globalization

glocalization, idea of 99

Greenfield, Edward 84

green pop (Islamic pop music) 56

Guardian, The (British newspaper) 1-2, 6, 12-13, 15, 19, 20n1, 33-34, 39, 46, 48-49, 56, 62-63, 65, 75, 86-90, 102, 105-107, 118, 135, 148n6, 153, 179, 182, 186, 191, 193, 198, 203, 209-212; aesthetic dimension of 69 ; approximate openness of 53; basic information about 14: Blondie's concert in Hammersmith, review of 79; breakdown of the data by year 16; classical music and pop-rock articles 45; classical music coverage 82-85; commercial dimension of 131 ; coverage of US cultural products 107; cover stories 193; cultural areas discussed in 38; distribution of articles in 42; film, radio, small emerging art forms articles 40; highbrow arts articles 51; journalistic style 85 ; literary fiction and non-fiction articles 42, 43; 
locations of culture sections in 183 ; origins of cultural products 105 ; political dimension of 153 ; pop-rock coverage 78-82; Russian art coverage in 116; size-adjusted proportions of main article 187; television coverage of $80-81$; theatre and the visual arts articles 50

Guy, Barry 83

Hallin, Daniel C. 32-33, 58n7, 128, 171, $172 \mathrm{n} 3$

Heart 136

Helsingin Sanomat (Finnish newspaper) 2-3, 6, 12-13, 15, 19, 20n2, 21n 3,34 , $39,42,46-49,56,62-63,75,79-80,82$, 85-87, 89-90, 106, 116, 118-119, 137, $179,181-182,184,186,191,193,198$, 203, 209-211; approximate openness of 53; basic information about 14 ; breakdown of the data by year 16 ; classical music and pop-rock articles 45 ; classical music coverage in $82,85-87$, 101-103; commercial dimension of 131; cultural areas discussed in 38; cultural coverage 77; film, radio, small emerging art forms articles 40; on highbrow arts 51 ; literary fiction and non-fiction articles 43; locations of culture sections in 183; music coverage 77; national aspect of 101; origins of cultural products 105; personification of aesthetic evaluations 77; political dimension of 153; pop-rock coverage 75-78; 'Rock Music Hits like a Tsunami in Turku' article 76; size-adjusted proportions of main article 187; on theatre and the visual arts 50

Hemingway, Ernest 1, 4

'high-art' evaluative criteria 67, 68, 85

'highbrow' arts 8, 27, 123; articles on 47; coverage of 46; decline of 31, 46-51, 61-62, 201; defined 125;

deinstitutionalization of 31,201 ; economic struggles of 130; half-page long and illustrated articles on 190; 'home court' of 17; newspaper coverage of 32; Old style 29; operationalization of 46; origins of cultural products 111 ; versus popular culture 125 ; popularization of 90,201 ; proportion of articles on 51; public funding for 27; rates of cultural participation in 29,31 ; shrinking theatre and 48-49; status of 31

higher education institutions 27

Hollywood 81, 113, 126, 139, 152, 208n9

Horkheimer, Max 125

Hours, The 193

Hvorostovsky, Dmitri 84

Il Trovatore (play) 49

'inside-art' development 154

intellectual art 125

Internet 21n9, 145, 177

Jacksonian, Michael 88

Jagger, Mick 141

Janssen, Susanne 22n19, 46, 58n6, 60n17, 101, 104, 120, 122n6, 180, 188, 195n4, $195 \mathrm{n} 5,206$

Jazz Festival of San Sebastián 66

jazz music 65-66

journalism: autonomous 33, 126; commercial 126; coverage of television products 80 ; independence of 161 ; personification of 188 ;

professionalization of 33; quality 126-127; service 84, 92n5, 127, 179; soft 127

journalistic means, popularization of 188 journalistic popularization 176,178 ; indicators of 189

journalist-writers 10

Kant, Immanuel 124

Keaton, Buster 87

Kerouac, Jack 65

Kings of Leon 78

Kominas, The 120

Kool and The Gang 136

Kullervo 102

language dependency 107, 111, 120

Latin America, language and cultural ties in $115-116$

Le Figaro (French newspaper) 15

legitimization 4, 6, 20, 35, 61-66, 90-91, $114,121,126,134,177,198-199$, 201-202, 205

Le Monde (French newspaper) 2, 6, 12, 15, 20n2, 34, 39, 45-47, 49, 56, 65, 104, 106-107, 112-113, 128, 138, 139, 147, 179-180, 182, 191, 197, 199, 203, 209, 211; academic writing style for cinema in 139; aesthetic dimension of 69 ; 
Le Monde (French newspaper) continued approximate openness of 53; basic information about 14 ; breakdown of the data by year 16 ; cinema coverage from 133; classical music and pop-rock articles 45; commercial elements in 130, 131, 138; coverage of Sartre's death in 198; cultural areas discussed in 38; cultural products discussed in 105; film, radio, small emerging art forms articles 40, 134, 138; film sections of 139; halfpage long first articles 192; on highbrow arts $\mathbf{5 1}$; internal hierarchies 184 ; literary fiction and non-fiction articles 42, 43; locations of culture sections in 183 ; on new music genres 135; news stories about culture 186; political dimension of 153; size-adjusted proportions of main article 187; theatre and the visual arts articles 50

Le Passage Du Rhin (film) 138

Lennon, John 1-6, 198

liberal democracies 149

Liberation Carved in Stone, A (African art exhibition) 117

Lieberson, Stanley 206

light music 85

'list culture' rating 84

literature genres, articles on different 42

Loquillo 137

Lydon, John 79

Lynch, David 114

magazine news 161

Mamas and the Papas, The 136

Mancini, Paolo 32-33, 58n7, 171, 172n3

Mankiewicz, Joseph L. 139

market economy 55, 123

markets of symbolic goods 11, 130

Martin, Ricky 88

mass-mediated distribution channels 8

Matchbox 76

McCartney, Paul 3

media markets, dimensions of 32, 195

media systems, models of: Mediterranean

Polarized Pluralist model 33; North

Atlantic Liberal model 33; North/

Central European Democratic

Corporatist model 33

Milliyet (Turkish newspaper) 3, 6, 12, 15, 19, 20n2, 33, 39, 42, 46, 53-55, 58n10, 68, 70, 106-107, 131, 159, 161, 166-169, 171, 172n4, 198, 202, 205,
209-211; aesthetic dimension of 69; basic information about 14 ; breakdown of the data by year 16 ; classical music and pop-rock articles 45; commercial dimension of 131 ; coverage of national culture in Turkey 166-170; cultural areas discussed in 38; cultural journalism 167; culture and art coverage 168; culture section of 169 ; editorial decision 167; film, radio, small emerging art forms articles 40; labour-intensive cultural content in 161; literary fiction and non-fiction articles 43; origins of cultural products 105; political and social content 169 ; political dimension of 153; size-adjusted proportions of main article 187; theme of national identity and belonging 169

Milliyet Sanat (Milliyet Art) 166

Mizoguchi, Kenji 139

modern art 56, 118, 124; ideology of 126; Stockholm Museum of Modern Art 158

modern music: avant-garde 86 ; Nordic festival of 65,86

Mood (jazz styled composition) 87

Moscow Art Theatre 116

MOS-Film 119

Mozart, Wolfgang Amadeus 2, 4

Muse 136

music competitions 102-103

music education institute 102

music, newspaper coverage of 34,42

Muxxic Latina 116, 137

'national' artists 118

national culture, characterizations of 112

national identities, in the making 159-162

national music, 'poprockization' of 108 Ndiaye, Iba 118

newspaper culture sections 31 ; aesthetic dimension of 130; autonomy of 151; classifications of 17 ; commercial aspects of 130-133; content of 98; coverage (size-adjusted proportion) of main article 186; French cinema coverage 138-142; locations of 183; packaging of culture in 184-187; place of culture in 181-184; pop-rock and classical music coverage 134-137; role of commercial elements in cultural coverage 133-142; six largest cultural areas discussed in 38 ; 
size-adjusted proportions of 187; sizes of articles by year 185 ; space of culture in 178-181; topics of advertisements published in 145; visually appealing 188

newspaper data: collecting and coding 209-231; commercialization of 130-133; political dimension in 153-159

newspaper industry 32, 216

newspapers: basic information about 14; breakdown of the data by year 16 ; censorship of 161; classical music and pop-rock articles 45 ; commercial dimension of 131 ; coverage of highbrow arts 32; coverage of whodunit/thrillers 41 ; cultural classifications of 17 ; cultural content of 98; French cinema coverage 138-142; institutional and field-level characteristics 32 ; literary fiction and non-fiction articles 43; musical coverage 34, 42; musical genres articles 44; poetry and plays articles 41 ; political dimension of 153 ; popular culture and highbrow arts articles 47, 51;

proportion of film articles in 39 newspaper supplements 179-180, 213-214 news reporting, costs of 186 newsrooms 177, 193 news stories 3, 71, 73-74, 101, 133, 155, 161, 185-186, 196n7

Nordic Contemporary Music 86

Nordic media system model 34, 127, 203 normative cosmopolitanism 100

object of art, monetary and aesthetic value of $128-130$

On Television (1998) 126

Ono, Yoko 4

orchestral playing 83

organizational journalistic independence 191

origins of cultural products 103, 104, 107, 118; art forms 109; articles on highbrow arts and popular culture 111; classical music and pop-rock articles 108; newspaper discussion on 105

Ottoman modernization 54

Pala, Iskender 56

Pavarotti, Luciano 89, 135

Peacemaker (computer game) 37

Penderecki, Krzysztof 134
Pereda, Pridencio de 118

Philharmonic, Vienna 89, 134

philosopher-celebrity, death of 197-199

Plant, Robert 79

Pletnev, Mikhael 85

Politkovskaya, Anna 158

pop-rock articles, proliferation of 44,46 , $72,74,75,91,107,108,135,137$

'poprockization' of music 30, 108

pop-rock music 4, 30, 44; aesthetic dimension of 74; artistic quality and aesthetic evaluations of 87-89; classical divide 71; conjectural dynamics of 136 ; cover stories on 193; dominance of 57; economic factors in 146; evaluations of 68, 78, 89; in The Guardian 78-82; in Helsingin Sanomat 75-78; ideology of 135; legitimization of $75,78,92 \mathrm{n} 10$; 'official' history for 78; reviews of 75; rise of 44, 61-62, 121

'popular' aesthetic criteria, for evaluation of music 67,68

'popular' culture 8, 29; commercial funding 125; criteria used in evaluations of 67; half-page long and illustrated articles on 190; high-art criteria of evaluation of 57; legitimization of 201; origins of cultural products 111 ; rise of 61; in Sweden 32; in UK 32

popular music industry 56

popular youth culture, rise of 13

popularization $4,6,20,61-66,68,72,87$, 90-91, 92n7, 114, 126, 134, 139, 176-178, 187-188, 191, 194-195, 197-202, 205

printed press 58n3, 175, 195, 200

print media, golden age of 9

PRISA 116, 140-142 professional cultural intermediaries 11 public funding of art 57n4, 149

Quadrophenia (film) 139

quality journalism 126-127

'quality' newspapers and magazines, critics of 10

'quality TV' discourses 152

quantitative content analysis, principles of $13,57,67,210$

Radio Symphony Orchestra 87

rap and hip-hop 43-44

Rattle, Simon 84, 103

real art 88, 92n10, 136, 146 
Reed, Lou 77

Regev, Motti 88, 140

Richter, Sviatoslav 135

rock as art, status of 1-3

Rolling Stones, The 76

Rosy la bourrasque (film) 139

Royal Shakespeare Company 49

Ruisrock festival 77

Rules of Art, The (1996) 10, 126

Rushdie, Salman 166

Russian cultural products 116

Rydström, Valma 86

Rymdresa (computer game) 36

Salmenhaara, Erkki 85

Salonen, Esa-Pekka 102

samba music 119

Sartre, Jean-Paul 197-199

Schmutz, Vaughn 52, 67-68, 78, 85, 90, 92n8, 92n10, 133, 137

Schumann, Robert 112

Scorsese, Martin 139

Serban, Andrei 118

service journalism 84, 92n5, 127, 179

Shadows, The 136

Sheen, Charlie 112

Shepp, Archie 66

Sibelius, Jean 85, 101-103; Kullervo 102

Sindicato Vertical 164

Slater, Ashley 112

'small and emerging' art forms 39

soap operas $123,126,169-170$

'social turn' of art 154-155

social welfare policies 161

soft journalism 127

solo singing 83

Spain, $A B C$ on national identity of 162-166

Spanish music industry 140-142

Spanish Society of Authors and Editors 141

Stanislavski, Konstantin 116

Stockholm Museum of Modern Art 158

Stoller, Mike 79

Sutinen, Asko 119

symphony orchestra $65,86-87$

Talking Heads: Remain in Light album 87; review of 88

Tavastia Club 77, 79

Tchaikovsky's music 83

Three Tenors, The 89

telenovelas 126 television broadcasting $58 \mathrm{n} 10$; from medium to an art form of its own 80-82

television products, reviews on 80-81, 169 television reporting 80

television viewing $39,58 \mathrm{n} 10$

Tetzlaff, Christian 89, 102

theatres 47, 108; Broadway theater 126; decline in audience numbers 48-49;

Moscow Art Theatre 116; newspaper coverage of 48; political dimension of coverage of 49; publicly funded 49;

quality and authenticity of play in 49;

Royal Shakespeare Company 49;

Western theatres in Turkey 54

Three Sisters (play) 116

Tiensuu, Jukka 87

Times Literary Supplement 179

Times, The 102

Tiomkin, Dmitri 119

Toto 136

'traditional' art 125

traditional legitimate culture, popularization of $30,61,197,198$

Travolta, John 138

Turkey, Milliyet's coverage of national culture in 166-170

Turkish Radio and Television (TRT) 168

TV serials 126

Twin Peaks (television series) 114

UMO (Finnish jazz orchestra) 77

US cultural products: aesthetic value of 114; American music 112; artistic quality of 113; attractiveness of 112 ; 'bad' American culture 113-114; counter-flow artists 113; creativity of 112-113; evaluation of 112; Hollywood 81, 113, 126, 139, 152; influence of 100, 190; legitimate status of 114; qualitative analysis of 112 ; reception of 112-114; theme of success of 112-113

Valdés, Chucho 66

Venrooij, Alex van 67-68, 78, 85, 90, $92 \mathrm{n} 8,92 \mathrm{n} 10$

Verboord, Marc 101, 180, 188, 195n4, $195 \mathrm{n} 5$

videogames see computer games

visual arts $8,18,34,39,46,47,52,70$, 108-110, 120, 129-131, 146, 154, 170, 181,193 
Waterboys 80

Western commercial capitalism 99

Western legitimate arts 59n14

Western quality newspapers 177

Williams, Raymond 200
Wilson Phillips 136

Woolf, Virginia 193

writer-journalists 10

Yeats, W.B. 80 


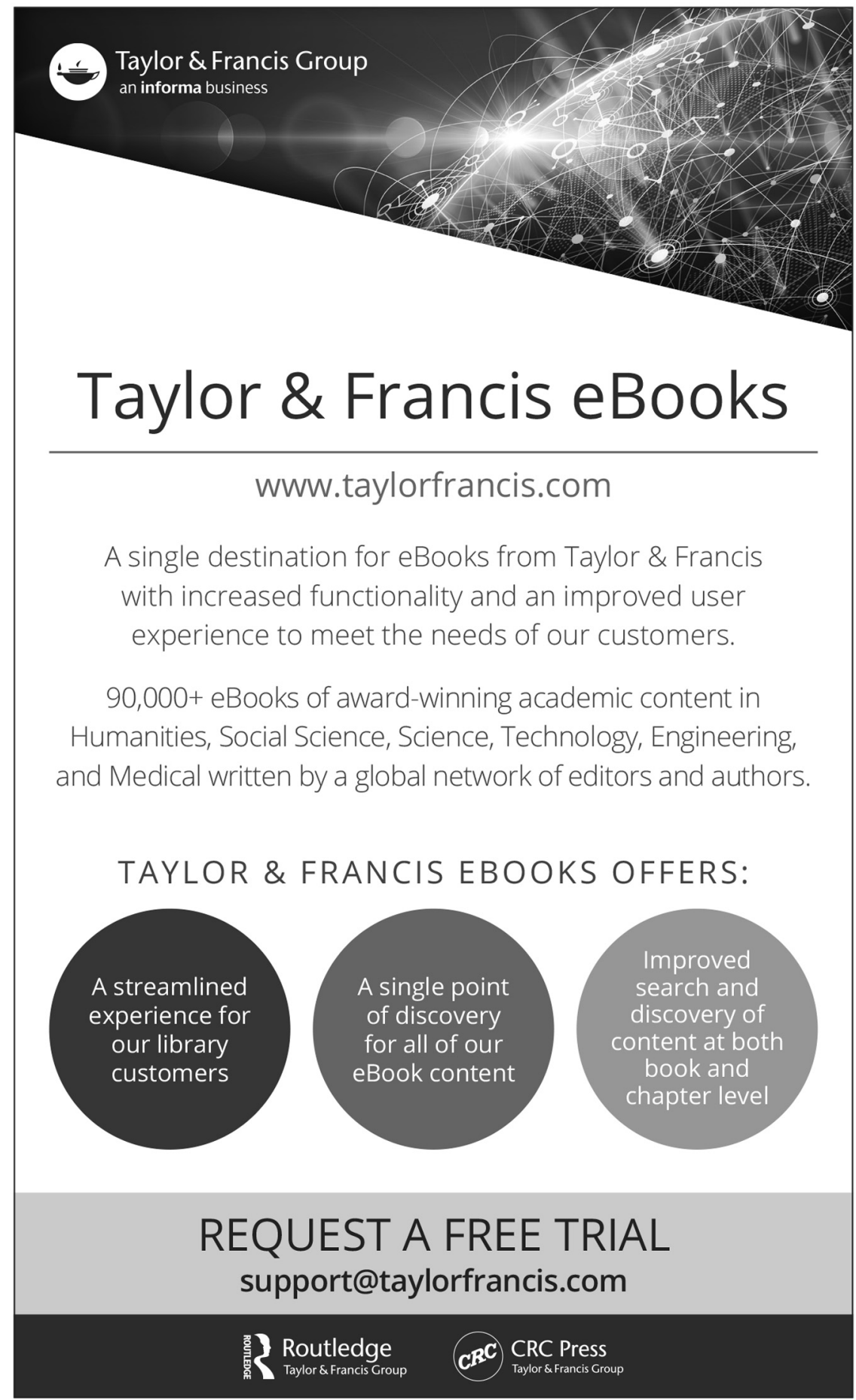

